\title{
ASSESSMENT AND DIVERSITY OF FISH COMMUNITIES IN NON-WADEABLE TRIBUTARIES OF THE MISSOURI AND MISSISSIPPI RIVERS
}

\begin{tabular}{c} 
A Dissertation \\
presented to \\
the Faculty of the Graduate School \\
at the University of Missouri-Columbia \\
In Partial Fulfillment \\
of the Requirements for the Degree \\
Doctor of Philosophy \\
\hline COREY GARLAND DUNN \\
Dr. Craig P. Paukert, Dissertation Supervisor \\
Cons
\end{tabular}

MAY 2020 
(C) Corey G Dunn 2020

All Rights Reserved 
The undersigned, appointed by the dean of the Graduate School, have examined the dissertation entitled

ASSESSMENT AND DIVERSITY OF FISH COMMUNITIES IN NONWADEABLE TRIBUTARIES OF THE MISSOURI AND MISSISSIPPI RIVERS

presented by Corey Garland Dunn, a candidate for the degree of doctor of philosophy, and hereby certify that, in their opinion, it is worthy of acceptance.

Dr. Craig Paukert

Dr. Amanda Rosenberger

Dr. Frank Thompson III

Dr. Christopher Wikle 


\section{DEDICATION}

To Glenn Dunn for the formative winter days along the Appomattox River and encouragement to do well in school. 


\section{ACKNOWLEDGEMENTS}

I thank my major adviser, Dr. Craig Paukert, and dissertation committee, Drs. Amanda Rosenberger, Frank Thompson, and Chris Wikle for volunteering their time to improve this research. Dr. Jodi Whittier and my lab-mates inevitably served as sounding boards: Elisa Baebler, Hadley Boehm, Dr. Kristen Bouska, John Brant, Julia Guyton, Ethan Kleekamp, Dr. Garth Lindner, Michael Moore, Zach Morris, Emily Pherigo, Dr. Landon Pierce, Jacob Schwoerer, Nick Sievert, Emily Tracy-Smith, Mike Thomas, Dr. Ralph Tingley, and Dr. James Whitney. I also thank staff with Research Computing Support Services and Greg Rotert with the School of Natural Resources for IT support.

I was fortunate to work with many outstanding managers and resource scientists at the Missouri Department of Conservation. These included Dave Herzog, Dr. Vince Travnichek, Matt Combes, Dr. Doug Novinger, Bob Hrabik, Brett Landwer, Greg Pitchford, Dr. Jacob Westhoff, Jason Persinger, Christina Kelsay, Dr. Paul Blanchard, Jen Girondo, Chris Brooke, Jason Crites, Nick Girondo, Rick Horton, Tory Mason, Brian McKeage, Darby Niswonger, and Chris Williamson.

I am especially grateful for the tireless effort put forth by the Mid-Sized Rivers field crew. Its core consisted of Jackman Eschenroeder ('14), Joshua Palmer ('14), Sharon Rayford ('14), Dillon Howe ('15), Mary Mabery ('15), Brandon Brooke ('15-16), and Randy Kramer ('16). The following volunteers and assistants served brief, but critical, stints on the field crew: David Broussard, Jenny Cunningham, Erin Hassett, Liz Heimer, Darcy Higgins, Travis Lyon, Ruth Anne Martin, Jack Niemeyer, Rory Mott, Brett Parra, Joey Rasco, Alex Simpher, Jeremy Williams, Brendon Woodall, and Autom Yount. Finally, I thank Laura Zseleczky for her unwavering support. 


\section{TABLE OF CONTENTS}

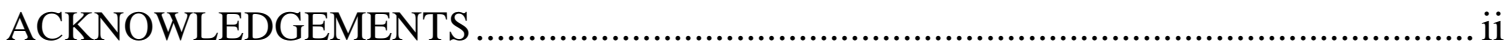

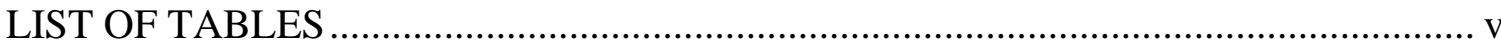

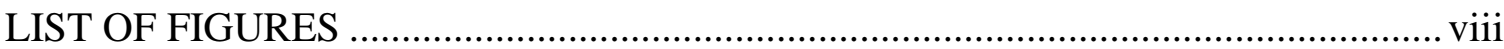

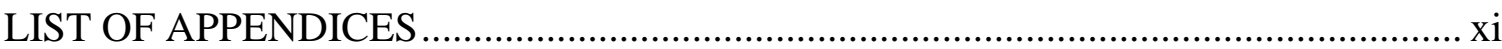

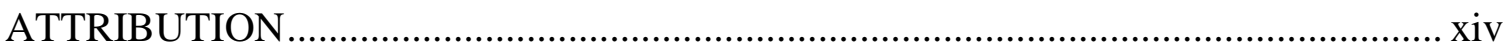

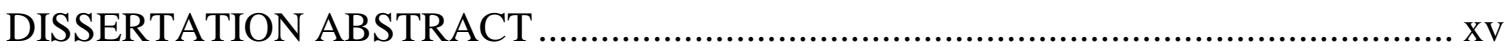

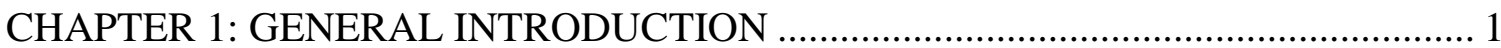

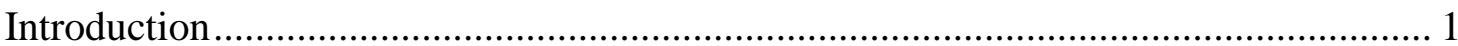

Brief profile of Missouri's mid-sized rivers …………………………………….... 5

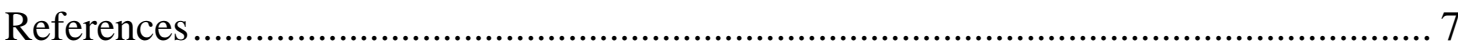

CHAPTER 2: A FLEXIBLE SURVEY DESIGN FOR MONITORING SPATIOTEMPORAL FISH RICHNESS IN NON-WADEABLE RIVERS: OPTIMIZING EFFICIENCY BY INTEGRATING GEARS ….................................... 15

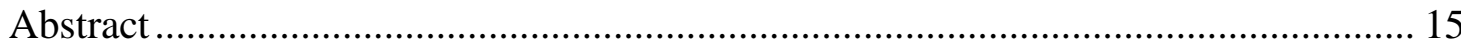

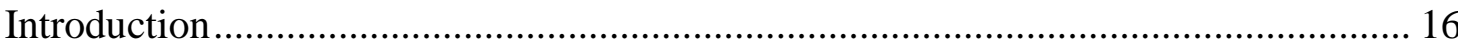

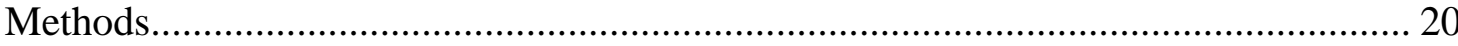

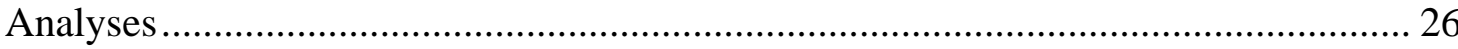

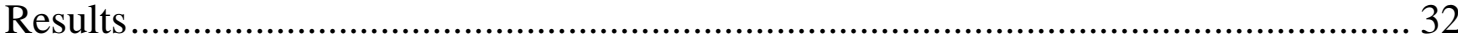

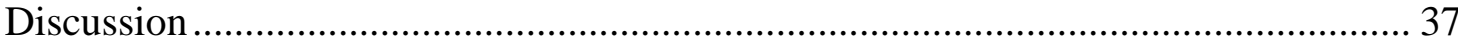

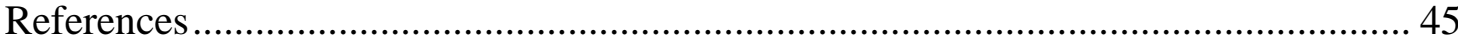

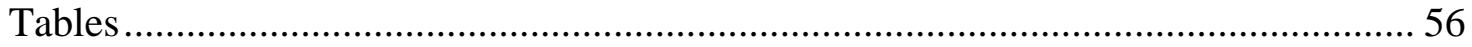

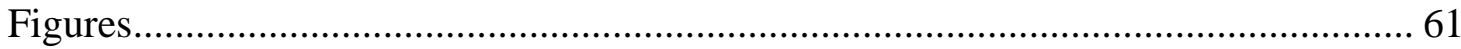

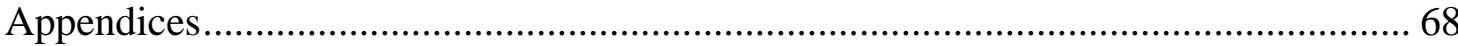

CHAPTER 3: ACCOUNTING FOR DOWNRIVER CONNECTIVITY AND HABITAT WHEN APPRAISING THE CONSERVATION VALUE OF TRIBUTARIES FOR LARGE-RIVER SPECIALIST FISHES ........................................................................ 71

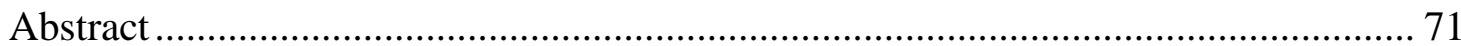

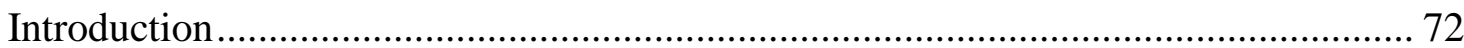

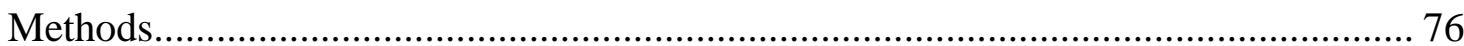

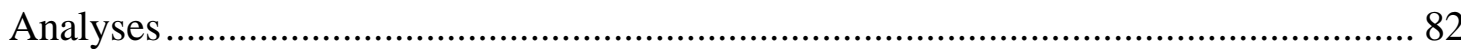

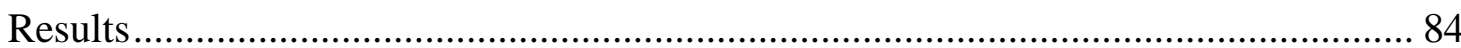

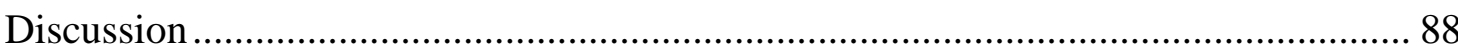

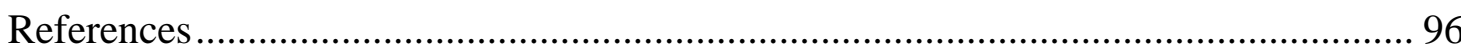

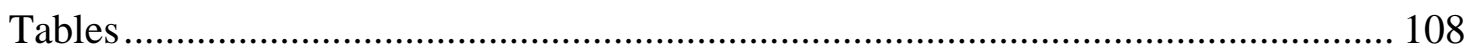




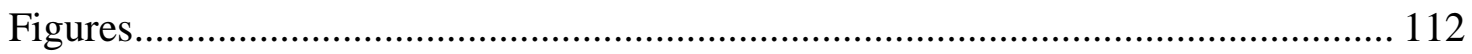

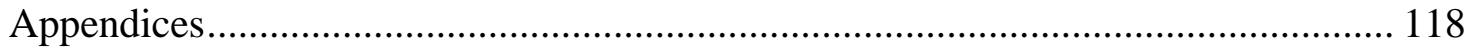

CHAPTER 4: PINPOINTING BIODIVERSITY HOTSPOTS: LOCAL HABITAT AND REGIONAL CONNECTIVITY SHAPE FISH RICHNESS WITHIN CONTRASTING RIVERINE METACOMMUNITIES ..................................................................... 128

Abstract




\section{LIST OF TABLES}

Table 2.1. Site characteristics and means (SD) of habitat variables from nine nonwadeable sites across two physiographic regions in Missouri (USA). $\mathrm{L}=$ Lower, $\mathrm{U}=$ Upper, $\mathrm{MWCW}=$ mean wetted-channel width, WSA = watershed area 56

Table 2.2. Mean (SD) species richness per sample within nine non-wadeable sites across 36 samples in Missouri (USA). $\mathrm{L}=$ lower, $\mathrm{U}=$ upper, $\mathrm{IG}=$ integrated-gear, $N=$ subsamples, $\mathrm{E}=$ electrofishing.

Table 2.3. Ranked competing models explaining sub-sample richness $(N=2,900)$ from 36 samples in nine non-wadeable sites in Missouri (USA). Also included are the number of fixed-effects (K), log-likelihoods (LL), $\triangle$ Akaike Information Criteria (AIC), model weights $\left(w_{i}\right)$, and marginal $(\mathrm{M})$ and conditional $(\mathrm{C}) R^{2}$ statistics. $\mathrm{G}=$ Gear, $\mathrm{R}=$ Region, $\mathrm{S}$ $=$ Season. 58

Table 2.4. Ranked competing models explaining the percentage of observed richness detected with the integrated-gear protocol ( $N=36$ samples) in nine non-wadeable sites in Missouri (USA). Also included are the number of fixed effects (K), log-likelihoods (LL), $\triangle$ Akaike Information Criteria (AICc) corrected for small sample size, model weights $\left(w_{i}\right)$, and marginal $(\mathrm{M})$ and conditional $(\mathrm{C}) R^{2}$ statistics. $\mathrm{R}=$ Region, $\mathrm{S}=$ Season.

Table 2.5. Ranked competing models explaining the percentage of observed richness detected with integrated-gear and 1-km electrofishing protocols from 36 samples in nine non-wadeable sites in Missouri. Rankings were based on $\Delta$ Akaike Information Criteria (AICc) corrected for small sample size. Also included are the number of fixed-effects $(\mathrm{K}), \log$-likelihoods (LL), and model weights $\left(w_{i}\right) . \mathrm{P}=$ protocol, $\mathrm{R}=$ Region, $\mathrm{S}=$ Season, MWCW = mean wetted-channel width.

Table 3.1. Habitat variables recorded at 24 sites in the Grand $(\mathrm{N}=10)$, Meramec $(N=$ $12)$, Missouri $(N=1)$, and Mississippi $(N=1)$ rivers in 2016 (Missouri, USA). "Scale" refers to the grain size at which variables were recorded. All variables were summarized to sites and five variables were transformed to reduce skew before performing a Principal Component (PC) analysis. Pearson product-moment correlations $(r)$ are between transformed or untransformed (-) variables and PC axes. Boldface indicates the PC axis most correlated with each habitat variable.

Table 3.2. Large-river specialist (LRS) fish tributary-use patterns and richness partitioning in the Grand and Meramec river systems in 2016 (Missouri, USA). Candidate LRS species are species with distributions historically centered in the Missouri and/or Mississippi rivers (listed in Appendix 3.1). Species with limited exchange distributional patterns were not detected by our surveys. Confluence exchange distributional patterns were exhibited by LRS species that were only detected at our lowermost sites in confluence zones (river km 1-6 from mouth). Species that exhibited network dispersal distributional were found upriver of lowermost sites ( $\geq$ rkm 24 in Grand R., $\geq$ rkm 30 in Meramec R.). Richness components are based on Whitaker's (1960) multiplicative 
partitioning $\left(\beta_{\mathrm{i}}=\gamma_{\mathrm{i}} / \alpha_{\mathrm{i}}\right) . \gamma_{\mathrm{i}}$ richness is the total LRS richness detected by our surveys within each tributary. $\alpha$ richness is mean (standard deviation) of LRS species at sites within each tributary. $\beta$ richness is a measure of compositional dissimilarity among sites within each tributary and can be adjusted to account for unequal sample size (standardized $\beta$ richness; Jost, 2007).

Table 3.3. Modeled effects $(\mathrm{K})$ and evaluation criteria for alternative models (i) depicting relationships between mean annual discharge $\left(\mathrm{m}^{3} \mathrm{~s}^{-1}\right)$ and large-river specialist fish richness (response) detected at sites in the Grand $(N=10)$ and Meramec $(N=12)$ river systems in 2016 (Missouri, USA). Lower $\Delta$ Akaike Information Criterion ( $\triangle \mathrm{AICc}$ ) and higher model weights $\left(w_{i}\right)$ indicate support for models. Evidence ratio $\left(w_{1} / w_{i}\right)$ is number of times the top model is better supported over lower-ranked models. Parameter estimates $(\beta \pm$ standard error) for top-ranked model: intercept $=9.50 \pm 1.78$, Discharge $=0.04 \pm$ 0.02 , River $=-9.62 \pm 2.61$, Discharge-x-River $=0.14 \pm 0.04$. Parameter estimates of all models are in Appendix 3.8.

Table 3.4. Modeled effects (K) and evaluation criteria for models (i) explaining residual large-river specialist fish richness from the best-supported model (Discharge-X-River) in Table (3.3). Connectivity is the downriver distance $(\mathrm{km})$ of tributary sites to the mouths of the Grand ( $N=10$ sites) or Meramec ( $N=12$ sites) rivers in 2016 (Missouri, USA). Great-river habitat is the Euclidean distance in multivariate space defined by three principal component axes between habitat at sites and reference great-river habitat in the Missouri (Grand R.) or Mississippi (Meramec R.) rivers. Lower delta Akaike Information Criterion $(\triangle \mathrm{AICc})$ and higher model weights $\left(w_{i}\right)$ indicate support for models. Evidence ratio $\left(w_{1} / w_{i}\right)$ is number of times the top model is better supported over lower-ranked models. Parameter estimates ( $\beta \pm$ standard error) for top-ranked model: intercept $=2.0 \pm$ 1.1 , Distance upriver from river mouth $=-0.02 \pm 0.01$. Parameter estimates for all models are in Appendix 3.9.

Table 4.1. Habitat variables recorded at 21 transects at each of the 22 sites in the Grand $(N=10)$ and Meramec $(N=12)$ rivers in 2016 (Missouri, USA). Habitat diversity at sites were from transformed or raw (“-”) variables based on average dispersion of transects around site centroids in principal component space. Pearson product-moment correlations $(r)$ were between standard deviations of habitat variables at sites and habitat diversity or discharge. Positive correlations indicate multivariate habitat diversity and discharge represent variability in specific habitat variables. No sampled macrophytes prevented us from calculating correlations in the Grand River system.

Table 4.2. Parameters (K) and evaluation criteria of competing linear regression models (hypotheses) explaining fish species richness of three stream-size fish guilds in the Grand $(N=10)$ and Meramec $(N=12)$ rivers in 2016 (Missouri, USA). Lower delta Akaike Information Criterion values ( $\triangle \mathrm{AICc})$ and higher weights $\left(w_{i}\right)$ are better-supported models. Exempting intercept-only (null) models, each model included both an intercept $\left(\beta_{0}\right)$ and slope $\left(\beta_{1}\right) \pm$ standard errors (SE). Habitat diversity was the average dispersion of habitat transects around multivariate centroids. Downriver isolation is the watercourse distance $(\mathrm{km})$ to the mouth of each river. Headwater (HW) isolation (basinwide) is the 
mean distance $(\mathrm{km})$ to $2^{\text {nd }}-3^{\text {rd }}$-order outlets within each river system. Headwater isolation (directional) is basinwide headwater isolation penalized for upstream movements.

Headwater sources are numbers of $2^{\text {nd }}-3^{\text {rd }}$-order outlets within specified watercourse

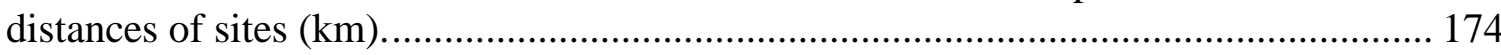

Table 4.3. Longitudinal positions and spatial extents of mainstem sites with fish species richness $\geq 75$ th percentile ("hotspot threshold") in the Grand ( $N=8$ mainstem sites) and Meramec ( $N=10$ mainstem sites) rivers in 2016 (Missouri, USA). Hotspot sites were first defined solely by core species and then with additional stream-size guilds (Appendix 4.1). Inclusion of headwater and/or large-river specialist species caused hotspot zones to shift and narrow relative to hotspots defined by core species (except core + headwater species). Positions are watercourse distances to respective mouths of each river. DS and US are downriver and upriver limits of hotspot zones, respectively. 176 


\section{LIST OF FIGURES}

Figure 2.1. Map of Missouri (USA) with nine non-wadeable sites repeatedly sampled between 2014 and 2016. "Great rivers" are the Missouri and Mississippi rivers.

Figure 2.2. Example of a georeferenced sample of a $2.65-\mathrm{km}$ site ( $=50$ mean wettedchannel widths [MWCWs]) in the Black River, Missouri (USA) in fall 2015. The inset details sub-samples in main and secondary channels. Note MWCW is $53 \mathrm{~m}$, sections (black lines) are $265 \mathrm{~m}$ (5 MWCWs), electrofishing (dark gray lines) distance $=1 \mathrm{~km}$ ( $20 \times 50-\mathrm{m}$ run), trawling (light gray lines) distance $=500 \mathrm{~m}$ ( $10 \times 50-\mathrm{m}$ run), and seining (dark gray circles) distance $=200 \mathrm{~m}(20 \times 10-\mathrm{m}$ seine haul). Passive gears (gray circles) include hoop, mini-fyke, and stationary trammel nets.

Figure 2.3. Predicted sub-sample richness by gear, region, and season $(N=2,900$ subsamples). Dashed vertical lines signify the reference condition in the best-supported model (intercept $=$ summer electrofishing in Ozark rivers).

Figure 2.4. Left: heat plot displaying the average compositional overlap (species presences/absences with Sørensen's coefficients) between two sub-samples within and among gears ( $N=2,900$ sub-samples). Higher coefficients (darker boxes) have greater overlap in species composition. Sub-samples were from 36 samples in nine non-wadeable sites in Missouri (USA). Right: average cumulative richness from two sub-samples from different gear combinations. E-fish = electrofishing, M-Fyke = mini-fyke net.

Figure 2.5. Mean species-accumulation curves ( $\pm 95 \%$ confidence intervals) from 36 samples for full-effort and integrated-gear protocols in Missouri (USA). Light and dark gray boxes depict the $41.5 \%$ and $7.6 \%$ of effort saved by only targeting $90 \%$ of species and minimizing redundant effort among gears, respectively.

Figure 2.6. Mean ( $\pm 95 \%$ confidence intervals) species-accumulation curves from 36 samples in Missouri (USA) for the integrated-gear protocol across regions and seasons. 66

Figure 2.7. Mean species-accumulation curves ( $\pm 95 \%$ confidence intervals) based on sub-samples from electrofishing-only (50-m run) and integrated-gear (multiple gears) protocols from 36 samples at nine sites (panels a-i) in the Ozark and Prairie regions of Missouri (USA). Lower-right panel (j) is percentage richness grouped by season with 20 sub-samples equaling either $1 \mathrm{~km}$ of electrofishing or a combination of gears (electrofishing, trawling, seining, mini-fyke nets) with the integrated-gear protocol.

Figure 3.1. Non-wadeable mainstem and branch sites in the Grand $(N=10$, prairie region) and Meramec $(N=12$, Ozark region) river systems surveyed for large-river specialists fish species in 2016 (Missouri, USA). Insets: sites extended at least $1 \mathrm{~km}$ away from major confluences, and watercourse distances (river $\mathrm{km}$ ) are upriver of each river system's mouth. 
Figure 3.2. Conceptual depiction of Thornbugh and Gido's (2010) classification of tributary use by mainstem fishes: limited exchange = limited movements between mainstem and tributary; confluence exchange $=$ localized movements between mainstem and lower tributary reach in confluence zone associated with habitat features near the mainstem's floodplain and backwater-affected hydrology; network dispersal = extensive use of tributary upriver beyond confluence zone

Figure 3.3. Percentages of species preferring high water-velocities (rheophilic) and coarse substrates (lithophilic) by distributional pattern in the Grand River (35 candidate species, 10 sites) and Meramec River, USA (42 candidate species, 12 sites). Species conforming to limited exchange were not detected in tributaries by fish sampling in 2016. Percentages for confluence exchange are the composition of species at lowermost sites within confluence zones ( $\mathrm{rkm} 1-5$ ). Percentages for network dispersal are from sites upriver of rkm 5 beyond confluence zones........................................................ 114

Figure 3.4. Principal components (PC) of 10 habitat variables (Table 3.1) from 24 sites in the Grand $(N=10)$, Meramec $(N=12)$, Missouri $(N=1)$, and Mississippi $(N=1)$ rivers (USA). Points are proportional to the natural log of mean annual discharge $\left(\mathrm{m}^{3} \mathrm{~s}^{-1}\right)$. Great-river habitat similarity was Euclidean distance of sites to the Missouri (Grand R.) or Mississippi (Meramec R.) rivers in multivariate space.

Figure 3.5. Pearson product-moment correlations ( $r$ ) between mean annual discharge at sites and variables potentially explaining large-river specialist fish richness in the Grand $(N=10$ sites) and Meramec $(N=12$ sites) river systems sampled in 2016 (Missouri, USA). (a) Distance-to-river mouth is watercourse distance of sites to the the Missouri (Grand R.) or Mississippi (Meramec R.) rivers. (b) Great-river habitat similarity is Euclidean distance of each site to habitat in the Missouri (Grand R.) or Mississippi (Meramec R.) rivers in principal component (PC) space constructed from 10 instream habitat variables and three PC axes. Correlations between PC axes and habitat variables are in Table 3.1. Mainstems are sites along mainstems of the Grand or Meramec rivers. Branches are tributaries to mainstems.

Figure 3.6. (Top) Species-discharge relationship (SDR) between mean annual discharge and large-river specialist fish richness at 22 sites in the Grand $(N=10)$ and Meramec $(N$ $=12$ ) rivers in 2016 (Missouri, USA). Polygons highlight grouped residuals that result from assuming rivers have identically sloped SDRs. (Middle) Species-discharge relationships with river-specific slopes and 90\% confidence intervals. Black arrows depict residual error. (Bottom) Relationship between residual SDRs and distance to the mouth of the Grand River (Missouri R. confluence) and Meramec River (Mississippi R. confluence). Residuals above and below 0 indicate SDRs in the middle panel that underand over-estimated large-river fish richness, respectively.

Figure 4.1. Non-wadeable mainstem and tributary branch sites in the Grand $(N=10$, Prairie region) and Meramec $(N=12$, Ozark region) river systems surveyed for fish in 2016 (Missouri, USA). Insets: sites extended at least $1 \mathrm{~km}$ away from major confluences, 
and watercourse distances (river km) are upriver of each river system's mouth. Gray areas are municipal boundaries indicative of urban development.

Figure 4.2. Left: within-site habitat diversity at sites in the Grand $(N=10)$ and Meramec $(N=12)$ rivers in 2016 (Missouri, USA). We calculated habitat diversity by first performing a principal component (PC) analysis of nine habitat variables summarized to 21 transects. Habitat diversity at each site was the average Euclidean distance of transects to a site's centroid in PC space (units $=$ PC axes). Right: among-site habitat heterogeneity (dissimilarity) was the pairwise Euclidean distances among site habitat centroids in PC space $(\mathrm{y}$-axis units $=$ Euclidean distances in PC space). Horizontal bars are averages. . 178

Figure 4.3. Secies-discharge relationships between mean annual discharge and fish species richness in the Grand $(N=10$ sites; bottom) and Meramec ( $N=12$ sites; top) rivers from 2016 (Missouri, USA). Pseudo- $R^{2}$ values (squared Pearson correlation $[r]$ between observed and predicted) are from Local Regression Smoothers (dashed lines \pm $90 \%$ confidence intervals) and were 0.60 and 0.71 for models in Grand and Meramec rivers, respectively. Labels are watercourse distances $(\mathrm{km})$ from the Missouri (Grand R.) and Mississippi (Meramec R.) rivers.

Figure 4.4. Relationships between mean annual discharge and fish species richness within three stream-size preference guilds (Appendix 4.1) for the Grand (left, $N=10$ sites) and Meramec (right, $N=12$ sites) rivers in 2016 (Missouri, USA). The top horizontal axis is watercourse distance upriver from a respective river mouth $(\mathrm{km})$. " $\mathrm{B}$ " = sites in tributary branches.

Figure 4.5. Habitat and spatial predictors of fish species richness $( \pm 90 \%$ confidence interval) for three river-size guilds in the Grand ( $N=10$ sites) and Meramec $(N=12$ sites) rivers in 2016 (Missouri, USA). Habitat diversity and distance-from-mouth were best-supported hypotheses explaining richness for core and large-river specialist species in both river systems, respectively. Headwater sources within $25 \mathrm{~km}$ of sites was the bestsupported hypothesis explaining headwater species for the Grand River system, but not the Meramec River system. Classifications for headwater and large-river species are in Appendix 4.1....

Figure 4.6. Longitudinal profiles of fish species richness for three stream-size guilds in the Grand ( $N=8$ mainstem sites) and Meramec ( $N=10$ mainstem sites) rivers in 2016 (Missouri, USA). Profiles are Local Regression Smoothers (LOESS) between distance from river mouth and richness. Hotspots (white) and coolspots (black) are sites where observed richness was $\geq 75$ th and $<75$ th percentile of predicted richness (dashed line), respectively. Shading reflects longitudinal richnes profiles constructed from different stream-size guilds. Profiles were developed for four combinations of stream-size guilds: (a, e) core species, (b, f) core + headwater (HW) species, (c, g) core + large-river specialist (LR) species, and (d, h) all species. Horizontal error bars show means and ranges of sites within hotspot zones. 


\section{LIST OF APPENDICES}

Appendix 2.1. Number of sub-samples with the full-effort and integrated-gear protocols in nine non-wadeable sites in Missouri (USA). One sub-sample by gear $=50 \mathrm{~m}$ electrofishing, $50 \mathrm{~m}$ trawling, one seine haul, one hoop net, one mini-fyke net, one trammel net. $\mathrm{L}=$ lower, $\mathrm{U}=$ upper, $\mathrm{Lg}=$ Large River, $\mathrm{S}=$ Small River, $\mathrm{E}=$ electrofishing, $\mathrm{T}=$ trawl, $\mathrm{S}=$ seine, $\mathrm{H}$ = hoop net, $\mathrm{FN}=$ mini-fyke net, $\mathrm{ST}$ = stationary trammel net.

Appendix 2.2. Residual plots for models of (a) fish richness in sub-sample in 36 samples in Missouri (USA), (b) percentage richness detected by the integrated-gear protocol based on region (Ozark, Prairie) and season (spring, summer, fall), (c-f) percentage richness detected with 20 sub-samples by seasons, regions, protocol (integrated gear, electrofishing only), and mean wetted-channel width (MWCW).

Appendix 2.3. Parameter estimates $(\beta)$ and standard errors (SE) for best-supported models in questions 1, 4, 5. Question 1: which gears detected the most species per unit effort? Question 4: did the most-efficient protocol detect a consistent percentage of species across regions and seasons? Question 5: was the integrated-gear protocol more effective and consistent than traditional effort with an electrofishing-only protocol? ..... 70

Appendix 3.1. Traits (possessed $=1$ ) of candidate large-river specialist fishes in the lower Missouri and middle Mississippi rivers (USA). Limited exchange (LE) are candidate large-river specialist fishes not detected in a respective tributary. Confluence exchange (CE) are species only detected at the lowermost site ( $\mathrm{rkm} \mathrm{1-6)}$ in a respective tributary. Network dispersal (ND) are species detected upriver of rkm 6 in a respective tributary. "-" are large-river specialist species unlikely to occur in the Missouri River. Lithophilic fishes prefer substrates coarser than sand (Frimpong \& Angermeier, 2010). Rheophilic fishes prefer fast or moderate water velocities (Frimpong \& Angermeier, 2010). Migratory behavior is based on O'Hara et al. (2007). NatureServe statuses for Missouri (USA): S1 = critically imperiled, S2 = imperiled, S3 = vulnerable, S4 = apparently secure, S5 = secure, I = introduced, "“"” = no listing. *Based on descriptions in Pflieger (1997) due to unavailability in Frimpong \& Angermeier (2010)...................... 118

Appendix 3.2. Images of Grand River (left column) and Meramec River (right column). Row one: confluence zones of Grand ( $\mathrm{rkm} 3$ ) and Meramec (rkm 3) rivers. Row two: sites upriver, beyond confluence zones of Grand (rkm 24) and Meramec (rkm 52) rivers. Row three: mid- to upper-course sites in Grand (rkm 145) and Meramec ( $\mathrm{rkm} 244)$ rivers.

Appendix 3.3. Imagery and georeferenced fish and habitat (inset) survey of a site ( $\mathrm{rkm}=$ 120) of the Meramec River in $2016(\mathrm{E}=686710, \mathrm{~N}=4246362$, UTM zone $15 \mathrm{~N}$ Missouri, USA). Habitat data were collected at five equidistant points along 21 transects plus additional points if transects intersected off-channel areas ( $\geq 105$ points per site). Image was obtained from Google Earth. 
Appendix 3.4. Fish sampling effort per site for the Grand $(N=10$ sites) and Meramec ( $N$ $=12$ sites) river systems in 2016 (Missouri, USA). Sampling effort was proportional to mean wetted channel width (MWCW). Distances are to the mouths of the Missouri (Grand R.) and Mississippi (Meramec R.) rivers. Total distances electrofished (Electro) and trawled per site were accumulated from individual 50-m runs. M-fyke $=$ mini-fyke net.

Appendix 3.5. Linear relationships $\pm 90 \%$ confidence intervals between watershed area and mean annual discharge (years 1920-2016) measured at six and five USGS stream gages in the Grand and Meramec river drainages, respectively. Estimated relationships were used to predict mean annual discharge at sites without discharge gages. Grand River gage IDs: 06899500, 06902000, 06897500, 06901500, 06899700, 06900000; Meramec River gage IDs: 07013000, 07014500, 07019000, 07018500, 07016500.

Appendix 3.6. Means (standard deviations) of 10 habitat variables at sites in the Grand $(\mathrm{G}$, sites $=10)$ and Meramec $(\mathrm{M}$, sites $=12)$ river systems and Missouri $(\mathrm{MO})$ and Mississippi (MS) rivers in 2016 (Missouri, USA). Variables were inputs into principal components analysis. Abbreviations: Sub. Size = Substrate size; LWD = Large woody debris; Aqua. veg. = Aquatic vegetation.

Appendix 3.7. Data collected in 2016 used for analyzing species-discharge relationships for sites in the Grand (sites $=10$ ) and Meramec ( USA). Branch (=1) signifies tributaries within each river system. LRS = large-river specialist fishes, $\mathrm{PC}=$ principal component. Distances are to the mouth of each respective river system.

Appendix 3.8. Variables and corresponding parameter estimates ( \pm standard errors) for models explaining large-river specialist fish richness in the Grand ( $N=10$ sites) and Meramec $(N=12$ sites) rivers in 2016. Models with lower $\triangle \mathrm{AICc}$ were better supported. The Grand River served as the reference level (i.e., intercept) 126

Appendix 3.9. Variables and parameter estimates ( \pm standard errors) for models explaining residual large-river specialist fish richness in the Grand ( $N=10$ sites) and Meramec $(N=12$ sites) rivers. Models with lower $\triangle$ AICc were better supported. Distance is to the respective mouth of each river system. $\mathrm{PC}=$ principal component... 127

Appendix 4.1. Memberships of fish species to three stream-size preference guilds for the Grand and Meramec river systems (Missouri, USA). Headwater fishes were likely sourced in $\leq 3^{\text {rd }}$-order streams. Their membership designations were slightly modified from the "headwater zone" (Pflieger 1989) to include updated records from Missouri Department of Conservation unpublished databases (Fish community database pre-2010; Resource Assessment and Monitoring program 1994-2014). Large-river specialists species in tributaries likely dispersed from, and/or have high population connectivity to, the Missouri (Grand R.) or Mississippi (Meramec R.) rivers. Large-river specialist designations were slightly modified from the "Big River" fishes group (Pflieger 1989) to include diadromous species, introduced large-river species, and lowland species 
associated with the Mississippi River floodplain. Species were either detected (1) or undetected (0) by our sampling in 2016, or unknown to occur (-) within a river system.

Appendix 4.2. Means (standard deviation) for habitat variables summarized to transects $(N=21$ transects per site) at sites in the Grand and Meramec river systems in 2016 (Missouri, USA). Distances are to the mouths of each system.

Appendix 4.3. Raw data for sites in the Grand $(N=10)$ and Meramec $(N=12)$ river systems in 2016 (Missouri, USA). Headwater (HW) sources were counts of $2^{\text {nd }}$ - and $3^{\text {rd }}$ order stream outlets within specified distances. System connectivity is mean distance of sites to $2^{\text {nd }}-3^{\text {rd }}$-order stream outlets across each river system. Upriver distances were penalized $20 \%$ (distance x $1.2 \mathrm{~km}$ ) for directional (system) connectivity. LRS = largeriver specialist species (spp.). Abreviations: Spp. $=$ species, conn $=$ connectivity.

Appendix 4.4. Relationships among fish and habitat diversity (core species) or dispersal source (headwater, large-river specialist species) for mainstem sites along the Grand ( $N=$ 8 sites) and Meramec ( $N=10$ sites) rivers sampled in 2016 (Missouri, USA). The dispersal source for large-river species is the mouth of respective rivers. See Fig. 4.5 for direct linear relationships. 189 


\section{ATTRIBUTION}

Chapters 2-4 were written as standalone manuscripts co-authored by Dr. Craig Paukert and myself, and therefore, the narratives are first-person plural. Dr. Paukert secured funding, contributed to study designs, and edited manuscripts. There are some methodological redundancies between Chapters 3-4 owing to a common dataset. With the exception of Chapter 2, this dissertation was formatted according to editorial conventions of the American Psychological Association (APA). Chapter 2 will be published in the Canadian Journal of Fisheries and Aquatic Sciences, which uses nonAPA formatting, while journal destinations for Chapters 3-4 have not been determined. We generally refer to the group of fish species co-occurring at sites as fish "communities" except for Chapter 2 for which reviewers requested that we refer to these as "assemblages" in the associated manuscript.

Reference for Chapter 2:

Dunn, C.G., \& Paukert, C.P. (2020). A flexible survey design for monitoring spatiotemporal fish richness in nonwadeable rivers: optimizing efficiency by integrating gears. Canadian Journal of Fisheries and Aquatic Sciences. https://doi.org/10.1139/cjfas2019-0315 


\section{DISSERTATION ABSTRACT}

As the geographical centers of riverscapes, rivers support fish populations at local and basin-wide scales. However, refinements to fish sampling protocols and theories underpinning basin-wide community ecology have been slowed by the inherent complexity and immensity of rivers. I conducted three extensive studies in non-wadeable tributaries of the lower Missouri and middle Mississippi rivers (Missouri, USA) to illuminate processes structuring riverine fish communities. In Chapter 2, I tested the efficacy of a six-gear fish community sampling protocol by repeatedly sampling nine sites in spring, summer, and fall ( $N=36$ surveys). I identified an efficient four-gear subprotocol that consistently detected $90 \%$ of observed species richness at sites and only required $52 \%$ of initial survey effort. In comparison, an electrofishing-only protocol detected lower percentages of fish richness, varied seasonally between summer and fall, and was nearly twice as variable. In Chapters 3 and 4, I contrasted fish communities inhabiting the Grand (10 sites, prairie region) and Meramec (12 sites, Ozark region) river systems. Chapter 3 examined tributary use by large-river specialist fishes (LRS), a guild of fishes that likely disperse into tributaries from the Missouri (Grand R.) and Mississippi (Meramec R.) rivers. I tested whether mean annual discharge consistently structured richness of LRS fishes at sites ( $\alpha$ richness) within tributaries, and if habitat and downriver connectivity to the Missouri and Mississippi rivers explained additional variation in LRS $\alpha$ richness. Although species-discharge relationships were positive, discharge effect sizes varied between rivers revealing discharge did not consistently structure LRS $\alpha$ richness. After accounting for river-specific effects of discharge, downriver connectivity explained residual variation in LRS $\alpha$ richness, indicating dispersal into tributaries likely structured 
LRS $\alpha$ richness. Consequently, LRS $\alpha$ richness solely estimated from discharge might be underestimated in connected network branches and overestimated in isolated mainstem reaches. Chapter 4 expanded the research scope beyond LRS species to test whether regional connectivity (distance to dispersal source) or site-level habitat diversity (multivariate dispersion of nine habitat variables) explained $\alpha$ richness of three streamsize guilds at sites: LRS species, headwater species likely sourced from $\leq 3^{\text {rd }}$ Strahlerorder streams, and core riverine fishes. In both river systems, downriver connectivity (distance upriver from mouth of mainstem river) and habitat diversity positively related to LRS- ( $R^{2}=0.44$ in Grand R, 0.91 in Meramec R.) and core-species $\left(R^{2}=0.37\right.$ in Grand R., 0.57 in Meramec R.) richness, respectively. Headwaters within $25 \mathrm{~km}$ of sites positively related to headwater species richness in the Grand River system $\left(R^{2}=0.85\right)$, but not in the Meramec River system where headwater richness was better explained by an inverse relationship with discharge $\left(R^{2}=0.32\right)$. Increasing LRS richness (13-17 spp.) downriver caused sites supporting the highest total species richness ( $\geq 75^{\text {th }}$ percentiles) to skew towards lower-midcourse reaches, rather than in midcourses where core-species richness and habitat diversity peaked. Because riverine fish richness manifests from regional dispersal and local habitat diversity, conserving areas of high richness will likely require management actions aimed at local and regional scales. Altogether these studies collecting 146 species and 145,147 individuals revealed non-wadeable tributaries are key riverscape elements that provide diverse riverine habitats and corridors for members of multiple regional fish species pools. 


\section{CHAPTER 1: GENERAL INTRODUCTION}

\section{Introduction}

Rivers are biophysically diverse ecosystems at the centers of broader riverine networks (i.e., riverscapes). High diversity, predictability, and accessibility of riverine habitats are key for supporting biota at local and regional scales (Schlosser, 1991; Ward, 1998). Water and navigation infrastructure have jeopardized many river systems (Dias et al., 2017; Kominoski et al., 2018), and contributed to high imperilment among riverdependent taxa (Cooke, Paukert, \& Hogan, 2012; Lackmann, Andrews, Butler, BielakLackmann, \& Clark, 2019). Irreplaceability and interconnectedness of rivers make them highly valued for restoration and preservation within conservation planning frameworks (Erős, Schmera, \& Schick, 2011). However, prioritizing specific reaches and evaluating restoration success often requires collecting comprehensive biodiversity data. Unfortunately, few standardized fish assessments were designed to measure the most unique aspects of riverine habitat - namely high lateral, vertical, and temporal dimensionality (Erős, Kuehne, Dolezsai, Sommerwerk, \& Wolter, 2019; Ward, 1989). Consequently, riverine richness might be increasingly underestimated downriver as habitats diversify. Over time, mismatches between low-dimensional sampling protocols and multi-dimensional riverine habitats could distort distributional data, thereby undermining modern-day riverscape conservation planning.

Riverscape conservation planning increasingly incorporates tributaries because they are smaller than larger mainstems and often have fewer competing management interests (Laub, Thiede, Macfarlane, \& Budy, 2018; Pracheil, McIntyre, \& Lyons, 2013). Tributaries are also key network elements marking the juxtaposition of unique habitats 
and species pools (Benda et al., 2004; Boddy, Booker, \& McIntosh, 2019). Elevated habitat diversity near confluences and rapid exchange across mainstem-tributary divides often manifests as biodiversity hotspots near tributary mouths (Hitt \& Angermeier, 2008; Schaefer \& Kerfoot, 2004). Tributaries also help support mainstem species by providing unique habitats rarely occurring in mainstems (Cathcart, McKinstry, MacKinnon, \& Ruffing, 2019). However, most insights into the roles of tributaries for supporting freshwater fishes often stem from wadeable streams and/or single species, meaning it is unclear to what extent tributaries support riverine fish communities. Community-wide investigations into tributary use are particularly needed with increasing interest into community-based management of riverine fishes (Cooke et al., 2012).

Conceptual models of rivers have shifted through time (Melles, Jones, \& Schmidt, 2012; Poole, 2010). Early conceptualizations depict larger rivers $\left(\geq 6^{\text {th }}\right.$ order) as endpoints of sediment-, nutrient-, and energy-processing chains within single-threaded downstreamoriented continua (Vannote, Minshall, Cummins, Sedell, \& Cushing, 1980). Subsequent refinements embraced added dimensionality and among-reach patchiness provided by riverine habitats (Poole, 2002; Thorp, Thoms, \& Delong, 2006). Under this multidimensional view, main channels are components within a broader diverse, productive, and dynamic riverine ecosystem that includes off-channel and deepwater refugia (Schlosser, 1991), and inundated floodplains ("riverine landscapes" sensu Ward, 1998). Overlaying among-reach habitat patchiness along the longitudinal profiles of rivers gave rise to the riverscape concept - a concept recognizing that survival of individuals and persistence of populations often requires connectivity among critical habitats spaced broadly throughout riverine networks (Fausch, Torgersen, Baxter, \& Li, 2002; Schlosser, 
1991). This multi-dimensional and interconnected view of rivers is particularly important for riverine fishes, many of which are migratory and require sequential access to specific habitats (McIntyre et al., 2016).

Recent progressions of river concepts emphasize the roles of rivers for structuring communities within broader drainage-wide macrosystems defined by watershed boundaries (Thorp, 2014). As the organizational centers of river networks, rivers are key to basin-wide properties, such as the sensitivity, resistance, and resilience of regional communities to anthropogenic disturbances (McCluney et al., 2014). Within macrosystems, rivers not only provide both productive habitats and pivotal corridors for riverine fishes (Galat \& Zweimuller, 2001), but also facilitate recolonization of disturbed network branches by stream fishes, thereby stabilizing long-term community dynamics at basins scales (McCluney et al., 2014; Van Looy et al., 2019). Consequently, river network configuration, permeability, and habitat patchiness are key underlying features shaping fish diversity throughout river macrosystems.

Metacommunity ecology provides a useful framework for explicitly linking regional species pools to local community structure via dispersal and environmental filtering (Brown et al., 2011; Hugueny, Oberdorff, \& Tedesco, 2010). Metacommunityframed studies in freshwaters often quantify the relative influences of environmental (a within-site local variable) and dispersal (an among-site regional variable) on local community composition and diversity (Erős, 2017). Relative contributions of the environment (i.e., habitat) versus dispersal to community assembly vary with the positioning of sites within river networks (Brown \& Swan, 2010). In relatively isolated wadeable streams, environmental variables often explain more variation in community 
structure than dispersal (Peláez \& Pavanelli, 2019; Zbinden \& Matthews, 2017).

Dispersal, however, is hypothesized to have heightened importance for structuring mainstem stream communities due to increasing network connectivity to downstream colonization sources and rescue effects (Brown \& Swan, 2010; Ferreira, Souza, Cetra, \& Petrere, 2019), and less selective environmental conditions (Zbinden \& Matthews, 2017).

An issue with emerging conceptualizations of riverine macrosystems is that nearly all metacommunity-framed studies are based in wadeable streams (Erős, 2017). This reflects the broader issue in freshwater ecology of investigators extrapolating findings from studies set in smaller, more manageable streams to explain phenomena within rivers (Thorp, 2014). Thus, metacommunity and macrosystem theory likely have outpaced empirical data from riverine communities. Recently, Vitorino Júnior, Fernandes, Agostinho, and Pelicice, (2016) supported meta-community predictions by concluding fish communities in non-wadeable Neotropical rivers were "probably" structured by dispersal; however, studies in Hungary (Erős, Takács, Specziár, Schmera, \& Sály, 2017) and Columbia (López-Delgado, Winemiller, \& Villa-Navarro, 2018) indicate riverine fish communities are more structured by environmental factors, meaning findings contrast among the few existing metacommunity-framed studies of riverine communities. Ultimately, if connected river networks contribute to metacommunity resiliency by enabling dispersal and by providing diverse habitats (Van Looy et al., 2019), then both spatial and environmental influences likely structure riverine fish communities. 


\section{Brief profile of Missouri's mid-sized rivers}

I focused on non-wadeable tributaries of the lower Missouri and middle Mississippi rivers. I occasionally refer to these systems as "large" rivers because most observations underpinning recent theoretical developments of freshwater fish community organization are based in smaller streams and rivers systems. Within the specific context of the state of Missouri, however, focal rivers are actually "mid-sized" due to their intermediate position connecting wadeable streams to the state's great rivers (Missouri and Mississippi rivers). By default, Missouri's mid-sized rivers have emerged as data gaps, following decades of standardized fish community sampling in Missouri's great rivers (Mississippi River Long Term Ecological Research program, overviewed in Sparks, 2010; Missouri River Benthic Fishes Study, overviewed in Wildhaber, Gladish, \& Arab, 2012) and wadeable streams (Resource Assessment and Monitoring program, Fischer \& Combes, 2003). Although less is known about biodiversity patterns in midsized rivers, these systems are among the most culturally important natural resources in Missouri (Turner, 2014) and support many imperiled species (Hinck et al., 2012; Mattingly \& Galat, 2002; Wheeler, Prosen, Mathis, \& Wilkinson, 2003) and popular fisheries (Vokoun \& Rabeni, 2005; Westhoff, Paukert, Ettinger-Dietzel, Dodd, \& Siepker, 2016). The companion report to this dissertation is Dunn (2019), which mainly focuses on developing standardized fish community sampling protocols for mid-sized rivers.

I defined mid-sized rivers as non-wadeable lotic systems smaller than the state's great rivers but having drainage areas $\geq 1,000 \mathrm{~km}^{2}$. As great-river tributaries, most midsized rivers contain distinctive regional species pools, and several have endemic fish 
species (Ecological Drainage Units; Sowa, Annis, Morey, \& Diamond, 2007). Over 200 of Missouri's approximately 230 fish species have been detected in mid-sized rivers, indicating these systems are collectively diverse despite comprising only $4 \%(6,230 \mathrm{~km})$ of Missouri's streams and rivers by length (RAM 1994-2014; MDC unpublished fish community database 1970-2009). After removing potentially non-representative fishcommunity surveys with $\leq 5$ species, historical surveys in mid-sized rivers report on average (SD) 16.8 (6.9) and 24.1 (9.5) fish species in Missouri's prairie $(N=141)$ and Ozark $(N=371)$ regions, respectively. However, results from this dissertation indicate these historical surveys likely substantially underestimated fish richness at sites.

My goal was to illuminate the processes structuring riverine fish richness within tributaries of the lower Missouri and middle Mississippi rivers. To accomplish this goal, I first designed a multi-gear fish sampling protocol capable of targeting most major habitats in rivers. In Chapter 2, I examined whether this protocol was more consistent and detected higher percentages of fish richness than traditional electrofishing-only protocols. In Chapter 3, I focused on a specific group of fishes that likely disperse into tributaries from the Missouri and Mississippi rivers (large-river specialists). I validated underlying assumptions of an increasingly used approach in riverscape conservation planning using discharge as a coarse surrogate for the capacity of tributaries to support large-river specialist fishes (i.e., species-discharge relationships; Laub et al., 2018; Pracheil et al., 2013). In Chapter 4, I conducted one of the largest-scale tests to date of the metacommunity hypothesis in lotic systems; I contrasted fish communities in two nonwadeable free-flowing tributaries to determine whether i) local communities were comprised of species structured by different community-organizing mechanisms (i.e., 
dispersal versus habitat) and ii) whether assembly mechanisms were consistent between rivers varying in habitat diversity. Altogether this dissertation addressed a mixture of applied and basic research questions collectively meant to improve understanding and management of riverine fish communities.

\section{References}

Benda, L., Poff, N. L., Miller, D., Dunne, T., Reeves, G., Pess, G., \& Pollock, M. (2004). The network dynamics hypothesis: How channel networks structure riverine habitats. Bioscience, 54(5), 413-427. https://doi.org/10.1641/00063568(2004)054[0413:tndhhc]2.0.co;2

Boddy, N. C., Booker, D. J., \& McIntosh, A. R. (2019). Confluence configuration of river networks controls spatial patterns in fish communities. Landscape Ecology, 34(1), 187-201. https://doi.org/10.1007/s10980-018-0763-4

Brown, B. L., \& Swan, C. M. (2010). Dendritic network structure constrains metacommunity properties in riverine ecosystems. Journal of Animal Ecology, 79(3), 571-580. https://doi.org/10.1111/j.1365-2656.2010.01668.x

Brown, B. L., Swan, C. M., Auerbach, D. A., Grant, E. H. C., Hitt, N. P., Maloney, K. O., \& Patrick, C. (2011). Metacommunity theory as a multispecies, multiscale framework for studying the influence of river network structure on riverine communities and ecosystems. Journal of the North American Benthological Society, 30(1), 310-327. http://dx.doi.org/10.1899/10-129.1

Cathcart, C. N., McKinstry, M. C., MacKinnon, P. D., \& Ruffing, C. M. (2019). A tribute to tributaries: Endangered fish distributions within critical habitat of the San Juan 
River, USA. North American Journal of Fisheries Management, 39(5), 10151025. https://doi.org/10.1002/nafm.10335

Cooke, S., Paukert, C., \& Hogan, Z. (2012). Endangered river fish: Factors hindering conservation and restoration. Endangered Species Research, 17(2), 179-191. https://doi.org/10.3354/esr00426

Dias, M. S., Tedesco, P. A., Hugueny, B., Jézéquel, C., Beauchard, O., Brosse, S., \& Oberdorff, T. (2017). Anthropogenic stressors and riverine fish extinctions. Ecological Indicators, 79, 37-46. https://doi.org/10.1016/j.ecolind.2017.03.053

Dunn, C.G. (2019). Conservation and management of Missouri's mid-sized rivers: development of sampling protocols and application to priority watershed rivers. Retrieved from the Missouri Department of Conservation.

Erős, T. (2017). Scaling fish metacommunities in stream networks: Synthesis and future research avenues. Community Ecology, 18(1), 72-86. https://doi.org/10.1556/168.2017.18.1.9

Erős, T., Kuehne, L., Dolezsai, A., Sommerwerk, N., \& Wolter, C. (2019). A systematic review of assessment and conservation management in large floodplain rivers Actions postponed. Ecological Indicators, 98, 453-461. https://doi.org/10.1016/j.ecolind.2018.11.026

Erős, T., Schmera, D., \& Schick, R. S. (2011). Network thinking in riverscape conservation-a graph-based approach. Biological Conservation, 144(1), 184-192. https://doi.org/10.1016/j.biocon.2010.08.013 
Erős, T., Takács, P., Specziár, A., Schmera, D., \& Sály, P. (2017). Effect of landscape context on fish metacommunity structuring in stream networks. Freshwater Biology, 62(2), 215-228. https://doi.org/10.1111/fwb.12857

Fausch, K. D., Torgersen, C. E., Baxter, C. V., \& Li, H. W. (2002). Landscapes to riverscapes: Bridging the gap between research and conservation of stream fishes. Bioscience, 52(6), 483-498. https://doi.org/10.1641/00063568(2002)052[0483:ltrbtg]2.0.co;2

Ferreira, F. C., Souza, U. P., Cetra, M., \& Petrere, M. (2019). Rhithronic and potamonic fishes coexist in wadeable streams under distinct metacommunity processes. Ecology of Freshwater Fish, 28(1), 85-96. https://doi.org/10.1111/eff.12433

Fischer, S., \& Combes, M. (2003). Resource assessment and monitoring program: standard operation procedures - fish sampling. Jefferson City, MO: Missouri Department of Conservation.

Galat, D. L., \& Zweimuller, I. (2001). Conserving large-river fishes: Is the highway analogy an appropriate paradigm? Journal of the North American Benthological Society, 20(2), 266-279. https://doi.org/10.2307/1468321

Hinck, J. E., McMurray, S. E., Roberts, A. D., Barnhart, M. C., Ingersoll, C. G., Wang, N., \& Augspurger, T. (2012). Spatial and temporal trends of freshwater mussel assemblages in the Meramec River basin, Missouri, USA. Journal of Fish and Wildlife Management, 3(2), 319-331. https://doi.org/10.3996/052012-JFWM-038

Hitt, N. P., \& Angermeier, P. L. (2008). Evidence for fish dispersal from spatial analysis of stream network topology. Journal of the North American Benthological Society, 27(2), 304-320. https://doi.org/10.1899/07-096.1 
Hugueny, B., Oberdorff, T., \& Tedesco, P. A. (2010). Community ecology or river fishes: a large-scale perspective. In K.B. Gido \& D.A. Jackson (Eds.), Community ecology of stream fishes: Concepts, approaches, and techniques (pp. 29-62).

Bethesda, MD: American Fisheries Society.

Kominoski, J. S., Ruhí, A., Hagler, M. M., Petersen, K., Sabo, J. L., Sinha, T., ... Olden, J. D. (2018). Patterns and drivers of fish extirpations in rivers of the American Southwest and Southeast. Global Change Biology, 24(3), 1175-1185. https://doi.org/10.1111/gcb.13940

Lackmann, A. R., Andrews, A. H., Butler, M. G., Bielak-Lackmann, E. S., \& Clark, M. E. (2019). Bigmouth Buffalo Ictiobus cyprinellus sets freshwater teleost record as improved age analysis reveals centenarian longevity. Communications Biology, 2(1), 197. https://doi.org/10.1038/s42003-019-0452-0

Laub, B. G., Thiede, G. P., Macfarlane, W. W., \& Budy, P. (2018). Evaluating the conservation potential of tributaries for native fishes in the upper Colorado River basin. Fisheries, 43(4), 194-206. https://doi.org/10.1002/fsh.10054

López-Delgado, E. O., Winemiller, K. O., \& Villa-Navarro, F. A. (2018). Do metacommunity theories explain spatial variation in fish assemblage structure in a pristine tropical river? Freshwater Biology, fwb.13229. https://doi.org/10.1111/fwb.13229

Mattingly, H. T., \& Galat, D. L. (2002). Distributional patterns of the threatened Niangua darter, Etheostoma nianguae, at three spatial scales, with implications for species conservation. Copeia, (3), 573-585. https://doi.org/10.1643/0045-

8511(2002)002[0573:dpottn]2.0.co;2 
McCluney, K. E., Poff, N. L., Palmer, M. A., Thorp, J. H., Poole, G. C., Williams, B. S., ... Baron, J. S. (2014). Riverine macrosystems ecology: Sensitivity, resistance, and resilience of whole river basins with human alterations. Frontiers in Ecology and the Environment, 12(1), 48-58. https://doi.org/10.1890/120367

McIntyre, P. B., Liermann, C. R., Childress, E., Hamann, E. J., Hogan, J. D., Januchowski-Hartley, S. R., ... Pracheil, B. M. (2016). Conservation of migratory fishes in freshwater ecosystems. In G.P. Closs, M. Krkošek, \& J.D. Olden (Eds.), Conservation of freshwater fishes (pp. 324-360). Cambridge, UK: Cambridge University Press

Melles, S. J., Jones, N. E., \& Schmidt, B. (2012). Review of theoretical developments in stream ecology and their influence on stream classification and conservation planning: Developments in fluvial ecosystem classification. Freshwater Biology, 57(3), 415-434. https://doi.org/10.1111/j.1365-2427.2011.02716.x

Peláez, O., \& Pavanelli, C. S. (2019). Environmental heterogeneity and dispersal limitation explain different aspects of $\beta$-diversity in Neotropical fish assemblages. Freshwater Biology, 64(3), 497-505. https://doi.org/10.1111/fwb.13237

Poole, G. C. (2002). Fluvial landscape ecology: Addressing uniqueness within the river discontinuum. Freshwater Biology, 47(4), 641-660. https://doi.org/10.1046/j.1365-2427.2002.00922.x

Poole, Geoffrey C. (2010). Stream hydrogeomorphology as a physical science basis for advances in stream ecology. Journal of the North American Benthological Society, 29(1), 12-25. https://doi.org/10.1899/08-070.1 
Pracheil, B. M., McIntyre, P. B., \& Lyons, J. D. (2013). Enhancing conservation of largeriver biodiversity by accounting for tributaries. Frontiers in Ecology and the Environment, 11(3), 124-128. https://doi.org/10.1890/120179

Schaefer, J. F., \& Kerfoot, J. R. (2004). Fish assemblage dynamics in an adventitious stream: A landscape perspective. American Midland Naturalist, 151(1), 134-145. https://doi.org/10.1674/0003-0031(2004)151[0134:FADIAA]2.0.CO;2

Schlosser, I. J. (1991). Stream fish ecology: A landscape perspective. Bioscience, 41(10), 704-712. https://doi.org/10.2307/1311765

Sowa, S. P., Annis, G., Morey, M. E., \& Diamond, D. D. (2007). A GAP analysis and comprehensive conservation strategy for riverine ecosystems of Missouri. Ecological Monographs, 77(3), 301-334. https://doi.org/10.1890/06-1253.1

Sparks, R. E. (2010). Forty years of science and management on the Upper Mississippi River: An analysis of the past and a view of the future. Hydrobiologia, 640(1), 315. https://doi.org/10.1007/s10750-009-0069-2

Thorp, J. H., Thoms, M. C., \& Delong, M. D. (2006). The riverine ecosystem synthesis: Biocomplexity in river networks across space and time. River Research and Applications, 22(2), 123-147. https://doi.org/10.1002/rra.901

Thorp, James H. (2014). Metamorphosis in river ecology: From reaches to macrosystems. Freshwater Biology, 59(1), 200-210. https://doi.org/10.1111/fwb.12237

Van Looy, K., Tonkin, J. D., Floury, M., Leigh, C., Soininen, J., Larsen, S., ... Wolter, C. (2019). The three Rs of river ecosystem resilience: Resources, recruitment, and refugia. River Research and Applications, 35(2), 107-120.

https://doi.org/10.1002/rra.3396 
Vannote, R. L., Minshall, G. W., Cummins, K. W., Sedell, J. R., \& Cushing, C. E. (1980). The river continuum concept. Canadian Journal of Fisheries and Aquatic Sciences, 37(1), 130-137. https://doi.org/10.1139/f80-017

Vitorino Júnior, O. B., Fernandes, R., Agostinho, C. S., \& Pelicice, F. M. (2016). Riverine networks constrain $\beta$-diversity patterns among fish assemblages in a large Neotropical river. Freshwater Biology, 61(10), 1733-1745. https://doi.org/10.1111/fwb.12813

Vokoun, J. C., \& Rabeni, C. F. (2005). Variation in an annual movement cycle of flathead catfish within and between two Missouri watersheds. North American Journal of Fisheries Management, 25(2), 563-572. https://doi.org/10.1577/M04043.1

Ward, J. V. (1989). The four-dimensional nature of lotic ecosystems. Journal of the North American Benthological Society, 8(1), 2-8. https://doi.org/10.2307/1467397

Ward, J. V. (1998). Riverine landscapes: Biodiversity patterns, disturbance regimes, and aquatic conservation. Biological Conservation, 83(3), 269-278. https://doi.org/10.1016/S0006-3207(97)00083-9

Westhoff, J. T., Paukert, C., Ettinger-Dietzel, S., Dodd, H., \& Siepker, M. (2016). Behavioural thermoregulation and bioenergetics of riverine smallmouth bass associated with ambient cold-period thermal refuge. Ecology of Freshwater Fish, 25(1), 72-85. https://doi.org/10.1111/eff.12192

Wheeler, B. A., Prosen, E., Mathis, A., \& Wilkinson, R. F. (2003). Population declines of a long-lived salamander: A 20+-year study of hellbenders, Cryptobranchus 
alleganiensis. Biological Conservation, 109(1), 151-156.

https://doi.org/10.1016/S0006-3207(02)00136-2

Wildhaber, M. L., Gladish, D. W., \& Arab, A. (2012). Distribution and habitat use of the Missouri River and lower Yellowstone River benthic fishes from 1996 to 1998: A baseline for fish community recovery: Missouri and Yellowstone river fishes.

River Research and Applications, 28(10), 1780-1803.

https://doi.org/10.1002/rra.1559

Zbinden, Z. D., \& Matthews, W. J. (2017). Beta diversity of stream fish assemblages: Partitioning variation between spatial and environmental factors. Freshwater Biology, 62(8), 1460-1471. https://doi.org/10.1111/fwb.12960 


\title{
CHAPTER 2: A FLEXIBLE SURVEY DESIGN FOR MONITORING SPATIOTEMPORAL FISH RICHNESS IN NON-WADEABLE RIVERS: OPTIMIZING EFFICIENCY BY INTEGRATING GEARS
}

\begin{abstract}
We designed a flexible protocol for monitoring fish species richness in non-wadeable rivers. Nine sites were sampled seasonally with six gears in two physiograph regions in Missouri (USA). Using a resampling procedure and mixed-effects modeling, we quantified richness and compositional overlap among gears, identified efficient gear combinations, and evaluated protocol performance across regions and seasons. We detected 25-75 species per sample and 89,185 fish. On average, no single gear detected $>62 \%$ of observed species, but an optimized, integrated-gear protocol with four complementary gears on average $( \pm$ SD) detected $90.1 \pm 1.5 \%$ of species while requiring only $52 \%$ of initial sampling effort. Neither season nor physiographic region explained low spatiotemporal variation in percentage richness detected by the integrated-gear protocol. In contrast, equivalent effort with an electrofishing-only protocol was $53.5 \%$ less efficient, seasonally biased and imprecise (36.1-82.3\% of richness), and on average detected $15.9 \%$ less of observed richness. Altogether, riverine fish richness is likely underestimated with single-gear survey designs. When paired with existing wadeablestream inventories, our customizable approach could benefit regional monitoring by comprehensively documenting riverine contributions to riverscape biodiversity.
\end{abstract}




\section{Introduction}

Conservation entities need efficient and unbiased methods for monitoring riverine biodiversity given the many stressors altering rivers worldwide (Vörösmarty et al. 2010). Rivers influence assemblage dynamics at regional extents by providing habitat for floodplain- and channel-dependent riverine fishes (Galat and Zweimuller 2001), and corridors connecting stream-fish populations throughout river basins (McCluney et al. 2014). Consequently, rivers are pivotal to how fish assemblages respond to drivers of global change by governing interactions among species range shifts, dispersal pathways, and expanding water infrastructure (Kominoski et al. 2018). However, survey-design developments for sampling riverine assemblages have lagged behind those for other freshwater systems (Reash 1999), likely because rivers are some of the most demanding aquatic systems to sample (Paukert and Galat 2010).

Fish assemblages and habitats become increasingly complex downriver (Ward et al. 2002), making riverine fishes particularly difficult to monitor (Flotemersch et al. 2011). Beyond logistics of sampling large areas, surveys can be hampered by riverine environmental conditions including high turbidity, depth, spatiotemporally variable flows, debris, and off-channel habitats affecting observational ability and assemblage dynamics (Flotemersch et al. 2011; Gibson-Reinemer et al. 2016a). Assessments of local riverine fish richness (hereafter, "richness assessments") typically account for these added complexities with greater effort (Hughes et al. 2002) and multiple gears (e.g., Neebling and Quist 2011; Loisl et al. 2014; Zajicek and Wolter 2018), which can result in highly customized designs for specific rivers and reaches (McManamay et al. 2014; Gibson-Reinemer et al. 2016a). However, these designs may lack versatility needed for 
regional biodiversity monitoring of multiple rivers across varying environmental conditions.

Versatile survey designs developed for monitoring richness and assemblage composition often emulate existing wadeable-stream protocols (Reash 1999; Hughes and Peck 2008). Consequently, these designs minimize sources of sampling variation arising from greater habitat diversity in rivers by standardizing data collection to a subset of habitats with one (Hughes et al. 2002; Maret et al. 2007) or two gears (Moulton et al. 2002; USEPA 2013). For example, several riverine fish assessments mainly target largebodied fishes by continuously electrofishing 500-1,600 m of river (Gammon and Simon 2000; Lyons et al. 2001; Flotemersch and Blocksom 2005). Moreover, most of these protocols assess riverine condition (i.e., degree of alteration to natural integrity) using multi-metric biotic indices that require less effort to estimate precisely than species richness (Flotemersch and Blocksom 2005; Maret et al. 2007). Although most multimetric indices incorporate richness-based metrics (Pearson et al. 2011), estimated richness often depends on limited standardized effort versus the effort needed to survey available habitats comprehensively. Over time underreported riverine richness could manifest as data gaps within increasingly used regional, basin-wide management plans. This is undesirable, as accurate indicators of local species richness throughout watersheds are needed to map biodiversity (Troia and McManamay 2020), designate and prioritize conservation areas (Abell et al. 2007), conduct threat assessments (Sievert et al. 2016), and monitor spatiotemporal trends in populations, assemblages, and communities (Radinger et al. 2019). 
Richness assessments intended to contribute to management objectives must also navigate complex logistics, and limited funding and timing (Hughes and Peck 2008). Consequently, survey designs for most assessments prioritize sampling efficiency. These designs typically improve efficiency by constraining observations to the single-most effective gear or use multiple gears by identifying the most effective gear for each habitat (Utrup and Fisher 2006; Loisl et al. 2014). The second approach is more comprehensive, but many species occupy multiple habitats, thereby predisposing these species to detection by multiple gears (i.e., redundant effort). Further, a single gear is unlikely to detect all species inhabiting a habitat type, especially if inhabitants vary widely in body size (Schloesser et al. 2012a). Ideally, investigators could further improve efficiency by distributing effort among gears to minimize redundancy across habitats and gears, yet still comprehensively represent fish assemblages.

Natural and user-induced variability can affect inferences made from ecological assessments. For example, species-sampling relationships can vary temporally by diel period (Flotemersch and Blocksom 2005) and year (Meador and McIntyre 2003).

Although surprisingly few riverine fish assessments have investigated seasonal influences, species-sampling relationships could be sensitive to high spring flows (Simon and Sanders 1999), temporary occurrences of migratory or schooling species (De Leeuw et al. 2007), and recruitment (Peterson and Rabeni 1995; Gammon and Simon 2000). In contrast to time, several studies have investigated species-sampling relationships across space. For example, sampling effort to detect the same percentage of species richness across sites can vary because of habitat heterogeneity (Angermeier and Smogor 1995), stream size (Paller 1995), and by assemblage attributes, including species rarity (Kanno 
et al. 2009), fish density (Paller 1995), and richness (Meador 2005). Options for overcoming variability include increasing effort (Peterson and Rabeni 1995), standardizing data collection (Bonar et al. 2009), stratifying results (e.g., by river size; Neebling and Quist 2011), and corrective modeling (McManamay et al. 2014). Failing to account for spatiotemporal variation may limit the ability of protocols to detect trends (Meador and McIntyre 2003) and/or bias results, which can undermine one-size-fits-all survey designs (Lindenmayer and Likens 2010).

Our goal was to develop a multi-gear survey design for assessing local fish species richness in medium-to-large ("mid-sized") non-wadeable rivers. Many standardized riverine assessments are in place for regulatory purposes to monitor fishassemblage condition in great rivers (i.e., 50,000 $\mathrm{km}^{2}>$ watershed areas; Guy et al. 2009), meaning there are few survey designs for smaller, and typically less-altered, rivers (Yoder and Kulik 2003). Mid-sized rivers can be particularly challenging to sample because they are too large to wade, but often feature wadeable habitats, which can hamper watercraft. Thus, documenting fish richness in our focal rivers required a mixture of wadeable and non-wadeable gears. We sampled nine sites seasonally with six gears across two distinct regions in Missouri (USA). This intensive effort allowed us to quantify effectiveness of individual and combined gears while varying effort via multiple randomizations. We had five specific research questions: (1) which gears detected the most species per unit effort? (2) which gears were most redundant? (3) on average, what combination of gears most efficiently detected $90 \%$ of observed species richness? (4) did the most-efficient protocol that integrated effort among gears detect a consistent percentage of richness across regions and seasons? and (5) was this integrated-gear 
protocol more effective and consistent than traditional effort with an electrofishing-only protocol? Our study is among the first riverine fish assessments to simultaneously examine species-sampling relationships across seasons and regions with such a comprehensive survey design. Investigators may benefit from knowing the effectiveness of individual gears (question 1-2) or emulate our entire approach (questions 3-5), which optimized efficiency by integrating effort among multiple gears and then evaluated protocol performance across broad spatiotemporal environmental conditions.

\section{Methods}

\section{Study area and timing}

We sampled the non-wadeable rivers linking wadeable streams to Missouri's two great rivers, the Mississippi and Missouri rivers (Table 2.1; Fig. 2.1). Northern Missouri, in the Central Lowland region (hereafter "Prairie"), is characterized by low topographical relief and grassland/pasture (43\%) or row-crops (38\%). Many Prairie river systems are now leveed, channelized, and otherwise engineered to limit flooding. Most Prairie rivers are low gradient, turbid, dominated by silt and sand substrates, and vary widely in physicochemical and hydrological conditions across seasons (Sowa et al. 2007). In contrast, the Ozark Plateaus region (hereafter, "Ozarks") has pine, mixed, or deciduous forests (52\%) and pasture/grassland (40\%). Ozark rivers typically have higher gradient channels that are semi-confined by bluffs, are less turbid, and have gravel-cobble alluvium and aquatic vegetation present within shallow areas (Sowa et al. 2007). Further, many Ozark rivers are groundwater-influenced, creating more seasonally stable hydrologic and physicochemical conditions. 
We sampled nine sites (5 Ozark, 4 Prairie; Table 2.1) between 2014 and 2016 across three seasons. State fisheries biologists pre-selected drainages that were accessible and geographically representative of Missouri, had few sampling restrictions posed by federally imperiled species, and had few impoundments. For example, biologists recommended the upper Meramec River drainage, so we randomly selected a sampling locality within the upper Meramec River from the six available river accesses. Our nine sites encompassed a variety of river sizes (watershed areas $=2,759 \mathrm{~km}^{2}-19,615 \mathrm{~km}^{2}$ ) and environmental conditions (lowland-upland). We sampled each site 3-5 times (36 total samples) with at least one sample in spring (Mar. 18-Jun. 13), summer (Jun. 25-Sept.8), and fall (Sept. 16-Nov. 11), and at least 20 days between consecutive samples at the same site.

\section{Site length}

Site lengths were 50 mean wetted-channel widths (MWCW) and typically encompassed at least one meander-bend with multiple habitats (e.g., shoals, pools). We estimated MWCW within $5 \mathrm{~km}$ of a river access point by measuring wetted channel width along eleven cross-sectional transects spaced $500 \mathrm{~m}$ apart using satellite imagery via Google Earth. If available, we used imagery from early spring during baseflow and leaf-off, and we used the same MWCW at sites across seasons. Finally, we randomly designated the starting point of each site as either $1 \mathrm{~km}$ up- or down-river of an access and extended the site in the opposite direction of the river access to limit anthropogenic influences often concentrated at accesses. 


\section{Sampling gears}

Selected gears were capable of sampling all major habitats within sites. Candidate habitats included all areas with an intact main-channel surface-water connection, including secondary channels, slackwater, and other lateral units, but excluding isolated floodplain waterbodies. We primarily used benthic trawling, boat electrofishing, and seining (hereafter, "active gears"). Rather than continuously sampling with each gear, we divided effort into several discrete sub-samples that could be placed in specific habitats and evenly distributed across a site. We supplemented active gears with five mini-fyke, hoop, and stationary trammel nets (hereafter, "passive gears"), which fished overnight and were placed in habitat units that were difficult to sample with active gears (15 total nets per sample). Importantly, a sub-sample refers to a basic unit of effort by each gear

(i.e., 1 overnight net set regardless of type, 1 seine haul, one 50-m electrofishing or trawl run).

Boat electrofishing sampled littoral areas (within $20 \mathrm{~m}$ from a bank) and shallow (0.5-1.5 m) mid-channel shoals. We used a 5.2-m flat-hull aluminum boat with a $40 \mathrm{Hp}$ jet-drive outboard motor. The electrofishing system consisted of a 5,000-W generator connected to a control unit and two bow-mounted booms with "spider"-style anodes (Midwest Lake Management, Inc. Polo, MO). We standardized the peak power transferred to fish at 3,000 W by adjusting voltage according to ambient conductivity (Miranda 2009). Our electrofishing settings broadly targeted fish assemblages and consisted of 60-Hz pulsed direct current with 25-35\% duty cycle (Guy et al. 2009). Electrofishing effort was divided into discrete 50-m downstream runs (= 1 sub-sample) lasting $189 \pm 61 \mathrm{~s}($ mean $\pm \mathrm{SD})$. An operator maneuvered the boat perpendicular to the 
shoreline, while two crewmembers netted stunned fish using dipnets with 46-cm deep bags and 6.4-mm mesh. If swift water velocities $(>0.70 \mathrm{~m} / \mathrm{s})$ in mid-channel shoals prevented lateral movements during the initial run, we made a second 50-m run adjacent to the first run but facing the opposite bank. Electrofishing was limited in shallow $(<0.5)$ habitats by navigability and likely at depths $\geq 1.8$ by vertically diminishing voltage needed to immobilize fish.

We used four seining techniques and two different seines (depending on habitat) to target small-bodied fishes inhabiting shallow areas with little structure. We sampled approximately $65 \mathrm{~m}^{2}$ of area per sub-sample regardless of technique and spaced subsamples at least $25 \mathrm{~m}$ apart to minimize spatial dependency among sub-samples. We primarily used a $9.1-\mathrm{m} \times 1.8-\mathrm{m}$ bag seine with a $1.8-\mathrm{m}$ bag and 6.4-mm delta knotless mesh netting (Guy et al. 2009) and a quarter-seine haul technique in areas with slow to moderate water velocities along riverbanks, or a purse method to secure the bag in wadeable areas where the seine could not be beached. Alternatively, we used a 4.5-m x 1.5-m straight (bagless) seine with 6.4-mm netting to drag the seine downriver along steeply sloped shorelines where wading was restricted, with drag length compensating for allowable seine width from the bank. In swift, shallow areas $(<0.3 \mathrm{~m})$, we used a kick-net technique with the straight seine to conduct adjacent kick nets while dislodging benthic fishes from substrates. We considered two adjacent kick nets as equivalent to one seine haul by the other techniques.

Benthic trawling was used in deep, mid-channel habitats. We used a modified mini-Missouri trawl with a 6.4-mm outer mesh and 38-mm inner mesh ("Gerken Siamese Benthic Trawl"; Innovative Net Systems, Milton, Louisiana). The trawl was $2.5 \mathrm{~m}$ long 
with a 2.5-m floated headrope, and a weighted 3-m footrope. We interchanged three sizes $(50 \mathrm{~cm}, 61 \mathrm{~cm}$, and $76 \mathrm{~cm})$ of otter boards depending on water velocity and adjusted towlines to approximate a 7:1 ratio of towline length to average river depth. The trawl was towed off the bow while reversing downriver with a sub-sample beginning once the towlines and the trailing buoy line were taut and ending after sampling $50 \mathrm{~m}$ (= $1 \mathrm{sub}-$ sample; trawl sub-sample $=65 \pm 16 \mathrm{~s}[$ mean $\pm \mathrm{SD}])$.

Five non-baited mini-fyke nets were set per sample primarily in habitats not effectively sampled by seining, including low-velocity, structurally complex habitats (vegetation, debris, boulders), and off-channel areas. Mini-fyke nets with two 0.6-m x 1.2-m frames were bisected by a 4.5-m lead extending to a riverbank or other structure, and a cod end with two steel hoops. Nets had 3.1-mm green-treated nylon bar mesh. Each mini-fyke net was set overnight for 18-24 h (= 1 sub-sample).

Five non-baited hoop nets were set per sample targeting large-bodied fishes inhabiting deep habitats $(>1.5 \mathrm{~m})$ that could not be effectively sampled by electrofishing. Hoop nets were $1.2 \mathrm{~m}$ in diameter and $4.9 \mathrm{~m}$ long with 3.8-cm bar mesh (Guy et al. 2009). Each net had seven fiberglass hoops with finger throats attached to the second and fourth hoops and were set overnight for 18-24 h (= 1 sub-sample).

Five stationary trammel nets were set per sample at the bottom of deep, lowvelocity habitats to target large-bodied fishes. Trammel nets were $15.2 \mathrm{~m}$ long x $1.8 \mathrm{~m}$ deep with $20.3-\mathrm{cm}$ and $9.5-\mathrm{cm}$ bar mesh for outer and inner panels, respectively, and held in place by attaching float- and lead-line ends to vertically suspended lines at each end. We deployed each trammel net overnight for approximately $12 \mathrm{~h}$ (= 1 sub-sample). 
All sampling was permitted by the Missouri Department of Conservation and performed under University of Missouri Animal Use and Care Protocol 8532. Sampled individuals that could not be field identified were preserved and subsequently identified. We limited passive-gear bycatch of non-fishes by using passive-set trammel nets rather than gill nets, limiting soak times to $12-24 \mathrm{~h}$ (vs. multiple days), and only partially submerging mini-fyke nets.

\section{Scaling sampling effort to river size}

The sizes of our sites varied nearly sevenfold (watershed areas $=2,759-19,615$

$\mathrm{km}^{2}$ ), so we scaled sampling effort with active gears according to each site's total length to ensure similar proportions of habitat were sampled at each site (Fig. 2.2; Appendix 2.1). We sampled approximately 40\% (20 MWCWs), 25\% (12.5 MWCWs), and 7\% (3.5 MWCWs) of each site's length with electrofishing, trawling, and seining, respectively. These site-length percentages balanced our field time among active gears during the initial phase of protocol development. We achieved these percentages by summing the lengths of sub-samples, with each electrofishing and trawling sub-samples equaling $50 \mathrm{~m}$ and seining sub-samples approximating $10 \mathrm{~m}$. We distributed sampling effort across a site by apportioning active-gear sub-samples among 10 equally sized sections ( 1 section $=5$ MWCWs; Fig. 2.2). We used equation (1) to calculate the number of sub-samples per section for each active gear $(i)$ and then rounded to the nearest sub-sample per section. For example, in the 53-m wide Black River (50 x MWCW =2,650 m), we conducted two 50-m electrofishing runs in each section, totaling $1,000 \mathrm{~m}$ of electrofishing (electrofishing length based on target percentage $[40 \%$ site extent $]=1,060 \mathrm{~m}$; Fig. 2.2). 
Balancing active effort among sections enabled a randomization procedure to identify optimal effort by resampling equal-effort sections (see Statistical analyses for question 3).

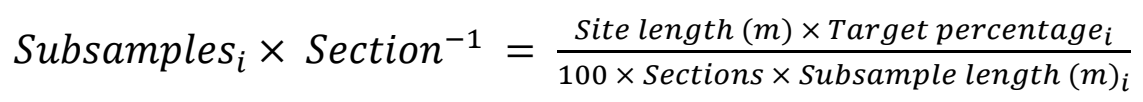

Passive-gear effort was not scaled to river size because passive effort was not in terms of distance, and the habitats sampled by these gears were often restricted (e.g., secondary channels, pools $>2 \mathrm{~m}$ deep). Each section was divided into fourths or sixths depending on river size, and then we randomly selected an area to sample with each gear using a random-number generator on a ruggedized tablet computer. If a gear could not be used effectively in habitats within the selected area, another area within the same section was randomly selected. Similarly, if a gear could not be used effectively in a section, an adjacent section was sampled. This process was repeated for each active gear and in each of the 10 sections. The sequence of gears varied by sample, but we avoided sampling sections after electrofishing on the same day to limit interference among gears. Overall, our design scaled effort by active gears across river sizes, supplemented active effort with passive gears, and balanced sampling effort spatially within sites. Hereafter, we refer to our original design as our "full-effort" protocol.

\section{Analyses}

We initially quantified pairwise species richness (question 1) and overlap (question 2) among gears by sub-sample rather than by cumulative effort (pooled subsamples) for two purposes; first, each sub-sample required a comparable crew investment 
to complete and process regardless of gear (20-35 $\mathrm{min}$ ), whereas cumulative effort varied widely among gears (e.g., 5 mini-fyke nets $\approx 3 \mathrm{~h}$ vs. $\geq 1 \mathrm{~km}$ electrofishing $\approx \geq 8 \mathrm{~h}$ ).

Second, it is instructive to demonstrate with two gears that total species richness detected by multi-gear designs depends on the interplay between effectiveness and overlap of constituent gears before presenting the same concept with combinations of six gears (question 3).

\section{Question 1: Which gears detected the most species per unit effort?}

We used generalized linear mixed-effects models to determine whether fish species richness per sub-sample varied by gear (e.g., one 50-m electrofishing run, 1 minifyke net, etc.). The candidate model set included a global model with a three-way interaction among the fixed effects gear (six), region (Prairie, Ozark), and season (spring, summer, fall), and nested models with gear effects, and a null intercept-only model (12 candidate models). Interactions enabled richness by gear to depend on seasons and regions. Our 36 samples were nested within nine sites, and both factors were treated as random effects in all models. We used a negative binomial error distribution to account for overdispersion and inspected residuals for non-independence and heteroscedasticity (Appendix 2.2). Finally, we evaluated the relative support of candidate models with Akaike's Information Criterion (AIC), and gauged model accuracy with pseudo $R^{2}$ statistics that estimated variation explained by fixed- (marginal $\left[R_{m}^{2}\right]$ ), and fixed + random effects (conditional $\left[R_{c}^{2}\right]$; Nakagawa et al. 2017).

Question 2: Which gears were most redundant? 
We used Sørensen's similarity coefficient to quantify the average compositional overlap in species (presence/absence) among sub-samples within (six gears) and among gears (30 gear combinations). Sørensen's coefficients were metrics for redundant sampling effort that excluded joint absences and could range from 0 (= no shared species) to 1 (= identical species; Anderson et al. 2011). We implemented a resampling procedure to estimate average sub-sample overlap for each combination. For example, overlap between electrofishing and seining within each sample was estimated by calculating Sørensen's coefficient from one randomly selected electrofishing sub-sample and one seining sub-sample. We also noted the cumulative species richness within these two subsamples. When calculating overlap between sub-samples from the same gear, we sampled without replacement to avoid pairing identical sub-samples. We replicated these steps 999 times, and averaged coefficients and sub-sample richness across replicates and samples.

Question 3: What combination of gears most efficiently detected $90 \%$ of observed species richness?

We identified the most efficient protocol that on average detected $90 \%$ of observed richness across samples, which is a common benchmark in richness assessments (Flotemersch et al. 2011). We hypothesized efficiency could be further improved by minimizing redundant effort within and among gears. Therefore, we developed a resampling procedure to estimate the average richness that would have been detected during each sample by each of the 287,496 candidate protocols nested within the fulleffort protocol (total protocols $=\prod_{i}^{6} x_{i}$, where $[x]$ equals 11 and 6 for each active and 
passive gear $[i]$, respectively). For example, the procedure randomly selected without replacement two mini-fyke nets and three sections worth of trawling sub-samples for a protocol requiring two mini-fyke nets and $30 \%$ of the full trawling effort (i.e., three sections $=$ three of 10 trawl sub-samples for a 40-m-wide river; six of 20 sub-samples for an $80-\mathrm{m}$-wide river). Then richness was calculated from these sub-samples. These steps were replicated 999 times, and we obtained final estimates of percentage richness for each candidate protocol by averaging richness across replicates.

Richness was standardized across samples by converting the estimated richness detected by each candidate protocol to the percentage of richness observed in each sample (hereafter, "percentage richness"). Then we selected the protocol requiring the least effort (fewest combined sections and nets) that detected $\geq 90 \%$ of species per sample (hereafter, "integrated-gear protocol") and examined its performance in further analyses (see below). Ours and most other richness assessments report percentage observed richness rather than percentage theoretical richness (observed species + unobserved species). For clarity, a Chao's (1987) incidence-based estimator of theoretical richness indicated the full-effort protocol detected on average $86 \pm 9 \%$ (mean \pm SD) of species at sites per sample, meaning our reported percentages of richness are lower than theoretical richness (Table 2.2).

Question 4: Did the most-efficient protocol detect a consistent percentage of richness across regions and seasons?

After formalizing the most efficient gears into the integrated-gear protocol, we examined the protocol's consistency across regions and seasons, which might be 
important if broadly using the protocol within regional monitoring programs. Rather than expecting investigators to emulate our exact scaling scheme in the field (i.e., eq. 1), we simplified the integrated-gear protocol by categorizing rivers into two groups (Small Rivers $<65 \mathrm{~m}$ wide, $n=5$; Large Rivers $\geq 65 \mathrm{~m}$ wide, $n=4$ ). The number of sub-samples corresponded to the average MWCW of sites within each category (average MWCW of Small Rivers $=52 \mathrm{~m}$, Large Rivers $=82 \mathrm{~m}$ ). Consequently, Small and Large rivers required 34 and 50 sub-samples, respectively, in further randomizations (see Results for expanded section on integrated-gear sub-sample requirements).

The spatiotemporal variability of the integrated-gear protocol was visualized by plotting the relationship between sampling effort and percentage observed richness for samples (i.e., species-accumulation curve [SAC]; Gotelli and Colwell 2001). We constructed a SAC for each sample using a re-sampling procedure to ensure its form was insensitive to any specific sampling sequence. The procedure first calculated observed richness of a randomly selected sub-sample from a pool of all sub-samples available to the integrated-gear protocol. Next, the procedure conducted 999 replicates and averaged richness across replicates. These steps were repeated while incrementally increasing the number of sub-samples by one without replacement until reaching 34 and 50 sub-samples for Small and Large rivers, respectively. Next, we examined whether the maximum observed percentage richness (= response variable) varied by season and/or region by fitting four linear mixed-effects regression models: intercept-only, region-only, seasononly, and region + season. We included a site-level random effect in all models to account for non-independence of multiple samples per site and used AICc and $R_{M}^{2}$ to evaluate relative support for competing models. 
Question 5: Was the integrated-gear protocol more effective and consistent than traditional effort with an electrofishing-only protocol?

We compared SACs constructed from the integrated-gear protocol and a traditional fish richness assessment requiring $1 \mathrm{~km}$ of electrofishing using the resampling procedures described immediately above. Curves were constructed by incrementally increasing sub-samples from 1 to 20 since each electrofishing sub-sample was $50 \mathrm{~m}$ (20 sub-samples $=1 \mathrm{~km}$ ). Next, we linearly regressed the percentage species richness after 20 sub-samples (= response) to one of nine models. These models evaluated whether (a) integrated-gear and 1-km electrofishing protocols detected different percentages of species richness (i.e., effect of protocol), (b) percentages varied by season and/or region (effects of region and/or season), and (c) one protocol was more sensitive to season and/or region than the other (interactions between protocol and region or season). We also included MWCW as a covariate in all models because both protocols required 20 sub-samples rather than scaling effort to river size. The 1-km electrofishing protocol was nearly twice as variable as the integrated-gear protocol $(\mathrm{SD}$ of $1-\mathrm{km}$ electrofishing $=$ $9.9 \%$, integrated-gear $=5.4 \%$ ), so we used generalized least squares regression to estimate separate variances for the two protocols. We also forced multiple observations from the same sites to have identical errors via a compound symmetry error structure and evaluated relative support for competing models with AICc and a pseudo- $R^{2}$ statistic from R package 'piecewiseSEM' (Lefcheck 2016). 


\section{Results}

We detected 89,185 individual fish and 140 species across 36 samples. Observed species richness per sample ranged from 25 to 75 (Table 2.2). Mean ( \pm SD) richness per sample by region equaled 59.6 \pm 9.2 species (Ozarks) and $37.1 \pm 7.8$ species (Prairie). By comparison, the historically (1970-2010) reported average species richness per sample (excluding samples with $\leq 5$ species) in Ozark $(n=371)$ and Prairie $(n=141)$ river sites (drainage area $\geq 1,000 \mathrm{~km}^{2}$ ) was $24.1 \pm 9.5$ species and $16.8 \pm 6.9$ species, respectively (Missouri Department of Conservation, unpublished fish assemblage database). Among historical surveys, $93 \%$ used one $(28 \%)$ or two $(65 \%)$ gears, with electrofishing and seining being predominant gears.

\section{Question 1: Which gears detected the most species per unit effort?}

Mini-fyke nets, seining, and electrofishing detected the most species per subsample, but the relative efficacy of gears varied slightly among seasons and regions (see Fig. 2.3 for estimated richness per sub-sample by gear). The best-supported model explaining sub-sample richness included all main effects and three two-way interactions among season, region, and gear (Akaike weight, $w_{l}=0.98 ; R_{M}^{2}=37 \%$; Table 2.3; see Appendix 2.3 for effect sizes). All effect sizes reference summer electrofishing in Ozark rivers. Overall, predicted sub-sample richness ranged from 1.1 to 8.3 species and was mainly structured by gear (gear-only model, $R_{M}^{2}=27 \%$ ) and region (gear + region model, $R_{M}^{2}=34 \%$ ), but not season (gear + season model, $R_{M}^{2}=27 \%$ ). Although two-way interactions indicated effect sizes interdependently varied by gear, season, and region, predicted sub-sample richness was generally consistent with the signs of main effects, 
making predictions more interpretable and generalizable. For example, predicted subsample richness by gear was almost always higher in Ozark rivers than Prairie rivers, but to varying degrees depending on gear and season. Notable exceptions resulting from the gear-X-region interaction were for hoop (mean predicted species $=1.3$ in Ozarks, 1.8 in Prairie) and trammel nets (= 1.6 in Ozarks, 1.9 in Prairie) when sub-sample richness was slightly higher in Prairie rivers. The effect of season was also notable with electrofishing sub-sample richness in spring (mean predicted species $=7.4$ in Ozarks, 4.2 in Prairie) and fall (= 8.3 in Ozarks, 4.4 in Prairie) being slightly higher than summer (5.4 in Ozarks, 3.6 in Prairie).

The ranked order of sub-sample richness by gears was generally consistent across seasons in Ozark (Spearman's $\rho>0.77)$ and Prairie $(\rho>0.89)$. For example, the most species were caught via mini-fyke nets (range of predicted richness per sub-sample $=$ 4.7-8.0 species), seining (3.9-7.3 species), and electrofishing (3.6-8.3 species), whereas hoop (1.1-2.1 species) and trammel nets (1.5-2.0 species) consistently detected the fewest species, and trawling was intermediate (2.4-4.5 species).

\section{Question 2: Which gears were most redundant?}

All Sørensen's coefficients within and among gears were $<0.50$, indicating fish species in sub-samples were compositionally more dissimilar than similar (Fig. 2.4). The six highest coefficients (Sørensen's coefficient $>0.27$; i.e., most redundant) were multiple sub-samples from the same gears (e.g., two electrofishing runs). In contrast, the lowest compositional overlap (Sørensen's coefficient $<0.10$; least redundant) was between gears targeting large-bodied fishes (hoop and trammel nets) and those targeting small-bodied 
fishes (seining and trawling). Coefficients were intermediate for gear combinations targeting similarly sized species but in different habitats.

Greater overlap within gears than among gears meant certain combinations of gears detected more species than two sub-samples from the single-most effective gear (mini-fyke nets). For example, two mini-fyke nets on average detected slightly fewer cumulative species (10.2) than three other gear combinations (electrofishing + mini-fyke $=11.3$ species, electrofishing + seine $=11.1$ species, mini-fyke net + seine $=10.8$ species; Fig. 2.4).

Questions 3-4: What gear combination most efficiently detected $90 \%$ of observed richness, and did this protocol detect a consistent percentage of richness across regions and seasons?

The average SAC constructed from sub-samples from the full-effort protocol across 36 samples showed most species were detected by $<20 \%$ of effort (Fig. 2.5). Only $2.0 \%$ of species $(0.5-1.5$ species $)$ were detected on average with our final $10 \%$ of effort (i.e., 2.5-4.0 hours of additional sampling). On average (mean \pm SD), detecting $90 \%$ of species required $59.5 \pm 3.3 \%$ of our original, full effort. No single gear detected on average $90 \%$ of observed species: electrofishing $=62.7 \pm 10.1 \%$, seining $=57.6 \pm 10.9 \%$, mini-fyke nets $=34.5 \pm 10.9 \%$, trawling $=29.5 \pm 8.9 \%$, trammel nets $=11.9 \pm 6.6 \%$, hoop nets $=11.1 \pm 6.1 \%$. Instead, detecting $90 \%$ of species required $\geq$ two gears and was achieved by 69,698 (24\%) of candidate protocols. The most efficient protocol (fewest sub-samples) that detected on average $90 \%$ of species, required $51.9 \%$ of our original effort. This protocol featured $70 \%$ of the original electrofishing effort, $60 \%$ of original 
seining effort, $30 \%$ of original trawling effort, and five mini-fyke nets, while excluding hoop and trammel nets. Accordingly, integrated-gear protocols for Small and Large rivers required 34 and 50 total sub-samples, respectively (Small-River sub-samples $=14$ electrofishing runs, 12 seine hauls, 3 trawl runs, 5 mini-fyke nets; Large-River subsamples $=21$ electrofishing runs, 18 seine hauls, 6 trawl runs, 5 mini-fyke nets; Appendix 2.1). A sample with these integrated-gear protocols would likely require $2-4$ days to complete with a three-person crew.

Species-accumulation curves from the integrated-gear protocol were similar across seasons and regions (Fig. 2.6). For example, the integrated-gear protocol on average achieved $90 \%$ of observed species richness with low variation $(\mathrm{SD}=1.6 \%)$. Moreover, no models were better supported than the null model $\left(w_{1}=0.64\right)$, with the region-only model having the second most, but only marginal, support $\left(\triangle \mathrm{AICc}=1.6 ; w_{2}\right.$ $=0.28 ; R_{M}^{2}=3 \% ;$ Table 2.4).

Question 5: Was the integrated-gear protocol more effective and consistent than traditional effort with an electrofishing-only protocol?

Percentages of observed richness varied widely with the $1-\mathrm{km}$ electrofishing protocol (range among samples $=36.1-82.3 \%$ ) compared to the integrated-gear protocol (64.0-86.6\%). The best-supported model explaining variation in percentage richness included effects of protocol type, season, region, a protocol-X-season interaction, and MWCW $\left(R_{M}^{2}=62 \% ; w_{1}=0.59\right.$; Table 2.5; Fig. 2.7). Protocol-type had the largest effect size $\left(\hat{\beta}_{\text {Integrated }}=20.2,5.9[\mathrm{SE}]\right)$. For example, 20 sub-samples with the integrated-gear protocol on average detected $15.9 \%$ (4-12 species) more of the fish assemblage than the 
$1-\mathrm{km}$ electrofishing protocol (mean $\pm \mathrm{SD}$; integrated gear $=74.4 \pm 5.4 \% ; 1 \mathrm{~km}$ electrofishing $=58.5 \pm 9.9 \%$ ). If $58.5 \%$ of richness is acceptable for monitoring purposes, then the integrated-gear protocol on average required only 10.7 sub-samples (i.e., $53.5 \%$ efficiency improvement over $1 \mathrm{~km}$ electrofishing). In fact, SACs between protocols were only similar in the Salt River, a flow-regulated river where fish congregated in effectively electrofished, shallow pools during frequent periods of artificially low discharge (Fig. 2.7f).

The protocol-x-season interaction indicated electrofishing-only protocols performed inconsistently across seasons compared to the integrated-gear protocol, especially from fall to summer $\left(\hat{\beta}_{\text {Integrated }}=-7.8,3.8 \mathrm{SE}\right)$. On average, the electrofishingonly protocol detected only $53.6 \%$ of species in summer compared to $62.7 \%$ in fall. In contrast, sampling with the integrated-gear protocol had little among-season variation (average percentage of species by season $=74.2 \%$ in spring, $73.7 \%$ in summer, $75.2 \%$ in fall; Fig. 2.7j). The effect of region was small, imprecise $\left(\hat{\beta}_{\text {Prairie }}=2.2,2.7 \mathrm{SE}\right)$, and equivocal based on moderate support for a model without a region effect $(\triangle \mathrm{AICc}=1.1$; pseudo- $\left.R^{2}=62 \% ; w_{2}=0.34\right)$ but still controlled for spatial variation. Finally, a precisely estimated effect for MWCW $\left(\hat{\beta}_{\mathrm{MWCW}}=-0.3,0.1 \mathrm{SE}\right)$ indicated the fixed 20-sub-sample effort detected lower percentages of richness as river size increased. Overall, SACs between the two protocols revealed the electrofishing-only protocol was more variable, less efficient, seasonally biased, and detected fewer species than comparable effort with the integrated-gear protocol. 


\section{Discussion}

Our study was among the first to evaluate the performance of an intensive multigear survey design for sampling riverine fish assemblages across seasons and regions. The intensity and extensiveness of sampling provided rare insights into richness and fishsampling dynamics. For example, we documented at least 23 new distributional accounts (Dunn et al. 2018) and re-discovered multiple imperiled species presumed extirpated from specific drainages or statewide. Overall, our sampling indicated rivers likely support more species than historically reported per sample, but detecting high percentages of richness requires an optimized design that distributes effort across complementary gears.

\section{Sub-sample richness and gear redundancy}

Boat electrofishing and seining were the most effective individual active gears across regions and seasons. Several gear-evaluation studies spanning broad geographical areas and river types have found electrofishing to be the single-most effective and versatile gear for sampling riverine fishes (Neebling and Quist 2011; Gibson-Reinemer et al. 2016a; Zajicek and Wolter 2018). In contrast, the effectiveness of seining often varies by study (Simon and Sanders 1999; Lapointe et al. 2006), and we suspect these disparities partly reflect the availability of easily seined habitats among studies. For example, similar to Neebling and Quist (2011), our seining sub-samples in Prairie sites detected fewer species than electrofishing (mean predicted species, seining $=4.3$, electrofishing $=4.7$ ), but in our Ozark sites, seining sub-samples detected more species than electrofishing (seining $=7.6$, electrofishing $=7.1$ ). Unlike most Prairie rivers, Ozark rivers are largely unchannelized and retain many shallow margins that may be inhabited 
by small-bodied species and juveniles that can be effectively seined. Nonetheless, our results indicate electrofishing and seining were both relatively effective individual gears. The effectiveness of passive effort varied considerably among gears. Riverine richness assessments often exclude passive gears because of additional retrieval costs, meaning there is limited information on the comparability of passive versus active gears. Although hoop and trammel nets targeted areas that were not easily sampled by other gears, neither gear detected many species on average per net ( $<2.5$ species), which is consistent with Pugh and Schramm (1998) and Lapointe et al. (2006). Moreover, despite Ozark sites supporting on average 23 more species, the mean predicted sub-sample richness of both gears was slightly higher in Prairie sites (hoop $=1.8$ species; trammel $=$ 1.7 species) than Ozark sites (hoop $=1.3$ species; Ozark $=1.6$ species). Consequently, neither gear would have provided an informative index of underlying fish richness if only used at low effort levels. In contrast, sub-sample richness for mini-fyke nets reflected regional differences in richness, and on average, detected the most species per subsample among all gears across spatiotemporal settings (mean predicted sub-sample richness $=6.4$ species). Standard- or mini-fyke nets are frequently used to sample fish assemblages within lentic and/or floodplain waterbodies (e.g., Fischer and Quist 2014), but their use is comparatively rare in riverine fish richness assessments (but see Schloesser et al. 2012b; Braun et al. 2016). Our findings indicate mini-fyke nets may be undervalued options for assessing riverine richness, especially if used in structurally complex and/or lateral low-velocity habitats.

The most efficient path to documenting high species richness is one that minimizes redundant effort, and compositional overlap among sub-samples signifies 
redundant sampling. Overlap was always lower among gears than within gears, which likely reflected the high habitat and taxonomic diversity of our study systems. For example, low overlap could have resulted from species- and life-stage-specific selection of the many different habitats within sites and gear-specific detections for certain fish morphologies and behaviors (Schloesser et al. 2012a). Consequently, our results using basic sampling units (sub-samples) indicate use of individually effective and complementary gears across habitats helps minimize redundant sampling effort, thereby more efficiently representing the high biophysical diversity of rivers.

\section{Integrated-gear protocols}

On average, we reduced our original sampling effort based on sub-samples by $48.1 \%$ by targeting only $90 \%$ of species and combining complementary gears. Difficultto-detect species are often rare, and require disproportionate effort to detect (Angermeier and Smogor 1995; Kanno et al. 2009). For example, SACs from our full-effort protocol indicated detecting $90 \%$ of species on average required $59.5 \%$ of effort. Similarly, Kanno et al. (2009) examined eight fish datasets across North America encompassing multiple stream sizes, and noted detecting $90-95 \%$ of observed richness required on average $58.0 \%$ of each study's full sampling effort. Other riverine fish assessments report similar findings (i.e., detecting $90 \%$ of species requires 54-65\% of full effort; Lapointe et al. 2006; Van Liefferinge et al. 2010; Neebling and Quist 2011). However, we saved on average another $7.6 \%$ of sampling effort by optimally integrating effort among effective gears and eliminating ineffective gears altogether. For example, our integrated-gear protocol mainly featured the three most individually effective gears (electrofishing, 
seining, and mini-fyke nets), eliminated the two least-effective gears (hoop and trammel nets), and used only enough trawling to detect the subset of benthic, mid-channel species. Our design could provide a practical means for comprehensively assessing riverine richness, but investigators could similarly optimize protocols to detect lower percentages of richness when logistics only afford rapid assessments.

Our approach also generated numerous alternative sampling protocols $(287,496)$ that could provide flexibility for accomplishing multiple, competing sampling objectives. This flexibility could allow protocol development to operate within structured decisionmaking frameworks that identify implicit sampling objectives from protocol-users (Gregory et al. 2012). Beyond optimizing efficiency, protocols could be customized simultaneously for additional objectives including sampling specific taxa, functional guilds, or multi-metric indices of riverine condition. Moreover, alternative protocols could circumvent anticipated sampling constraints, such as eliminating passive gears in rivers with unpredictable flow regimes, and increasing trawling effort in lieu of seining in deeper sites. Customizable protocols may be especially suited for regional monitoring programs requiring versatility and/or richness assessments wishing to integrate gears used to inventory main and off-channel components of riverine landscape diversity (Erős et al. 2019).

\section{Spatiotemporal sampling variation}

Species-sampling relationships were surprisingly similar with the integrated-gear protocol in Ozark and Prairie rivers despite different environmental conditions and assemblages. This finding was unexpected given several factors that cause species to 
accumulate more slowly are associated with Prairie rivers, including lower fish densities (Angermeier and Smogor 1995), lower habitat diversity (Fischer and Paukert 2009; Van Liefferinge et al. 2010), and greater anthropogenic disturbance (Hughes et al. 2002). However, species can also accumulate more slowly in species-rich sites (Meador 2005), which might have slowed accumulation rates in Ozark rivers, thereby equalizing SACs across both regions.

We also found SACs were similar across seasons with the integrated-gear protocol. This finding was similar to Erös et al. (2008), who noted SACs constructed from littoral fish assemblages in the Danube River (HU) were more sensitive to finegrain spatial and diel influences than seasonal influences. However, many fish species richness assessments do not investigate species-sampling relationships across seasons, and instead, limit sampling to specific seasons (late summer-early fall; Reash 1999). Although we caution that assemblage composition and other metrics could vary seasonally (Simon and Sanders 1999; Wolter and Bischoff 2001), our protocol offers a less restrictive sampling window if solely monitoring changes in species richness. This flexibility could prove valuable when conducting emergency impact assessments, avoiding critical periods for sensitive species, and accommodating overburdened field schedules.

In contrast to the integrated-gear protocol, the electrofishing-only protocol was more variable and seasonally biased, especially from summer to fall. One $\mathrm{km}$ of electrofishing in summer detected $36.1-80.0 \%$ of richness, which we suspect resulted from varying fish behavior and available habitats among sites. For example, our electrofishing effort mainly sampled littoral areas, which can be temporarily occupied by 
fish depending on flow and temperature (Wolter and Bischoff 2001; Erös et al. 2008), life stage (Wolter et al. 2016), and behavior (De Leeuw et al. 2007). Especially in summer, many species are restricted to deep areas during daylight that are inaccessible to electrofishing (Simon and Sanders 1999; Flotemersch and Blocksom 2005). The prevalence of these areas varied across our focal rivers spanning a nearly sevenfold difference in river size, which may have contributed to low percentages richness and high summer variability. In contrast, the integrated-gear protocol was less sensitive to these influences for at least two reasons; first, variability in species-accumulation data decreases as higher percentages of richness are detected (Angermeier and Smogor 1995), and equal effort with the integrated-gear protocol detected more species than electrofishing (mean with 20 sub-samples $=74.4 \%$ with multiple gears, $58.5 \%$ with electrofishing). Second, the four gears within the integrated-gear protocol sampled multiple habitats, thereby detecting species regardless of varying habitat use across seasons and sites. Consequently, less sampling variability should result in greater power to detect trends in species richness, which might be more cost effective for monitoring over time (Wagner et al. 2013).

Increasing sampling effort at sites often detects additional species and reduces variability in assemblage indicators, especially multi-metric indices of riverine ecological condition (Flotemersch and Blocksom 2005; Maret et al. 2007). Many fish richness assessments increase effort by lengthening sampling distances, thereby expanding the longitudinal extent of their sites (Flotemersch et al. 2011). These designs originated in small streams where a pass with a single gear (i.e., electrofishing) often samples most available areas (e.g., Lyons 1992; Angermeier and Smogor 1995), such that conflating 
sampling effort with stream length is unavoidable. However, lengthening sites also accumulates rare species by incorporating additional habitats into sites from longitudinal gradients, which may induce sampling variability, causing investigators to lengthen sites further. Because riverscapes are continuous and unique species are distributed throughout river networks (Fischer and Paukert 2009), there may not be a finite site length for entirely sampling assemblages. For example, the recommended site lengths from fish assessments reexamined by Kanno et al. (2009) were mostly proportional to each assessment's initial sampling length. In contrast to longitudinally expanding designs, we controlled effort by varying sampling intensity, allowing us to focus on available withinsite habitat diversity (i.e., sub-samples per $50 \mathrm{MWCW}$ ). Sampling intensity-focused designs, such as ours, may be especially relevant for large rivers with diverse, laterally and vertically distributed habitats.

\section{Adaptations and future applications}

Our survey design distributed effort across sites with multiple gears using a scaling scheme proportional to river size. The design's main benefits are comprehensively sampling available habitats, and at a species level, potentially providing information on habitat use, detection, and density from sub-samples. Moreover, the comprehensiveness of the survey design could help validate emerging molecular techniques (environmental DNA, metabarcording) for biodiversity monitoring (Pont et al. 2018). Our general design could be adapted for different objectives and rivers. For example, investigators could eliminate the scaling scheme (eq. 1) by developing separate protocols for different river-size classes beforehand (e.g., Neebling and Quist 2011) or 
applying identical effort across river sizes (Bayley and Peterson 2001). Our design could also likely be adapted to provide abundance- and/or guild-based metrics needed for most riverine multi-metric indices. For example, investigators could calibrate catch-per-effort data among gears using clustered sub-samples within sections (Peterson and Paukert 2009) and/or combine effort across sub-samples via several techniques (GibsonReinemer et al. 2016b). Alternatively, investigators could designate certain gears for specific biotic metrics (De Leeuw et al. 2007). Regardless, multiple gears and the hierarchical design afford flexibility for making inferences at site and sub-sample grain sizes.

\section{Conclusion}

Our approach and intensive sampling provided several findings relevant to riverine fish assessments. Electrofishing, seining, and mini-fyke nets detected the most species with comparable effort across three seasons in rivers spanning two distinct regions. However, a protocol integrating effort among complementary gears that targeted different habitats was more effective than any single gear. Similarly, compared to a traditional electrofishing-only protocol, an integrated-gear protocol consistently detected more species with greater precision regardless of season and region.

Protocols that accurately assess riverine fish species richness may be needed as freshwater species and management organizations cope with rapidly changing environments. Kanno et al. (2009) noted that the main goal of most fish assessments has been monitoring assemblage condition, rather than documenting richness and species distributions. Traditional monitoring designs and condition-based assessments are critical 
tools for documenting fish-assemblage responses to changing water-body condition (USEPA 2016). However, their restricted focus on specific taxa might underestimate local richness, especially in diverse and difficult-to-sample systems, thus distorting reported diversity patterns at riverscape scales. Our approach may provide a template for improving the comprehensiveness of surveys, which could assist efforts to conserve riverine biodiversity by clarifying distributions of declining or introduced species and informing riverscape biodiversity planning and prioritization.

\section{Acknowledgements}

This research was funded by the Missouri Department of Conservation (MDC). We thank MDC Resource Scientists who served as team members throughout this study: D. Herzog, V. Travnichek, M. Combes, and D. Novinger. The field crew consisted of B. Brooke, D. Howe, R. Kramer, S. Rayford, J. Eschenroeder, J. Palmer, and M. Mabery, and we appreciate the 16 volunteers who also collected data for this project. The computation for this work was performed on the high performance computing infrastructure provided by Research Computing Support Services and in part by the National Science Foundation under grant number CNS-1429294 at the University of Missouri, Columbia Mo.

\section{References}

Abell, R., Allan, J.D., and Lehner, B. 2007. Unlocking the potential of protected areas for freshwaters. Biological Conservation 134(1): 48-63. doi:10.1016/j.biocon.2006.08.017. 
Anderson, M.J., Crist, T.O., Chase, J.M., Vellend, M., Inouye, B.D., Freestone, A.L., Sanders, N.J., Cornell, H.V., Comita, L.S., and Davies, K.F. 2011. Navigating the

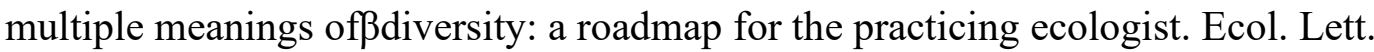
14(1): 19-28. doi:10.1111/j.1461-0248.2010.01552.x.

Angermeier, P.L., and Smogor, R.A. 1995. Estimating number of species and relative abundances in stream-fish communities: effects of sampling effort and discontinuous spatial distributions. Can. J. Fish. Aquat. Sci. 52(5): 936-949. doi:10.1139/f95-093.

Bayley, P.B., and Peterson, J.T. 2001. An approach to estimate probability of presence and richness of fish species. T. Am. Fish. Soc. 130(4): 620-633. doi:10.1577/1548-8659(2001)130<0620:AATEPO>2.0.CO;2.

Bonar, S.A., Hubert, W.A., and Willis, D.W. 2009. Standard Methods for Sampling North American Freshwater Fishes. American Fisheries Society, Bethesda, Md.

Braun, A.P., Sobotka, M.J., and Phelps, Q.E. 2016. Fish associations among un-notched, notched and L-head dikes in the middle Mississippi River. River Res. Appl. 32(4): 804-811. doi:10.1002/rra.2892.

Chao, A. 1987. Estimating the population size for capture-recapture data with unequal catchability. Biometrics 43(4): 783-791. doi:10.2307/2531532.

De Leeuw, J., Buijse, A., Haidvogl, G., Lapinska, M., Noble, R., Repecka, R., Virbickas, T., Wiśniewolski, W., and Wolter, C. 2007. Challenges in developing fish-based ecological assessment methods for large floodplain rivers. Fisheries Manag. Ecol. 14(6): 483-494. doi:10.1111/j.1365-2400.2007.00576.x. 
Dunn, C.G., Brooke, B.L., Hrabik, R.A., and Paukert, C.P. 2018. Intensive sampling reveals underreported use of great-river tributaries by large-river fishes in Missouri. Southeast Nat. 17(3): 512-521. doi:10.1656/058.017.0316.

Erős, T., Tóth, B., Sevcsik, A., and Schmera, D. 2008. Comparison of fish assemblage diversity in natural and artificial rip-rap habitats in the littoral zone of a large river (River Danube, Hungary). Int. Rev. Hydrobiol. 93(1): 88-105. doi:10.1002/iroh.200710976.

Erős, T., Kuehne, L., Dolezsai, A., Sommerwerk, N., and Wolter, C. 2019. A systematic review of assessment and conservation management in large floodplain rivers Actions postponed. Ecol. Indic. 98: 453-461. doi:10.1016/j.ecolind.2018.11.026.

Fischer, J.R., and Paukert, C.P. 2009. Effects of sampling effort, assemblage similarity, and habitat heterogeneity on estimates of species richness and relative abundance of stream fishes. Can. J. Fish. Aquat. Sci. 66(2): 277-290. doi:10.1139/F08-209.

Fischer, J.R., and Quist, M.C. 2014. Characterizing lentic freshwater fish assemblages using multiple sampling methods. Environ. Monit. Assess. 186(7): 4461-4474. doi:10.1007/s10661-014-3711-z.

Flotemersch, J.E., and Blocksom, K.A. 2005. Electrofishing in boatable rivers: does sampling design affect bioassessment metrics? Environ. Monit. Assess. 102(1-3): 263-283. doi:10.1007/s10661-005-6026-2.

Flotemersch, J.E., Stribling, J.B., Hughes, R.M., Reynolds, L., Paul, M.J., and Wolter, C. 2011. Site length for biological assessment of boatable rivers. River Res. Appl. 27(4): 520-535. doi:10.1002/rra.1367. 
Galat, D.L., and Zweimuller, I. 2001. Conserving large-river fishes: is the highway analogy an appropriate paradigm? J. N. Am. Benthol. Soc. 20(2): 266-279. doi: $10.2307 / 1468321$.

Gammon, J.R., and Simon, T.P. 2000. Variation in a great river index of biotic integrity over a 20-year period. Hydrobiologia 422/423: 291-304. doi:10.1007/978-94011-4164-2_24.

Gibson-Reinemer, D.K., Ickes, B.S., and Chick, J.H. 2016b. Development and assessment of a new method for combining catch per unit effort data from different fish sampling gears: multigear mean standardization (MGMS). Can. J. Fish. Aquat. Sci. 74(1): 8-14. doi:10.1139/cjfas-2016-0003.

Gibson-Reinemer, D.K., Stewart, D.R., Fritts, M.W., DeBoer, J.A., and Casper, A.F. 2016a. Estimating the effects of environmental variables and gear type on the detection and occupancy of large-river fishes in a standardized sampling program using multiseason Bayesian mixture models. N. Am. J. Fish. Manage. 36(6): 1445-1456. doi:10.1080/02755947.2016.1206642.

Gotelli, N.J., and Colwell, R.K. 2001. Quantifying biodiversity: procedures and pitfalls in the measurement and comparison of species richness. Ecol. Lett. 4(4): 379-391. doi:10.1046/j.1461-0248.2001.00230.x.

Gregory, R., Failing, L., Harstone, M., Long, G., McDaniels, T., and Ohlson, D. 2012. Structured decision making: a practical guide to environmental management choices. Wiley-Blackwell, Oxford, U.K.

Guy, C.S., P.J. Braaten, D.P Herzog, J. Pitlo, R.S. Rogers, S. Bonar, W. Hubert, and D. Willis. 2009. Warmwater fish in rivers. In Standard methods for sampling North 
American freshwater fishes. Edited by S.A. Bonar, W.A Hubert, and D.W. Willis. American Fisheries Society, Bethesda, Md. pp. 59-84.

Hughes, R.M., and Peck, D.V. 2008. Acquiring data for large aquatic resource surveys: the art of compromise among science, logistics, and reality. J. N. Am. Benthol. Soc. 27(4): 837-859. doi:10.1899/08-028.1.

Hughes, R.M., Kaufmann, P.R., Herlihy, A.T., Intelmann, S.S., Corbett, S.C., Arbogast, M.C., and Hjort, R.C. 2002. Electrofishing distance needed to estimate fish species richness in raftable Oregon rivers. N. Am. J. Fish. Manage. 22(4): 12291240. doi:10.1577/1548-8675(2002)022<1229:EDNTEF>2.0.CO;2.

Kanno, Y., Vokoun, J.C., Dauwalter, D.C., Hughes, R.M., Herlihy, A.T., Maret, T.R., and Patton, T.M. 2009. Influence of rare species on electrofishing distance when estimating species richness of stream and river reaches. T. Am. Fish. Soc. 138(6): 1240-1251. doi:10.1577/T08-210.1.

Kominoski, J.S., Ruhí, A., Hagler, M.M., Petersen, K., Sabo, J.L., Sinha, T., Sankarasubramanian, A., and Olden, J.D. 2018. Patterns and drivers of fish extirpations in rivers of the American Southwest and Southeast. Glob. Change Biology 24(3): 1175-1185. doi:10.1111/gcb.13940.

Lapointe, N.W., Corkum, L.D., and Mandrak, N.E. 2006. A comparison of methods for sampling fish diversity in shallow offshore waters of large rivers. N. Am. J. Fish. Manage. 26(3): 503-513. doi:10.1577/M05-091.1.

Lefcheck, J.S. 2016. piecewiseSEM: piecewise structural equation modelling in R for ecology, evolution, and systematics. Methods Ecol Evol 7(5): 573-579. doi:10.1111/2041-210X.12512. 
Lindenmayer, D.B., and Likens, G.E. 2010. The science and application of ecological monitoring. Biol. Conserv. 143(6): 1317-1328. doi:10.1016/j.biocon.2010.02.013.

Loisl, F., Singer, G., and Keckeis, H. 2014. Method-integrated fish assemblage structure at two spatial scales along a free-flowing stretch of the Austrian Danube. Hydrobiologia 729(1): 77-94. doi:10.1007/s10750-013-1588-4.

Lyons, J. 1992. The length of stream to sample with a towed electrofishing unit when fish species richness is estimated. N. Am. J. Fish. Manage. 12(1): 198-203. doi:10.1577/1548-8675(1992)012<0198:TLOSTS>2.3.CO;2.

Lyons, J., Piette, R.R., and Niermeyer, K.W. 2001. Development, validation, and application of a fish-based index of biotic integrity for Wisconsin's large warmwater rivers. T. Am. Fish. Soc. 130(6): 1077-1094. doi:10.1577/15488659(2001)130<1077:DVAAOA>2.0.CO;2.

Maret, T.R., Ott, D.S., and Herlihy, A.T. 2007. Electrofishing effort required to estimate biotic condition in southern Idaho rivers. N. Am. J. Fish. Manage. 27(3): 10411052. doi:10.1577/M06-115.1.

McCluney, K.E., Poff, N.L., Palmer, M.A., Thorp, J.H., Poole, G.C., Williams, B.S., Williams, M.R., and Baron, J.S. 2014. Riverine macrosystems ecology: sensitivity, resistance, and resilience of whole river basins with human alterations. Front. Ecol. Environ. 12(1): 48-58. doi:10.1890/120367.

McManamay, R.A., Orth, D.J., and Jager, H.I. 2014. Accounting for variation in species detection in fish community monitoring. Fisheries Manag. Ecol. 21(2): 96-112. doi:10.1111/fme.12056. 
Meador, M.R. 2005. Single-pass versus two-pass boat electrofishing for characterizing river fish assemblages: species richness estimates and sampling distance. T. Am. Fish. Soc. 134(1): 59-67. doi:10.1577/FT03-094.1.

Meador, M.R., and McIntyre, J.P. 2003. Effects of electrofishing gear type on spatial and temporal variability in fish community sampling. T. Am. Fish. Soc. 132(4): 709716. doi:10.1577/T01-135.

Miranda, L. 2009. Standardizing electrofishing power for boat electrofishing. In Standard methods for sampling North American freshwater fishes. Edited by S.A. Bonar, W.A Hubert, and D.W. Willis. American Fisheries Society, Bethesda, Md. pp. $223-230$.

Moulton, S.R., J.G. Kennen, R.M. Goldstein, and J.A. Hambrook (editors). 2002. Revised protocols for sampling algal, invertebrate, and fish communities as part of the National Water-Quality Assessment Program. U.S. Geological Survey, 2331-1258, Reston, Va.

Nakagawa, S., Johnson, P.C., and Schielzeth, H. 2017. The coefficient of determination $R^{2}$ and intra-class correlation coefficient from generalized linear mixed-effects models revisited and expanded. J. Roy. Soc. Interface 14(134): 20170213. doi:10.1098/rsif.2017.0213.

Neebling, T.E., and Quist, M.C. 2011. Comparison of boat electrofishing, trawling, and seining for sampling fish assemblages in Iowa's nonwadeable rivers. N. Am. J. Fish. Manage. 31(2): 390-402. doi:10.1080/02755947.2011.576198.

Paller, M.H. 1995. Relationships among number of fish species sampled, reach length surveyed, and sampling effort in South Carolina coastal plain streams. N. Am. J. 
Fish. Manage. 15(1): 110-120. doi:10.1577/1548-

8675(1995)015<0110:RANOFS >2.3.CO;2.

Paukert, C.P., and Galat, D.L. 2010. Warmwater rivers. In Inland fisheries management in North America. Edited by W.A. Hubert and M.C. Quist, American Fisheries Society, Bethesda, Md. pp. 699-736.

Pearson, M.S., Angradi, T.R., Bolgrien, D.W., Jicha, T.M., Taylor, D.L., Moffett, M.F., and Hill, B.H. 2011. Multimetric fish indices for midcontinent (USA) great rivers. T. Am. Fish. Soc. 140(6): 1547-1564. doi:10.1080/00028487.2011.639269.

Peterson, J.T., and Rabeni, C.F. 1995. Optimizing sampling effort for sampling warmwater stream fish communities. N. Am. J. Fish. Manage. 15(3): 528-541. doi:10.1577/1548-8675(1995)015<0528:OSEFSW>2.3.CO;2.

Peterson, J.T., and Paukert, C.P. 2009. Converting nonstandard fish sampling data to standardized data. In Standard methods for sampling North American freshwater fishes. Edited by S.A. Bonar, W.A. Hubert, and D.W. Willis. American Fisheries Society, Bethesda, Md. pp. 195-216.

Pont, D., Rocle, M., Valentini, A., Civade, R., Jean, P., Maire, A., Roset, N., Schabuss, M., Zornig, H., and Dejean, T. 2018. Environmental DNA reveals quantitative patterns of fish biodiversity in large rivers despite its downstream transportation. Sci. Rep. 8(1): 10361. doi:10.1038/s41598-018-28424-8.

Pugh, L.L., and Schramm Jr, H.L. 1998. Comparison of electrofishing and hoopnetting in lotic habitats of the lower Mississippi River. N. Am. J. Fish. Manage. 18(3): 649656. doi:10.1577/1548-8675(1998)018<0649:COEAHI>2.0.CO;2. 
Radinger, J., Britton, J.R., Carlson, S.M., Magurran, A.E., Alcaraz-Hernández, J.D., Almodóvar, A., Benejam, L., Fernández-Delgado, C., Nicola, G.G., and OlivaPaterna, F.J. 2019. Effective monitoring of freshwater fish. Fish Fish. 2019(00): 1-19. doi:10.1111/faf.12373.

Reash, R. 1999. Considerations for characterizing Midwestern large river habitats. In Assessing the sustainability and biological integrity of water resources using fish communities. Edited by T.P. Simon. CRC Press, Boca Raton, Fl. pp. 463-474

Schloesser, J.T., Paukert, C.P., Doyle, W.J., Hill, T.D., Steffensen, K.D., and Travnichek, V.H. 2012a. Heterogeneous detection probabilities for imperiled Missouri River fishes: implications for large-river monitoring programs. Endanger. Species Res. 16(3): 211-224. doi:10.3354/esr00399.

Schloesser, J., Paukert, C.P., Doyle, W., Hill, T., Steffensen, K., and Travnichek, V.H. 2012b. Fish assemblages at engineered and natural channel structures in the lower Missouri River: implications for modified dike structures. River Res. Appl. 28(10): 1695-1707. doi:10.1002/rra.1578.

Sievert, N.A., Paukert, C.P., Tsang, Y.P., and Infante, D. 2016. Development and assessment of indices to determine stream fish vulnerability to climate change and habitat alteration. Ecol. Indic. 67: 403-416. doi:10.1016/j.ecolind.2016.03.013.

Simon, T., and R. Sanders. 1999. Applying an index of biotic integrity based on great river fish communities: considerations in sampling and interpretation. In Assessing the sustainability and biological integrity of water resources using fish communities. Edited by T.P. Simon. CRC Press, Boca Raton, Fl. pp. 475-506. 
Sowa, S.P., Annis, G., Morey, M.E., and Diamond, D.D. 2007. A gap analysis and comprehensive conservation strategy for riverine ecosystems of missouri. Ecol. Monogr. 77(3): 301-334. doi:10.1890/06-1253.1.

Troia, M.J., and McManamay, R.A. 2020. Biogeographic classification of streams using fish community- and trait-environment relationships. Divers Distrib 26(1): 108125. doi:10.1111/ddi.13001.

USEPA. 2013. National Rivers and Streams Assessment 2013-2014: field operations manual — non-wadeable (EPA-841-B-12-009a). U.S. Environmental Protection Agency, Office of Water, Washington, D.C.

USEPA. 2016. National Rivers and Streams Assessment 2008-2009: a collaborative survey (EPA/841/R-16/007). U.S. Environmental Protection Agency, Office of Research and Development, Washington, D.C.

Utrup, N.J., and Fisher, W.L. 2006. Development of a rapid bioassessment protocol for sampling fish in large prairie rivers. N. Am. J. Fish. Manage. 26(3): 714-726. doi:10.1577/M05-104.1.

Van Liefferinge, C., Simoens, I., Vogt, C., Cox, T.J., Breine, J., Ercken, D., Goethals, P., Belpaire, C., and Meire, P. 2010. Impact of habitat diversity on the sampling effort required for the assessment of river fish communities and IBI. Hydrobiologia 644(1): 169-183. doi:10.1007/s10750-010-0110-5.

Vörösmarty, C.J., McIntyre, P.B., Gessner, M.O., Dudgeon, D., Prusevich, A., Green, P., Glidden, S., Bunn, S.E., Sullivan, C.A., Liermann, C.R., and Davies, P.M. 2010. Global threats to human water security and river biodiversity. Nature 467(7315): 555-561. doi:10.1038/nature09440. 
Wagner, T., Irwin, B.J., Bence, J.R., and Hayes, D.B. 2013. Detecting temporal trends in freshwater fisheries surveys: statistical power and the important linkages between management questions and monitoring objectives. Fisheries 38(7): 309-319. doi:10.1080/03632415.2013.799466.

Ward, J., Tockner, K., Arscott, D., and Claret, C. 2002. Riverine landscape diversity. Freshwater Biol. 47(4): 517-539. doi:10.1046/j.1365-2427.2002.00893.x.

Wolter, C., and Bischoff, A. 2001. Seasonal changes of fish diversity in the main channel of the large lowland River Oder. Regul. River 17(4-5): 595-608. doi:10.1002/rrr.645.

Wolter, C., Buijse, A., and Parasiewicz, P. 2016. Temporal and spatial patterns of fish response to hydromorphological processes. River Res. Appl. 32(2): 190-201. doi:10.1002/rra.2980.

Yoder, C.O., and Kulik, B.H. 2003. The development and application of multimetric indices for the assessment of impacts to fish assemblages in large rivers: a review of current science and applications. Can. Water Resour. J. 28(2): 301-328. doi:10.4296/cwrj2802301. Zajicek, P., and Wolter, C. 2018. The gain of additional sampling methods for the fish-based assessment of large rivers. Fish. Res. 197: 15-24. doi:10.1016/j.fishres.2017.09.018. 


\section{Tables}

Table 2.1. Site characteristics and means (SD) of habitat variables from nine nonwadeable sites across two physiographic regions in Missouri (USA). L = Lower, $\mathrm{U}=$ Upper, MWCW = mean wetted-channel width, WSA = watershed area.

\begin{tabular}{lcccccccc}
\hline \multicolumn{1}{c}{ Site } & Region & $N$ & $(\mathrm{~m})$ & \multicolumn{1}{c}{$\begin{array}{c}\text { Site } \\
(\mathrm{m})\end{array}$} & $\begin{array}{r}\text { WSA } \\
\left(\mathrm{km}^{2}\right)\end{array}$ & $\begin{array}{c}\text { Secchi } \\
(\mathrm{m})\end{array}$ & $\begin{array}{c}\text { Depth } \\
(\mathrm{m})\end{array}$ & $\begin{array}{c}\text { Velocity } \\
(\mathrm{m} / \mathrm{s})\end{array}$ \\
\hline L. Gasconade & Ozarks & 5 & 92 & 4,600 & 9025 & $0.9(0.5)$ & $1.6(0.8)$ & $0.3(0.3)$ \\
L. Meramec & Ozarks & 4 & 84 & 4,200 & 9,780 & $0.8(0.4)$ & $1.5(0.8)$ & $0.5(0.4)$ \\
L. Grand & Prairie & 4 & 78 & 3,900 & 19,615 & $0.3(0.3)$ & $2.1(1.1)$ & $0.4(0.3)$ \\
U. Gasconade & Ozarks & 4 & 75 & 3,750 & 7,245 & $1.8(0.4)$ & $1.2(0.6)$ & $0.5(0.4)$ \\
Salt & Prairie & 4 & 59 & 2,950 & 6,466 & $0.7(0.6)$ & $1.4(0.6)$ & $0.4(0.4)$ \\
Black & Ozarks & 4 & 53 & 2,650 & 3,012 & $1.5(0.4)$ & $1.4(0.6)$ & $0.5(0.4)$ \\
U. Grand & Prairie & 4 & 52 & 2,600 & 5,825 & $0.2(0.1)$ & $1.4(0.7)$ & $0.4(0.3)$ \\
U. Meramec & Ozarks & 3 & 52 & 2,600 & 3,826 & $1.7(0.5)$ & $1.0(0.5)$ & $0.5(0.3)$ \\
Lamine & Prairie & 4 & 43 & 2,150 & 2,759 & $0.5(0.1)$ & $2.0(0.1)$ & $0.1(0.1)$ \\
\hline
\end{tabular}

Note: Depth and velocity are indices measured from electrofishing and trawling subsamples in boatable areas. Depth was measured from side-scan sonar, and velocity at approximately $60 \%$ depth with a pole-mounted digital velocity meter. 
Table 2.2. Mean (SD) species richness per sample within nine non-wadeable sites across 36 samples in Missouri (USA). L = lower, $\mathrm{U}=$ upper, $\mathrm{IG}=$ integrated-gear, $N=$ subsamples, E = electrofishing.

\begin{tabular}{lccccccc}
\hline \multicolumn{5}{c}{ River } & \multicolumn{5}{c}{ Mini- } & Maxi- & IG, & E, \\
& Observed & mum & mum & Theoretical & IG, 90\% & $N=20$ & $N=20$ \\
\hline Black & $67(6)$ & 61 & 75 & $85(20)$ & $60(6)$ & $52(5)$ & $40(8)$ \\
L. Gasconade & $60(3)$ & 55 & 64 & $65(4)$ & $54(4)$ & $43(4)$ & $35(8)$ \\
L. Grand & $33(3)$ & 29 & 35 & $39(6)$ & $29(3)$ & $23(3)$ & $16(1)$ \\
L. Meramec & $69(1)$ & 68 & 70 & $77(4)$ & $62(3)$ & $48(3)$ & $40(4)$ \\
Lamine & $40(4)$ & 36 & 45 & $46(5)$ & $35(3)$ & $31(3)$ & $22(8)$ \\
Salt & $47(2)$ & 45 & 50 & $52(5)$ & $43(2)$ & $38(2)$ & $34(5)$ \\
U. Gasconade & $52(4)$ & 47 & 55 & $68(17)$ & $47(2)$ & $37(2)$ & $31(2)$ \\
U. Grand & $29(4)$ & 25 & 34 & $40(8)$ & $25(3)$ & $21(2)$ & $18(3)$ \\
U. Meramec & $46(3)$ & 43 & 48 & $52(3)$ & $42(3)$ & $38(3)$ & $25(5)$ \\
\hline
\end{tabular}

Note: Theoretical richness values are estimates of total (observed + unobserved) species obtained from Chao's (1987) incidence-based estimator. Richness (IG, 90\%) is from the integrated-gear protocol. Richness (IG, $N=20)$ is from 20 sub-samples via the integratedgear protocol (multiple gears). Richness $(\mathrm{E}, N=20)$ is from 20 fifty-m electrofishing subsamples. 
Table 2.3. Ranked competing models explaining sub-sample richness $(N=2,900)$ from 36 samples in nine non-wadeable sites in Missouri (USA). Also included are the number of fixed-effects (K), log-likelihoods (LL), $\Delta$ Akaike Information Criteria (AIC), model weights $\left(w_{i}\right)$, and marginal $(\mathrm{M})$ and conditional $(\mathrm{C}) R^{2}$ statistics. $\mathrm{G}=$ Gear, $\mathrm{R}=$ Region, $\mathrm{S}$ $=$ Season.

\begin{tabular}{|c|c|c|c|c|c|c|c|}
\hline Rank & Model & $\mathrm{K}$ & $\mathrm{LL}$ & $\Delta \mathrm{AIC}$ & $w_{i}$ & $R_{M}^{2}$ & $R_{C}^{2}$ \\
\hline 1 & $\mathrm{G}+\mathrm{R}+\mathrm{S}+\mathrm{G}^{*} \mathrm{R}+\mathrm{G}^{*} \mathrm{~S}+\mathrm{R} * \mathrm{~S}$ & 26 & -6895.8 & 0.0 & 0.98 & 0.37 & 0.42 \\
\hline 2 & $G+R+S+G^{*} R+G^{*} S+R * S+G^{*} R * S$ & 36 & -6889.5 & 7.5 & 0.02 & 0.37 & 0.42 \\
\hline 3 & $G+M+G^{*} M$ & 12 & -6929.7 & 40.0 & $<0.01$ & 0.35 & 0.40 \\
\hline 4 & $\mathrm{G}+\mathrm{R}+\mathrm{S}+\mathrm{G}^{*} \mathrm{R}$ & 14 & -6928.3 & 41.1 & $<0.01$ & 0.35 & 0.40 \\
\hline 5 & $\mathrm{G}+\mathrm{R}+\mathrm{S}+\mathrm{G}^{*} \mathrm{~S}$ & 19 & -6932.7 & 60.0 & $<0.01$ & 0.36 & 0.41 \\
\hline 6 & $\mathrm{G}+\mathrm{S}+\mathrm{G}^{*} \mathrm{~S}$ & 18 & -6937.6 & 67.6 & $<0.01$ & 0.28 & 0.41 \\
\hline 7 & $G+R$ & 7 & -6965.1 & 100.8 & $<0.01$ & 0.34 & 0.40 \\
\hline 8 & $G+R+S$ & 9 & -6963.7 & 101.9 & $<0.01$ & 0.34 & 0.40 \\
\hline 9 & $\mathrm{G}+\mathrm{R}+\mathrm{S}+\mathrm{R} * \mathrm{~S}$ & 11 & -6961.9 & 102.3 & $<0.01$ & 0.35 & 0.39 \\
\hline 10 & $\mathrm{G}$ & 6 & -6970.1 & 108.6 & $<0.01$ & 0.27 & 0.40 \\
\hline 11 & $G+S$ & 8 & -6968.5 & 109.5 & $<0.01$ & 0.27 & 0.40 \\
\hline 12 & Intercept-only (null) & 1 & -7409.3 & 977.1 & $<0.01$ & $<0.01$ & 0.13 \\
\hline
\end{tabular}

Note: All models included random effects for site and sample. Estimated fixed-effects in model 1 are in Appendix 2.3. 
Table 2.4. Ranked competing models explaining the percentage of observed richness detected with the integrated-gear protocol $(N=36$ samples $)$ in nine non-wadeable sites in Missouri (USA). Also included are the number of fixed effects (K), log-likelihoods (LL), $\triangle$ Akaike Information Criteria (AICc) corrected for small sample size, model weights $\left(w_{i}\right)$, and marginal $(\mathrm{M})$ and conditional $(\mathrm{C}) R^{2}$ statistics. $\mathrm{R}=$ Region, $\mathrm{S}=$ Season.

\begin{tabular}{cccccccc}
\hline Rank & \multicolumn{1}{c}{ Model } & $\mathrm{K}$ & $\mathrm{LL}$ & $\Delta \mathrm{AICc}$ & $w_{i}$ & $R_{M}^{2}$ & $R_{C}^{2}$ \\
\hline 1 & Intercept-only (null) & 1 & 78.1 & 0.0 & 0.64 & 0.00 & 0.00 \\
2 & $\mathrm{R}$ & 2 & 78.6 & 1.6 & 0.28 & 0.03 & 0.03 \\
3 & $\mathrm{~S}$ & 3 & 78.3 & 4.9 & 0.06 & 0.01 & 0.01 \\
4 & $\mathrm{R}+\mathrm{S}$ & 4 & 78.7 & 6.9 & 0.02 & 0.04 & 0.04 \\
5 & $\mathrm{R}+\mathrm{S}+\mathrm{R} * \mathrm{~S}$ & 6 & 79.1 & 12.7 & $<0.01$ & 0.05 & 0.05 \\
\hline
\end{tabular}

Note: All models included a random effect for site. The estimated intercept in model 1 is in Appendix 2.3. 
Table 2.5. Ranked competing models explaining the percentage of observed richness detected with integrated-gear and 1-km electrofishing protocols from 36 samples in nine non-wadeable sites in Missouri. Rankings were based on $\triangle$ Akaike Information Criteria (AICc) corrected for small sample size. Also included are the number of fixed-effects $(\mathrm{K}), \log$-likelihoods (LL), and model weights $\left(w_{i}\right) . \mathrm{P}=$ protocol, $\mathrm{R}=$ Region, $\mathrm{S}=$ Season, MWCW = mean wetted-channel width .

\begin{tabular}{clccccc}
\hline Rank & \multicolumn{1}{c}{ Model } & $\mathrm{K}$ & $\mathrm{LL}$ & $\Delta \mathrm{AICc}$ & $w_{i}$ & Pseudo $R^{2}$ \\
\hline 1 & $\mathrm{P}+\mathrm{R}+\mathrm{S}+\mathrm{P} * \mathrm{~S}+\mathrm{MWCW}$ & 8 & -218.0 & 0.0 & 0.59 & 0.62 \\
2 & $\mathrm{P}+\mathrm{S}+\mathrm{P} * \mathrm{~S}+\mathrm{MWCW}$ & 7 & -219.9 & 1.1 & 0.34 & 0.62 \\
3 & $\mathrm{P}+\mathrm{R}+\mathrm{S}+\mathrm{P} * \mathrm{R}+\mathrm{MWCW}$ & 7 & -222.1 & 5.4 & 0.04 & 0.59 \\
4 & $\mathrm{P}+\mathrm{R}+\mathrm{S}+\mathrm{MWCW}$ & 6 & -224.4 & 7.3 & 0.02 & 0.59 \\
5 & $\mathrm{P}+\mathrm{S}+\mathrm{MWCW}$ & 5 & -226.3 & 8.6 & 0.01 & 0.59 \\
6 & $\mathrm{P}+\mathrm{R}+\mathrm{P} * \mathrm{R}+\mathrm{MWCW}$ & 5 & -227.1 & 10.1 & $<0.01$ & 0.57 \\
7 & $\mathrm{P}+\mathrm{R}+\mathrm{MWCW}$ & 4 & -229.4 & 12.2 & $<0.01$ & 0.57 \\
8 & $\mathrm{P}+\mathrm{MWCW}$ & 3 & -231.3 & 13.6 & $<0.01$ & 0.57 \\
9 & MWCW(null) & 2 & -244.8 & 38.2 & $<0.01$ & 0.14 \\
\hline
\end{tabular}

Note: All models accounted for non-independence of multiple samples per site and allowed variance to vary by protocol. Estimated fixed-effects in model 1 are in Appendix 2.3 . 
Figures

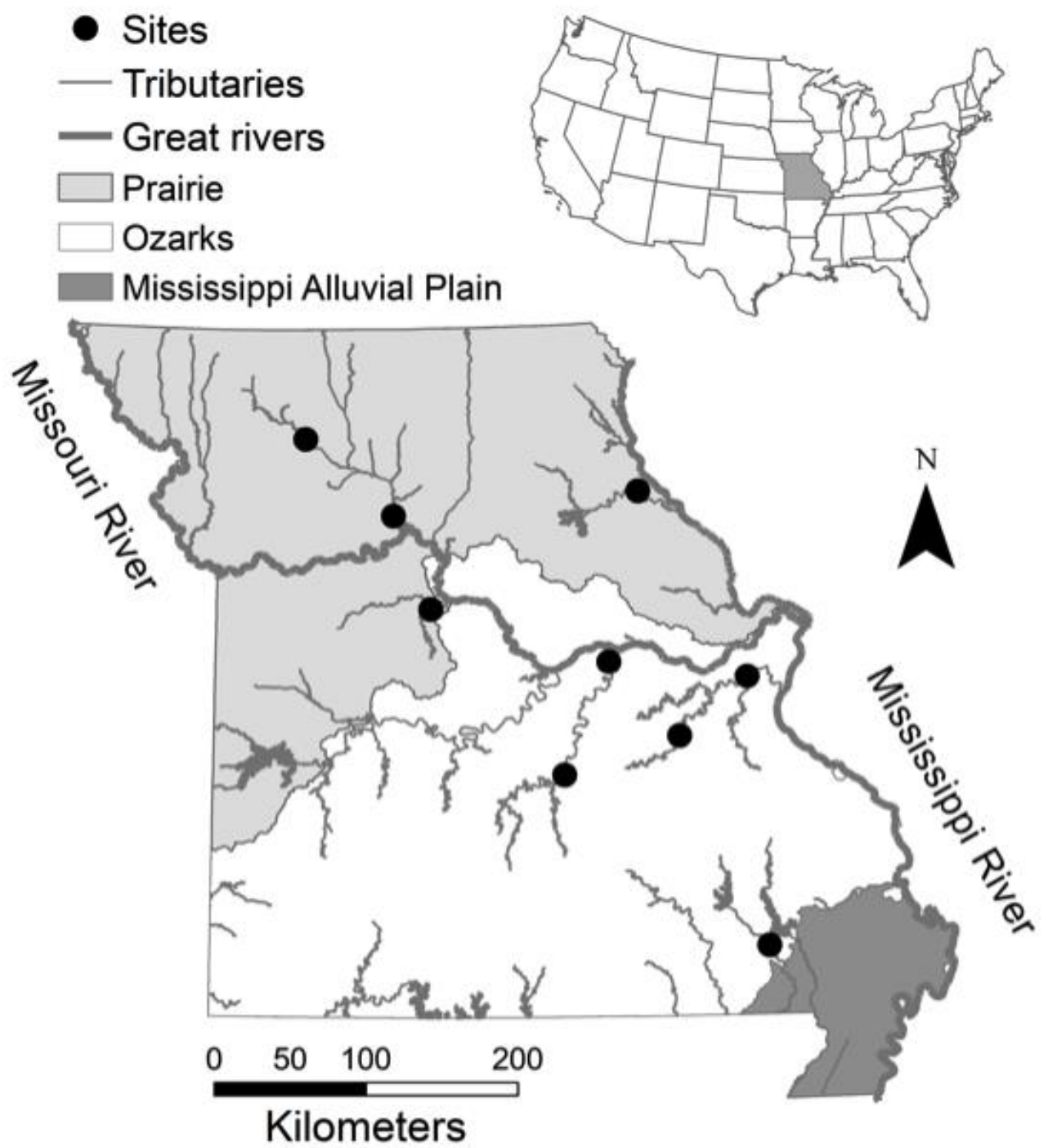

Figure 2.1. Map of Missouri (USA) with nine non-wadeable sites repeatedly sampled between 2014 and 2016. "Great rivers" are the Missouri and Mississippi rivers. 


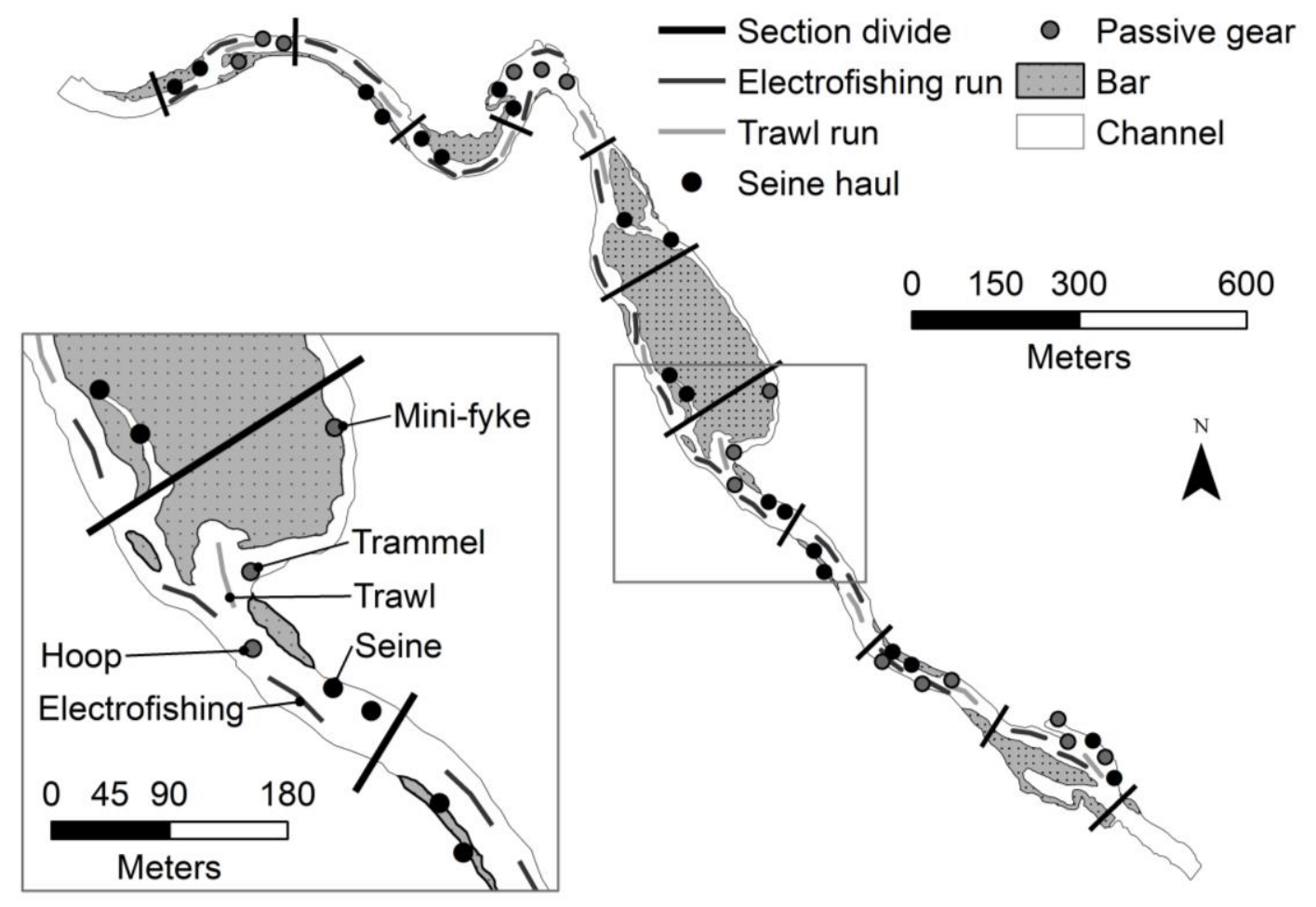

Figure 2.2. Example of a georeferenced sample of a $2.65-\mathrm{km}$ site ( $=50$ mean wettedchannel widths [MWCWs]) in the Black River, Missouri (USA) in fall 2015. The inset details sub-samples in main and secondary channels. Note MWCW is $53 \mathrm{~m}$, sections (black lines) are $265 \mathrm{~m}$ (5 MWCWs), electrofishing (dark gray lines) distance $=1 \mathrm{~km}$ ( $20 \times 50-\mathrm{m}$ run), trawling (light gray lines) distance $=500 \mathrm{~m}(10 \times 50-\mathrm{m}$ run), and seining (dark gray circles) distance $=200 \mathrm{~m}(20 \times 10-\mathrm{m}$ seine haul). Passive gears (gray circles) include hoop, mini-fyke, and stationary trammel nets. 


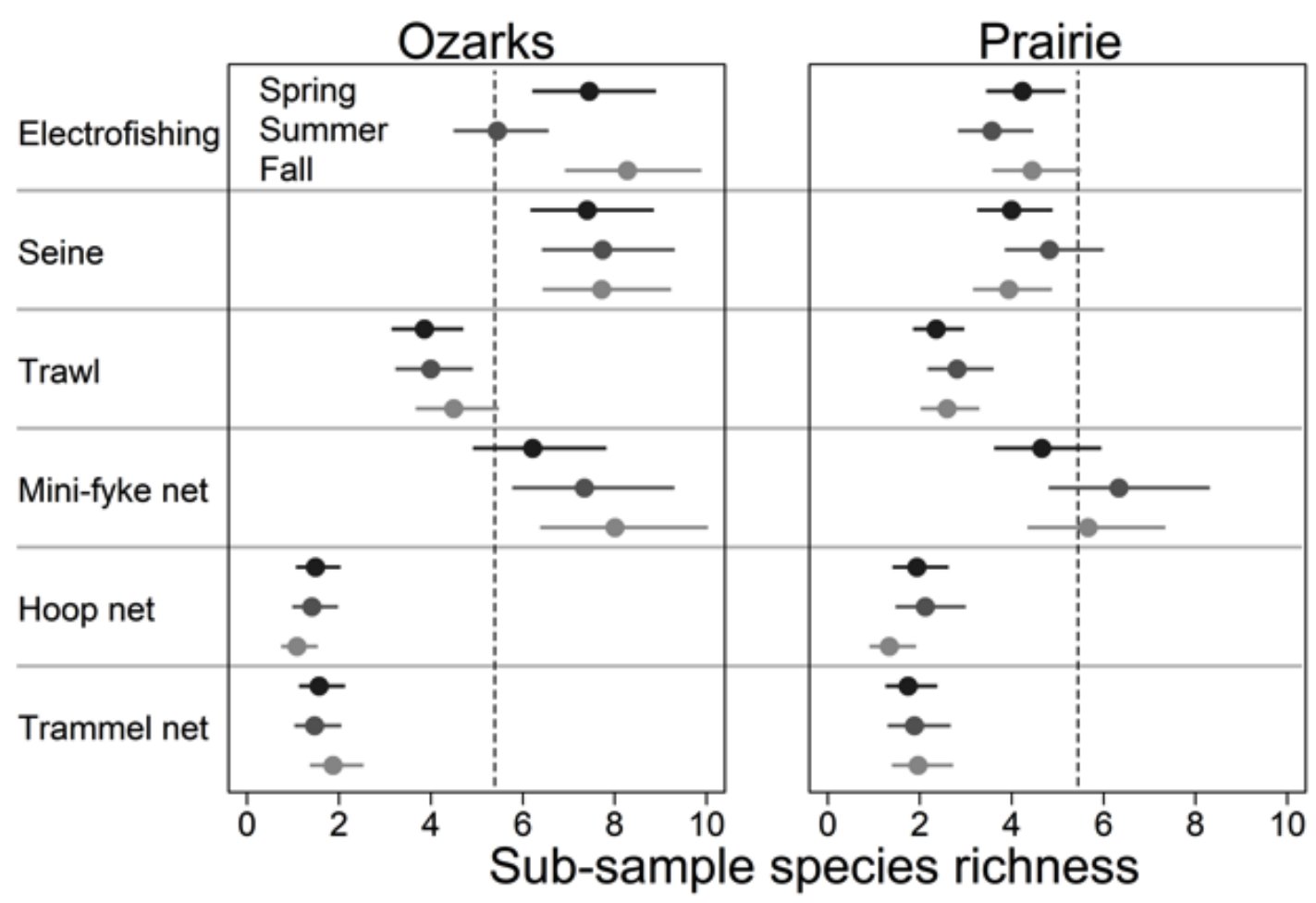

Figure 2.3. Predicted sub-sample richness by gear, region, and season $(N=2,900$ subsamples). Dashed vertical lines signify the reference condition in the best-supported model (intercept $=$ summer electrofishing in Ozark rivers). 


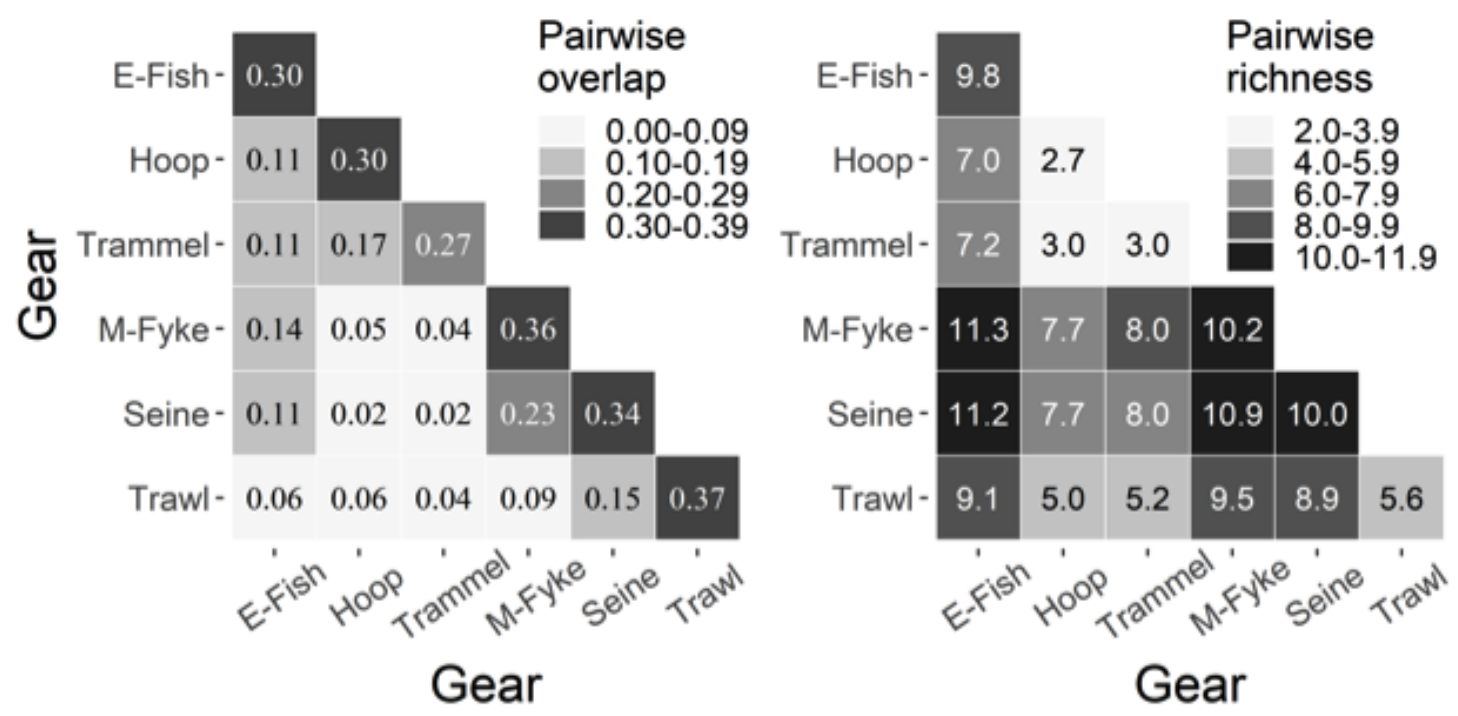

Figure 2.4. Left: heat plot displaying the average compositional overlap (species presences/absences with Sørensen's coefficients) between two sub-samples within and among gears ( $N=2,900$ sub-samples). Higher coefficients (darker boxes) have greater overlap in species composition. Sub-samples were from 36 samples in nine non-wadeable sites in Missouri (USA). Right: average cumulative richness from two sub-samples from different gear combinations. E-fish $=$ electrofishing, $\mathrm{M}$-Fyke $=$ mini-fyke net. 


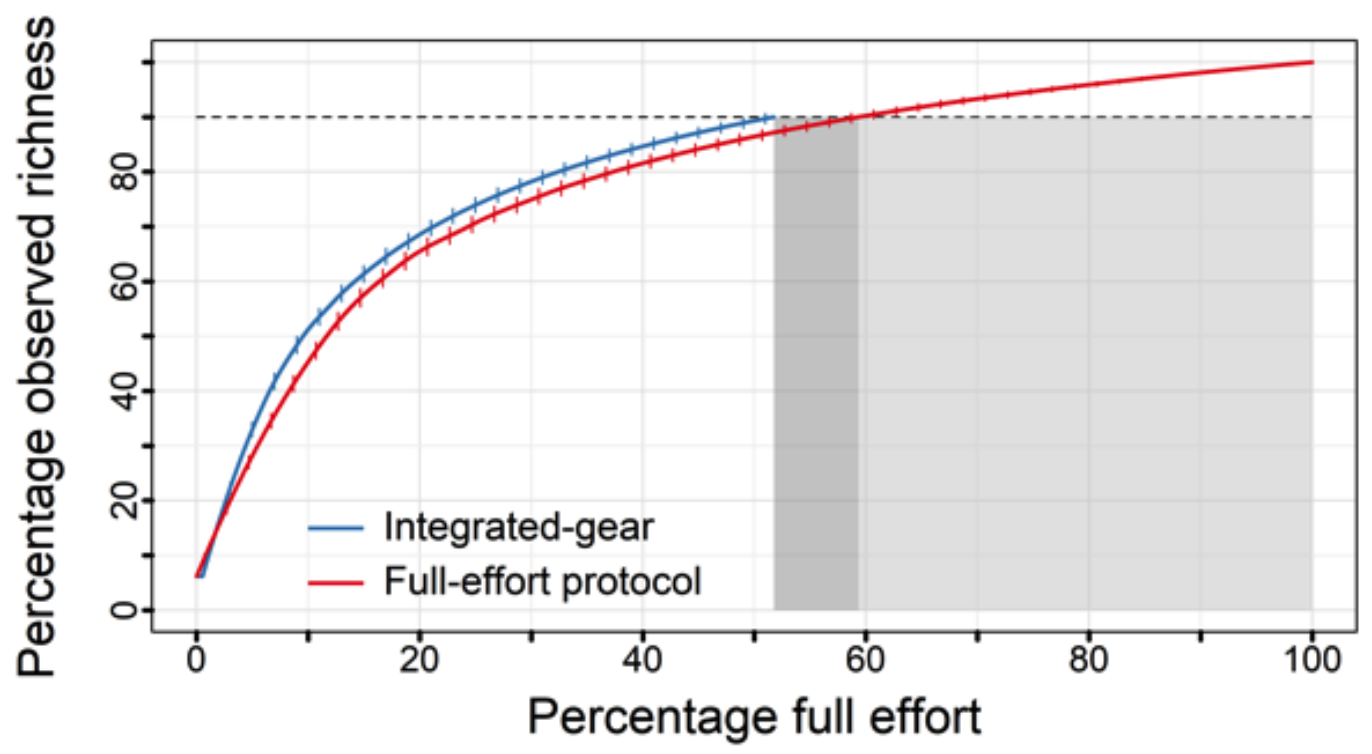

Figure 2.5. Mean species-accumulation curves ( $\pm 95 \%$ confidence intervals) from 36 samples for full-effort and integrated-gear protocols in Missouri (USA). Light and dark gray boxes depict the $41.5 \%$ and $7.6 \%$ of effort saved by only targeting $90 \%$ of species and minimizing redundant effort among gears, respectively. 


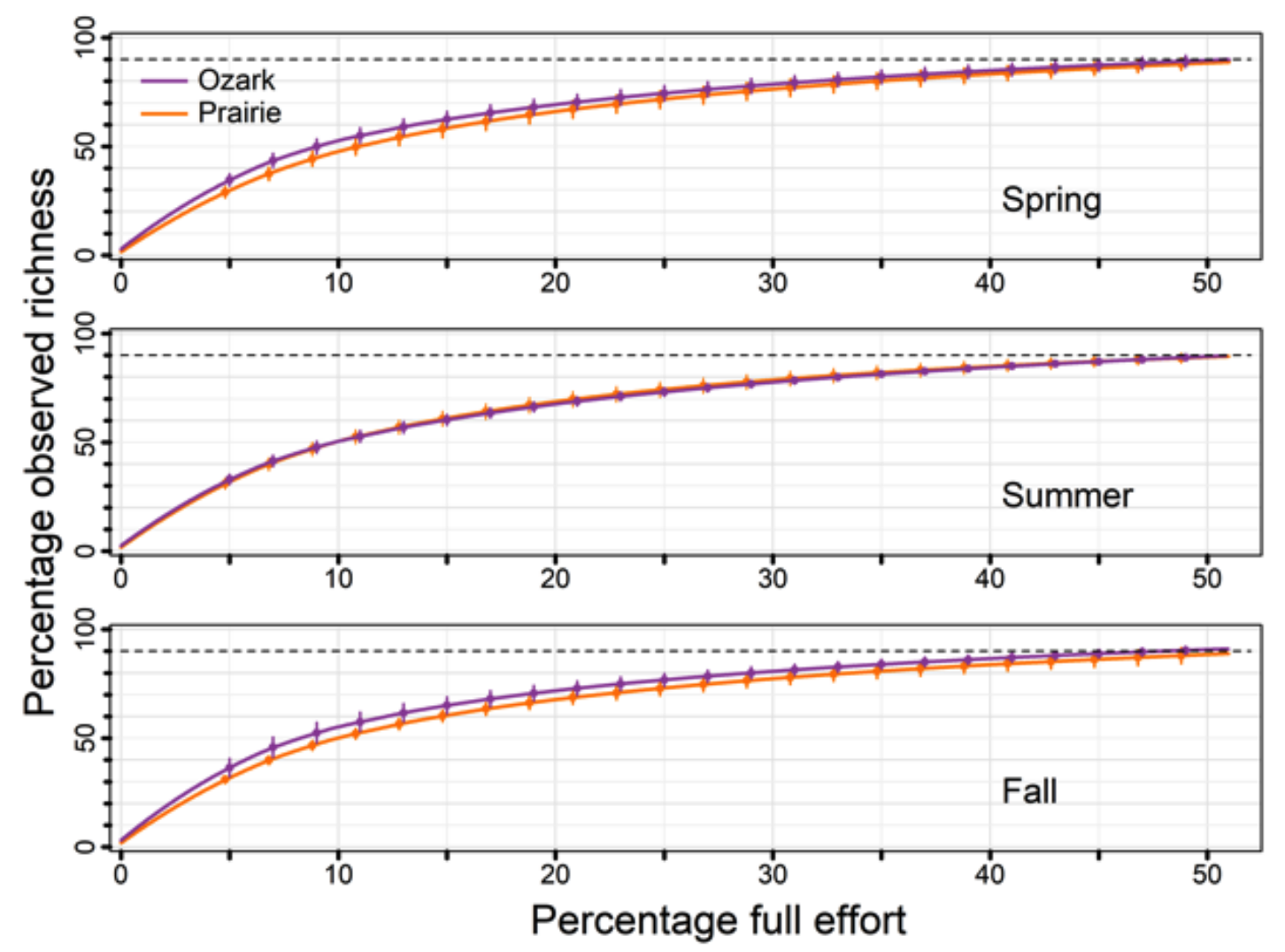

Figure 2.6. Mean ( $\pm 95 \%$ confidence intervals) species-accumulation curves from 36 samples in Missouri (USA) for the integrated-gear protocol across regions and seasons. 


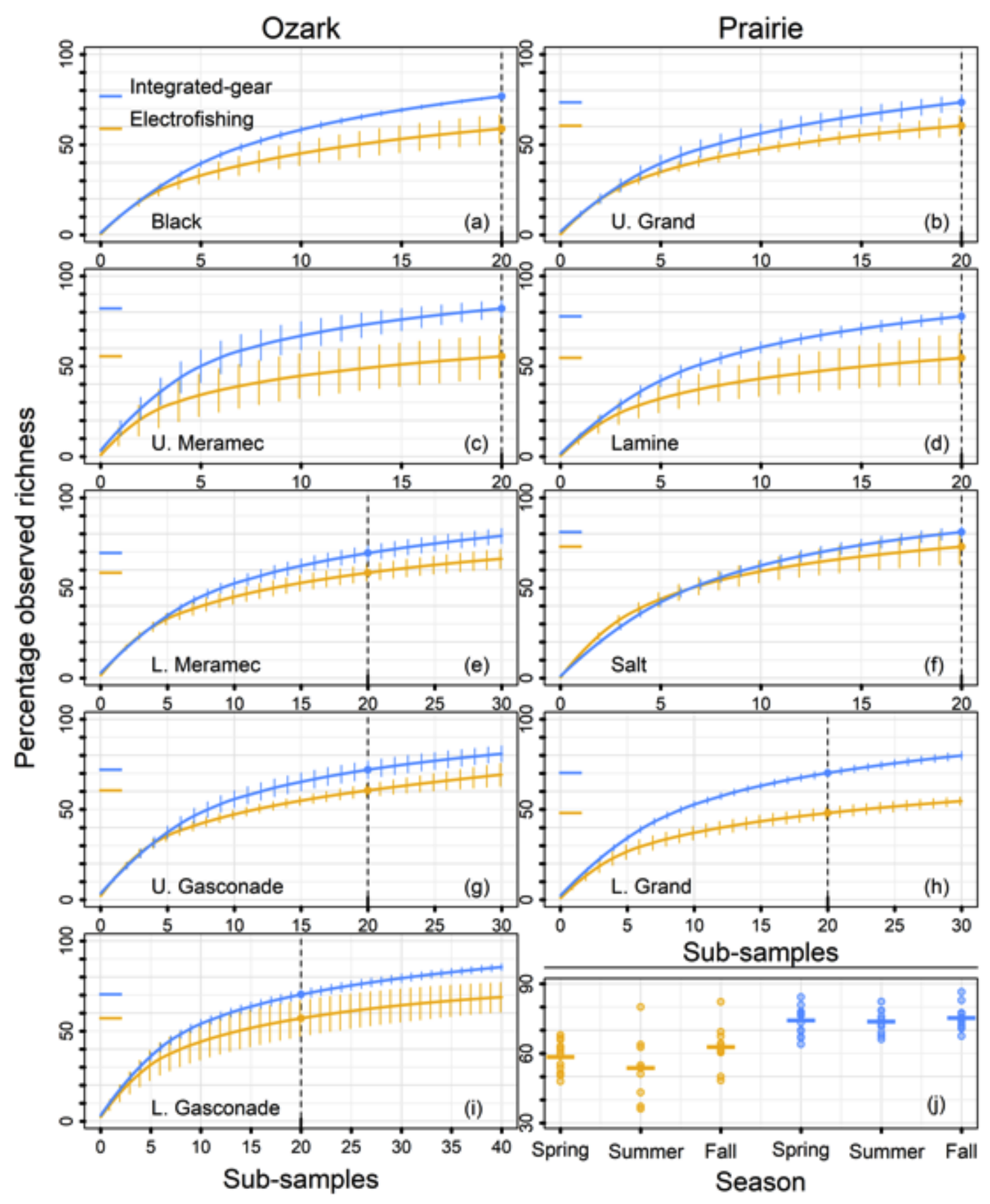

Figure 2.7. Mean species-accumulation curves ( $\pm 95 \%$ confidence intervals) based on sub-samples from electrofishing-only (50-m run) and integrated-gear (multiple gears) protocols from 36 samples at nine sites (panels a-i) in the Ozark and Prairie regions of Missouri (USA). Lower-right panel (j) is percentage richness grouped by season with 20 sub-samples equaling either $1 \mathrm{~km}$ of electrofishing or a combination of gears (electrofishing, trawling, seining, mini-fyke nets) with the integrated-gear protocol. 


\section{Appendices}

Appendix 2.1. Number of sub-samples with the full-effort and integrated-gear protocols in nine non-wadeable sites in Missouri (USA). One sub-sample by gear $=50 \mathrm{~m}$ electrofishing, $50 \mathrm{~m}$ trawling, one seine haul, one hoop net, one mini-fyke net, one trammel net. $\mathrm{L}=$ lower, $\mathrm{U}=$ upper, $\mathrm{Lg}=$ Large River, $\mathrm{S}=$ Small River, $\mathrm{E}=$ electrofishing, $\mathrm{T}=$ trawl, $\mathrm{S}=$ seine, $\mathrm{H}=$ hoop net, $\mathrm{FN}=$ mini-fyke net, $\mathrm{ST}=$ stationary trammel net.

\begin{tabular}{|c|c|c|c|c|c|c|c|c|c|c|c|c|c|c|c|}
\hline \multirow[b]{2}{*}{ River } & \multirow[b]{2}{*}{ Size } & \multicolumn{7}{|c|}{ Full-effort protocol } & \multicolumn{7}{|c|}{ Integrated-gear protocol } \\
\hline & & $\mathrm{E}$ & $\mathrm{T}$ & $\mathrm{S}$ & $\mathrm{H}$ & $\mathrm{FN}$ & ST & Total & $\mathrm{E}$ & $\mathrm{T}$ & $\mathrm{S}$ & $\mathrm{H}$ & $\mathrm{FN}$ & $\mathrm{ST}$ & Total \\
\hline L. Gasconade & $\mathrm{Lg}$ & 40 & 20 & 30 & 5 & 5 & 5 & 105 & 21 & 6 & 18 & 0 & 5 & 0 & 50 \\
\hline L. Grand & $\mathrm{Lg}$ & 30 & 20 & 30 & 5 & 5 & 5 & 95 & 21 & 6 & 18 & 0 & 5 & 0 & 50 \\
\hline L. Meramec & Lg & 30 & 20 & 30 & 5 & 5 & 5 & 95 & 21 & 6 & 18 & 0 & 5 & 0 & 50 \\
\hline U. Gasconade & $\mathrm{Lg}$ & 30 & 20 & 30 & 5 & 5 & 5 & 95 & 21 & 6 & 18 & 0 & 5 & 0 & 50 \\
\hline Black & S & 20 & 10 & 20 & 5 & 5 & 5 & 65 & 14 & 3 & 12 & 0 & 5 & 0 & 34 \\
\hline Lamine & S & 20 & 10 & 20 & 5 & 5 & 5 & 65 & 14 & 3 & 12 & 0 & 5 & 0 & 34 \\
\hline Salt & S & 20 & 10 & 20 & 5 & 5 & 5 & 65 & 14 & 3 & 12 & 0 & 5 & 0 & 34 \\
\hline U. Granc & S & 20 & 10 & 20 & 5 & 5 & 5 & 65 & 14 & 3 & 12 & 0 & 5 & 0 & 34 \\
\hline U. Meramec & S & 20 & 10 & 20 & 5 & 5 & 5 & 65 & 14 & 3 & 12 & 0 & 5 & 0 & 34 \\
\hline
\end{tabular}

Note: Large and Small rivers were distinguished by mean wetted-channel widths $\geq 65 \mathrm{~m}$ and $<65 \mathrm{~m}$, respectively. 
Appendix 2.2. Residual plots for models of (a) fish richness in sub-sample in 36 samples in Missouri (USA), (b) percentage richness detected by the integrated-gear protocol based on region (Ozark, Prairie) and season (spring, summer, fall), (c-f) percentage richness detected with 20 sub-samples by seasons, regions, protocol (integrated gear, electrofishing only), and mean wetted-channel width (MWCW).
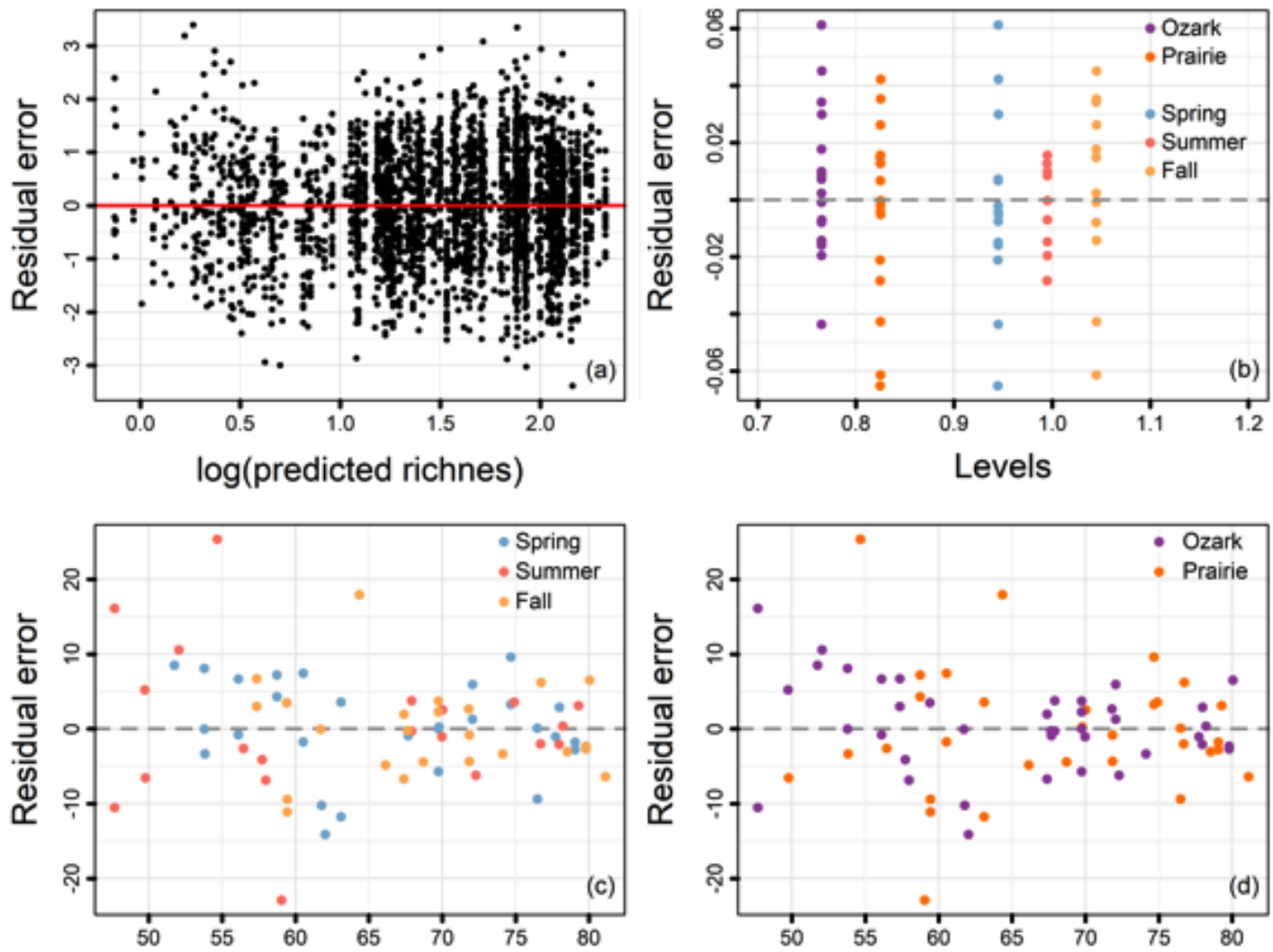

Predicted percentage richness

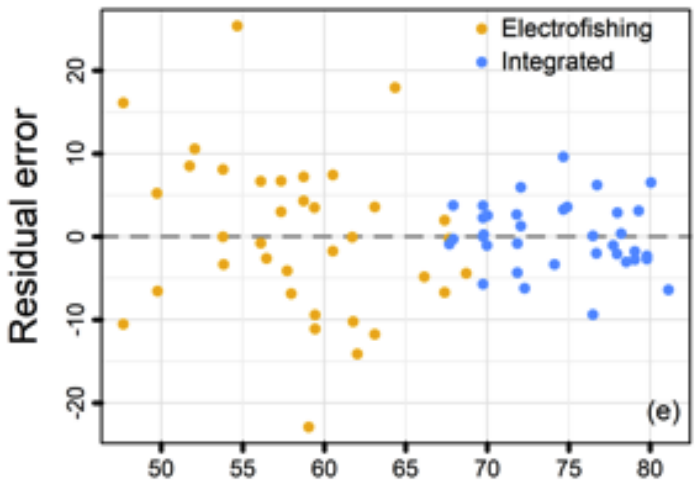

Predicted percentage richness

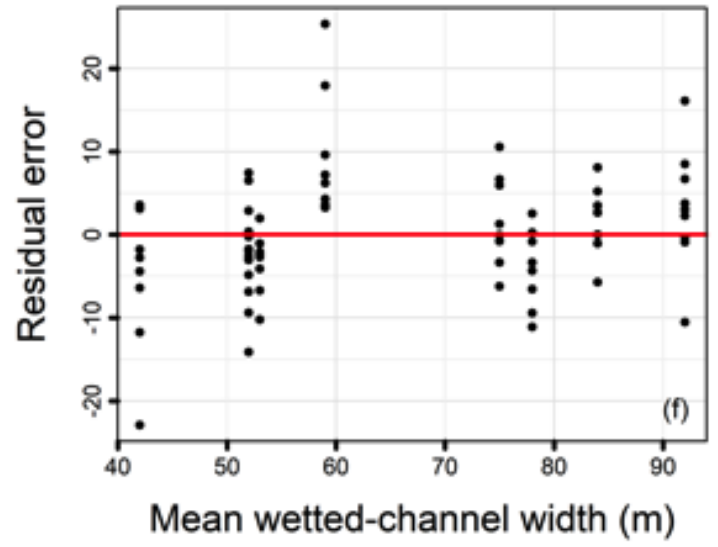


Appendix 2.3. Parameter estimates $(\hat{\beta})$ and standard errors (SE) for best-supported models in questions 1, 4, 5. Question 1: which gears detected the most species per unit effort? Question 4: did the most-efficient protocol detect a consistent percentage of species across regions and seasons? Question 5: was the integrated-gear protocol more effective and consistent than traditional effort with an electrofishing-only protocol?

\begin{tabular}{|c|c|c|c|}
\hline \multirow{2}{*}{$\frac{\text { Question (response) }}{\text { Question } 1(\log [\text { richness]) }}$} & Variable & \multicolumn{2}{|c|}{$\log (\beta) \log (\mathrm{SE})$} \\
\hline & \multicolumn{2}{|c|}{ Intercept = E-fishing, Ozarks, Summer 1.69} & 0.09 \\
\hline & Prairie & -0.42 & 0.14 \\
\hline & Fall & 0.42 & 0.08 \\
\hline & Spring & 0.31 & 0.08 \\
\hline & Mini-fyke net & 0.30 & 0.09 \\
\hline & Hoop net & -1.35 & 0.14 \\
\hline & Seine haul & 0.35 & 0.05 \\
\hline & Stationary trammel net (STN) & -1.31 & 0.14 \\
\hline & Trawl run & -0.31 & 0.07 \\
\hline & Prairie, Fall & -0.20 & 0.12 \\
\hline & Prairie, Spring & -0.14 & 0.11 \\
\hline & Prairie, Mini-fyke net & 0.28 & 0.09 \\
\hline & Prairie, Hoop net & 0.83 & 0.14 \\
\hline & Prairie, Seine haul & -0.05 & 0.06 \\
\hline & Prairie, STN & 0.67 & 0.13 \\
\hline & Prairie, Trawl run & 0.07 & 0.08 \\
\hline & Fall, Mini-fyke net & -0.33 & 0.12 \\
\hline & Spring, Mini-fyke net & -0.48 & 0.12 \\
\hline & Fall, Hoop net & -0.68 & 0.19 \\
\hline & Spring, Hoop net & -0.26 & 0.17 \\
\hline & Fall, Seine haul & -0.42 & 0.07 \\
\hline & Spring, Seine haul & -0.36 & 0.07 \\
\hline & Fall, STN & -0.18 & 0.17 \\
\hline & Spring, STN & -0.25 & 0.17 \\
\hline & Fall, Trawl run & -0.30 & 0.09 \\
\hline & Spring, Trawl run & -0.35 & 0.09 \\
\hline & Variable & $\beta$ & SE \\
\hline Question 4 (percentage richness) & Intercept & 90.01 & 0.47 \\
\hline & Variable & $\beta$ & SE \\
\hline Question 5 (percentage richness) & Intercept $=$ E-fishing, Ozarks, Summer & 71.37 & 5.90 \\
\hline & Integrated-gear (IG) protocol & 20.24 & 3.01 \\
\hline & Spring & 4.06 & 3.37 \\
\hline & Fall & 9.67 & 3.47 \\
\hline & Prairie & -1.51 & 2.27 \\
\hline & Mean wetted-channel width (m) & -0.26 & 0.07 \\
\hline & IG protocol, Spring & -4.29 & 3.67 \\
\hline & IG protocol, Fall & -7.84 & 3.79 \\
\hline
\end{tabular}




\title{
CHAPTER 3: ACCOUNTING FOR DOWNRIVER CONNECTIVITY AND HABITAT WHEN APPRAISING THE CONSERVATION VALUE OF TRIBUTARIES FOR LARGE-RIVER SPECIALIST FISHES
}

\begin{abstract}
Conservation planners increasingly use outlet discharge as a landscape metric for the capacity of tributaries to support mainstem large-river specialist (LRS) fishes. However, causal mechanisms underpinning species-discharge relationships (SDRs) are often unknown, and it is unclear if discharge consistently structures LRS richness within and among tributaries. Therefore, we extensively (200-244 km) sampled LRS fishes within two non-wadeable tributaries with broadly differing habitats of the Missouri River (Grand River, prairie region) and Mississippi River (Meramec River, Ozark region) to address four research questions: (1) do $\alpha$ (site) and $\beta$ (among-site species heterogeneity) richness vary between tributaries? (2) how does mean annual discharge relate to local habitat and downriver connectivity? (3) are SDRs consistent between rivers? and (4) do local habitat and downriver connectivity explain residual richness beyond variation already explained by SDRs? We detected 30 of 42 potential LRS species. Although $\alpha$ richness was higher in the Grand River (12.5 spp. vs. 9.8 spp. in Meramec R.), LRS fishes partitioned reaches in the Meramec River, causing $\beta$ richness to be twice as high. Discharge was correlated with multivariate habitat availability (Pearson's $r=0.80$ ) and downriver connectivity ( $r \geq 0.76)$ at sites. Species-discharge relationships were positive but had river-specific slopes $\left(R^{2}=0.71\right)$. Analyzing SDR residuals revealed discharge imperfectly represented connectivity, causing richness to be underestimated in network
\end{abstract}


branches (maximum underestimate $=8.7 \mathrm{spp}$.) and overestimated in isolated mainstems

( maximum overestimate $=5.8 \mathrm{spp}$.$) . Conservation planners may consider pairing region-$ specific SDRs with metrics for downriver connectivity when valuing tributaries for fishes with dispersal-dependent life histories.

\section{Introduction}

Large rivers often support unique fish communities comprised of species adapted for life in seasonally predictable, expansive, and open riverine ecosystems (Winemiller, 2005). However, large rivers are among the most impacted ecosystems in the world (Vörösmarty et al., 2010), causing declines in many large-river fishes and fisheries (He et al., 2019; Rinne, Hughes, \& Calamusso, 2005). Although several stressors collectively jeopardize large-river fish populations (Cooke, Paukert, \& Hogan, 2012), large-river fishes appear particularly sensitive to diminished connectivity throughout watersheds (Dias et al., 2017; Kominoski et al., 2018). Few free-flowing mainstem rivers remain in industrialized countries (Grill et al., 2019), and habitats in many of these rivers have been compromised through dredging, channelization, and flow regulation. However, several mainstems have undammed tributaries that provide access to less-impacted channel and floodplain habitats (Pracheil, McIntyre, \& Lyons, 2013; Silva et al., 2019). Moreover, the smaller sizes of tributaries have several logistical advantages for river conservation, including more manageable scales for restoration and fewer interjurisdictional boundaries, and competing uses (Dolezsai, Sály, Takács, Hermoso, \& Erős, 2015; Laub, Thiede, Macfarlane, \& Budy, 2018). Consequently, the conservation value of tributaries 
is increasingly recognized within riverscape-scale management and planning (Neeson et al., 2015; Winemiller et al., 2016; Ziv, Baran, Nam, Rodríguez-Iturbe, \& Levin, 2012). The value of tributaries likely depends on the spatial and temporal extents that riverine fishes use tributaries to fulfill critical life-history functions (e.g., reproduction, survival, growth). However, the mechanisms facilitating tributary use by mainstem fishes are often unclear, and most observations are set in wadeable streams. For example, wadeable tributaries of larger mainstems often support higher fish richness than similarly sized streams due to dispersal from mainstem sources (adventitious stream concept [ASC]; Osborne \& Wiley, 1992). The upstream extent of tributary use by mainstem dispersers can depend on species (Schaefer \& Kerfoot, 2004), life stage (Cathcart, McKinstry, MacKinnon, \& Ruffing, 2019), and resistance of local conditions in tributaries to dispersal (Ferreira, Souza, Cetra, \& Petrere, 2019; Hitt \& Angermeier, 2008). Larger tributaries seem particularly conducive to upstream dispersal (Grenouillet, Pont, \& Hérissé, 2004; Hitt \& Angermeier, 2008). For example, Hitt and Angermeier (2008) found more extensive dispersal into larger tributaries from mainstems, especially for "river" species and other mobile fish taxa. Extending findings from Hitt and Angermeier (2008) beyond wadeable streams suggests tributary use is likely particularly high in non-wadeable rivers and for riverine fishes (Radinger \& Wolter, 2014).

Differing availability of specific habitats within tributaries could cause varying degrees of tributary use among similarly sized tributaries (Cathcart et al., 2019). For example, if habitats within tributaries are homogenous and/or redundant with habitats already available in mainstems (i.e., "supplementary” sensu Dunning, Danielson, \& Pulliam, 1992; Schlosser, 1995), then distributional patterns within tributaries should be 
structured mainly by the cost of dispersal from mainstems (Ferreira et al., 2019; Miyazono \& Taylor, 2013). Dispersal from mainstems often results in a nested distributional pattern in wadeable tributaries, whereby richness decreases upstream as local communities are comprised of sequentially smaller subsets of downstream communities (Taylor \& Warren Jr, 2001). However, riverine fishes could bypass lowercourses of tributaries if searching for complementary "attractive" habitats not available in mainstems (e.g., rocky shoals for spawning; Lyons, Walchak, Haglund, Panehl, \& Pracheil, 2016; Vokoun, Guerrant, \& Rabeni, 2003). Thus, even if local ( $\alpha$ ) richness at sites is similar, partitioning of reaches within tributaries by fish could increase among-site compositional variation ( $\beta$ richness), which could signify a mixture of supplementary and complementary habitats within tributaries.

An issue with appraising the conservation value of non-wadeable tributaries is fish communities and habitats within rivers are often unknown (Cooke et al., 2012). Data deficiency partly stems from inadequate survey effort within tributaries. For example, standardized fish community sampling in the Missouri and Mississippi rivers monitor imperiled species and riverine condition (Ratcliff, Gittinger, O'Hara, \& Ickes, 2014; Welker and Drobish, 2011), but neither program typically extends sampling far beyond tributary mouths, despite several LRS species having the high abundances in tributary mouths (Brown \& Coon, 1994; Wildhaber, Gladish, \& Arab, 2012). Data deficiency also stems from fish assessments that often solely rely on surface- and bank-oriented seining and boat electrofishing, which are methods that may not detect benthic species in deep, turbid rivers (Flotemersch et al., 2011). 
Landscape-scale approaches for estimating tributary value often attempt to overcome insufficient, fine-scale riverine fish and habitat data by downscaling relationships between coarse environmental variables and fish community data aggregated across broad spatiotemporal scales (Laub et al., 2018; Miranda, Killgore, \& Slack, 2018; Pracheil et al., 2013). For example, Pracheil et al. (2013) discovered that tributaries in the Mississippi River basin with mean annual outlet discharges $\geq 166 \mathrm{~m}^{3} \mathrm{~s}^{-1}$ supported $\geq 80 \%$ of large-river fish species, thereby providing an easily measured indicator of high-value tributaries. Species-discharge relationships (SDRs), however, are often scale-dependent (McGarvey \& Ward, 2008), meaning it is unclear whether discharge-based metrics accurately predict LRS richness at sites within tributaries.

Our goal was to assess whether discharge explained large-river fish richness at sites within two contrasting non-wadeable tributaries. Although we generally expected positive SDRs, we hypothesized two situations where discharge would underestimate fish species richness: low-discharge sites that i) contain similar habitats to the Missouri or Mississippi rivers, and ii) were highly connected and easily accessed by fish dispersing from the Missouri or Mississippi rivers. We framed our study with four research questions: (1) do $\alpha$ (site) and $\beta$ (among-site) richness vary between tributaries? (2) how does mean annual discharge relate to local habitat and downriver connectivity? (3) are SDRs consistent between rivers? and (4) do local habitat and downriver connectivity explain residual richness beyond variation already explained by discharge? These questions will help prioritize specific areas within tributaries with high conservation value for riverine fishes, while examining linkages between mainstems and their tributaries within broader riverine networks. 


\section{Methods}

\section{Large-river specialist fishes}

We examined richness of large-river specialist (LRS) fishes — a group of fishes with populations in Missouri (USA) historically centered in the Missouri and Mississippi river mainstems and/or floodplains (Appendix 3.1). Occurrences of LRS species in tributaries likely result from migratory individuals fulfilling life-history requirements (i.e., spawning, growth, survival) and/or populations subsidized by dispersers from the Mississippi and/or Missouri rivers (metapopulation dynamics). Our list of LRS species largely follows Pflieger's (1989) “big river” fishes guild, except we added four species that are either diadromous (Alabama Shad Alosa alabamae), recently introduced largeriver species (Bighead Carp Hypophthalmichthys nobilis, Silver Carp H. molitrix), or lowland species (Mud Darter Etheostoma asprigene) associated with the Mississippi River floodplain (candidate LRS spp. = 35 in Grand R., 42 in Meramec R.). At least 15 LRS species are migratory (diadromous or potamodromous; O'Hara et al., 2007). Many LRS species have declined within the Missouri and Mississippi rivers following massive engineering projects to aid navigation and limit flooding (Galat et al., 2005; Schramm, Hatch, Hrabik, \& Slack, 2016).

Despite common preferences for larger rivers, LRS species possess varying habitat preferences, which could contribute to variation in distributional patterns between tributaries. Therefore, to gain further insight into distributional patterns, we reference water-velocity and substrate-size preferences of LRS species based on Frimpong \& Angermeier (2009): rheophilic species (13 spp.) preferred "high" or "moderate currents" 
(water velocities); lithophilic species (24 spp.) preferred substrate sizes coarser than sand while avoiding "silt", "clays", and "muck." We used natural history descriptions in Pflieger (1997) for missing trait data.

\section{Grand and Meramec river systems}

We sampled mainstems and their principal tributary branches along the lower 200 and $244 \mathrm{~km}$ of the Grand and Meramec rivers, respectively (Missouri, USA; Fig. 3.1; see site images in Appendix 3.2). The Grand River is a prairie river draining the Interior Plains region of northern Missouri and contributes 7.9\% of discharge to the Missouri River at their confluence (USEPA \& USGS, 2012; Grand River drainage area $=20,417$ $\mathrm{km}^{2}$ ). The Grand River is turbid and dominated by fine sediments (clay-sand) that form unstable river channels reinforced by woody debris. Most of the Grand River watershed is agricultural (76\%, USGS 2014), and much of the main channel is leveed to minimize flooding, but semi-natural meandering channels still occur, especially reaches throughout the lower $60 \mathrm{~km}$.

The Meramec River drains the Ozark Plateau, a topographically diverse, upland region in southern Missouri. Although the Meramec River is large (drainage area $=$ $10,270 \mathrm{~km}^{2}$ ), it contributes only $1.7 \%$ the flow to the Mississippi River at their confluence (USEPA \& USGS, 2012). In contrast to the Grand River, the Meramec River has high structural habitat diversity; channels are semi-confined by bluffs and consist of well-defined alternating pools, shoals, and off-channel areas often associated with point bars (Rabeni \& Jacobson, 1993). High groundwater and watershed forest cover (68\%, 
USGS 2014) result in high water clarity, especially in reaches upstream of metro St. Louis, MO.

Although the Grand and Meramec rivers broadly differ in habitat, both systems have similar network architecture. Neither river is impounded, such that LRS species can potentially disperse across broad spatial extents (>200 km). Further, both mainstems span $5-7^{\text {th }}$ orders and are joined mid-course by non-wadeable $5^{\text {th }}$-order tributary branches in close succession. Network branching decouples downriver connectivity and discharge by providing low-discharge tributary branches that are close to the Missouri or Mississippi rivers, thus, accessible to dispersing LRS species.

In the Grand River system, we placed eight sites approximately every $25 \mathrm{~km}$ along the mainstem and one site in two principal tributary branches beginning $1 \mathrm{~km}$ upriver from the mainstem (Shoal Creek, Thompson River; 10 total sites in Grand River system; Fig. 3.1). In the Meramec River system, we placed nine sites approximately every $30 \mathrm{~km}$ along the mainstem, and we re-sampled a mainstem Meramec River site (river $\mathrm{km}[\mathrm{rkm}] 53$ ) from Chapter 2. Due to limited access, we relocated some sites to be within $5 \mathrm{~km}$ of the nearest access. We also had a site in each of the Meramec River's two principal tributary branches, the Big River and Bourbeuse rivers, beginning $1 \mathrm{~km}$ and 7 $\mathrm{km}$ upriver of the Meramec River mainstem, respectively. All sites began at least $1 \mathrm{~km}$ away from any major confluence to minimize detections of random short-distance dispersers, meaning lowermost sites began at rkm 1 .

Throughout we refer to the Mississippi and Missouri rivers as "great rivers," mainstems of the Grand and Meramec rivers as "mainstems," principal tributary branches of the Grand and Meramec rivers as "branches," and the Grand and Meramec river 
systems (mainstems plus branches) as "tributaries." We also refer to the two most downriver sites in the Grand (rkm 1, 24) and Meramec (rkm 1, 30) rivers as "lowercourse," the two most upriver sites as "upper-course" (Grand R. = rkm 151-200, Meramec R. rkm 215-244), and intermediate mainstem sites as "mid-course."

Lower-most sites of both tributaries traverse floodplains and have backwateraffected flows mediated by surface elevations of the Missouri and Mississippi rivers. Reaches within these "confluence zones" are characterized by deep, wide (>100 m) channels with slow water velocities (Thornbrugh \& Gido, 2010). Based on surface elevations at our lowermost sites (1-6 km upriver of mouth) are backwater-affected near constantly, whereas sites farther upriver (Grand R. =rkm 24, Meramec R. =rkm 30) are likely backwater-affected only during high ( $\geq 80$ percentiles) Missouri and Mississippi river surface elevations (Remo, Carlson, \& Pinter, 2012; USAC, 2018).

\section{Fish and habitat sampling}

We sampled sites between April and September 2016 with a comprehensive sixgear protocol designed for Missouri's non-wadeable rivers (see Appendix 3.3 for example of fish and habitat sampling). We slightly modified protocols from Chapter 2 by including hoop and trammel nets to detect species inhabiting deep habitats prevalent throughout lower-course sites. Site lengths were approximately 50 mean wetted-channel widths (MWCW; measured from satellite imagery along eleven cross-sectional transects), and ranged from 1.5-5.0 km. Our absolute effort with active-sampling gears was proportional to each site's MWCW, which kept ratios of effort among active gears approximately constant among sites (See Appendix 3.4 for effort by site). Active gears 
were boat electrofishing (11-32 fifty-m sub-samples equaling 550-1,600 total m per site), seining (7-25 ten-m hauls per site), and benthic trawling (3-10 fifty-m sub-samples equaling 150-500 m per site). To distribute effort within sites, each sub-sample was randomly placed within 1 of 10 equal-length sections. We complemented active gears with three different passive gears that were set overnight and meant to sample difficultto-sample habitats: (a) one stationary trammel net (30.5 m long x $1.8 \mathrm{~m}$ deep) with 20.3$\mathrm{cm}$ and 9.5-cm bar mesh outer and inner panels, respectively; (b) two non-baited hoop nets (1.2-m diameter) with 3.8-cm bar mesh; (c) four non-baited mini-fyke nets (3.1-mm bar mesh, two 0.6-m x 1.2-m frames and 4.5-m lead). Trammel and hoop nets were set in deep (>1.5 m) pools, while mini-fyke nets were placed in shallow off-channel and/or structurally complex areas. We first electrofished and set trammel nets in all sites in late spring and early summer to detect large-bodied migratory fishes residing in tributaries for spawning, and returned to sites to seine, trawl, and set hoop and mini-fyke nets throughout summer. This protocol targeted $93-94 \%$ of fish species per survey at sites that would have been detected using the intensive, full-effort sampling protocol in Chapter 2.

Between September 26 and October 27, 2016, we measured 10 river habitat variables at sites and in one site in each of the Missouri and Mississippi rivers. Sites in the Missouri and Mississippi rivers were $5 \mathrm{~km}$ long, extending $2.5 \mathrm{~km}$ up and downriver of confluences with the Grand and Meramec rivers, respectively (i.e., 5-km long sites). Our habitat protocol was a rapid $(<1 \mathrm{~d})$, modified point-transect design based on USEPA (2013). Each site was divided by 21 equally spaced cross-sectional transects spanning the main channel. Along each transect, we placed five equidistant points, with the two outer points $2 \mathrm{~m}$ from each bank. We added an additional point at the center of off-channel 
habitats intersected by transects ( $\geq 105$ total points per site). At each point we recorded depth, water-column velocity, substrate size, abundance of large-woody debris (LWD), and whether the point was in a shoal (i.e., steepened channel with swifter, turbulent water than surrounding channel-units). Depth was recorded to the nearest decimeter with sidescan sonar (Lowrance HDS-10). We mounted a velocity sensor (Hach FH950) to a pole to measure water-column velocity at approximately $60 \%$ depth or averaged velocities at $20 \%$ and $80 \%$ for depths $>1 \mathrm{~m}$. In wadeable areas, depth and water-column velocity at $60 \%$-depth were recorded with a top-setting wading rod. Next, we used size-scan sonar imagery, corroborated by a sounding pole (depths $<4 \mathrm{~m}$ ) or weighted sounding rope (depth $\geq 4 \mathrm{~m}$ ), to classify predominant substrate into six categories: silt/clay $(1=\leq 0.06$ $\mathrm{mm})$, sand $(2=0.07-2.0 \mathrm{~mm})$, gravel/pebble $(3=3.0-64 \mathrm{~mm})$, cobble $(4=65-256 \mathrm{~mm})$, boulder $(5=\geq 257 \mathrm{~mm})$, and bedrock (6). We also used side-scan sonar to enumerate LWD ( $\geq 5 \mathrm{~m}$ long) and large boulders ( $\geq 1 \mathrm{~m}$ diameter) intersecting a 5-x-5-m area centered at each point.

Three variables were recorded at the ends of each transect. First, we categorized the percentage of shoreline covered by macrophytes within $10 \mathrm{~m}$ up- and down-river of each transect $(0=\leq 5 \%, 1=6-25 \%, 2=26-50 \%, 3=51-75 \%, 4=>75 \%)$. Next, we categorized whether the riparian area extending $25 \mathrm{~m}$ from the river bank was confined by bluffs. Then, we visually estimated the percentage of shoreline (lengthwise) with offchannel areas between consecutive transects. Off-channel areas were often characterized by slackwater habitats (e.g., sloughs, alcoves, secondary channels). We also measured turbidity once per site as Secchi depth in a well-lit area using polarized glasses. Finally, 
we summarized point- and transect-based variables at site scales by calculating means or percentages of habitat observations.

\section{Analyses}

\section{Spatial variation in tributary use}

We used two approaches to contrast tributary use patterns and richness components between rivers. First, we used Thornbrugh and Gido's (2010) three-category scheme to classify the upriver extent of tributary use by LRS species (Fig. 3.2); we considered species not caught by our sampling as evidence for limited exchange between tributaries and great rivers. Species caught only in backwater-affected lowermost sites spanning rkm 1-6 in tributaries conformed to confluence exchange, and species dispersing upriver in tributaries beyond confluence zones supported network dispersal $(\geq$ rkm 24 in Grand R., $\geq$ rkm 30 in Meramec R.). We summarized percentages of rheophilic and lithophilic species at our lowermost sites (confluence exchange), sites upriver of our lowermost site (network dispersal), and species not detected in tributaries (limited exchange). Second, to examine the distribution of richness within systems, we deconstructed total LRS richness $\left(\gamma_{\mathrm{i}}\right)$ within each river system $(i)$ into constituent $\bar{\alpha}_{\mathrm{i}}$ (average site richness) and $\beta_{\mathrm{i}}$ richness (compositional dissimilarity among sites) components using Whitaker's (1960) multiplicative partitioning $\left(\beta_{\mathrm{i}}=\gamma_{\mathrm{i}} / \bar{\alpha}_{\mathrm{i}}\right)$. We also calculated a standardized estimate of $\beta_{\mathrm{i}}$ corrected for unequal sites between systems (Jost, 2007, Eq. 25).

Species-discharge relationships and residual analysis of LRS richness 
We used a two-step process to first estimate SDRs within tributaries and then test whether residual variation in LRS $\alpha$ richness at a site could be explained by habitat and downriver connectivity. This sequence was meant to identify potential biases created by not fully accounting for habitat and connectivity when using SDRs as proxies for LRS $\alpha$ richness. Long-term (1920-2016) discharge data $\left(\mathrm{m}^{3} \mathrm{~s}^{-1}\right)$ was only available at six and five gages within the Grand and Meramec river systems, respectively. However, linear regressions between mean annual discharge at these sites and drainage area were precise $\left(R^{2}>0.99\right)$, indicating discharge closely aligned with drainage area (Appendix 3.5). Therefore, we subsequently predicted mean annual discharge at each site based on drainage areas in the National Hydrography Dataset plus version 2 (USGS \& USEPA, 2012).

We first examined whether discharge explained richness (i.e., SDR) within tributaries and whether model slopes of SDRs varied between tributaries. Our candidate model set included linear regressions between LRS $\alpha$ richness (response variable) and river, discharge, discharge ${ }^{2}$ and interactions between discharge-metrics and river (i.e., seven candidate models plus intercept-only model; equation 1). We used an informationtheoretic framework that treated each model as a competing hypothesis and evaluated relative model support (i.e., Akaike weight [w]) among hypotheses using Akaike's Information Criterion corrected for small sample size (AICc). Although LRS $\alpha$ richness are counts (response variable), linear regression models were more supported than Poisson generalized linear models.

We then examined whether sites with high downriver connectivity and/or habitats similar to those in great rivers (great-river habitat similarity) supported more LRS species 
than predicted by discharge. Thus, our response variable was ordinary residuals extracted from the best-supported SDR in modeling step one. We quantified downriver connectivity as watercourse distance to the Missouri (Grand R.) or Mississippi (Meramec R.) rivers. We calculated great-river habitat by first performing a Principal Component Analysis (PCA) on a correlation matrix of habitat data from both rivers. Then we calculated Euclidean distances between the multivariate centroids of sites to those of either the Missouri (reference for Grand R.) or Mississippi (reference for Meramec R.) rivers based on principal component (PC) axes with eigenvalues $>1$. We also included each constituent PC axis as a candidate predictor variable. Before performing PCA, we reduced skew of five habitat variables via normalizing transformations (Table 3.1). Finally, we linearly regressed residual LRS $\alpha$ richness against each predictor variable and evaluated relative support among predictors against an intercept-only (null) model with AICc. Equation 1 presents a linear regression where $\mathrm{Y}_{\mathrm{i}}$ is observed LRS $\alpha$ richness for site $\mathrm{i}, \hat{\beta}$ are the estimated intercept $\left(\hat{\beta}_{0}\right)$ and slope parameters for 1 through $\mathrm{n}$ predictor variables $(\mathrm{X})$.

$\mathrm{Y}_{\mathrm{i}}=\hat{\beta}_{0}+\hat{\beta}_{1} * \mathrm{X}_{1 \mathrm{i}}+\ldots \hat{\beta}_{\mathrm{n}} * \mathrm{X}_{\mathrm{ni}}+\mathrm{e}_{\mathrm{i}}$, where $\mathrm{e}_{\mathrm{i}} \sim \mathrm{N}\left(0, \sigma^{2}\right)$ and independent

\section{Results}

Patterns in tributary use and species richness

We collected most of the candidate LRS species within the Grand (18 of 35 candidate LRS spp., 51\%; sites = 10) and Meramec (29 of 42 candidate LRS spp., 69\%; sites $=12$ ) river systems. Consequently, we categorized the 17 and 13 species not 
detected by us in the Grand and Meramec river systems as limited exchange, respectively. Among the LRS species observed within tributaries were six species with conservation statuses of "vulnerable", "imperiled", or "critically imperiled" in Missouri (NatureServe, Appendix 3.1), including 134 Plains Minnows Hybognathus placitus ("vulnerable") in the Grand River system and 21 Alabama Shad ("imperiled") in the Meramec River system.

Most LRS species observed within tributaries ranged upriver beyond confluence zones (Grand R = 17 of 18 spp., 94\%; Meramec R. = 23 of 29 spp., 79\%), supporting network dispersal as the predominant distributional pattern. Only one (6\%) and six (20\%) LRS species were solely detected in confluence zones (i.e., conforming to confluence exchange) in the Grand and Meramec rivers, respectively (Table 3.2).

Percentages of LRS rheophilic fishes observed in tributaries were lower (confluence exchange, Grand R. = 20\%, Meramec R. = 21\%; network dispersal, Grand R. $=24 \%$, Meramec R. $=26 \%$ ) than species not observed in tributaries (limited exchange, Missouri R. = 41\%, Mississippi R. = 39\%), indicating water velocities within tributaries may not be sufficient to attract LRS species into tributaries (Fig. 3.3). Similarly, percentages of lithophilic LRS species were lower in the fine sediment-dominated Grand River $($ confluence exchange $=47 \%$, network dispersal $=47 \%)$ than species not collected in tributaries (limited exchange, 65\%). In contrast, percentages of lithophilic LRS species were higher in the Meramec River system (confluence exchange $=58 \%$, network dispersal $=74 \%$ ) than species exhibiting limited exchange in the Mississippi River (limited exchange $=39 \%$ ), indicating coarse substrates in the Meramec River may be 
sources of complementary habitat for LRS fishes, especially in sites upriver of confluence zones.

Although $\alpha$ richness was higher in the Grand River (12.5 spp. in Grand R. versus 9.8 spp. in Meramec R.), $\beta$ richness was over twice as high in the Meramec River system (1.4 spp. in Grand R. versus 2.9 spp. in Meramec R.; Table 3.2). Similarly, standardized $\beta$ richness was nearly four times higher in the Meramec River system (standardized $\beta=$ 0.18 ) than Grand River system (standardized $\beta=0.05$ ). Altogether trait frequencies and $\beta$ richness indicated the distributions of LRS species were relatively partitioned among reaches in Meramec River system, yet broadly overlapped throughout the Grand River system.

Relationships between discharge, habitat, and downriver connectivity

Three PC axes had eigenvalues $>1$ and collectively explained $80 \%$ of variation in among-site habitat within and among tributaries (Fig. 3.4): PC 1 (49\%) represented upland conditions based on maximum correlations with coarse substrate, channel confinement, low turbidity, and numbers of boulders, shoals, and macrophytes (Table 3.1); PC 2 (20\%) reflected increasing off-channel areas and depth; PC 3 (11\%) represented increasing water velocities and decreasing LWD. Overall, habitat at sites within Grand River was more similar to the Missouri River than habitat in the Meramec River was to the Mississippi River (Fig. 3.4, see Appendix 3.6 for habitat data). An exception was the lowermost site in the confluence zone of the Meramec River, which grouped with Grand River sites closer to the Missouri and Mississippi rivers based on habitat (Fig. 3.4). Pearson product-moment correlations $(r)$ between discharge and great- 
river habitat similarity and distance-to-river mouth were $\geq 0.75$ in both systems, indicating discharge is a coarse metric for both habitat availability and downriver connectivity (Fig. 3.5). Correlations between discharge and PC1 were notably lower in the Grand River $(r=-0.06)$ than Meramec River $(r=0.42)$, revealing stronger environmental gradients across sites in the Meramec River system (Fig. 3.5).

\section{Species-discharge relationships and residual analysis}

Models that assumed common SDRs in the Grand and Meramec river systems (i.e., no discharge-x-river interaction) indicated LRS $\alpha$ richness increased with discharge $\left(R^{2}=0.46\right.$; Fig. 3.6 top panel); however, a model that allowed linear SDRs to vary between systems was better supported (Akaike weight of top-ranked model $\left[w_{1}\right]=0.82$ ) and explained more variation (river-X-discharge interaction $[\hat{\beta} \pm \mathrm{SE}]=0.14 \pm 0.04, R^{2}=$ 0.71; Table 3.3; Fig. 3.6 middle panel). The varying slopes of SDRs between systems resulted from LRS species being more extensively distributed in the Grand River than the Meramec system. For example, LRS $\alpha$ richness at the mouths of both rivers was comparable (Grand R. = 15 spp., Meramec R. = 19 spp.), but we detected only 1-2 LRS species at three sites between rkm 184-244 in Meramec River. In contrast, LRS $\alpha$ richness declined only gradually upriver in the Grand River system, with 10-12 LRS species occurring even at sites rkm 145-200 away from the Missouri River. Predictor variables and parameter estimates for models are in Appendices 3.7 and 3.8, respectively. Analyzing residuals of SDRs from the best-supported model in the first modeling step revealed discharge alone underestimated LRS $\alpha$ richness in low-discharge branches with high connectivity, while overestimating richness in more isolated mainstem sites 
(Table 3.4; Fig. 3.6 bottom panel). The model with a linear $\left(\hat{\beta}_{\text {distance }}=-0.02 \pm 0.01\right.$, $\left.\Delta \mathrm{AICc}=0.0, w_{1}=0.51, R^{2}=0.20\right)$ effect of distance from river mouth was better supported than the intercept-only model $\left(\triangle \mathrm{AICc}=2.2, w_{3}=0.17\right)$. Underestimated richness was most apparent near confluences between mainstems and branches in the Meramec River system. Small (low-discharge) and connected mid-course branches in the Meramec River at rkm 62 (Big R.) and rkm 116 (Bourbeuse R.) supported 8.7 and 3.2 more LRS species than predicted by discharge, respectively. Further, mainstem sites located 1 and $30 \mathrm{~km}$ upriver of the Meramec River confluence with the Big River (rkm 62) had 3.2 and 0.7 more species than expected, indicating spatial effects taper with distance upriver of confluences. Neither great-river habitat similarity nor PC axes were better supported than the intercept-only model, indicating discharge adequately represented underlying effects of habitat on LRS $\alpha$ richness in both rivers $(\triangle \mathrm{AICc} \geq 4.8$, $w_{4-7} \leq 0.00-0.05, R^{2}=0.00-0.23$; see Appendix 3.9 for parameter estimates).

\section{Discussion}

We documented varying degrees of limited exchange, confluence exchange, and network exchange by LRS species in two contrasting river systems. We suspect at least two riverscape attributes contributed to observed spatial and taxonomic variation (Dunning et al., 1992; Schlosser, 1995): the availability of (i) supplementary habitats similar to those in the great rivers and (ii), complementary, but critical, habitats naturally lacking or anthropogenically reduced within great rivers. The broad and local availabilities of these habitats likely affected whether LRS species used tributaries altogether and the distributions of LRS species within tributaries, respectively. 
Most LRS species that were observed in tributaries occurred upriver of confluence zones ( $>6 \mathrm{~km}$ upriver) within the Grand (94\% of spp.) and Meramec (80\% of spp.) river systems, respectively, demonstrating network dispersal was the predominant distributional pattern exhibited by LRS fishes. This finding in non-wadeable rivers conceptually and spatially extends findings from Hitt and Angermeier (2008), who found more extensive upstream dispersal within larger streams. Beyond stream size, less is known about specific factors mediating tributary use by freshwater fishes, which likely depends on the availability of suitable habitat within tributaries and permeability of local habitats to dispersal (Ferreira et al., 2019; Hitt \& Angermeier, 2008). The combination of deeper habitats (Matthews, 1998, pp. 288; Roberts \& Hitt, 2010), and availability of lower-velocity resting areas and swimways might be important for dispersal upriver (McElroy, DeLonay, \& Jacobson, 2012). Consequentially, riverine habitats such as lowvelocity pools, meanders, deeper shoals, and lateral areas may explain physical mechanisms facilitating more extensive tributary use in our rivers than previously documented in streams.

Tributary use could also be inherently higher among LRS species, many of which have life histories refined by adaptive benefits of exploiting spatiotemporally predictable resources within rivers (McIntyre et al., 2016). For example, many LRS species possess traits indicative of wide-ranging life-cycles including large-body sizes (Radinger \& Wolter, 2014), long generation times (Winemiller, 2005), and drift-dependent early lifestages (Perkin \& Gido, 2011). Hence, tributary use is within the scopes of several LRS species' expansive life cycles covering discrete habitat patches throughout riverine networks. Lower percentages of rheophilic fishes in both tributaries and higher 
percentages of lithophilic fishes in the Meramec River indicate tributaries could provide lower velocity habitat patches and complementary coarse substrates not widely available in great rivers.

\section{Landscape influences on LRS richness patterns}

Our results showed LRS $\alpha$ richness at sites within tributaries positively related to discharge, which supports applications of SDRs to assess conservation value of tributaries (e.g., Laub et al., 2018; Pracheil et al., 2013). Positive correlations between discharge and in-stream habitat PCA axes indicated discharge is likely a coarse surrogate for habitat availability. Riverine habitats, however, are also created by other regional(e.g., geologic, topographic, climatic) and finer-scale (e.g., channel confinement, terrestrial linkages) factors (Ward, Tockner, Arscott, \& Claret, 2002); therefore, habitats and SDRs could vary among similarly sized rivers with different geologic histories and drainage contexts. For example, supplementary habitats similar to those in the Missouri River predominated in Grand River system and may have facilitated extensive tributary use by LRS species, manifested as gradual SDRs. In contrast, few (1-2) LRS species ranged beyond rkm 184 in Meramec River system, where discharge was low $\left(\leq 37 \mathrm{~m}^{3} \mathrm{~s}^{-1}\right)$ and upland habitats sharply contrasted with those in the Mississippi River. Thus, conservation plans that transcend physiographic boundaries (e.g., prairie versus Ozarks) may need to account for broadly differing habitats within tributaries by developing region- or river-specific SDRs.

Despite LRS $\alpha$ richness being lower in the Meramec River system, $\beta$ richness was nearly two-times higher than in the Grand River system, indicating LRS species were 
spatially stratified in the Meramec River system. Stratification may have resulted from contrasting habitats between confluence zones and sites upriver. Confluence zones might mainly function as corridors (Neely, Pegg, \& Mestl, 2010), supplemental foraging habitats (e.g., Braaten \& Guy, 1999), and complementary low-velocity nurseries and backwaters (e.g., Brown \& Coon, 1994; Love, Phelps, Tripp, \& Herzog, 2017; Naus \& Reid Adams, 2018) for LRS fishes. In contrast, a slightly higher percentage of rheophilic fishes and a markedly higher percentage of lithophilic fishes at sites upriver of the confluence zone in the Meramec River system indicated these reaches might provide complementary spawning habitats (i.e., shoals) for migratory species dependent on flow and coarse substrates (e.g., Lyons et al., 2016). High-discharge reaches above confluence zone are likely particularly important for shoal-dependent LRS species given these habitats have been reduced or isolated in great rivers (Coker, 1930; Galat \& Zweimuller, 2001). Consequently, these vestiges of semi-natural large-river habitat might function as distributional refugia capable of supporting small populations of some non-migratory LRS species (e.g., River Darter Percina shumardi, Western Sand Darter Ammocrypta clara).

Complementary habitats also exist above confluence zones in the Grand River system (e.g., Vokoun et al., 2003), but likely to a lesser degree given the overall similarity of habitats in the Grand River system to the Missouri River. Alternative forms of complementation in the Grand River system could be free-flowing, unchannelized reaches with semi-natural prairie habitats that allow eggs and larvae to drift unimpeded downriver. For example, three pelagic-spawning minnows that are declining across much of the Interior Plains were distributed throughout ( $\geq$ nine sites) the Grand River system 
(Plains Minnow, Shoal Chub Macrhybopsis hyostoma, Silver Chub M. storeriana; Perkin \& Gido, 2011).

Spatial aspects of species-discharge relationships for large-river specialist fishes

Discharge imperfectly represented downriver connectivity based on spatially structured mismatches between observed and SDR-predicted richness, especially in the Meramec River system. Mismatches arose near areas of network branching where sites can have low discharge, yet be spatially accessible to dispersing LRS species from great rivers. For example, Meramec River SDRs underestimated richness in both branches (by 2.3-8.7 spp.) and mainstem sites between branches (by 0.6-3.2 spp.), while overestimating mainstem richness at more isolated mainstem sites upriver (by 1.1-5.8 spp.). Higher risks of stranding and predation in shallower upper-courses (Schlosser, 1987) or accumulating dispersal costs (Brönmark et al., 2014) could inhibit LRS species from dispersing farther upriver in the Meramec River system. Moreover, upper-courses could fail to attract LRS species beyond mid-courses where potential complementary habitats (e.g., shoals) are already available. Downriver connectivity also likely structured LRS $\alpha$ richness in the Grand River system (see Chapter 4), but effects of connectivity might be less apparent in SDR residuals because LRS $\alpha$ richness remained high throughout the Grand River system. Accordingly, the lack of dispersal limitation in the Grand River system allowed discharge to explain LRS $\alpha$ richness. Altogether, the residual analysis indicated SDRs might undervalue small branches that are accessible to dispersing LRS species while overvaluing isolated mainstem reaches, particularly in tributaries spanning strong environmental gradients such as the Meramec River system. 
Failing to account for downriver connectivity could impact decisions related to basinwide conservation planning and restoration. The area of reconnected habitat for migratory fishes is often a guiding criterion for prioritizing barrier removals (Kemp \& O’Hanley, 2010; Puijenbroek, Buijse, Kraak, \& Verdonschot, 2019). If distributional patterns of LRS species in the Meramec River are generalizable to other upland tributaries, discharge might underestimate important habitats for migratory species in branches with high connectivity. One migratory LRS species detected in the Big River is Alabama Shad, an anadromous species that has been extirpated throughout much of its northern range following construction of semi- and impermeable barriers in the great rivers (Mettee \& O'Neil, 2003). Nine of twenty-one age-0 Alabama Shad collected in the Meramec River system were in the Big River (rkm 62), whereas none were collected in mainstems upriver of rkm 120 despite these sites having discharge comparable to Big River. Further, given wide-ranging life-cycles of many LRS species, undervaluing downriver connectivity in tributaries could impact other imperiled species (Galbraith et al., 2018). For example, at least 19 LRS species that we collected are hosts for larval freshwater mussels in the Meramec River system (FMHD, 2017; see Hinck et al., 2012 for mussel list). Thus, pairing discharge with metrics for downriver connectivity could help identify reaches where barrier removals might mutually benefit multiple imperiled taxonomic groups.

\section{Tributaries as patches within broader riverine ecosystems}

The habitats within our study tributaries are likely insufficient to solely support populations of many large-river fishes. Although our surveys undoubtedly missed some 
LRS species within our study systems (e.g., Paddlefish Polyodon spathula, Tripp et al., 2019), our surveys indicate tributary use by at least some LRS species is limited (i.e., support limited exchange). For example, we caught 437 Shoal Chubs and 283 Silver Chubs across tributaries but did not collect any Sicklefin Chubs M. meeki or Sturgeon Chubs M. gelida, revealing a spectrum of tributary use even among congeners (Dunn, Brooke, Hrabik, \& Paukert, 2018). Limited exchange by some species was also recently supported by two studies finding only a fraction of recruits of two LRS species in the middle Mississippi River with known natal origins were spawned in tributaries (natal origins in tributaries $=1-11 \%$ of Blue Catfish Ictalurus furcatus, Laughlin, Whitledge, Oliver, \& Rude, 2016; $\leq 13 \%$ of Paddlefish Polyodon spathula, Rude \& Whitledge, 2019). Thus, tributaries are unlikely to be equivalent substitutes for the large-river habitat within great rivers, but instead may function as peripheral patches variably perceived by LRS species within broader large-river networks. Ultimately, because the life cycles of many LRS species transcend both tributaries and great rivers (e.g., Pracheil, Lyons, Hamann, Short, \& McIntyre, 2019), the value of tributaries likely depends on the condition of great rivers and vice versa.

\section{Conclusions and research gaps}

Our study revealed LRS $\alpha$ fish richness was structured by discharge, broad and fine-scale habitat availability, and downriver connectivity within tributaries. Our finding that higher-discharge sites support more LRS species generally validates at local scales the utility of SDRs for identifying high-value areas within tributaries (Laub et al., 2018; Pracheil et al., 2013). The predictive strength of discharge likely results from its 
integration of a suite of longitudinal changes in habitat, which might vary among rivers and regions. Discharge, however, imperfectly represented downriver connectivity within complex river networks. Thus, conservation practitioners should be aware that discharge might underestimate the conservation value of network branches for mobile species with spatially extensive life cycles.

There are several other factors that might impact the value tributaries for LRS fishes. Many of these factors are research gaps stemming from insufficient fine-scale (i.e., river reach) data on the spatiotemporal availability of habitat and LRS fish distributions (Cooke et al., 2012). Beyond mean annual discharge, other dimensions of flow regime, such as timing and duration, could impact the extent of tributary use (Laub et al., 2018). Moreover, little is known about what specific habitats are important for several LRS fishes and whether these habitats are supplementary or complementary to habitats in great rivers (sensu Galat \& Zweimuller, 2001). Synchrony between key dimensions of flow regime and availabilities of complementary habitats in tributaries is likely especially important for recruitment and survival of LRS fishes (Pracheil, Pegg, \& Mestl, 2009). Addressing these research gaps will be important for prioritizing conservation actions within and among tributaries to maintain populations of riverine fishes.

\section{Acknowledgements}

The Missouri Department of Conservation (MDC) funded this research. We thank the following MDC Fisheries Management Biologist and Research Scientists for input on the study design — Dave Herzog, Dr. Vince Travnichek, Matt Combes, Dr. Doug Novinger, 
Greg Pitchford, Jen Girondo, and Dr. Paul Blanchard. Drs. Amanda Rosenberger, Frank Thompson, and Chris Wikle also provided input on the study design. Bob Hrabik (MDC ichthyologist) provided input on candidate large-river specialists and assisted with field work. The core field crew consisted of Brandon Brooke and Randy Kramer, and we appreciate the following people for their temporary stints - Erin Hassett, Liz Heimer, Christina Kelsay, Rory Mott, Brett Parra, Jason Persinger, Dr. Amanda Rosenberger, Bob Hrabik, and Autom Yount. This study was performed under the auspices of University of Missouri Animal Use and Care Protocol 8532.

\section{References}

Braaten, P. J., \& Guy, C. S. (1999). Relations between physicochemical factors and abundance of fishes in tributary confluences of the lower channelized Missouri River. Transactions of the American Fisheries Society, 128(6), 1213-1221. https://doi.org/10.1577/1548-8659(1999)128<1213:RBPFAA>2.0.CO;2

Brönmark, C., Hulthén, K., Nilsson, P. A., Skov, C., Hansson, L.-A., Brodersen, J., \& Chapman, B. B. (2014). There and back again: Migration in freshwater fishes. Canadian Journal of Zoology, 92(6), 467-479. https://doi.org/10.1139/cjz-20120277

Brown, D. J., \& Coon, T. G. (1994). Abundance and assemblage structure of fish larvae in the lower Missouri River and its tributaries. Transactions of the American Fisheries Society, 123(5), 718-732. https://doi.org/10.1577/15488659(1994)123<0718:AAASOF>2.3.CO;2 
Cathcart, C. N., McKinstry, M. C., MacKinnon, P. D., \& Ruffing, C. M. (2019). A tribute to tributaries: Endangered fish distributions within critical habitat of the San Juan River, USA. North American Journal of Fisheries Management, 39(5), 10151025. https://doi.org/10.1002/nafm.10335

Coker, R. E. (1930). Studies of common fishes of the Mississippi River at Keokuk. US Government Print Office.

Cooke, S., Paukert, C., \& Hogan, Z. (2012). Endangered river fish: Factors hindering conservation and restoration. Endangered Species Research, 17(2), 179-191. https://doi.org/10.3354/esr00426

Dias, M. S., Tedesco, P. A., Hugueny, B., Jézéquel, C., Beauchard, O., Brosse, S., \& Oberdorff, T. (2017). Anthropogenic stressors and riverine fish extinctions. Ecological Indicators, 79, 37-46. https://doi.org/10.1016/j.ecolind.2017.03.053

Dolezsai, A., Sály, P., Takács, P., Hermoso, V., \& Erős, T. (2015). Restricted by borders: Trade-offs in transboundary conservation planning for large river systems. Biodiversity and Conservation, 24(6), 1403-1421. https://doi.org/10.1007/s10531-015-0864-1

Dunn, C. G., Brooke, B. L., Hrabik, R. A., \& Paukert, C. P. (2018). Intensive sampling reveals underreported use of great-river tributaries by large-river fishes in Missouri. Southeastern Naturalist, 17(3), 512-521. https://doi.org/10.1656/058.017.0316

Dunning, J. B., Danielson, B. J., \& Pulliam, H. R. (1992). Ecological processes that affect populations in complex landscapes. Oikos, 65(1), 169-175. https://doi.org/10.2307/3544901 
Ferreira, F. C., Souza, U. P., Cetra, M., \& Petrere, M. (2019). Rhithronic and potamonic fishes coexist in wadeable streams under distinct metacommunity processes. Ecology of Freshwater Fish, 28(1), 85-96. https://doi.org/10.1111/eff.12433

Flotemersch, J. E., Stribling, J. B., Hughes, R. M., Reynolds, L., Paul, M. J., \& Wolter, C. (2011). Site length for biological assessment of boatable rivers. River Research and Applications, 27(4), 520-535. https://doi.org/10.1002/rra.1367

Freshwater Mussel Host Database (FMHD) (2017). The freshwater mussel host database, Illinois Natural History Survey and Ohio State University Museum of Biological Diversity. Retrieved from http://wwx.inhs.illinois.edu/collections/mollusk/data/freshwater-mussel-hostdatabase. (accessed November, 2019).

Frimpong, E. A., \& Angermeier, P. L. (2009). Fish traits: A database of ecological and life-history traits of freshwater fishes of the United States. Fisheries, 34(10), 487495. https://doi.org/10.1577/1548-8446-34.10.487

Galat, D. L., \& Zweimuller, I. (2001). Conserving large-river fishes: Is the highway analogy an appropriate paradigm? Journal of the North American Benthological Society, 20(2), 266-279. https://doi.org/10.2307/1468321

Galat, D.L., Berry, C.R., Gardner, W.M., Hendrickson, J.C., Mestl, G.E., Power, G.J., Stone, C., \& Winston, M.R. (2005). Spatiotemporal patterns and changes in Missouri River fishes. In J.N. Rinne, R.M. Hughes, \& B. Calamusso (Eds.), Historical changes in large river fish assemblages of the Americas (pp. 249-292). Bethesda, MD: American Fisheries Society. 
Galbraith, H. S., Devers, J. L., Blakeslee, C. J., Cole, J. C., St. John White, B., Minkkinen, S., \& Lellis, W. A. (2018). Reestablishing a host-affiliate relationship: Migratory fish reintroduction increases native mussel recruitment. Ecological Applications, 28(7), 1841-1852. https://doi.org/10.1002/eap.1775

Grenouillet, G., Pont, D., \& Hérissé, C. (2004). Within-basin fish assemblage structure: The relative influence of habitat versus stream spatial position on local species richness. Canadian Journal of Fisheries and Aquatic Sciences, 61(1), 93-102. https://doi.org/10.1139/f03-145

Grill, G., Lehner, B., Thieme, M., Geenen, B., Tickner, D., Antonelli, F., ... Zarfl, C. (2019). Mapping the world's free-flowing rivers. Nature, 569(7755), 215-221. https://doi.org/10.1038/s41586-019-1111-9

He, F., Zarfl, C., Bremerich, V., David, J. N. W., Hogan, Z., Kalinkat, G., .. Jähnig, S. C. (2019). The global decline of freshwater megafauna. Global Change Biology, 25(11), 3883-3892. https://doi.org/10.1111/gcb.14753

Hinck, J. E., McMurray, S. E., Roberts, A. D., Barnhart, M. C., Ingersoll, C. G., Wang, N., \& Augspurger, T. (2012). Spatial and temporal trends of freshwater mussel assemblages in the Meramec River basin, Missouri, USA. Journal of Fish and Wildlife Management, 3(2), 319-331. https://doi.org/10.3996/052012-JFWM-038

Hitt, N. P., \& Angermeier, P. L. (2008). Evidence for fish dispersal from spatial analysis of stream network topology. Journal of the North American Benthological Society, 27(2), 304-320. https://doi.org/10.1899/07-096.1

Jost, L. 2007. Partitioning diversity in independent alpha and beta components. Ecology 88: 2427-2439. https://doi.org/10.1890/06-1736.1 
Kemp, P. S., \& O’Hanley, J. R. (2010). Procedures for evaluating and prioritising the removal of fish passage barriers: A synthesis. Fisheries Management and Ecology, 17, 297-322. https://doi.org/10.1111/j.1365-2400.2010.00751.x

Kominoski, J. S., Ruhí, A., Hagler, M. M., Petersen, K., Sabo, J. L., Sinha, T., ... Olden, J. D. (2018). Patterns and drivers of fish extirpations in rivers of the American Southwest and Southeast. Global Change Biology, 24(3), 1175-1185. https://doi.org/10.1111/gcb.13940

Laub, B. G., Thiede, G. P., Macfarlane, W. W., \& Budy, P. (2018). Evaluating the conservation potential of tributaries for native fishes in the upper Colorado River basin. Fisheries, 43(4), 194-206. https://doi.org/10.1002/fsh.10054

Laughlin, T. W., Whitledge, G. W., Oliver, D. C., \& Rude, N. P. (2016). Recruitment sources of Channel and Blue catfishes inhabiting the middle Mississippi River: Natal environment of Mississippi River catfishes. River Research and Applications, 32(8), 1808-1818. https://doi.org/10.1002/rra.3015

Love, S. A., Phelps, Q. E., Tripp, S. J., \& Herzog, D. P. (2017). The importance of shallow-low velocity habitats to juvenile fish in the middle Mississippi River: The importance of shallow-low velocity habitats to juvenile fish. River Research and Applications, 33(3), 321-327. https://doi.org/10.1002/rra.3075

Lyons, J., Walchak, D., Haglund, J., Kanehl, P., \& Pracheil, B. (2016). Habitat use and population characteristics of potentially spawning shovelnose sturgeon Scaphirhynchus platorynchus (Rafinesque, 1820), blue sucker (Cycleptus elongatus (Lesueur, 1817), and associated species in the lower Wisconsin River, 
USA. Journal of Applied Ichthyology, 32(6), 1003-1015.

https://doi.org/10.1111/jai.13201

Matthews, W.J. (1998). Physical factors within drainages as related to fish assemblages.

In W.J. Matthews (Ed.), Patterns in freshwater fish ecology (pp. 264-315).

Norwell, MA: Kluwer Academic Publishers.

McElroy, B., DeLonay, A., \& Jacobson, R. (2012). Optimum swimming pathways of fish spawning migrations in rivers. Ecology, 93(1), 29-34. https://doi.org/10.1890/111082.1

McGarvey, D. J., \& Ward, G. M. (2008). Scale dependence in the species-discharge relationship for fishes of the southeastern USA. Freshwater Biology, 53(11), 2206-2219. https://doi.org/10.1111/j.1365-2427.2008.02046.x

McIntyre, P.B., Reidy Liermann, C., Childress, E., Hamann, E.J., Hogan, J.D., Januchowski-Hartley, S.R., Koning, A.A., Neeson, T.M., Oele, D.L., \& Pracheil, B.M. (2015). Conservation of migratory fishes in freshwater ecosystems. In G.P. Closs, M. Krkošek, \& J.D. Olden (Eds.), Conservation of freshwater fishes (pp. 324-360). Cambridge, UK: Cambridge University Press.

Metee, M.F., \& O'Neil. (2003). Status of Alabama Shad and Skipjack Herring in Gulf of Mexico drainages. In K.E. Limburg, \& J.R. Waldman (Eds.), Biodiversity, status, and conservation of the world's shads (pp. 157-170). Bethesda, MD. American Fisheries Society.

Miranda, L. E., Killgore, K. J., \& Slack, W. T. (2018). Spatial organization of fish diversity in a species-rich basin. River Research and Applications, rra.3392. https://doi.org/10.1002/rra.3392 
Miyazono, S., \& Taylor, C. M. (2013). Effects of habitat size and isolation on species immigration-extinction dynamics and community nestedness in a desert river system. Freshwater Biology, 58(7), 1303-1312.

https://doi.org/10.1111/fwb.12127

Naus, C. J., \& Reid Adams, S. (2018). Fish nursery habitat function of the main channel, floodplain tributaries and oxbow lakes of a medium-sized river. Ecology of Freshwater Fish, 27(1), 4-18. https://doi.org/10.1111/eff.12319

Neely, B. C., Pegg, M. A., \& Mestl, G. E. (2010). Seasonal resource selection by blue suckers Cycleptus elongatus. Journal of Fish Biology, 76(4), 836-851. https://doi.org/10.1111/j.1095-8649.2009.02532.x

Neeson, T. M., Ferris, M. C., Diebel, M. W., Doran, P. J., O’Hanley, J. R., \& McIntyre, P. B. (2015). Enhancing ecosystem restoration efficiency through spatial and temporal coordination. Proceedings of the National Academy of Sciences, 112(19), 6236-6241. https://doi.org/10.1073/pnas.1423812112

O’Hara, M., Ickes, B.S., Gittinger, E., DeLain, S., Dukerschein, T., Pegg, M., \& Kalas, J. (2007). Development of a life history database for upper Mississippi River fishes. (Report 2007-T001). La Crosse, WS: US Geological Survey.

Osborne, L. L., \& Wiley, M. J. (1992). Influence of tributary spatial position on the structure of warmwater fish communities. Canadian Journal of Fisheries and Aquatic Sciences, 49(4), 671-681. https://doi.org/10.1139/f92-076

Perkin, J. S., \& Gido, K. B. (2011). Stream fragmentation thresholds for a reproductive guild of Great Plains fishes. Fisheries, 36(8), 371-383.

https://doi.org/10.1080/03632415.2011.597666 
Pflieger, W.L. (1989). Aquatic community classification system for Missouri. Jefferson City, MO: Missouri Department of Conservation.

Pflieger, W.L. (1997). The Fishes of Missouri. Jefferson City, MO: Missouri Department of Conservation.

Pracheil, B. M., Lyons, J., Hamann, E. J., Short, P. H., \& McIntyre, P. B. (2019).

Lifelong population connectivity between large rivers and their tributaries: A case study of shovelnose sturgeon from the Mississippi and Wisconsin rivers. Ecology of Freshwater Fish, 28(1), 20-32. https://doi.org/10.1111/eff.12423

Pracheil, B. M., McIntyre, P. B., \& Lyons, J. D. (2013). Enhancing conservation of largeriver biodiversity by accounting for tributaries. Frontiers in Ecology and the Environment, 11(3), 124-128. https://doi.org/10.1890/120179

Pracheil, B. M., Pegg, M. A., \& Mestl, G. E. (2009). Tributaries influence recruitment of fish in large rivers. Ecology of Freshwater Fish, 18(4), 603-609. https://doi.org/10.1111/j.1600-0633.2009.00376.x

Puijenbroek, P. J. T. M., Buijse, A. D., Kraak, M. H. S., \& Verdonschot, P. F. M. (2019). Species and river specific effects of river fragmentation on European anadromous fish species. River Research and Applications, 35(1), 68-77. https://doi.org/10.1002/rra.3386

Rabeni, C. F., \& Jacobson, R. B. (1993). The importance of fluvial hydraulics to fishhabitat restoration in low-gradient alluvial streams. Freshwater Biology, 29(2), 211-220. https://doi.org/10.1111/j.1365-2427.1993.tb00758.x

Radinger, J., \& Wolter, C. (2014). Patterns and predictors of fish dispersal in rivers. Fish and Fisheries, 15(3), 456-473. https://doi.org/10.1111/faf.12028 
Ratcliff, E. N., Gittinger, E. J., O’Hara, T. M., \& Ickes, B. S. (2014). Long term resource monitoring program procedures: Fish monitoring. (Report LTRMP-2014-P001). Rock Island, IL: US Army Corps of Engineers.

Remo, J. W., Carlson, M., \& Pinter, N. (2012). Hydraulic and flood-loss modeling of levee, floodplain, and river management strategies, Middle Mississippi River, USA. Natural Hazards, 61(2), 551-575. https://doi.org/10.1007/s11069-0119938-X

Rinne, J.N., R.M. Hughes, \& Calamusso, B. (Eds). (2005). Historical changes in large river fish assemblages of the Americas. Bethesda, MD: American Fisheries Society.

Roberts J.H., \& Hitt N.P. (2010). Longitudinal structure in temperate stream fish communities: evaluating conceptual models with temporal data. In K.B. Gido \& D.A. Jackson (Eds.), Community ecology of stream fishes: Concepts, approaches, and techniques (pp. 281-299). Bethesda, MD: American Fisheries Society.

Rude, N. P., \& Whitledge, G. W. (2019). Natal environments of age-0 paddlefish in the middle Mississippi River inferred from dentary microchemistry. River Research and Applications, rra.3526. https://doi.org/10.1002/rra.3526

Schaefer, J. F., \& Kerfoot, J. R. (2004). Fish assemblage dynamics in an adventitious stream: A landscape perspective. American Midland Naturalist, 151(1), 134-145. https://doi.org/10.1674/0003-0031(2004)151[0134:FADIAA]2.0.CO;2

Schlosser I.J. (1987). A conceptual framework for fish communities in small warmwater streams. In W.J. Matthews, \& D.C. Heins (Eds.), Community and evolutionary ecology of North American stream fishes (pp. 17-24). Norman, OK: University of 
Oklahoma Press.

Schlosser, I. J. (1995). Critical landscape attributes that influence fish populationdynamics in headwater streams. Hydrobiologia, 303(1-3), 71-81. https://doi.org/10.1007/bf00034045

Schramm, H. L., Hatch, J. T., Hrabik, R. A., \& Slack, W. T. (2016). Fishes of the Mississippi River. In Y. Chen, D. Chapman, J. Jackson, D. Chen, Z. Li, J. Kilgore, ... M. Eggleton (Eds.), Fishery Resources, Environment, and Conservation in the Mississippi and Yangtze (Changjiang) River Basins. (Vol. 84, pp. 53-77). Bethesda, Maryland: American Fisheries Society.

Silva, P. S., Miranda, L. E., Makrakis, S., Assumpção, L., Dias, J. H. P., \& Makrakis, M. C. (2019). Tributaries as biodiversity preserves: An ichthyoplankton perspective from the severely impounded Upper Paraná River. Aquatic Conservation: Marine and Freshwater Ecosystems, 29(2), 258-269. https://doi.org/10.1002/aqc.3037

Taylor, C. M., \& Warren Jr, M. L. (2001). Dynamics in species composition of stream fish assemblages: Environmental variability and nested subsets. Ecology, 82(8), 2320-2330. https://doi.org/10.1890/00129658(2001)082[2320:DISCOS]2.0.CO;2

Thornbrugh, D. J., \& Gido, K. B. (2010). Influence of spatial positioning within stream networks on fish assemblage structure in the Kansas River basin, USA. Canadian Journal of Fisheries and Aquatic Sciences, 67(1), 143-156.

https://doi.org/10.1139/f09-169

Tripp, S. J., Phelps, Q. E., Hupfeld, R. N., Herzog, D. P., Ostendorf, D. E., Moore, T. L., ... Garvey, J. E. (2019). Sturgeon and Paddlefish migration: Evidence to support 
the need for interjurisdictional management. Fisheries, 44(4), 183-193.

https://doi.org/10.1002/fsh.10215

USAC (2018). Missouri River mainstem HEC-ResSim modeling. Omaha District, Yankton, SD: United States Army Corps of Engineers.

USEPA (2013). National rivers and streams assessment 2013-2014: Field operations manual-Non-wadeable (EPA-841-B-12-009a). Washington, DC: Office of Water, U.S. Environmental Protection Agency.

USGS (2014). NLCD 2011 land cover. Sioux Falls, SD: United States Geological Survey.

USGS \& USEPA. (2012). National hydrography dataset plus - NHDPlus v.2.10. Sioux Falls, SD: United States Environmental Protection Agency \& United States Geological Survey.

Vokoun, J. C., Guerrant, T. L., \& Rabeni, C. F. (2003). Demographics and chronology of a spawning aggregation of blue sucker (Cycleptus elongatus) in the Grand River, Missouri, USA. Journal of Freshwater Ecology, 18(4), 567-575. https://doi.org/10.1080/02705060.2003.9663997

Vörösmarty, C. J., McIntyre, P. B., Gessner, M. O., Dudgeon, D., Prusevich, A., Green, P., ... Davies, P. M. (2010). Global threats to human water security and river biodiversity. Nature, 467(7315), 555-561. https://doi.org/10.1038/nature09440

Welker, T. L., \& Drobish, M.R.. 2011. Missouri river standard operating procedures for fish sampling and data collection. Omaha District, Yankton, SD: U.S. Army Corps of Engineers. 
Ward, J. V., Tockner, K., Arscott, D. B., \& Claret, C. (2002). Riverine landscape diversity. Freshwater Biology, 47(4), 517-539. https://doi.org/10.1046/j.13652427.2002.00893.x

Whittaker, R.H. (1960). Vegetation of the Siskiyou Mountains, Oregon and California. Ecological Monographs, 30(3), 279-338. https://doi.org/10.2307/1943563

Wildhaber, M. L., Gladish, D. W., \& Arab, A. (2012). Distribution and habitat use of the Missouri river and lower Yellowstone river benthic fishes from 1996 to 1998: A baseline for fish community recovery. River Research and Applications, 28(10), 1780-1803. https://doi.org/10.1002/rra.1559

Winemiller, K. O. (2005). Life history strategies, population regulation, and implications for fisheries management. Canadian Journal of Fisheries and Aquatic Sciences, 62(4), 872-885. https://doi.org/10.1139/f05-040

Winemiller, K. O., McIntyre, P. B., Castello, L., Fluet-Chouinard, E., Giarrizzo, T., Nam, S., ... Saenz, L. (2016). Balancing hydropower and biodiversity in the Amazon, Congo, and Mekong. Science, 351(6269), 128-129. https://doi.org/10.1126/science.aac7082

Ziv, G., Baran, E., Nam, S., Rodríguez-Iturbe, I., \& Levin, S. A. (2012). Trading-off fish biodiversity, food security, and hydropower in the Mekong River Basin. Proceedings of the National Academy of Sciences, 109(15), 5609-5614. https://doi.org/10.1073/pnas.1201423109 


\section{Tables}

Table 3.1. Habitat variables recorded at 24 sites in the Grand $(\mathrm{N}=10)$, Meramec $(N=$ $12)$, Missouri $(N=1)$, and Mississippi $(N=1)$ rivers in 2016 (Missouri, USA). "Scale" refers to the grain size at which variables were recorded. All variables were summarized to sites and five variables were transformed to reduce skew before performing a Principal Component (PC) analysis. Pearson product-moment correlations $(r)$ are between transformed or untransformed (-) variables and PC axes. Boldface indicates the PC axis most correlated with each habitat variable.

\begin{tabular}{lcccccc}
\hline & & & & \multicolumn{2}{c}{ Pearson correlations $(r)$} \\
\cline { 5 - 7 } \multicolumn{1}{c}{ Variable } & Unit & Scale & Transformation & PC1 & PC2 & PC3 \\
\hline Boulder & Count & Point & $\log (\mathrm{x}+0.1)$ & $\mathbf{- 0 . 7 6}$ & 0.56 & -0.20 \\
Confinement & $\%$ & Transect & $\operatorname{Arcsine} \sqrt{x}$ & $\mathbf{- 0 . 9 2}$ & 0.07 & -0.05 \\
Large wood & Count & Point & - & -0.41 & -0.31 & $\mathbf{- 0 . 7 1}$ \\
Macrophytes & Ordinal & Point & - & $\mathbf{- 0 . 9 3}$ & -0.11 & -0.02 \\
Off-channel & $\%$ & Transect & Arcsine $\sqrt{x}$ & -0.62 & $\mathbf{0 . 6 3}$ & 0.17 \\
Secchi depth & $\mathrm{m}$ & Site & - & $\mathbf{- 0 . 7 7}$ & -0.36 & 0.14 \\
Shoal habitat & $\%$ & Point & - & $\mathbf{- 0 . 7 8}$ & -0.40 & -0.03 \\
Substrate size & Ordinal & Point & - & $\mathbf{- 0 . 8 6}$ & -0.01 & 0.08 \\
Water depth & $\mathrm{m}$ & Point & $\log (\mathrm{x}+0.1)$ & 0.19 & $\mathbf{0 . 8 7}$ & -0.42 \\
Water velocity & $\mathrm{m} \mathrm{s}{ }^{-1}$ & Point & $\sqrt{x}$ & -0.31 & 0.34 & $\mathbf{0 . 5 5}$ \\
\hline
\end{tabular}


Table 3.2. Large-river specialist (LRS) fish tributary-use patterns and richness partitioning in the Grand and Meramec river systems in 2016 (Missouri, USA). Candidate LRS species are species with distributions historically centered in the Missouri and/or Mississippi rivers (listed in Appendix 3.1). Species with limited exchange distributional patterns were not detected by our surveys. Confluence exchange distributional patterns were exhibited by LRS species that were only detected at our lowermost sites in confluence zones (river km 1-6 from mouth). Species that exhibited network dispersal distributional were found upriver of lowermost sites ( $\geq$ rkm 24 in Grand R., $\geq$ rkm 30 in Meramec R.). Richness components are based on Whitaker's (1960) multiplicative partitioning $\left(\beta_{\mathrm{i}}=\gamma_{\mathrm{i}} / \bar{\alpha}_{\mathrm{i}}\right) \cdot \gamma_{\mathrm{i}}$ richness is the total LRS richness detected by our surveys within each tributary. $\bar{\alpha}$ richness is mean (standard deviation) of LRS species at sites within each tributary. $\beta$ richness is a measure of compositional dissimilarity among sites within each tributary and can be adjusted to account for unequal sample size (standardized $\beta$ richness; Jost, 2007).

\begin{tabular}{lcc}
\hline \multicolumn{1}{c}{ Category } & Grand River & Meramec River \\
\hline Candidate large-river specialists & 35 & 42 \\
Limited exchange species & 17 & 13 \\
Confluence exchange species & 1 & 6 \\
Network dispersal species & 17 & 23 \\
Detected large-river specialists $(\gamma$ richness) & 18 & 29 \\
$\bar{\alpha}$ (standard deviation) richness & $12.5(2.7)$ & $9.8(6.7)$ \\
$\beta$ richness & 1.4 & 2.9 \\
Standardized $\beta$ richness & 0.05 & 0.18 \\
\hline
\end{tabular}


Table 3.3. Modeled effects (K) and evaluation criteria for alternative models (i) depicting relationships between mean annual discharge $\left(\mathrm{m}^{3} \mathrm{~s}^{-1}\right)$ and large-river specialist fish richness (response) detected at sites in the Grand $(N=10)$ and Meramec $(N=12)$ river systems in 2016 (Missouri, USA). Lower $\Delta$ Akaike Information Criterion $(\triangle \mathrm{AICc})$ and higher model weights $\left(w_{i}\right)$ indicate support for models. Evidence ratio $\left(w_{1} / w_{i}\right)$ is number of times the top model is better supported over lower-ranked models. Parameter estimates $(\hat{\beta} \pm$ standard error) for top-ranked model: intercept $=9.50 \pm 1.78$, Discharge $=0.04 \pm$ 0.02 , River $=-9.62 \pm 2.61$, Discharge-x-River $=0.14 \pm 0.04$. Parameter estimates of all models are in Appendix 3.8.

\begin{tabular}{|c|c|c|c|c|c|c|}
\hline Model & $K$ & $\begin{array}{c}\text { Log- } \\
\text { likelihood }\end{array}$ & $\triangle \mathrm{AICc}$ & $w_{i}$ & $w_{1} / w_{i}$ & $R^{2}$ \\
\hline Discharge $x$ River & 4 & -54.2 & 0.0 & 0.82 & 1.0 & 0.71 \\
\hline Discharge $^{2} \mathrm{x}$ River & 5 & -54.2 & 3.8 & 0.12 & 6.8 & 0.71 \\
\hline Discharge & 2 & -60.9 & 7.0 & 0.03 & 27.3 & 0.46 \\
\hline Discharge $^{2}$ & 3 & -59.7 & 7.6 & 0.02 & 41.0 & 0.52 \\
\hline Discharge $^{2}+$ River & 4 & -58.5 & 8.7 & 0.01 & 82.0 & 0.57 \\
\hline Discharge + River & 3 & -60.6 & 9.4 & 0.01 & 82.0 & 0.47 \\
\hline Intercept-only (null) & 1 & -67.7 & 17.8 & 0.00 & $>1,000$ & 0.00 \\
\hline River & 2 & -66.9 & 19.1 & 0.00 & $>1,000$ & 0.07 \\
\hline
\end{tabular}


Table 3.4. Modeled effects $(\mathrm{K})$ and evaluation criteria for models (i) explaining residual large-river specialist fish richness from the best-supported model (Discharge-x-River) in Table (3.3). Connectivity is the downriver distance $(\mathrm{km})$ of tributary sites to the mouths of the Grand ( $N=10$ sites) or Meramec $(N=12$ sites) rivers in 2016 (Missouri, USA). Great-river habitat is the Euclidean distance in multivariate space defined by three principal component axes between habitat at sites and reference great-river habitat in the Missouri (Grand R.) or Mississippi (Meramec R.) rivers. Lower delta Akaike Information Criterion $(\triangle \mathrm{AICc})$ and higher model weights $\left(w_{i}\right)$ indicate support for models. Evidence ratio $\left(w_{1} / w_{i}\right)$ is number of times the top model is better supported over lower-ranked models. Parameter estimates ( $\hat{\beta} \pm$ standard error) for top-ranked model: intercept $=2.0 \pm$ 1.1 , Distance upriver from river mouth $=-0.02 \pm 0.01$. Parameter estimates for all models are in Appendix 3.9.

\begin{tabular}{|c|c|c|c|c|c|c|}
\hline \multicolumn{7}{|c|}{ Log- } \\
\hline Model & $K$ & likelihood & $\triangle \mathrm{AICc}$ & $w_{i}$ & $w_{1} / w_{i}$ & $R^{2}$ \\
\hline Distance & 2 & -51.8 & 0.0 & 0.43 & 1.0 & 0.20 \\
\hline Intercept-only $(r$ & 1 & -54.2 & 2.2 & 0.15 & 2.9 & 0.00 \\
\hline Principal component 1 & 2 & -53.7 & 3.9 & 0.06 & 7.2 & 0.04 \\
\hline Principal component 2 & 2 & -53.8 & 4.1 & 0.06 & 7.2 & 0.03 \\
\hline Great-river habitat & 2 & -54.2 & 4.8 & 0.04 & 10.8 & 0.00 \\
\hline Principal component 3 & 2 & -54.2 & 4.8 & 0.04 & 10.8 & 0.00 \\
\hline
\end{tabular}




\section{Figures}

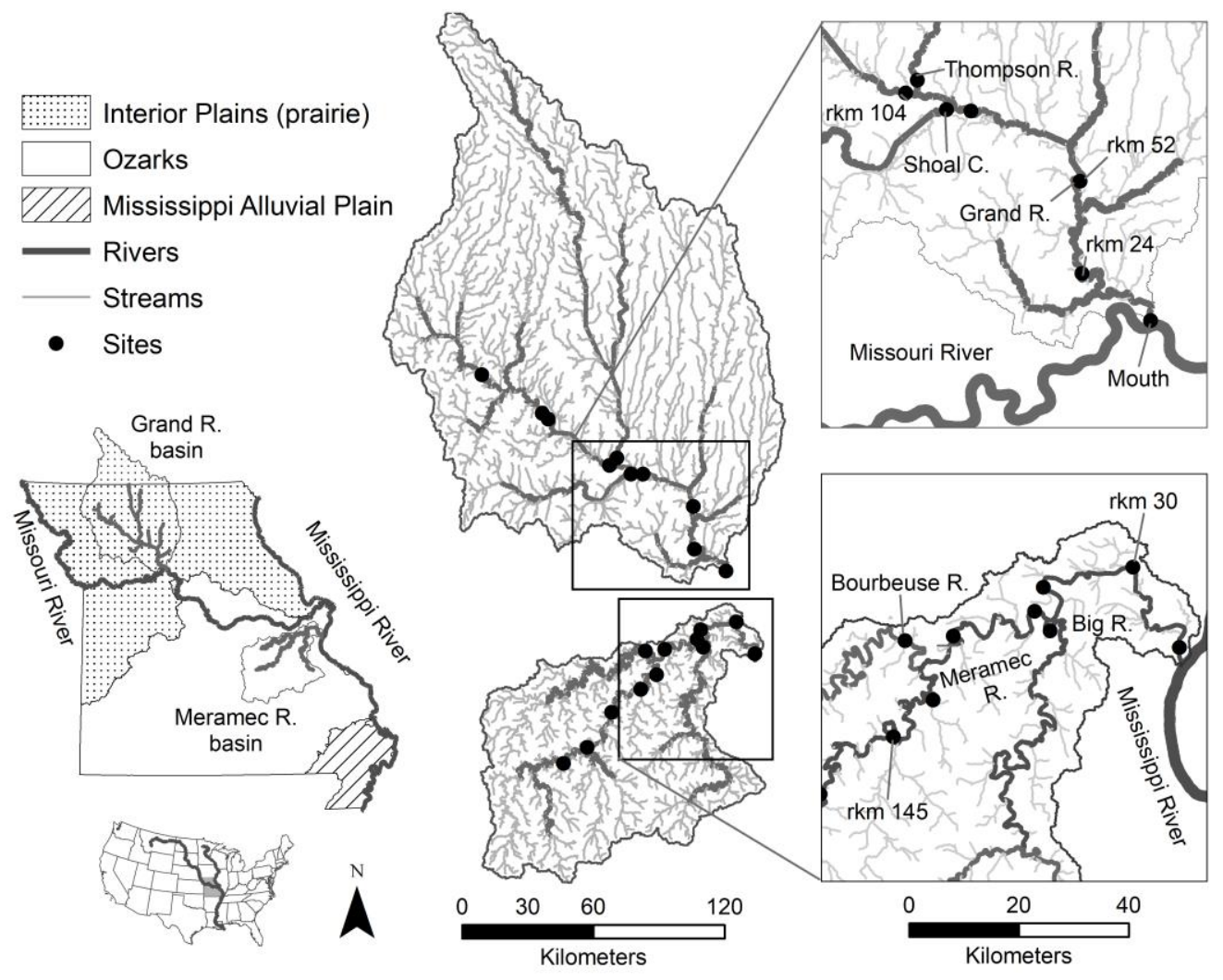

Figure 3.1. Non-wadeable mainstem and branch sites in the Grand $(N=10$, prairie region) and Meramec ( $N=12$, Ozark region) river systems surveyed for large-river specialists fish species in 2016 (Missouri, USA). Insets: sites extended at least $1 \mathrm{~km}$ away from major confluences, and watercourse distances (river $\mathrm{km}$ ) are upriver of each river system's mouth. 


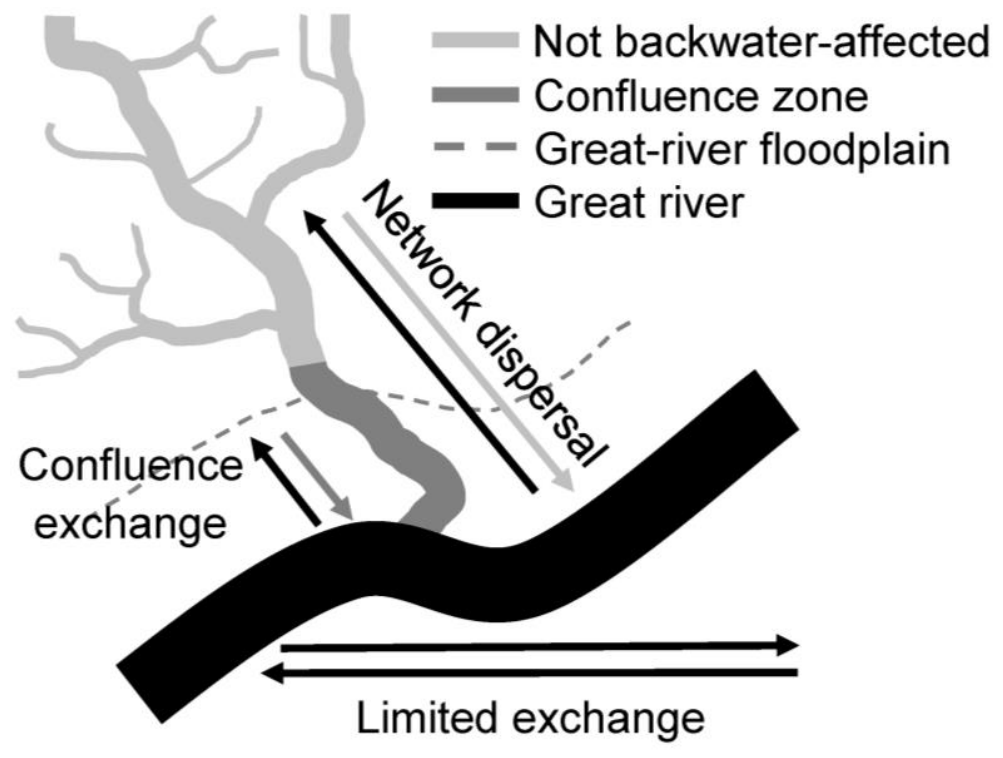

Figure 3.2. Conceptual depiction of Thornbugh and Gido's (2010) classification of tributary use by mainstem fishes: limited exchange = limited movements between mainstem and tributary; confluence exchange $=$ localized movements between mainstem and lower tributary reach in confluence zone associated with habitat features near the mainstem's floodplain and backwater-affected hydrology; network dispersal = extensive use of tributary upriver beyond confluence zone. 

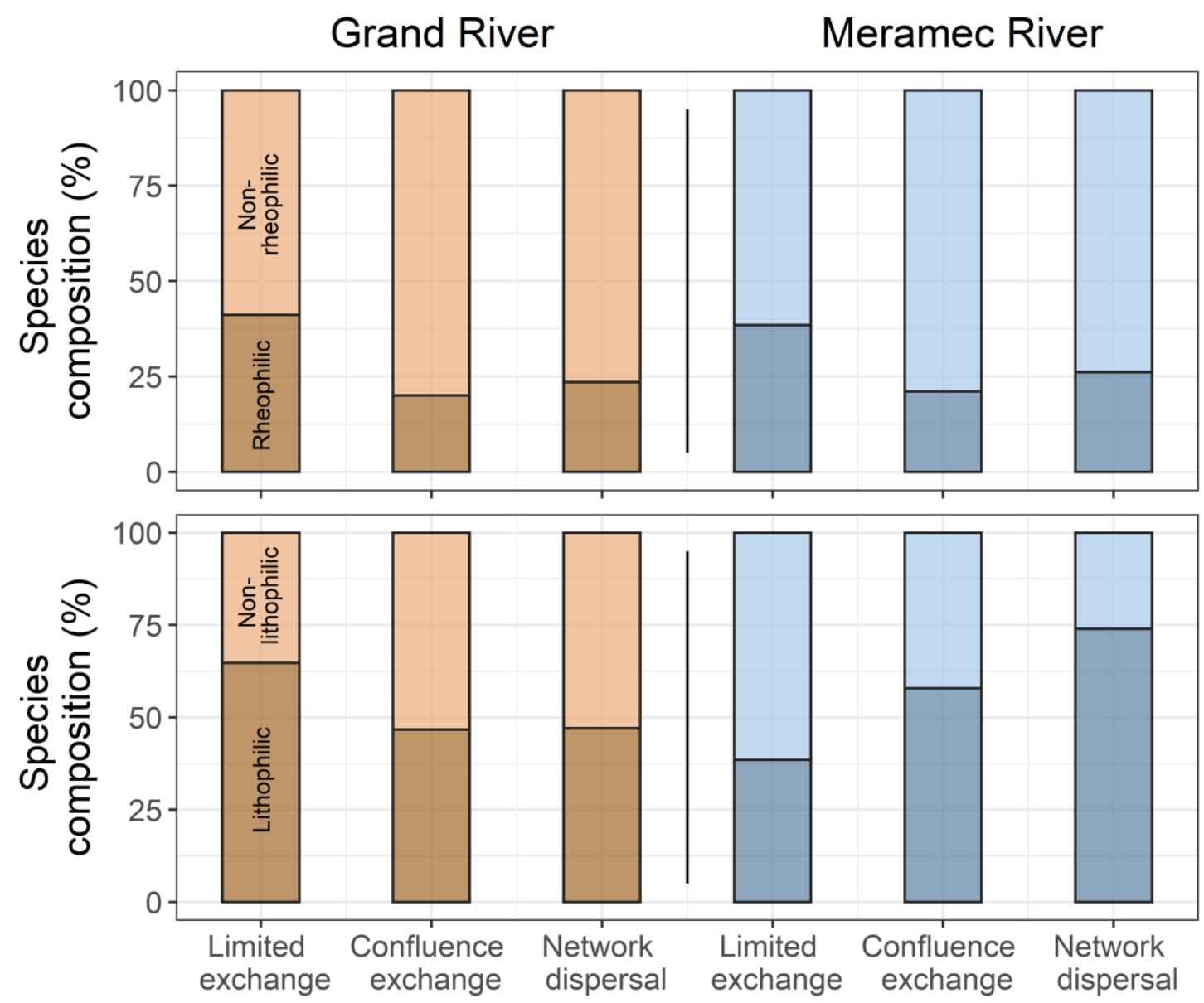

Figure 3.3. Percentages of species preferring high water-velocities (rheophilic) and coarse substrates (lithophilic) by distributional pattern in the Grand River (35 candidate species, 10 sites) and Meramec River, USA (42 candidate species, 12 sites). Species conforming to limited exchange were not detected in tributaries by fish sampling in 2016 . Percentages for confluence exchange are the composition of species at lowermost sites within confluence zones (rkm 1-5). Percentages for network dispersal are from sites upriver of rkm 5 beyond confluence zones. 

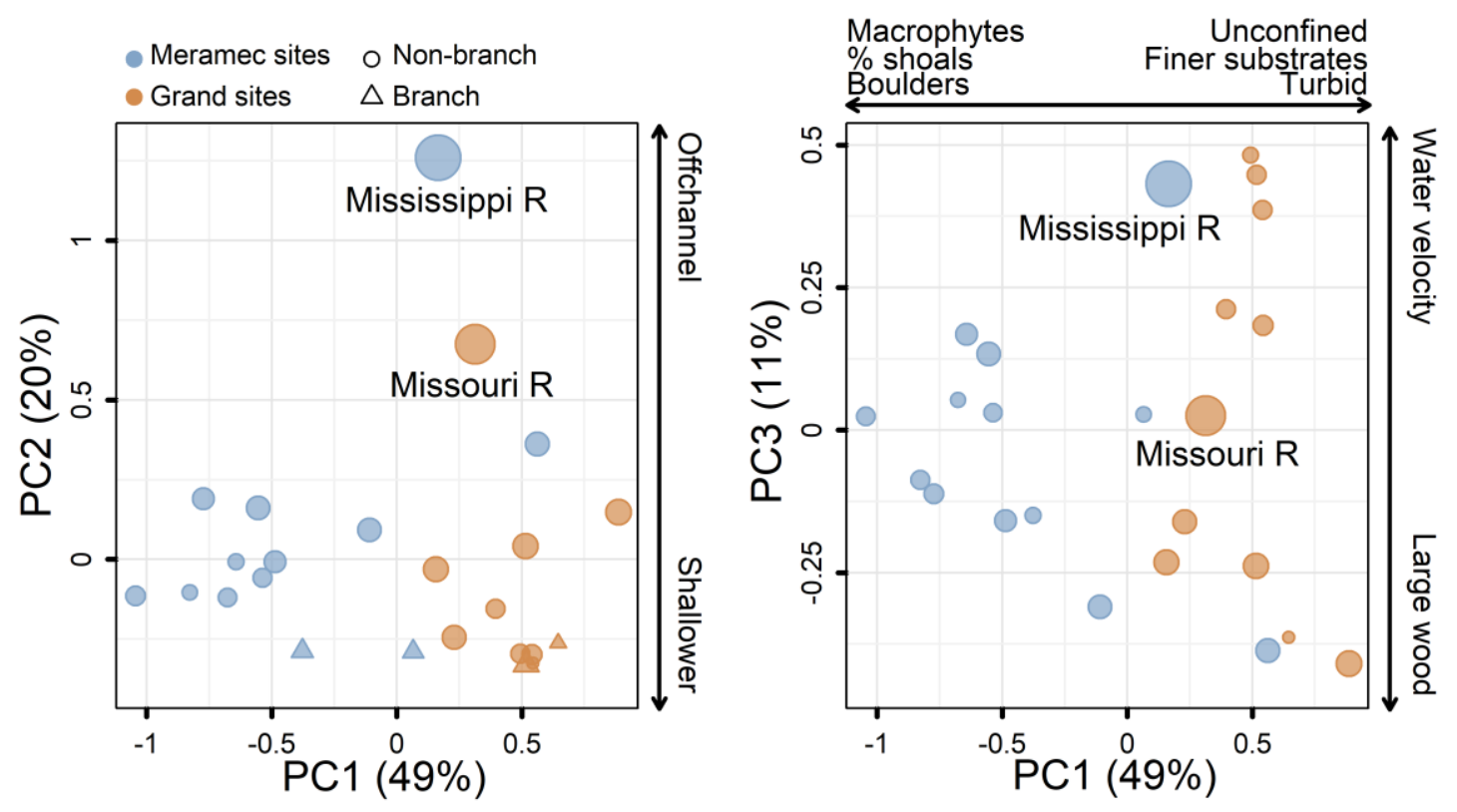

Figure 3.4. Principal components (PC) of 10 habitat variables (Table 3.1) from 24 sites in the Grand $(N=10)$, Meramec $(N=12)$, Missouri $(N=1)$, and Mississippi $(N=1)$ rivers (USA). Points are proportional to the natural log of mean annual discharge $\left(\mathrm{m}^{3} \mathrm{~s}^{-1}\right)$. Great-river habitat similarity was Euclidean distance of sites to the Missouri (Grand R.) or Mississippi (Meramec R.) rivers in multivariate space. 


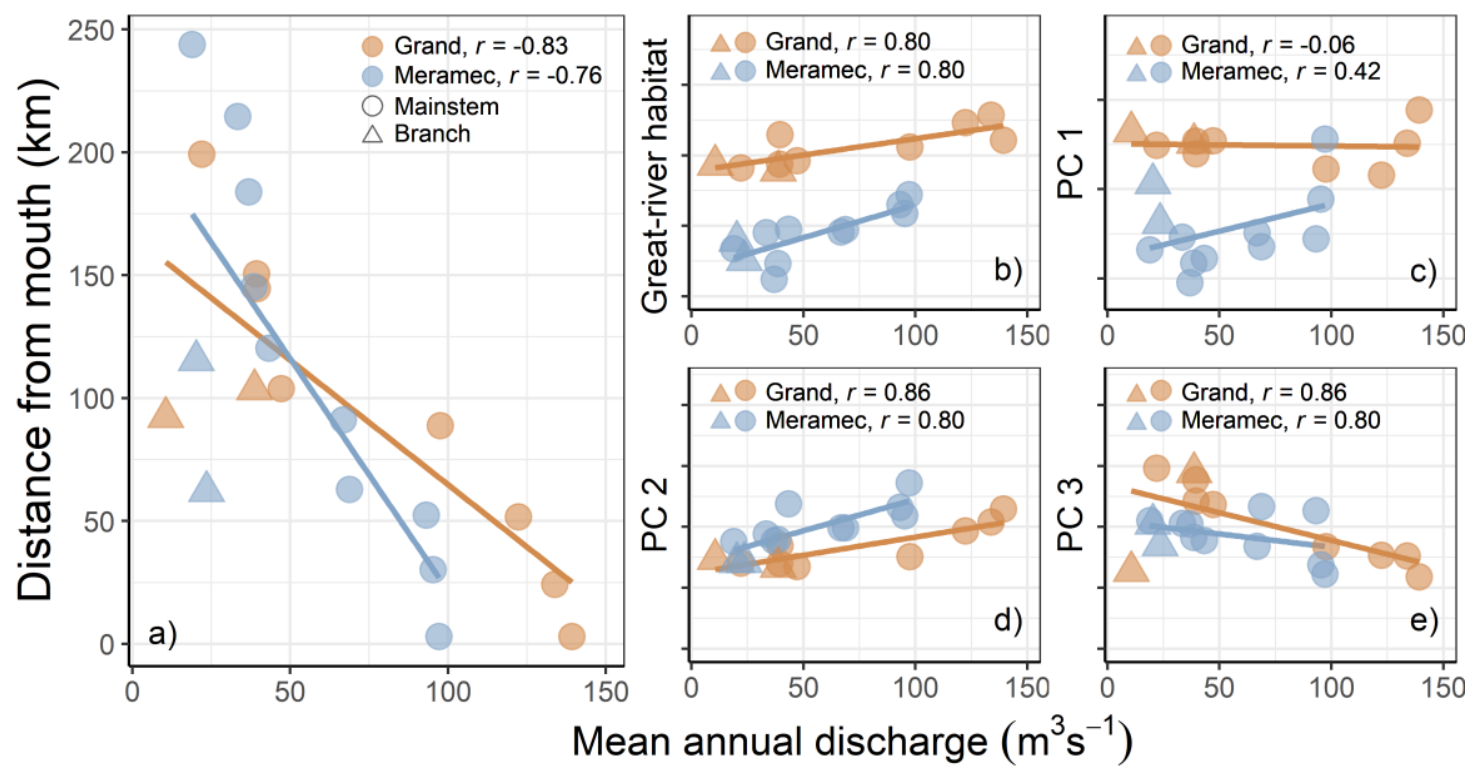

Figure 3.5. Pearson product-moment correlations $(r)$ between mean annual discharge at sites and variables potentially explaining large-river specialist fish richness in the Grand $(N=10$ sites) and Meramec $(N=12$ sites) river systems sampled in 2016 (Missouri, USA). (a) Distance-to-river mouth is watercourse distance of sites to the Missouri (Grand R.) or Mississippi (Meramec R.) rivers. (b) Great-river habitat similarity is Euclidean distance of each site to habitat in the Missouri (Grand R.) or Mississippi (Meramec R.) rivers in principal component (PC) space constructed from 10 instream habitat variables and three PC axes. Correlations between PC axes and habitat variables are in Table 3.1. Mainstems are sites along mainstems of the Grand or Meramec rivers. Branches are tributaries to mainstems. 

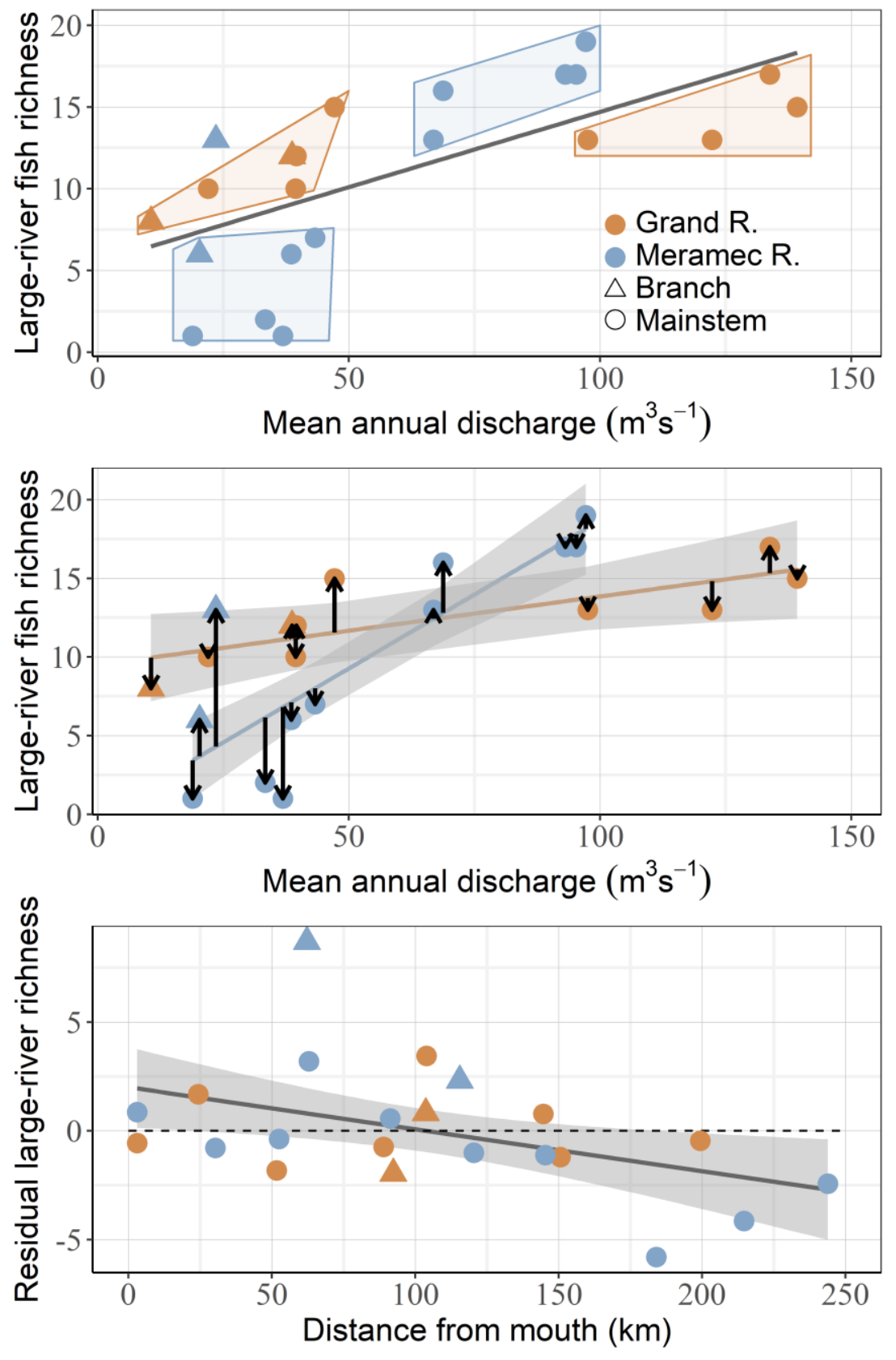

Figure 3.6. (Top) Species-discharge relationship (SDR) between mean annual discharge and large-river specialist fish richness at 22 sites in the Grand $(N=10)$ and Meramec $(N$ $=12$ ) rivers in 2016 (Missouri, USA). Polygons highlight grouped residuals that result from assuming rivers have identically sloped SDRs. (Middle) Species-discharge relationships with river-specific slopes and $90 \%$ confidence intervals. Black arrows depict residual error. (Bottom) Relationship between residual SDRs and distance to the mouth of the Grand River (Missouri R. confluence) and Meramec River (Mississippi R. confluence). Residuals above and below 0 indicate SDRs in the middle panel that underand over-estimated large-river fish richness, respectively. 


\section{Appendices}

Appendix 3.1. Traits (possessed $=1$ ) of candidate large-river specialist fishes in the lower Missouri and middle Mississippi rivers (USA). Limited exchange (LE) are candidate large-river specialist fishes not detected in a respective tributary. Confluence exchange (CE) are species only detected at the lowermost site (rkm 1-6) in a respective tributary. Network dispersal (ND) are species detected upriver of rkm 6 in a respective tributary. "-" are large-river specialist species unlikely to occur in the Missouri River. Lithophilic fishes prefer substrates coarser than sand (Frimpong \& Angermeier, 2010). Rheophilic fishes prefer fast or moderate water velocities (Frimpong \& Angermeier, 2010). Migratory behavior is based on O'Hara et al. (2007). NatureServe statuses for Missouri (USA): S1 = critically imperiled, S2 = imperiled, S3 = vulnerable, S4 = apparently secure, S5 = secure, I = introduced, “-” = no listing. *Based on descriptions in Pflieger (1997) due to unavailability in Frimpong \& Angermeier (2010).

\begin{tabular}{|c|c|c|c|c|c|c|}
\hline Species & $\begin{array}{l}\text { Grand } \\
\text { River }\end{array}$ & $\begin{array}{c}\text { Meramec } \\
\text { River }\end{array}$ & $\begin{array}{l}\text { Migr- } \\
\text { atory }\end{array}$ & $\begin{array}{l}\text { Litho } \\
\text { philic }\end{array}$ & $\begin{array}{l}\text { Rheo- } \\
\text { philic }\end{array}$ & $\begin{array}{c}\text { Nature } \\
\text { Serve }\end{array}$ \\
\hline Alabama Shad Alosa alabamae & LE & ND & 1 & $1 *$ & $1 *$ & $\mathrm{~S} 2$ \\
\hline Alligator Gar Atractosteus spatula & - & $\mathrm{LE}$ & 0 & 0 & 0 & S1 \\
\hline American Eel Anguilla rostrata & LE & ND & 1 & $0 *$ & $0 *$ & - \\
\hline Bighead Carp Hypophthalmichthys nobilis & ND & $\mathrm{CE}$ & 0 & $0 *$ & 0 & $\mathrm{I}$ \\
\hline Bigmouth Buffalo Ictiobus cyprinellus & ND & ND & 1 & 1 & 0 & - \\
\hline Black Buffalo Ictiobus niger & ND & ND & 0 & 0 & 0 & - \\
\hline Blue Catfish Ictalurus furcatus & ND & $\mathrm{CE}$ & 1 & 0 & 1 & - \\
\hline Blue Sucker Cycleptus elongatus & ND & ND & 1 & 1 & 1 & S3 \\
\hline Bowfin Amia calva & - & ND & 0 & 1 & 0 & - \\
\hline Bullhead Minnow Pimephales vigilax & ND & ND & 0 & 1 & 0 & S5 \\
\hline Channel Shiner Notropis wickliffi & LE & ND & 0 & $1 *$ & $1 *$ & - \\
\hline Emerald Shiner Notropis atherinoides & ND & ND & 0 & 1 & 0 & - \\
\hline Flathead Chub Platygobio gracilis & LE & $\mathrm{LE}$ & 0 & 0 & 1 & $\mathrm{~S} 1$ \\
\hline Ghost Shiner Notropis buchanani & LE & ND & 0 & 1 & 0 & $\mathrm{~S} 2$ \\
\hline Goldeye Hiodon alosoides & ND & ND & 1 & 1 & 0 & - \\
\hline Grass Carp Ctenopharyngodon idella & ND & ND & 0 & 0 & 0 & I \\
\hline Lake Sturgeon Acipenser fulvescens & LE & LE & 1 & 0 & 0 & $\mathrm{~S} 1$ \\
\hline MS. Silvery Minnow Hybognathus nuchalis & - & $\mathrm{LE}$ & 0 & 0 & 0 & S3 \\
\hline Mud Darter Etheostoma asprigene & - & $\mathrm{CE}$ & 0 & $0 *$ & $0 *$ & - \\
\hline Paddlefish Polyodon spathula & LE & LE & 1 & 1 & 0 & S3 \\
\hline Pallid Sturgeon Scaphirhynchus albus & LE & $\mathrm{LE}$ & 1 & 1 & 1 & $\mathrm{~S} 1$ \\
\hline Plains Minnow Hybognathus placitus & ND & LE & 0 & 0 & 0 & $\mathrm{~S} 2$ \\
\hline River Carpsucker Carpiodes carpio & ND & ND & 0 & 0 & 0 & - \\
\hline River Darter Percina shumardi & - & ND & 0 & $1 *$ & $1 *$ & S3 \\
\hline River Shiner Notropis blennius & $\mathrm{LE}$ & $\mathrm{CE}$ & 0 & 1 & 0 & - \\
\hline
\end{tabular}




\begin{tabular}{|c|c|c|c|c|c|c|}
\hline \multicolumn{7}{|c|}{ Appendix 3.1. continued: Traits of large-river specialist fishes } \\
\hline \multirow{2}{*}{ 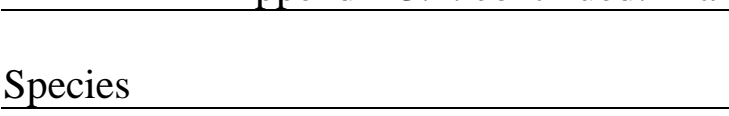 } & \multicolumn{6}{|c|}{ Grand Meramec Migr- Litho- Rheo- Nature } \\
\hline & River & River & atory & philic & philic & Serve \\
\hline Sauger Sander canadensis & LE & ND & 1 & 1 & 0 & - \\
\hline Shoal Chub Macrhybopsis hyostoma & ND & $\mathrm{CE}$ & 0 & 0 & 1 & - \\
\hline Shortnose Gar Lepisosteus platostomus & ND & ND & 0 & 1 & 0 & - \\
\hline Shovelnose Sturgeon S. platorynchus & ND & ND & 1 & 1 & 1 & $\mathrm{~S} 4$ \\
\hline Sicklefin Chub Macrhybopsis meeki & LE & LE & 0 & 1 & 1 & $\mathrm{~S} 1$ \\
\hline Silver Carp Hypophthalmichthys molitrix & ND & ND & 0 & $0 *$ & $0 *$ & I \\
\hline Silver Chub Macrhybopsis storeriana & ND & ND & 0 & 0 & 0 & S5 \\
\hline Silver Lamprey Ichthyomyzon unicuspis & LE & ND & 1 & $1 *$ & $0 *$ & - \\
\hline Silverband Shiner Notropis shumardi & LE & LE & 0 & 0 & 1 & - \\
\hline Skipjack Herring Alosa chrysochloris & ND & ND & 1 & 1 & 0 & SU \\
\hline Spottail Shiner Notropis hudsonius & - & LE & 0 & $1 *$ & $0 *$ & - \\
\hline Sturgeon Chub Macrhybopsis gelida & LE & $\mathrm{LE}$ & 0 & 1 & 1 & S3 \\
\hline Threadfin Shad Dorosoma petenense & LE & LE & 0 & 0 & 0 & - \\
\hline Western Sand Darter Ammocrypta clara & - & ND & 0 & $1 *$ & $1 *$ & $\mathrm{~S} 2$ \\
\hline W. Silvery Minnow Hybognathus argyritis & LE & LE & 0 & 0 & 0 & $\mathrm{~S} 2$ \\
\hline White Bass Morone chrysops & $\mathrm{CE}$ & ND & 1 & 1 & 0 & - \\
\hline Yellow Bass Morone mississippiensis & LE & $\mathrm{CE}$ & 1 & 1 & 0 & - \\
\hline
\end{tabular}

Note: All but four species on this list were also listed in Pfliegers's (1989) "big river" fishes guild: Alabama Shad, Bighead Carp, Mud Darter, and Silver Carp. This list excludes the following species listed in Pflieger's (1989) big-river fishes guild due to rarity in Missouri: Burbot Lota lota, Inland Silverside Menidia beryllina, Northern Pike Esox lucius, Plains Killifish Fundulus zebrinus, Rainbow Smelt Osmerus mordax, Striped Bass Morone saxatilis, Striped Mullet Mugil cephalus. This list excluded the following species a priori that were listed in Pflieger's (1989) "big river fishes guild" for lack of great-river specialization in Missouri: Chestnut Lamprey Ichthyomyzon castaneus, Logperch Percina caprodes, Red Shiner Cyprinella lutrensis, Walleye Sander vitreus, Sand Shiner Notropis stramineus. 
Appendix 3.2. Images of Grand River (left column) and Meramec River (right column). Row one: confluence zones of Grand ( $\mathrm{rkm} 3$ ) and Meramec (rkm 3) rivers. Row two: sites upriver, beyond confluence zones of Grand (rkm 24) and Meramec (rkm 52) rivers. Row three: mid- to upper-course sites in Grand (rkm 145) and Meramec (rkm 244) rivers.
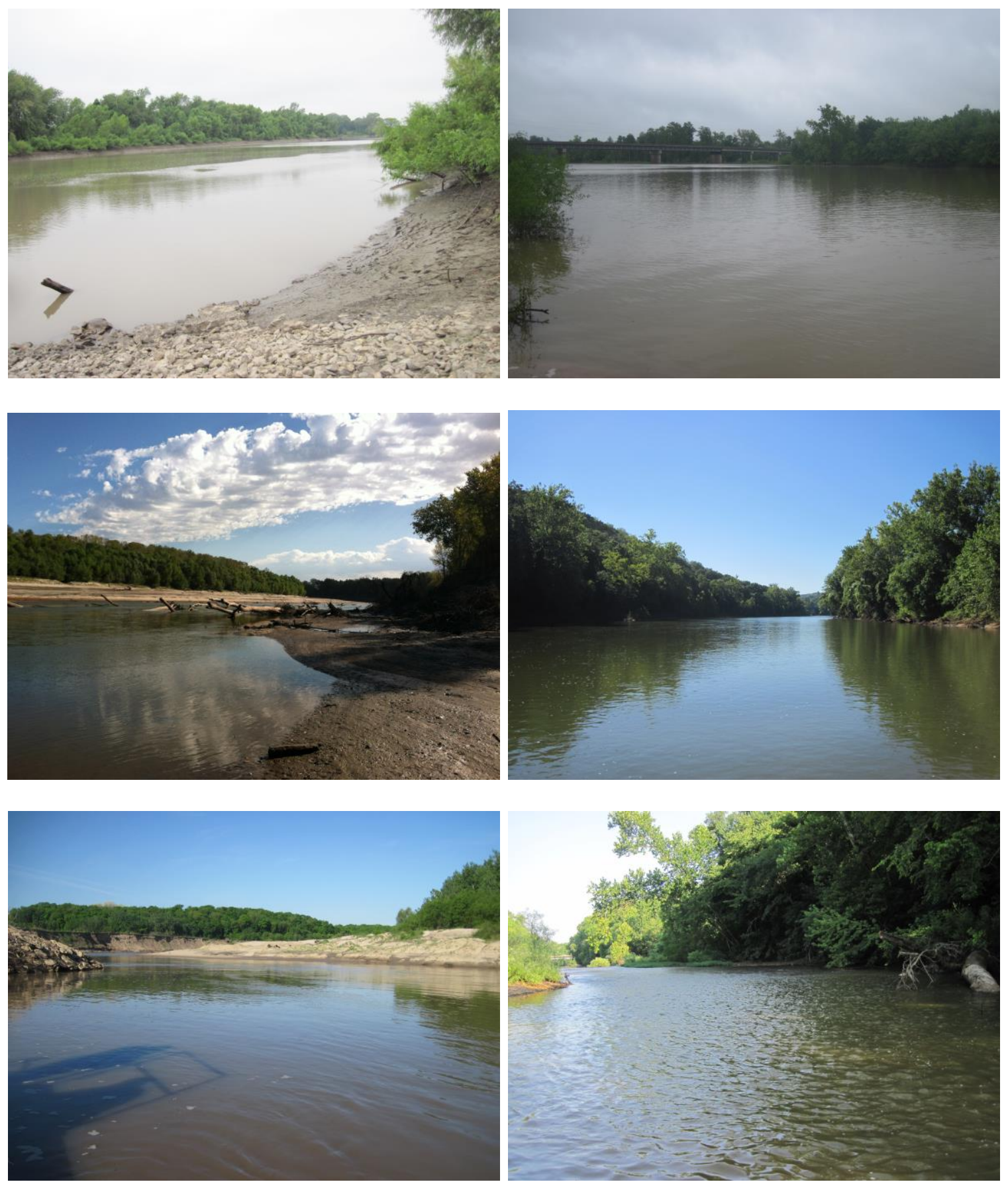
Appendix 3.3. Imagery and georeferenced fish and habitat (inset) survey of a site (rkm = 120) of the Meramec River in $2016(\mathrm{E}=686710, \mathrm{~N}=4246362$, UTM zone $15 \mathrm{~N}$

Missouri, USA). Habitat data were collected at five equidistant points along 21 transects plus additional points if transects intersected off-channel areas ( $\geq 105$ points per site). Image was obtained from 2012 National Agriculture Imagery Program.

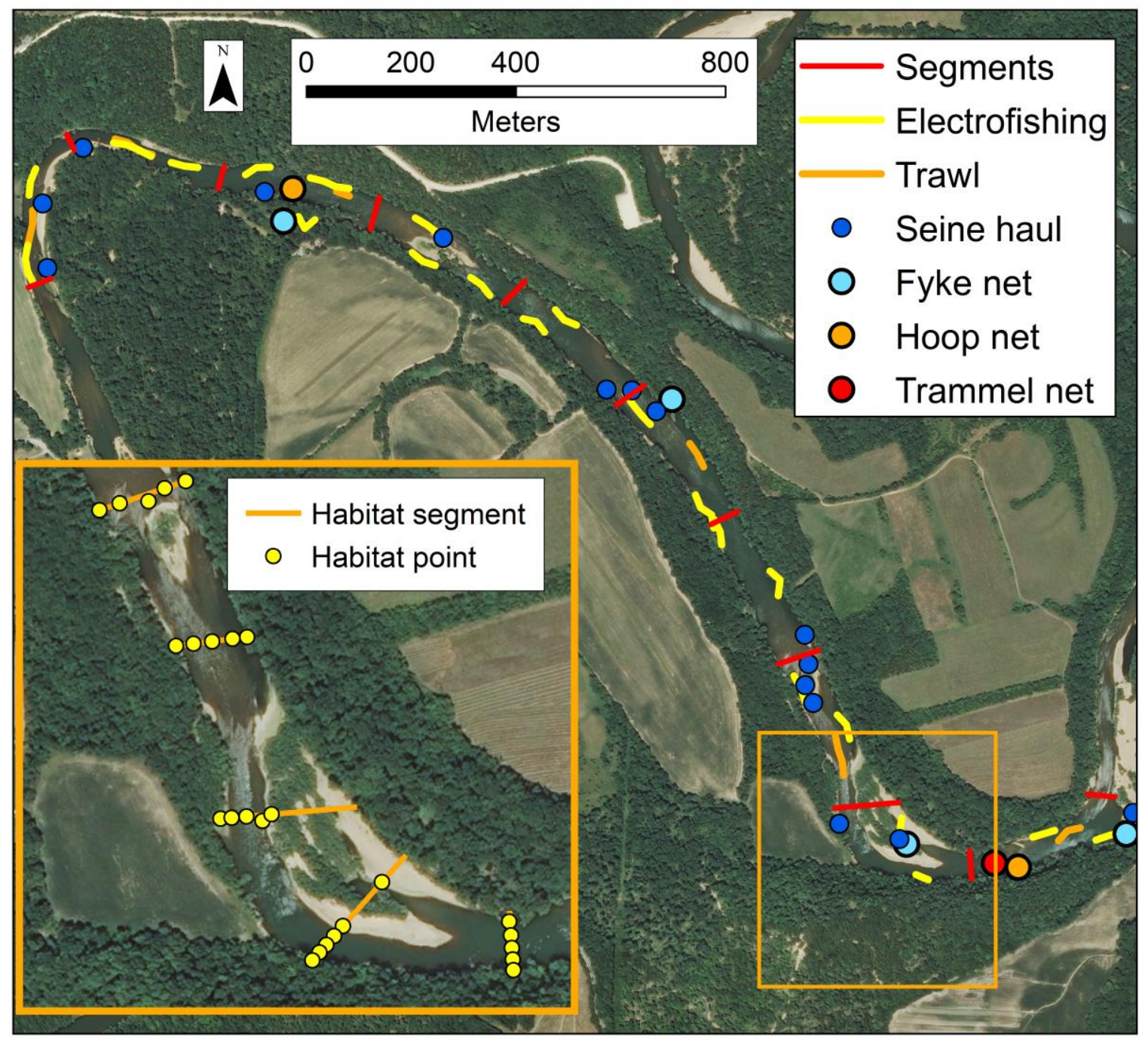


Appendix 3.4. Fish sampling effort per site for the Grand ( $N=10$ sites) and Meramec ( $N$ $=12$ sites) river systems in 2016 (Missouri, USA). Sampling effort was proportional to mean wetted channel width (MWCW). Distances are to the mouths of the Missouri (Grand R.) and Mississippi (Meramec R.) rivers. Total distances electrofished (Electro) and trawled per site were accumulated from individual 50-m runs. M-fyke $=$ mini-fyke net.

\begin{tabular}{|c|c|c|c|c|c|c|c|c|}
\hline $\begin{array}{c}\text { Location } \\
\text { (rkm) }\end{array}$ & $\begin{array}{l}\text { Category } \\
\text { (MWCW) }\end{array}$ & $\begin{array}{c}\text { Length } \\
(\mathrm{km})\end{array}$ & $\begin{array}{l}\text { Electro } \\
(\mathrm{m})\end{array}$ & $\begin{array}{l}\text { M-fyke } \\
\text { (nets) }\end{array}$ & $\begin{array}{l}\text { Hoop } \\
\text { (nets) }\end{array}$ & $\begin{array}{l}\text { Seine } \\
\text { (hauls) }\end{array}$ & $\begin{array}{c}\text { Trammel } \\
\text { (net) }\end{array}$ & $\begin{array}{c}\text { Trawl } \\
(\mathrm{m})\end{array}$ \\
\hline \multicolumn{9}{|c|}{ Grand River } \\
\hline 3 & $>95$ & 5.0 & 1800 & 4 & 2 & 25 & 1 & 500 \\
\hline 24 & $75-84$ & 4.0 & 1450 & 4 & 2 & 20 & 1 & 400 \\
\hline 52 & $75-84$ & 4.0 & 1450 & 4 & 2 & 20 & 1 & 400 \\
\hline 89 & $65-74$ & 3.5 & 1250 & 4 & 2 & 17 & 1 & 350 \\
\hline${ }^{b} 103.6$ & $45-54$ & 2.5 & 900 & 4 & 2 & 12 & 1 & 250 \\
\hline 103.9 & $45-54$ & 2.5 & 900 & 4 & 2 & 12 & 1 & 250 \\
\hline 145 & $45-54$ & 2.5 & 900 & 4 & 2 & 12 & 1 & 250 \\
\hline 151 & $45-54$ & 2.5 & 900 & 4 & 2 & 12 & 1 & 250 \\
\hline 199 & $35-44$ & 2.0 & 700 & 4 & 2 & 10 & 1 & 200 \\
\hline b 92 & $25-34$ & 1.5 & 550 & 4 & 2 & 7 & 1 & 150 \\
\hline \multicolumn{9}{|c|}{ Meramec River } \\
\hline 3 & $>95$ & 5.0 & 1800 & 4 & 2 & 25 & 1 & 500 \\
\hline 30 & 85-94 & 4.5 & 1600 & 4 & 2 & 22 & 1 & 450 \\
\hline 53 & $75-84$ & 4.0 & 1450 & 4 & 2 & 20 & 1 & 400 \\
\hline 63 & $65-74$ & 3.5 & 1250 & 4 & 2 & 17 & 1 & 350 \\
\hline 91 & $65-74$ & 3.5 & 1250 & 4 & 2 & 17 & 1 & 350 \\
\hline 120 & $55-64$ & 3.0 & 1100 & 4 & 2 & 15 & 1 & 300 \\
\hline 145 & $45-54$ & 2.5 & 900 & 4 & 2 & 12 & 1 & 250 \\
\hline 184 & $45-54$ & 2.5 & 900 & 4 & 2 & 12 & 1 & 250 \\
\hline 215 & $45-54$ & 2.5 & 900 & 4 & 2 & 12 & 1 & 250 \\
\hline${ }^{\mathrm{b}} 62$ & $35-44$ & 2.0 & 700 & 4 & 2 & 10 & 1 & 200 \\
\hline 244 & $35-44$ & 2.0 & 700 & 4 & 2 & 10 & 1 & 200 \\
\hline${ }^{\mathrm{b}} 116$ & $25-34$ & 1.5 & 550 & 4 & 2 & 7 & 1 & 150 \\
\hline
\end{tabular}


Appendix 3.5. Linear relationships $\pm 90 \%$ confidence intervals between watershed area and mean annual discharge (years 1920-2016) measured at six and five USGS stream gages in the Grand and Meramec river drainages, respectively. Estimated relationships were used to predict mean annual discharge at sites without discharge gages. Grand River gage IDs: 06899500, 06902000, 06897500, 06901500, 06899700, 06900000; Meramec River gage IDs: 07013000, 07014500, 07019000, 07018500, 07016500.

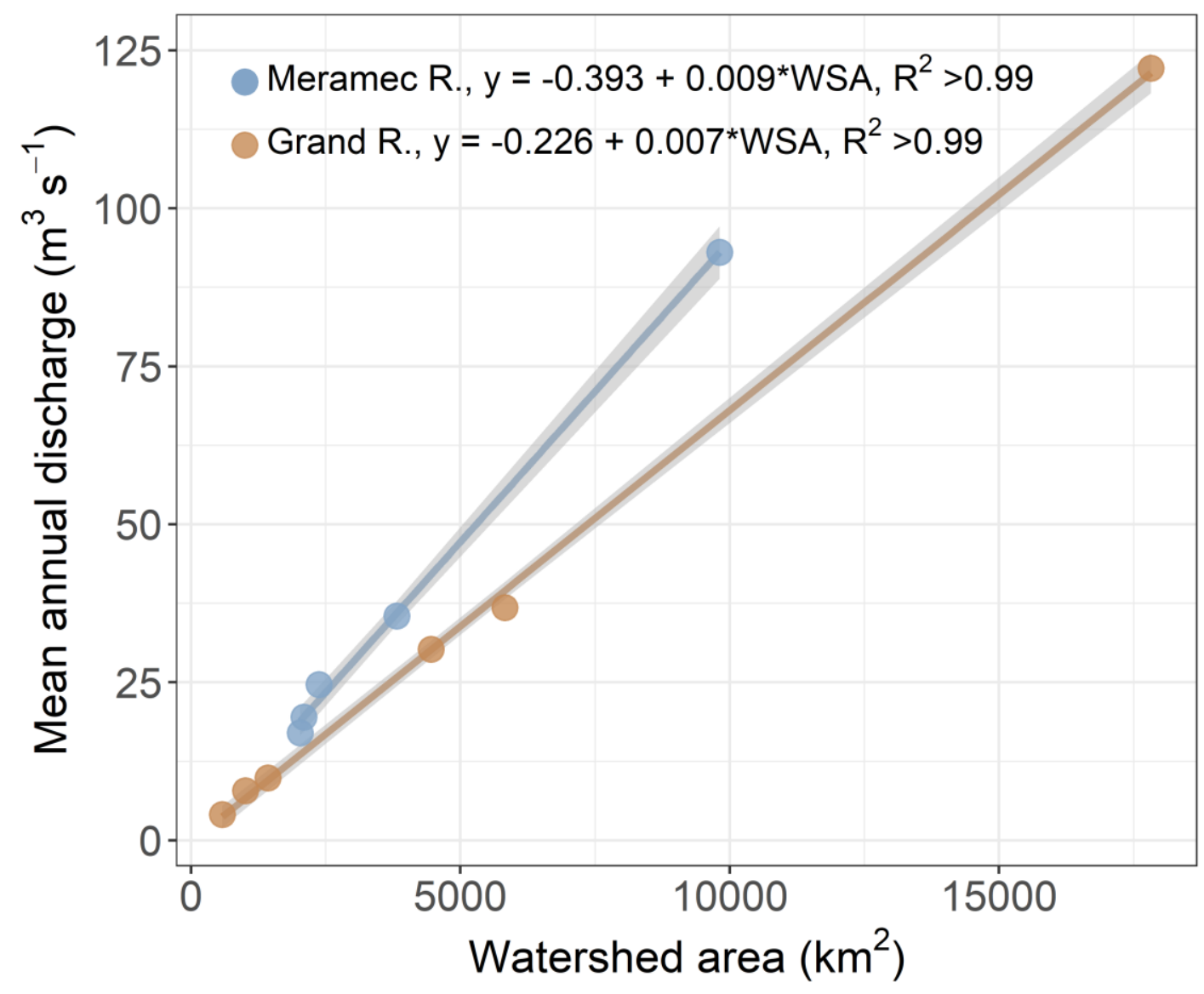


Appendix 3.6. Means (standard deviations) of 10 habitat variables at sites in the Grand $(\mathrm{G}$, sites $=10)$ and Meramec $(\mathrm{M}$, sites $=12)$ river systems and Missouri $(\mathrm{MO})$ and Mississippi (MS) rivers in 2016 (Missouri, USA). Variables were inputs into principal components analysis. Abbreviations: Sub. Size $=$ Substrate size, LWD = Large woody debris, Aqua. veg. = Aquatic vegetation, $\mathrm{BC}=$ Bluff confined, $\mathrm{OC}=$ Off-channel.

\begin{tabular}{|c|c|c|c|c|c|c|c|c|c|c|}
\hline $\begin{array}{l}\text { Site } \\
\text { ID }\end{array}$ & $\begin{array}{l}\text { Depth } \\
\text { (m) }\end{array}$ & $\begin{array}{c}\text { Velocity } \\
\left(\mathrm{m} \mathrm{s}^{-1}\right)\end{array}$ & $\begin{array}{c}\text { Sub. } \\
\text { size } \\
\text { (ordinal) }\end{array}$ & $\begin{array}{c}\text { Boulders } \\
\text { (count) }\end{array}$ & $\begin{array}{c}\text { LWD } \\
\text { (Count) }\end{array}$ & $\begin{array}{c}\text { Aqua. } \\
\text { veg. } \\
\text { (ordinal) }\end{array}$ & $\begin{array}{c}\text { Secchi } \\
\text { depth } \\
(\mathrm{m})\end{array}$ & $\begin{array}{c}\text { Shoal } \\
(\%)\end{array}$ & $\begin{array}{l}\mathrm{BC} \\
(\%)\end{array}$ & $\begin{array}{l}\mathrm{OC} \\
(\%)\end{array}$ \\
\hline MO & $2.7(2.1)$ & $0.71(0.57)$ & $2.1(1.1)$ & $1.1(3.4)$ & $0.1(0.6)$ & $0.0(0.0)$ & 0.28 & 0 & 0 & $2(14)$ \\
\hline G1 & $2.7(1.8)$ & $0.09(0.09)$ & $1.1(0.5)$ & $0.1(0.7)$ & $0.1(0.3)$ & $0.0(0.0)$ & 0.33 & 0 & $\sigma$ & $0(0)$ \\
\hline $\mathrm{G} 2$ & $1.4(1.4)$ & 0.24 & $1.8(0.6)$ & $0.3(2.0)$ & $0.1(0.4)$ & $0.0(0.0)$ & 0.25 & 14 & 0 & $0(0)$ \\
\hline G3 & $1.3(0.9)$ & $0.36(0.26)$ & $1.8(0.6)$ & $0.3(1.5)$ & $0.2(0.5)$ & $0.0(0.0)$ & 0.27 & 33 & 1 & $1(5)$ \\
\hline G4 & $0.8(0.6)$ & $0.35(0.20)$ & $1.9(0.5)$ & $1(0.7)$ & $0.2(0.5)$ & $0.0(0.0)$ & 0.62 & 24 & 5 & $1(2)$ \\
\hline G5 & $0.7(0.4)$ & $0.31(0.20)$ & $1.8(0.4)$ & $0.0(0.0)$ & $0.1(0.3)$ & $0.0(0.0)$ & 0.72 & 19 & 0 & $0(0)$ \\
\hline G6 & $0.8(0.5)$ & 0.22 & $1.9(0.8)$ & $1(0.4)$ & $0.1(0.2)$ & $0.0(0.0)$ & 0.84 & 16 & 5 & $1(4)$ \\
\hline G7 & $0.6(0.4)$ & $0.27(0.18)$ & $2.1(0.5)$ & $0.0(0.0)$ & $0.0(0.3)$ & $0.0(0.0)$ & 1.33 & 6 & 0 & $0(0)$ \\
\hline G8 & 0.4 & 0) & $1.9(0.3)$ & $0(0.1)$ & $0.1(0.3)$ & $0.0(0.0)$ & 0.9 & 12 & 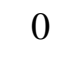 & $0(2)$ \\
\hline G9 & $0.4(0.3)$ & $0.31(0.17)$ & $2.0(0.5)$ & $0.0(0.3)$ & $0.0(0.2)$ & $0.0(0.0)$ & 0.94 & 12 & 0 & $0(2)$ \\
\hline G10 & $1.0(0.6)$ & 0.12 & $1.4(0.6)$ & 0.1 & 0.2 & $0.0(0.0)$ & .97 & 0 & 0 & $0(0)$ \\
\hline MS & $5.0(4.3)$ & $0.60(0.58)$ & $2.1(0.9)$ & $1.0(3.3)$ & $0.0(0.0)$ & $0.0(0.0)$ & 035 & 0 & 7 & $27(42$ \\
\hline M1 & $3.5(2.2)$ & $0.04(0.04)$ & $2.2(1.0)$ & $0.3(1.5)$ & $0.1(0.3)$ & $0.0(0.0)$ & 0.63 & 0 & 0 & $4(8)$ \\
\hline $\mathrm{M} 2$ & 1.8 & 3) & 3.0 & 0. & 0. & )) & 15 & 1 & 17 & $2(5)$ \\
\hline M3 & $1.1(0.9)$ & $0.34(0.30)$ & $3.0(0.9)$ & $0.8(2.2)$ & $0.1(0.3)$ & $0.9(1.5)$ & 1.2 & 27 & 29 & $7(20)$ \\
\hline M4 & 0.9 & ) & 3.1 & 8) & 0.1 & 1.2 & 1.32 & 2 & 31 & J \\
\hline M5 & $1.0(0.8)$ & $0.33(0.29)$ & $2.8(0.8)$ & $0.8(2.4)$ & $0.2(0.5)$ & $1.0(1.6)$ & 1.1 & 27 & 17 & $3(7)$ \\
\hline M6 & 1.2( & 0.27 & 3.0 & ) & 0.1 & $1.1(1.7)$ & 1.31 & 2 & 36 & 11 \\
\hline M7 & $0.8(0.5)$ & $0.34(0.31)$ & $2.8(0.9)$ & $0.7(2.1)$ & $0.2(0.5)$ & $1.2(1.7)$ & 1.9 & 30 & 26 & $10(28)$ \\
\hline M8 & $0.7(0.5)$ & $0.39(0.35)$ & $2.9(1.0)$ & $1.5(3.8)$ & $0.2(0.5)$ & $1.1(1.6)$ & 2.32 & 43 & 21 & $13(31)$ \\
\hline M9 & $0.9(0.6)$ & $0.28(0.25)$ & $2.8(0.9)$ & $0.8(2.7)$ & $0.1(0.4)$ & $0.7(1.2)$ & 1.75 & 29 & 19 & $5(19)$ \\
\hline M10 & $1.0(0.6)$ & $0.30(0.26)$ & $3.0(0.9)$ & $0.3(1.0)$ & $0.2(0.4)$ & 0.9 (1.6) & 1.26 & 29 & 17 & $0(0)$ \\
\hline M & $0.7(0.4)$ & $0.19(0.18)$ & $3.0(0.5)$ & $0.1(0.4)$ & $0.1(0.4)$ & $0.5(1.0)$ & 0.76 & 20 & 0 & $J(12)$ \\
\hline M12 & $0.6(0.3)$ & $0.24(0.20)$ & $2.8(0.9)$ & $0.7(1.7)$ & $0.1(0.4)$ & $1.2(1.3)$ & 1.8 & 20 & 36 & $5(19)$ \\
\hline
\end{tabular}


Appendix 3.7. Data collected in 2016 used for analyzing species-discharge relationships for sites in the Grand (sites $=10$ ) and Meramec ( sites $=12$ ) river systems (Missouri, USA). Branch (=1) signifies tributaries within each river system. LRS = large-river specialist fishes, $\mathrm{PC}=$ principal component. Distances are to the mouth of each respective river system.

\begin{tabular}{|c|c|c|c|c|c|c|c|c|}
\hline $\begin{array}{l}\text { Site } \\
\text { ID }\end{array}$ & Branch & $\begin{array}{c}\text { LRS } \\
\text { (species) }\end{array}$ & $\begin{array}{c}\text { Discharge } \\
\left(\mathrm{m}^{3} \mathrm{~s}^{-1}\right)\end{array}$ & $\begin{array}{c}\text { Distance } \\
(\mathrm{km})\end{array}$ & $\begin{array}{c}\text { Great-river } \\
\text { habitat }\end{array}$ & PC1 & PC2 & PC3 \\
\hline \multicolumn{9}{|c|}{ Grand River drainage } \\
\hline G1 & 0 & 15 & 139 & 3 & -0.89 & 0.89 & 0.15 & -0.41 \\
\hline $\mathrm{G} 2$ & 0 & 17 & 134 & 24 & -0.71 & 0.51 & 0.04 & -0.24 \\
\hline G3 & 0 & 13 & 122 & 52 & -0.77 & 0.16 & -0.03 & -0.23 \\
\hline G4 & 0 & 13 & 98 & 89 & -0.94 & 0.23 & -0.24 & -0.16 \\
\hline G5 & 0 & 15 & 47 & 104 & -1.04 & 0.54 & -0.33 & 0.18 \\
\hline G6 & 0 & 12 & 40 & 145 & -0.85 & 0.39 & -0.15 & 0.21 \\
\hline G7 & 0 & 10 & 39 & 151 & -1.06 & 0.54 & -0.3 & 0.39 \\
\hline G8 & 1 & 12 & 39 & 104 & -1.11 & 0.52 & -0.33 & 0.45 \\
\hline G9 & 0 & 10 & 22 & 199 & -1.09 & 0.49 & -0.3 & 0.48 \\
\hline G10 & 1 & 8 & 11 & 92 & -1.07 & 0.64 & -0.26 & -0.36 \\
\hline \multicolumn{9}{|c|}{ Meramec River drainage } \\
\hline M1 & 0 & 19 & 97 & 3 & -1.28 & 0.56 & 0.36 & -0.39 \\
\hline M2 & 0 & 17 & 95 & 30 & -1.41 & -0.11 & 0.09 & -0.31 \\
\hline M3 & 0 & 17 & 93 & 52 & -1.35 & -0.55 & 0.16 & 0.13 \\
\hline M4 & 0 & 16 & 69 & 63 & -1.53 & -0.64 & -0.01 & 0.17 \\
\hline M5 & 0 & 13 & 67 & 91 & -1.54 & -0.49 & -0.01 & -0.16 \\
\hline M6 & 0 & 7 & 43 & 120 & -1.52 & -0.77 & 0.19 & -0.11 \\
\hline M7 & 0 & 6 & 39 & 145 & -1.77 & -0.83 & -0.1 & -0.09 \\
\hline M8 & 0 & 1 & 37 & 184 & -1.88 & -1.05 & -0.11 & 0.02 \\
\hline M9 & 0 & 2 & 33 & 215 & -1.55 & -0.54 & -0.06 & 0.03 \\
\hline M10 & 1 & 13 & 24 & 62 & -1.74 & -0.38 & -0.29 & -0.15 \\
\hline M11 & 1 & 6 & 20 & 116 & -1.61 & 0.07 & -0.29 & 0.03 \\
\hline M12 & 0 & 1 & 19 & 244 & -1.66 & -0.68 & -0.12 & 0.05 \\
\hline
\end{tabular}


Appendix 3.8. Variables and corresponding parameter estimates ( \pm standard errors) for models explaining large-river specialist fish richness in the Grand ( $N=10$ sites) and Meramec $(N=12$ sites $)$ rivers in 2016. Models with lower $\triangle$ AICc were better supported. The Grand River served as the reference level (i.e., intercept).

\begin{tabular}{|c|c|c|}
\hline$\triangle \mathrm{AICc}$ & Variables & Parameter estimates \\
\hline 0.0 & $\begin{array}{l}1+\text { Discharge + River + } \\
\text { Discharge x River }\end{array}$ & $\begin{array}{l}9.50(1.78)+0.04(0.02)+-9.62(2.61)+ \\
0.14(0.04)\end{array}$ \\
\hline 3.8 & $\begin{array}{l}\text { 1 + Discharge + River }+ \\
\text { Discharge }^{2}+\text { Discharge } x \text { River }\end{array}$ & $\begin{array}{l}8.96(3.37)+0.07(0.12)+-9.44(2.84)+ \\
>-0.01(<0.01)+0.14(0.05)\end{array}$ \\
\hline 7.0 & $1+$ Discharge & $5.49(1.60)+0.09(0.02)$ \\
\hline 7.6 & $\begin{array}{l}1+\text { Discharge + } \\
\text { Discharge }^{2}\end{array}$ & $1.82(2.93)+0.24(0.10)+>-0.01(<0.01)$ \\
\hline 8.7 & $\begin{array}{l}1+\text { Discharge }+ \\
\text { Discharge }^{2}+\text { River }\end{array}$ & $\begin{array}{l}2.23(2.87)+0.28(0.10)+ \\
>-0.01(<0.01)+\end{array}$ \\
\hline 9.4 & $1+$ Discharge + River & $6.37(2.06)+0.09(0.02)+-1.24(1.79)$ \\
\hline 17.8 & 1 (null) & $11.05(1.14)$ \\
\hline 19.1 & $1+$ River & $12.50(1.68)+-2.67(2.28)$ \\
\hline
\end{tabular}


Appendix 3.9. Variables and parameter estimates ( \pm standard errors) for models explaining residual large-river specialist fish richness in the Grand ( $N=10$ sites) and Meramec $(N=12$ sites) rivers. Models with lower $\triangle \mathrm{AICc}$ were better supported.

Distance is to the respective mouth of each river system. $\mathrm{PC}=$ principal component.

\begin{tabular}{cll}
\hline$\Delta \mathrm{AICc}$ & \multicolumn{1}{c}{ Variables } & \multicolumn{1}{c}{ Parameter estimates } \\
\hline 0.0 & $1+$ Distance & $2.007(1.067)+-0.019(0.009)$ \\
2.2 & 1 & $<0.001(0.620)$ \\
3.9 & $1+\mathrm{PC} 1$ & $0.022(0.623)+0.997(1.077)$ \\
4.1 & $1+\mathrm{PC} 2$ & $-0.238(0.688)+-2.701(3.260)$ \\
4.8 & $1+\mathrm{Great}-$ river habitat & $0.399(2.471)+0.310(1.853)$ \\
4.8 & $1+\mathrm{PC} 3$ & $0.006(0.638)+0.306(2.475)$ \\
\hline
\end{tabular}




\title{
CHAPTER 4: PINPOINTING BIODIVERSITY HOTSPOTS: LOCAL HABITAT AND REGIONAL CONNECTIVITY SHAPE FISH RICHNESS WITHIN CONTRASTING RIVERINE METACOMMUNITIES
}

\begin{abstract}
1. Preserving biodiversity is a core goal of riverscape conservation planning, but the relative importance of connectivity and habitat diversity for maintaining fish richness is often unclear in non-wadeable rivers.

2. We sampled fish communities across $\geq 200 \mathrm{~km}$ of non-wadeable mainstems $\left(5-7^{\text {th }}\right.$ order) and tributary branches of the Grand (low habitat diversity) and Meramec (high habitat diversity) river systems (Missouri, USA). We asked whether local habitat diversity and regional connectivity explained site-level richness of three stream-size preference guilds: core species, large-river specialist (LRS) dispersers from the Mississippi and Missouri rivers, and headwater specialists dispersing from network branches. We defined biodiversity hotspots as sites with high fish richness $\left(\geq 75^{\text {th }}\right.$ percentile among sites) and examined whether occurrences of LRS and headwater species shifted hotspots longitudinally compared to hotspots defined solely by core species. 3. Species richness peaked in mid- to lower-courses in both rivers (maximum richness $=$ 39 spp. in Grand River, 73 spp. in Meramec R.) but not at either river mouth. Downriver connectivity (distance from mouth of mainstem river) and habitat diversity predicted LRS- $\left(R^{2}=0.44-0.91\right)$ and core-species $\left(R^{2}=0.37-0.57\right)$ richness, respectively. Headwaters within $25 \mathrm{~km}$ of sites positively related to headwater species richness in the Grand River system $\left(R^{2}=0.85\right)$ but not the Meramec River system, indicating rivers
\end{abstract}


constrained headwater species pools differently. Biodiversity hotspots based on core species extensively spanned sites with high habitat diversity covering 63\% (Grand) and $50 \%$ (Meramec) of mainstem sites. When viewing all species collectively, contributions of LRS fishes (13-17 spp.) to hotspots outweighed those of headwater species ( $\leq 6 \mathrm{spp}$.), causing hotspot ranges to narrow and shift downriver.

4. Overall, riverine metacommunities contain downriver, core, and headwater constituents, and thus, richness patterns are spatially explicit. Conserving hotspots likely requires strategies that preserve both habitat diversity and connectivity to surrounding species pools.

\section{Introduction}

Accurate depictions of biodiversity are needed for conservation planning at regional scales. For example, landscape-planning strategies often protect regional diversity by first safeguarding areas supporting the highest local species richness (i.e., biodiversity hotspots; Loury et al., 2018; Smith et al., 2018). In stream networks, these hotspots function as reserves for species that recolonize disturbed areas (Taylor \& Warren Jr, 2001) and often harbor rare and imperiled species (Cucherousset et al., 2008; Miranda, Killgore \& Slack, 2018). However, processes maintaining riverine biodiversity are often unclear, creating uncertainty about which management actions to prioritize (Erős, 2017). Metacommunity frameworks explicitly recognize that spatial (dispersal) and environmental (niche-based) processes affect community composition throughout river networks, and thus, may help explain biodiversity patterns (Brown et al., 2011). To date, however, the vast majority of metacommunity-framed studies are set in wadeable 
streams, leaving uncertainty about community-assembly processes in larger rivers where fish richness is typically highest (Erős, 2017; Vitorino Júnior et al., 2016).

Predictions about where fish richness peaks in rivers contrast among several classic river concepts. The River Continuum Concept (RCC, Vannote et al., 1980) continues to serve as a useful touchstone for potential longitudinal changes in fish communities (Mee, Robins \& Post, 2018; Vander Vorste et al., 2017). Although the RCC does not single-out fish, it predicts total "biotic diversity" peaks in $4-6^{\text {th }}$ order rivers where spatiotemporal diversity in habitat, thermal, and trophic resources are presumably maximized. Consequently, the RCC is inherently niche-based, predicting community structuring by local environmental conditions (Roberts \& Hitt, 2010). Multiple studies spanning non-wadeable rivers report mid-course peak or "hump-shaped" fish richness (Hughes \& Gammon, 1987; Oberdorff, Guilbert \& Lucchetta, 1993). However, declining lower-course richness could also result from diminished ecosystem integrity in urban areas along larger rivers and/or increasing sampling difficulty with traditional surfaceand bank-oriented sampling gears (e.g., electrofishing, seining) as rivers deepen and widen downriver (Erős, 2017).

Alternatively, many studies report that fish species richness continuously increases downstream (Matthews, 1998). This is partly attributed to the development of structurally complex habitats (deep pools, off-channel areas) and increasingly predictable flows downstream (Roberts \& Hitt, 2010; Schlosser, 1987). Because fish richness often increases downriver, discharge is often used to identify species rich areas (Laub et al., 2018), and simulate consequences of water abstraction (Xenopoulos et al., 2005) and climate change (Xenopoulos \& Lodge, 2006). However, despite the increasing use of 
discharge in conservation planning, few studies have investigated causal mechanisms underlying species-discharge relationships (SDRs; McGarvey \& Ward, 2008). Moreover, both the RCC and SDRs assume habitat diversity partly explains fish richness at sites, meaning these concepts also have conflicting expectations for where habitat diversity is greatest within rivers $(\mathrm{RCC}=$ mid-course, $\mathrm{SDR}=$ lower-course $)$. Surprisingly, few of the numerous studies examining longitudinal fish richness encompass non-wadeable rivers (Jackson, Peres-Neto \& Olden, 2001; Vander Vorste et al., 2017), and even fewer quantify habitat diversity, meaning there are little data to validate predictions from either the RCC or SDRs. Greater clarity into mechanisms underpinning SDRs is especially warranted before their broad adoption as tools in conservation planning.

Connectivity to regional species pools can also affect local species richness (Sarremejane et al., 2017). For example, fish dispersal from mainstem rivers sometimes heightens richness in lower-courses of adventitious tributaries, creating local hotspots near tributary mouths (Adventitious Stream Concept [ASC]; Hitt \& Angermeier, 2008; Osborne \& Wiley, 1992). Although most studies identify only localized spatial influences that are concentrated near mainstem-tributary ecotones, Hitt \& Angermeier (2008) detected dispersal-related community patterns extending $20 \mathrm{~km}$ upstream into mid to large wadeable tributaries, indicating upstream dispersal may increase in larger streams. A generalized extension of the ASC is the Network Position Hypothesis (NPH), which posits community dynamics are increasingly structured by spatial processes (i.e., dispersal) in more centrally located streams in networks due to greater accessibility to colonizers and heightened rescue effects (Brown \& Swan, 2010; Schmera et al., 2018). At an extreme, high dispersal in large mainstem rivers could de-couple local community- 
environmental relationships. Support for the NPH is context dependent, varying by taxa, species' traits, watershed, and season (Henriques-Silva et al., 2019; Schmera et al., 2018). In mainstem rivers, however, Vitorino Júnior et al. (2016) and López-Delgado et al. (2018) found elevated importance of spatial processes for structuring fish communities than in more isolated tributaries, hence supporting the NPH.

Headwater species may also contribute to fish richness in mainstems. For example, headwaters often support unique species (Meyer et al., 2007; Zbinden \& Matthews, 2017), which might drift downstream into mainstems during early life stages (Thornbrugh \& Gido, 2010), and mainstems could serve as temporary refugia for headwater fishes during flow intermittency (Magoulick \& Kobza, 2003; Meyer et al., 2007). Further, mainstems can serve as corridors connecting headwater fish populations throughout river networks. For example, landscape-genetic approaches indicate intervening mainstem dispersal distances, dams, and impoundments spatially structure genetics of stream-fish populations (Fluker et al., 2014; Schmidt \& Schaefer, 2018). Consequently, even though stream species are often disregarded as "waifs" when detected in mainstems, these detections may indicate important spatial processes affecting basinwide genetic exchange, and meta-population and -community dynamics (McCluney et al., 2014; Van Looy et al., 2019).

Our goal was to compare the mechanisms structuring longitudinal fish richness within two nonwadeable-river networks that contrast in habitat diversity and longitudinal environmental gradients. We accomplished this goal via three objectives: 1) first, we examined SDRs to determine whether species richness increased downriver (SDR), peaked mid-course (RCC), or showed other non-linear patterns indicative of underlying 
heterogeneity or connectivity (Rosenfeld, 2017); 2) then we disassembled fish

communities to ask whether habitat diversity and/or regional connectivity explained local richness of core, downriver, and headwater species at sites; 3 ) finally, we asked whether the longitudinal positions and/or profiles of richness hotspots defined by core species were affected by occurrences of species from downriver and headwater regional species pools. Our study is among the largest real-time tests of the metacommunity framework to date; because rivers were centrally located within river systems, we hypothesized "local" fish communities were comingled species originating from disparate locations within river systems and responsive to different assembly processes. Classic riverine theories often treat mainstem rivers as uniform blocks without examining processes that give rise to among-river differences in community-assembly mechanisms. (e.g., NPH). In contrast, we solely focus on rivers to highlight the multiple processes that structure riverine communities and demonstrate how structuring processes can vary spatially within and between rivers.

\section{Methods}

Grand and Meramec river systems

We surveyed mainstems and principal tributary branches of two non-wadeable rivers with contrasting environmental conditions (Missouri, USA; Fig. 4.1; see Appendix 3.2 in Chapter 3 for site images). The Grand River is a prairie river that drains 20,417 $\mathrm{km}^{2}$ of the Interior Plains region before joining the lower Missouri River. Fine sediments from glacial soils predominate, creating high turbidity and unstable channels reinforced by woody debris. Most tall-grass prairies and upland forests have been converted to row 
crops or pasture (drainage agriculture $=76 \%$; USGS, 2014). Surveys have detected 79 fish species throughout the system, consisting mainly of habitat and physiological generalists (Galat et al., 2005; Missouri Department of Conservation [MDC], unpublished fish community [pre-2010] and research assessment program [RAM, 19702014] databases). However, the Grand River system still supports several prairie fishes that are otherwise declining partly because of river fragmentation throughout the Interior Plains (Worthington et al., 2018).

The Meramec River system (drainage area $=10,270 \mathrm{~km}^{2}$ ) is one of the most biologically diverse river systems in North America (129 fish species, MDC [pre-1940] and RAM [1994-2014] unpublished fish community databases). It is a tributary of the Mississippi River and drains the Interior Highlands region (Ozark Plateau or "Ozarks" province), a topographically diverse, upland region. High groundwater connectivity sustains baseflow, moderates stream temperatures, and is conducive to low turbidity. Primary land uses are forest (68\%) and agriculture (22.5\%), but much of the lower drainage is urban development (metro St. Louis Missouri USA area; USGS 2014). Channels are semi-confined by bluffs and consist of well-defined alternating pools, shoals, and off-channel areas often associated with gravel bars (Rabeni \& Jacobson, 1993). Clear water and stable substrates (gravel-boulder) afford abundant water-willow (Justicia spp.) along channel margins.

Although environmental conditions differ between Grand and Meramec river systems (e.g., substrate, turbidity, etc.), both have similarly large and complex river networks (mean annual discharges at mouths $=139 \mathrm{~m}^{3} \mathrm{~s}^{-1}$ in Grand River, $97 \mathrm{~m}^{3} \mathrm{~s}^{-1}$ in Meramec R.). For example, both systems' mainstems are rare examples of unimpounded 
rivers where fish can disperse across broad spatial extents (>200 km). Further, both mainstems span $5-7^{\text {th }}$ orders and are joined mid-course by two non-wadeable $\left(5^{\text {th }}\right.$-order $)$ tributary branches in close succession. Finally, both rivers join much larger rivers (i.e., Mississippi or Missouri river). For clarity, we refer to the Mississippi and Missouri rivers as "great rivers," mainstems of the Grand and Meramec rivers as "mainstems," principal tributaries of the Grand and Meramec rivers as "branches," and the Grand and Meramec river systems (mainstems plus branches) as "tributaries." We refer to the two most downriver sites in the Grand (river km [rkm] 1-24) and Meramec (rkm 1-30) rivers as "lower-course," the two most upriver sites as "upper-course" (Grand R. = rkm 151-200, Meramec R. rkm 215-244), and intermediate mainstem sites as "mid-course."

Similar river networks allowed us to replicate our study design by sampling sites spanning the lower 200 (Grand R.) and 244 (Meramec R.) km of each system. Along the Grand River mainstem, we placed eight sites approximately every $25 \mathrm{~km}$ and one site within the lower reaches of two branches (Shoal Creek and Thompson River; 10 total Grand River system sites). In the Meramec River system, we placed nine sites every 30 $\mathrm{km}$ along the mainstem, and one site within lower reaches of two principal branches (Bourbeuse and Big rivers). We also added a mainstem site ( $\mathrm{rkm} 53)$ to provide greater resolution into richness changes near confluences (12 total Meramec River system sites). Access and navigability were limited, so we adjusted sites to be within $5 \mathrm{~km}$ of the nearest access, but no sites overlapped access points other than the lowermost 5-km-long sites. To minimize detections of random short-distance dispersers, we placed sites at least $1 \mathrm{~km}$ away from any major confluence (i.e., mainstem-great river or branch-mainstem confluences). 


\section{Fish and habitat sampling}

We used an intensive six-gear fish community sampling protocol developed for non-wadeable rivers (Chapter 2, sampling protocols). We sampled sites from April to September 2016 and targeted 93-94\% of fish species per site by sampling all major habitats (Chapter 2). Sites ranged from 1.5-5.0 km depending on mean wetted-channel width (MWCW). We scaled effort with active-sampling gears to each site's MWCW, while keeping the ratios of effort among active gears approximately constant (see Appendix 3.4 in Chapter 3 for sampling effort by site). Total effort by each gear was divided into discrete sub-samples to distribute sampling spatially within sites. Our active gears (effort per site) were boat electrofishing (550-1,600 m, 11-32 sub-samples), seining (7-25 hauls), and benthic trawling (150-500 m, 3-10 sub-samples). We complemented active gears by setting three passive gears overnight at each site: one stationary trammel net (30.5 m long x $1.8 \mathrm{~m}$ deep) with $20.3-\mathrm{cm}$ and $9.5-\mathrm{cm}$ bar mesh outer and inner panels, respectively; two hoop nets (1.2-m diameter) with 3.8-cm bar mesh; four mini-fyke nets (3.1-mm bar mesh). We set trammel and hoop nets in deep $(>1.5 \mathrm{~m})$ pools and mini-fyke nets in shallow off-channel and/or structurally complex areas.

We returned to each site after completing fish surveys to record nine local habitat variables contributing to local habitat diversity (September 26-October 27). Our habitat protocol was rapid (<1 d) and modified from USEPA (2013). Each site was divided into 20 sections by 21 cross-sectional transects spanning the main channel and off-channel habitats with surface-water connections. Along each transect, we placed five equally 
spaced points (minimum of 105 total points per site) and added a point at the center of off-channel habitats intersected by transects. At each point, we directly measured five habitat variables or documented if the point was in a shoal or pool (two variables). We mounted a sensor (Hach FH950) to the base of a wading rod (wadeable) or sounding pole (non-wadeable) to measure water-column velocity at approximately $60 \%$ depth or averaged velocities at $20 \%$ and $80 \%$ for depths $>1 \mathrm{~m}$. Next, we used side-scan sonar imagery, corroborated by a sounding pole (depths $<4 \mathrm{~m}$ ) or weighted sounding rope (depth $\geq 4 \mathrm{~m}$ ), to classify predominant substrate into six categories: silt/clay $(1=\leq 0.06$ $\mathrm{mm})$, sand $(2=0.07-2.0 \mathrm{~mm})$, gravel $/ \mathrm{pebble}(3=3-64 \mathrm{~mm})$, cobble $(4=65-256 \mathrm{~mm})$, boulder $(5=\geq 257 \mathrm{~mm})$, and bedrock (6). We also used side-scan sonar to quantify woody debris ( $\geq 5 \mathrm{~m}$ long) and large boulders ( $\geq 1 \mathrm{~m}$ diameter) within a 5-x-5-m area centered at each point.

We recorded two habitat variables at the ends of each transect. We estimated the percentage of shoreline covered by macrophytes within $10 \mathrm{~m}$ up- and down-river of each transect $(0=\leq 5 \%, 1=6-25 \%, 2=26-50 \%, 3=51-75 \%, 4=>75 \%)$. We also visually estimated the percentage of shoreline (lengthwise) with off-cannel areas between consecutive transects. The availability of off-channel areas was corroborated with satellite imagery while in the field. Off-channel areas were often characterized by slackwater habitats (e.g., sloughs, alcoves, secondary channels; see Appendix 3.3 in Chapter 3 for a georeferenced example of fish and habitat surveys). 


\section{Analyses}

Our analyses required several intermediate steps to derive predictor variables and test research questions. First, we estimated discharge at un-gaged sites to construct SDRs within each river system (objectives 1 and 3). To support objective 2, we integrated habitat data into an index of habitat diversity and then tested whether the Grand and Meramec rivers represented systems with low and high habitat diversity, respectively.

\section{Objective 1. Examine where species richness peaks based on discharge}

We used stream-discharge gages within each river system to estimate the longterm mean annual discharge at each site based on drainage area. First, we averaged annual discharge data at each gage in the Grand (5 gages) and Meramec (6 gages) with near-continuous discharge data (years 1920-2016). Then we linearly regressed mean annual discharge against drainage area from the National Hydrography Dataset Plus (USEPA \& USGS, 2012). A high coefficient of variation $\left(R^{2}>0.99\right)$ indicated discharge linearly reflected drainage area after allowing slopes to vary by river (see Appendix 3.5 in Chapter 3 for drainage area-discharge relationships). Therefore, we used this model to predict mean annual discharge based on drainage areas at lowermost boundaries of sites without stream gages. Finally, we related fish richness at sites to predicted discharge using Local Regression Smoothers (LOESS), which is a flexible technique for visually depicting nonlinear patterns via a moving window across an environmental gradient (Zuur et al., 2010). 
Objective 2: Determine whether habitat diversity and/or regional connectivity explained local richness of core, downriver, and headwater species at sites

We first classified each species potentially inhabiting river systems as a largeriver specialist (LRS, great-river-sourced species), core, or headwater species (Appendix 4.1). Designations of LRS and headwater species mostly align with "Big River" and “Headwater" species lists in Pflieger (1989). Historically, LRS species had populations centered in the Missouri and Mississippi rivers in Missouri. We added six species to Pflieger's (1989) designation that are either diadromous (Alabama Shad Alosa alabamae, American Eel Anguilla rostrata), recently introduced large-river species (Bighead Carp Hypophthalmichthys nobilis, Silver Carp H. molitrix), or lowland species (Mud Darter Etheostoma asprigene) associated with the Mississippi River floodplain (candidate LRS spp. $=35$ in Grand R., 42 in Meramec R.). Headwater species have distributions that center in small $\left(<4^{\text {th }}\right.$ order) streams (candidate headwater spp. $=14$ in Grand R., 23 in Meramec R.). Non-LRS species and non-headwater species were classified as "core" riverine species because they either specialize in mainstem rivers (e.g., Crystal Darter Crystallaria asprella) or are common throughout mainstems and another stream-size category (e.g., Smallmouth Buffalo Ictiobus bubalus in mainstems and great rivers; Carmine Shiner Notropis percobromus in mainstems and headwaters).

For objective 2, we also examined influences of habitat diversity and regional connectivity on local richness of members of each stream-size guild. Habitat diversity reflects lateral, hydrogeomorphic, and microhabitat variability, so we integrated the nine measured habitat variables into a single multivariate index of habitat diversity (hereafter, habitat-diversity index; Astorga et al., 2014). Accordingly, we created a correlation 
matrix of habitat variables by transect ( 21 transects per site), and then performed a Principal Component Analysis (PCA). We summarized the seven point-based variables to transect by either averaging (continuous or ordinal) or summing occurrences (pool, riffle habitat) along transects. Before performing PCA, we reduced skew by $\log (\mathrm{x}+0.1)$ or square-root transforming six variables (Table 4.1). Finally, we calculated habitat diversity as the mean Euclidean distance of transects to each site's multivariate centroid in PCA space (i.e., dispersion of transects around the centroid). To assess whether the habitatdiversity index represented variability in habitat variables, we examined the correlation (Pearson's product-moment, $r$ ) between the index with standard deviations of habitat variables. Similarly, we calculated correlations between standard deviations of habitat variables and mean annual discharge to assess whether discharge representing variability in habitat variables.

To examine whether both habitat diversity (within-site habitat variability) and heterogeneity (among-site habitat variability) were low and high in the Grand and Meramec river systems, respectively, we performed two permutations analogous to onesided two-sample $t$-tests with unequal variances. The first permutation used values from the habitat-diversity index (response) and river system (predictor) as inputs. For the second permutation (habitat heterogeneity), we tested whether the pairwise Euclidean distances among site PCA centroids were on average greater in the Meramec River system than the Grand River system. Permutations were performed using the 'Deducer' package (Fellows, 2012) in program R.

Regional connectivity to downriver and headwater species pools was represented with a suite of structural and functional connectivity indices (Heino et al., 2017; Tonkin 
et al., 2018). We used watercourse distance of each site upriver from the Missouri (Grand R.) or Mississippi (Meramec R.) rivers as a metric for downriver connectivity. Headwater connectivity is less straightforward because of multiple potential sources of colonists within network branches, so we calculated structural indices at three different spatial scales. For local and intermediate scales, we calculated the number of $2^{\text {nd }}$ - and $3^{\text {rd }}$-order stream endpoints within $5 \mathrm{~km}$ (local) and $25 \mathrm{~km}$ (intermediate) of each site, respectively. We were uncertain about potential carrying capacity and flow permanence of $1^{\text {st }}$-order streams, so we excluded these as sources of headwater fishes. At a system-wide scale, we calculated the average distance of each site to 2 - and $3^{\text {rd }}$-order stream endpoints. In case headwater fish were passively dispersed into mainstems or had biased movements downriver (Peláez \& Pavanelli, 2019), we included an index that penalized basinwide upstream movements by an extra $0.2 \mathrm{~km}^{-1}$, which served as a conservative indicator of potential functional connectivity that could be further explored if initially found important. Finally, we included discharge as a candidate predictor in case headwater fishes were restricted to smaller non-wadeable sites rather than using structural or functional corridors. All distances were calculated using a 1:100,000 stream network developed by Sowa, Annis, Morey, and Diamond (2007) for the study region.

We treated metrics of regional connectivity and habitat diversity as multiple competing hypotheses within an information-theoretic framework. All predictor variables were standardized by centering means on 0 and dividing by their standard deviations. We linearly regressed site-level richness of each stream-size guild to each predictor and evaluated relative support using Akaike's Information Criterion corrected for small sample size (AICc). We hypothesized local habitat diversity would predict core-species 
richness, whereas LRS- and headwater-species richness would respond to downriver and headwater connectivity, respectively. Equation 1 presents a linear regression where $\mathrm{Y}_{\mathrm{i}}$ is observed $\alpha$ richness for core, headwater, or LRS species for site i, $\hat{\beta}$ are the estimated intercept $\left(\hat{\beta}_{0}\right)$ and slope parameters for variables $(\mathrm{X}) 1$ through $\mathrm{n}$.

$\mathrm{Y}_{\mathrm{i}}=\hat{\beta}_{0}+\hat{\beta}_{1} * \mathrm{X}_{1 \mathrm{i}}+\ldots \hat{\beta}_{\mathrm{n}} * \mathrm{X}_{\mathrm{ni}}+\mathrm{e}_{\mathrm{i}}$, where $\mathrm{e}_{\mathrm{i}} \sim \mathrm{N}\left(0, \sigma^{2}\right)$ and independent

Objective 3: Do large-river and headwater species affect positions and profiles of hotspots?

We used the distribution of core-species along mainstems as references and examined how the addition of LRS species and headwater species affected the longitudinal positions and profiles of hotspots. Our purpose was to simulate effects of lost up- and/or down-river connectivity on riverine richness. We constructed longitudinalrichness profiles of mainstem sites by relating the longitudinal position of sites (distance to mouth) to richness via LOESS regression. We then defined hotspots as mainstem sites that exceeded $75^{\mathrm{h}}$ percentiles of predicted richness within each system. We summarized longitudinal profiles and positions of hotspots by calculating the number, mean distance upriver from the mouth, and longitudinal extent $(\mathrm{km})$ of mainstem sites qualifying as hotspots.

\section{Results}

Altogether 109 species and 46,696 individuals were collected across rivers. We detected $47(60 \%)$ and $102(79 \%)$ of 79 and 129 potential species in the Grand and 
Meramec river systems, respectively, demonstrating most species comprising regional species pools occurred within our non-wadeable rivers (Appendix 4.1). Only six species were unique to the Grand River system. In the Meramec River system, we collected more North American minnows (Leuciscidae, Grand R. = 14 spp., Meramec R. = 28 spp.) and darters (Etheostomatinae, Grand R. = 1 spp., Meramec R. = 14 spp.), along with seven additional families $($ Grand R. $=13$ families, Meramec R. $=20$ ). Higher regional richness translated to higher local richness (mean $\pm \mathrm{SD}$ ); sites in the Meramec River system (57.9 $\pm 7.5)$ supported nearly twice as many species as those in the Grand River system (33.4 \pm 4.4).

We observed large differences in habitat diversity (within-site habitat variability) and among-site habitat heterogeneity between rivers (Fig. 4.2). Sites in the Grand River system lacked macrophytes, off-channel habitats, and boulders, and had lower variability in most other habitat variables (see Appendix 4.2 for habitat data). Habitat diversity (mean \pm SD among sites) was lower in the Grand River system ( $0.70 \pm 0.14)$ than Meramec $(1.04 \pm 0.16$, permutation-based one-sided $t$ statistic $=-5.3, p<0.01)$. Our habitat diversity metric positively correlated with standard deviations of all habitat variables in both rivers, confirming it represented habitat variability at sites (Table 4.1). Correlations between standard deviations of habitat variables and discharge were generally positive for the Grand River system but mixed for the Meramec River system. Exempting branches, habitat diversity was high throughout mid-sections of both systems (Grand R. sites rkm 24-145 $\geq 0.77$ habitat-diversity index; Meramec R. sites rkm 53-215 $\geq 1.07$ habitat-diversity index; Appendix 4.3). 
Among-site habitat heterogeneity within the Meramec River system was nearly twice that of the Grand River system (permutation-based one-sided $t$ statistic $t=-4.9, p<$ 0.01, Fig. 4.2), mainly due to habitat changes in the lower-course of Meramec River system. Specifically, lower-course sites (rkm 1-30) in the Meramec River system were notably deeper and had lower water velocities, and limited macrophytes and shoal habitat (Appendix 4.2). Similar downriver geomorphic changes (deepening, slowing) occurred in the Grand River, but to a lesser degree, and changes were mainly noticeable at the lowermost site near its confluence with the Missouri River.

\section{Species-discharge relationships}

Changes in richness closely matched changes in discharge $(Q)$ until richness peaked in mid- to lower-course sites and then dropped towards the mouths of both rivers, resulting in unimodal SDRs (pseudo- $R^{2}=0.60$ in Grand R., = 0.71 in Meramec R.; Fig. 4.3). Pseudo- $R^{2}$ was calculated as the squared Pearson correlation coefficient between observed versus predicted species richness with LOESS regression curves. In the Grand River system, changes in species richness were generally gradual. For example, richness ranged by only 13 species across sites, and two sites contained 39 species (maximum richness) spaced $78 \mathrm{~km}$ apart. In contrast, richness steadily increased downriver in the Meramec River system from rkm 244 (51 spp., $Q=19 \mathrm{~m}^{3} \mathrm{~s}^{-1}$ ) to rkm 53 (73 spp., $Q=93$ $\mathrm{m}^{3} \mathrm{~s}^{-1}$ ), until sharply declining by 23 species along the lower $53 \mathrm{~km}$, despite discharge increasing by $5 \mathrm{~m}^{3} \mathrm{~s}^{-1}$ (50 spp. near the mouth). This decline coincided with decreasing habitat diversity (habitat diversity at $\mathrm{rkm} 52=1.07$ versus $\mathrm{rkm} 3=0.68$ ). We observed a 
similar, albeit subtle, decline in species ( $8 \mathrm{spp}$.) in the Grand River system between rkm $24\left(Q=134 \mathrm{~m}^{3} \mathrm{~s}^{-1}\right)$ and the mouth $\left(Q=139 \mathrm{~m}^{3} \mathrm{~s}^{-1}\right)$.

Distributions of core, headwater, and LRS species

We collected a mixture of core and non-core species at all sites across river systems (Fig. 4.4). A higher percentage of the Grand River system's fish community was comprised of LRS species and headwater species (51\%) than the Meramec River system's (41\%); this discrepancy resulted from a higher percentage of LRS species in the Grand River (Grand R. LRS spp. $=38 \%$, Meramec R. LRS spp. $=28 \%$ ), meaning approximately $12 \%$ of total species collected in each river system were headwater specialists.

Large-river specialist species were rare in the Meramec River system upriver of rkm 184 ( $\leq 2$ LRS spp., $\leq 4 \%$ of species), but increased sharply downriver (6-19 spp., $12-$ $38 \%$ of species). In contrast, the percentage LRS richness was $\geq 28 \%$ ( $\geq 8$ LRS spp.) at all sites in the Grand River system, indicating LRS species likely move throughout the lower $200 \mathrm{~km}$ of non-wadeable reaches. As expected, the highest percentages of LRS species were in lower-courses of both rivers, comprising 48\% (15 LRS spp.) and 38\% (19 LRS spp.) of species near the mouths of the Grand and Meramec rivers, respectively.

Patterns of headwater species diverged between systems in mid- to upper-course sites. In the Meramec River system, headwater species richness was highest in sites upriver of rkm 184 and the Bourbeuse River (rkm 116, 7-10\% of community, 4-5 spp.). We did not detect any headwater species in our similarly sized lower branch site (Big River, rkm 62). In contrast, percentages of headwater species richness in the Grand River 
system peaked in mid-course mainstem sites and in branches (13-18\%; 5-6 spp.). We collected $\leq 3$ headwater species at lower-course sites in both rivers.

Predictors of core, large-river, and headwater species

Processes structuring richness varied among stream-size guilds and slightly between systems (see Fig. 4.5 for linear relationships; see Appendix 4.4 for non-linear relationships along rivers). Habitat diversity was the best-supported variable explaining core-species richness in both systems (Grand R., Akaike weight $w_{l}=0.47$; Meramec R., $\left.w_{1}=0.85\right)$, but the relationship was stronger in the Meramec River system $(\hat{\beta} \pm$ standard error, $\left.\hat{\beta}=4.8 \pm 1.3, R^{2}=0.57\right)$ than Grand River system $\left(\hat{\beta}=1.3 \pm 0.6, R^{2}=0.37\right.$; Table 4.2). In contrast, LRS richness was better explained by downriver connectivity than habitat diversity in both systems (support for downriver connectivity, $w_{l}=0.62$ in Grand R.; $w_{1}>0.99$ in Meramec R.) with lower LRS species richness as connectivity decreased upriver (effect size $\hat{\beta}=-1.8 \pm 0.7$ in Grand R.; $\hat{\beta}=-6.4 \pm 0.6$ in Meramec R.). Note distances to sources actually represent isolation, so signs of effects are reversed than if interpreted strictly as connectivity. In contrast to downriver connectivity, variables explaining headwater richness varied between systems; in the Meramec River system, none of the four candidate metrics for headwater connectivity were better supported than an intercept-only model. Instead, discharge was slightly better supported $\left(w_{l}=0.45 ; R^{2}=\right.$ 0.44 ; slope $=\hat{\beta}=-1.0 \pm 0.5$ ), indicating there were more headwater fishes at lowerdischarge sites. In the Grand River system, however, three of four headwater connectivity metrics were better supported than an intercept-only model, indicating headwater richness increased with higher connectivity to headwater sources. Among headwater 
metrics, the number of $2^{\text {nd }}-3^{\text {rd }}$-order outlets within 25 river km of sites garnered nearly all Akaike weight $\left(w_{1}=0.91\right)$ and explained the most variation $\left(\hat{\beta}=1.3 \pm 0.2, R^{2}=0.85\right)$. The number of $2^{\text {nd }}-3^{\text {rd }}$-order outlets within $5 \mathrm{~km}$ (local connectivity) had almost no $\operatorname{support}\left(w_{7}<0.01, \hat{\beta}=0.2 \pm 0.5, R^{2}=0.03\right)$.

Occurrences of LRS species and headwater species affected the positions and spatial extents of hotspots along each river (Table 4.3; Fig. 4.6). If solely based on core species, both systems would have broad hotspots (>120 km; >55\% of mainstem lengths sampled) encompassing mid-course reaches with high habitat diversity (mean hotspot position $=$ rkm 83 in Grand R., rkm 102 in Meramec R.). However, headwater and LRS species shifted distributional centers of hotspots upriver (14-19 km) and downriver (10$44 \mathrm{~km}$ ), respectively. When hotspots were based on all species, higher richness of LRS species than headwater species caused net downriver shifts (= $10 \mathrm{~km}$ in Grand R., $33 \mathrm{~km}$ in Meramec R.; Fig. 4.6d, h). Moreover, because LRS species and headwater species were not evenly distributed throughout either system, their occurrences typically narrowed the extents of hotspots relative to broad hotspots defined by core species. For example, the Meramec River hotspot defined by all species spanned only three lowermidcourse sites (rkm 53-91) with both high LRS species and core species richness. Despite hotspots being narrowed and shifted by non-core species, they still encompassed 94\% (44 spp.) and 80\% (82 spp.) of species detected by our surveys in the Grand and Meramec river systems, respectively. 


\section{Discussion}

Our study revealed non-wadeable, free-flowing rivers supported most species comprising regional species pools, including headwater and large-river specialist species. Instead of conforming to a single river concept, the distribution of fish richness in both systems supported elements of spatial- (e.g., Adventitious Stream, Network Position) and niche-based (River Continuum) river concepts. Moreover, support for specific concepts varied spatially within and between river systems. Overall, our results indicate riverine fish communities are likely metacommunities blended from core, downriver, and headwater species pools. Superimposition of regional connectivity and local habitat diversity contributes to uneven distributions of species, thereby affecting the positions of hotspots and shaping the longitudinal profiles of richness within each system.

\section{Scale dependency of species-discharge relationships}

Species richness did not linearly or monotonically increase downriver in either system, and in the Meramec River system, the fewest species were detected at the highest-discharge site (i.e., Meramec River mouth). Our results contrast with positive linear or linearized SDRs in other macroecological studies (Laub et al., 2018; Xenopoulos \& Lodge, 2006). We hypothesize discrepancies between our findings and existing SDRs partly result from the finer resolution of our observational units (1.5-5.0 $\mathrm{km})$. In comparison, most investigations of SDRs aggregate fish-collection data from multiple sources across coarse spatial grains (e.g., $\geq 50$ km, Hydrologic Unit Codes), which may not reflect finer-grain habitat changes within units (McKerrow et al., 2018). For example, if sites in the Meramec River system were aggregated into three groups 
based on discharge (4 sites per group), richness would appear to increase downriver, thereby masking lower-course declining richness (lowest discharge group = 77 spp., medium discharge $=79$ spp., highest discharge $=90$ spp.). Similarly, McGarvey and Hughes (2008; Pacific Northwest, USA), and McGarvey and Ward (2008; southeastern, USA) reported scale-dependent SDRs from within-river heterogeneity in geology, elevation, and temperature. Although coarse-grained SDRs have useful basinwide applications, their predictions may not provide realistic baselines of richness that match observations at finer scales typical of most site-level ecological assessments. Instead, finer-grained SDRs or other patch-based classification schemes (e.g.,Troia \& McManamay, 2019) might be more applicable for monitoring and management at local scales.

\section{Core species-habitat diversity relationships}

Core-species richness increased with habitat diversity in both river systems, indicating many riverine fishes exploit locally available resources. These positive species-habitat diversity relationships implicate habitat homogenization as a potential contributor to widespread declines in riverine biodiversity (Koel, 2004; Peipoch et al., 2015), while indicating habitat diversity might be an important ingredient for successful river restoration (Palmer, Menninger \& Bernhardt, 2010; Swan \& Brown, 2017). In contrast to the SDR expectation of continuously increasing habitat diversity downriver, habitat diversity decreased towards both river mouths due to lost variability in water velocities (both rivers), substrates (Meramec R.), and aquatic vegetation (Meramec R.). 
Consequently, lower habitat diversity and fewer core species underpinned declining total richness near the mouths of both rivers.

Our finding that species richness declined near river mouths contrasts with biodiversity hotspots often reported near river mouths of wadeable streams (Boddy, Booker \& McIntosh, 2019; Hitt \& Angermeier, 2008; Schaefer \& Kerfoot, 2004). This discrepancy might result from the larger-scale hydrogeomorphic changes upstream of river confluences compared with those in wadeable streams. For example, river flows in lower-course reaches of our focal rivers are influenced by backwater effects mediated by surface elevations of the Missouri and Mississippi rivers (Brown \& Coon, 1994). Backwater effects slow water velocities, meaning the availability of habitat for fluvialdependent species varies spatially and temporally in backwater-affected sites. Backwaters are also symptomatic of ecotones or "confluence zones" that develop in tributaries upstream of confluences (Rice, 2017; Thornbrugh \& Gido, 2010). Extensive homogenous ecotones in low-gradient rivers could result in low fish richness above large-tributary mouths, whereas rapid dispersal (i.e., mass effects) across smaller ecotones in streams may manifest as hotspots above small tributary mouths (e.g., Hitt \& Angermeier, 2008; Miyazono \& Taylor, 2013). Our findings also contrast with Fernandes, Podos, and Lundberg (2004), who found backwaters increased fish richness in non-wadeable Amazon River tributaries by concentrating food resources, albeit only for electric fishes (Gymnotiformes). Thus, "tributary effects" may be taxon- or system-specific.

Reduced fish richness also likely resulted from accumulating effects of local and regional stressors downriver. Locally, lower-course reaches of both rivers are partially channelized and leveed, which can reduce habitat diversity and mainstem-floodplain 
connectivity (Johnson, Richardson \& Naimo, 1995). Channel modifications may have been compounded by near- and up-stream intensive land uses. For example, we observed a 12-species decline between rkm 53 and $\mathrm{rkm} 30$, coinciding with intensifying urban land use (St. Louis metropolitan area near rkm 30). Most species underpinning declines (e.g., Bleeding Shiner Luxilus zonatus, Rainbow Darter Etheostoma caeruleum, Black Redhorse Moxostoma duquesnei) were core species reliant on upland habitats (silt-free shoals, aquatic vegetation), which are often lost in rivers with urbanizing watersheds (Allan, 2004). Our findings parallel those of other studies in non-wadeable rivers, which attribute declining downstream richness to byproducts of intensifying land use, including diminished water and habitat quality (Hughes \& Gammon, 1987; Oberdorff et al., 1993). Specifically, Argentina, Freeman, and Freeman (2010) found fewer benthic fishes in downstream reaches of a southeastern river (USA) corresponding to intensifying land use, elevated turbidity, and fewer macrophytes. Together our work and these studies suggest that biodiversity hotspots in non-wadeable rivers might be artificially truncated by accumulating stressors downriver.

\section{Large-river and headwater specialist species}

Downriver declines in core richness in lowercourses were partially masked by increasing richness of LRS species downriver, demonstrating that spatial processes linked to the ASC and NPH theories partially explain fish richness patterns in non-wadeable rivers. Upriver dispersal appears more extensive in our study systems than many existing examples of the ASC and NPH. For example, LRS richness was $\geq 13$ throughout the lower $90 \mathrm{~km}$ of mainstems in both systems, and we detected at least one LRS species at 
our uppermost sites ( $\geq 200 \mathrm{~km}$ from great rivers). In contrast, the ASC has primarily explained locally elevated richness and compositional changes in wadeable tributaries near mainstem confluences (Cilleros et al., 2017; Osborne \& Wiley, 1992; Schaefer \& Kerfoot, 2004). Grossman et al. (2010) and Ferreira et al. (2019) indicated riverine species were restricted from accessing upstream reaches by environmental conditions in smaller streams, and our results suggest these resistance mechanisms may subside as river size increases. Similarly, Hitt and Angermeier (2008) and Grenouillet, Pont, and Hérissé (2004) indicated upstream dispersal by mainstem fish increased in larger branches of river networks. Although richness did not peak at either river's mouth within our study, the extensive reach of LRS species contributed to total richness in mid- to lower-course sites causing the extent of mid-course hotspots to skew downriver. By extension, if downriver connectivity were diminished, hotspots might be re-centered slightly upriver at sites where habitat diversity and/or headwater connectivity were maximized.

Despite maximized headwater connectivity in mid-courses of both rivers, headwater fish richness only peaked mid-course in the Grand River system, indicating headwater fishes interact with mainstems differently across river systems. Moreover, Grand River headwater species richness was predicted by headwater sources at intermediate $(\leq 25 \mathrm{~km})$ rather than local $(\leq 5 \mathrm{~km}$; Stoll et al., 2013) scales, indicating headwater fish disperse broadly in this system. The ability of headwater fishes to disperse via non-wadeable rivers may be particularly important in the Grand River (a prairie system) because prairie headwaters typically have highly variable flows prone to drying (Dodds et al., 2004). Thus, long-term persistence of headwater fishes in prairie river 
systems likely depends on periodic usage of non-wadeable rivers for refuge and as corridors to recolonize re-wetted sites. This aligns with Hudman and Gido (2013), who found a headwater fish, Creek Chub Semotilus atromaculatus, likely disperses throughout mainstems of prairie rivers in the absence of dams and impounding. Although we are unaware of community-focused studies examining use of non-wadeable prairie rivers by headwater fishes, both Falke et al. (2012) and Whitney et al. (2015) found fish community dynamics in ephemeral prairie streams depended on re-colonization from downstream sources. Hence, compatible findings from riverine and headwater perspectives indicate dispersal and connectivity are particularly important for structuring prairie fish metacommunities.

In the Meramec River system, headwater species richness was highest in smaller upper-course sites, indicating larger mainstems might function as dispersal barriers for headwater fishes. The discrepancy in headwater fish richness patterns between the Grand and Meramec river systems likely resulted from stronger environmental gradients in the Meramec River system, causing starker contrasts between headwaters and larger mainstems. Accordingly, mainstem environmental conditions (e.g., presumably warmer temperatures, lower dissolved oxygen, higher turbidity) might have filtered headwater fishes, especially upland species in the Meramec River system that prefer cool water, high dissolved oxygen, and/or low turbidity (Smale \& Rabeni, 1995). Similar to our study, Kanno et al. (2012) detected few headwater species in mainstems of an upland southeastern river system (USA), and Schmidt and Schaefer (2018) found large rivers restricted genetic connectivity (and presumably among-population dispersal) of two headwater fishes in southern Mississippi River drainages. If temperature and dissolved 
oxygen contributed to mainstem-filtering, then warming temperatures may intensify mainstem-filtering strength, thereby further inhibiting headwater fishes from tracking climatic changes within upland river systems (Troia, Kaz, Niemeyer, \& Giam, 2019).

Mainstem filtering of headwater species in the Meramec River might have offset contributions of LRS species to total richness in sites with lower, more accessible network positions. For example, a lower network position enabled at least 13 LRS species to access a smaller branch site (Big River, rkm 62, $Q=24 \mathrm{~m}^{3} \mathrm{~s}^{-1}$ ), whereas we detected $\leq 2$ LRS species in similarly sized $\left(Q=19-33 \mathrm{~m}^{3} \mathrm{~s}^{-1}\right)$, but less accessible uppercourse sites (i.e., rkm 215-244). However, we did not detect any headwater species in the Big River causing total species richness at our Big River site (55 spp.) to be comparable to upper-course sites (51-54 total spp.; 4-5 headwater spp.). One possible explanation is the lower Big River is functionally isolated from all mainstem pathways for headwater colonizers because of its location only $1 \mathrm{~km}$ upriver of the large, mid-course mainstem. Similarly, we detected 51 species in the other similarly sized branch site (Bourbeuse R., $\mathrm{rkm}=116, Q=20 \mathrm{~m}^{3} \mathrm{~s}^{-1}$ ) located $7 \mathrm{~km}$ from the mid-course mainstem Meramec River, mainly because gains in headwater species ( 4 spp.) were offset by fewer LRS species (7 spp.). Thornbrugh and Gido (2010) noted a similar tradeoff in wadeable tributaries of the Kansas River where they suspected lower abundances of "stream" species resulted from increasing headwater isolation and higher abundances of large-river predatory fishes near confluences. Thus, our findings demonstrate after accounting for river size, fish communities positioned lower in networks can vary compositionally without large increases in richness. These findings support hypothesized dispersal mechanisms underpinning the ASC and NPH. 
Alternatively, chronic lead contamination of upper reaches of the Big River could have reduced the pool of headwater species available to colonize our Big River site. However, Krause, Wu, Chu, and Knouft (2018) did not find differences in richness or abundance of minnows or darters (13 of 23 of candidate Meramec headwater species) between led- and non-led contaminated sites within the Big River watershed.

\section{Riverine fish communities as metacommunities}

Both spatial and niche-based mechanisms likely contributed to longitudinal riverine richness, demonstrating the utility of metacommunity theory for explaining patterns in riverine communities (López-Delgado et al., 2018; Vitorino Júnior et al., 2016). We provide rare insight into underlying heterogeneity in habitat and communities within non-wadeable rivers. Spatial processes (e.g., mass effects, long-distance dispersal) are thought to predominate community dynamics in larger streams and rivers (Brown \& Swan, 2010; Erős, 2017; Vitorino Júnior et al., 2016). However, we found core species richness responded to local habitat diversity, demonstrating niche-based processes (e.g., species-sorting) structure substantial percentages of riverine fish richness.

We also showed that the relative importance of spatial and niche-based processes varies longitudinally along mainstems. For example, spatial processes are likely more important in lower-course reaches with lower habitat diversity but higher accessibility to downriver regional species pools (Ferreira et al., 2019; Peláez \& Pavanelli, 2019). The between-river comparative component of our study indicated these phenomena also apply at a basin scale; higher percentages of non-core species at sites in the Grand River system indicated regional connectivity and dispersal are likely more important in structuring 
communities within systems spanning weak environmental gradients. Unfortunately, few metacommunity-framed studies are set in non-wadeable rivers to corroborate our findings; greater representation in literature may further clarify mechanisms and contingencies of community assembly within free-flowing rivers.

\section{Implications for conserving riverine hotspots}

Increasingly, riverine biodiversity is managed at landscape scales, and conserving hotspots is at the core of many landscape conservation strategies (Smith et al., 2018). However, underlying processes maintaining riverine richness, and thus biodiversity hotspots, are often unclear (Erös, 2017). Our findings suggest some common actions may benefit conserving hotspots in both systems. For example, LRS species comprised large percentages of species $(23-44 \%)$ in hotspots in both rivers, demonstrating the importance of downriver connectivity to riverine fish richness (King et al., 2017). Lower-course river reaches often harbor unique species (Kanno et al., 2012; Miranda et al., 2018), and our results indicate many of these species are likely linked to downriver species pools (Chapter 2, sampling protocols).

Other aspects of conservation planning strategies may need unique tailoring for different systems with varying levels of habitat diversity and connectivity. Habitat diversity contributed to hotspots in both systems, but species-habitat diversity relationships were far stronger in the Meramec River system. Consequently, protecting the narrowly distributed Meramec River hotspot likely depends on prioritizing actions that maintain mid-course habitat diversity, such as minimizing channel modifications and mitigating impacts from intensive upstream land uses (Abell et al., 2017). In contrast, 
preserving hotspots in temporally variable systems with low habitat diversity, such as prairie rivers, may require prioritizing watershed connectivity via targeted barrier removals and modifying dispersal-inhibiting infrastructure (e.g., Perkin \& Gido, 2012; Schumann et al., 2019).

\section{Conclusions}

Our study indicated riverine richness is spatially explicit and highly integrated with both downriver and headwater surrounding species pools. We support contentions of Vitorino Júnior et al. (2016), and López-Delgado et al. (2018) that riverine fishes within non-wadeable rivers are likely organized into metacommunities. Regional connectivity contributed LRS species and headwater species along longitudinal gradients in habitat diversity to generate river-specific profiles of fish richness.

Rivers are among the most globally impacted ecosystems, and relatively few freeflowing rivers remain in industrialized nations (Grill et al., 2019). Given local riverine richness is also regionally sourced, diminished connectivity and habitat diversity may shift and misshapen longitudinal patterns of riverine richness. For example, diminished downriver connectivity could re-center hotspots upriver, and broad habitat homogenization might flatten longitudinal profiles of local richness. Thus, longitudinal profiles of richness could indicate mechanisms shaping richness and the resiliency of riverine macrosystems to stressors operating across scales.

\section{Acknowledgements}


The Missouri Department of Conservation (MDC) funded this research. We thank the following MDC Fisheries Management Biologist and Research Scientists for input on the study design — Dave Herzog, Dr. Vince Travnichek, Matt Combes, Dr. Doug Novinger, Greg Pitchford, Jen Girondo, and Dr. Paul Blanchard. Drs. Amanda Rosenberger, Frank Thompson, and Chris Wikle also provided input on the study design. Bob Hrabik (MDC ichthyologist) helped modify stream-size guilds and assisted with field work. The core field crew consisted of Brandon Brooke and Randy Kramer, and we appreciate the following people for temporary stints - Erin Hassett, Liz Heimer, Christina Kelsay, Rory Mott, Brett Parra, Jason Persinger, Dr. Amanda Rosenberger, and Autom Yount. This study was performed under the auspices of University of Missouri protocol 8532. Any use of trade, firm, or product names is for descriptive purposes only and does not imply endorsement by the U.S. Government. The Missouri Cooperative Fish and Wildlife Research Unit is jointly sponsored by the Missouri Department of Conservation, the University of Missouri, the U.S. Geological Survey, the U.S. Fish and Wildlife Service, and the Wildlife Management Institute.

\section{References}

Abell, R., Lehner, B., Thieme, M., \& Linke, S. (2017). Looking beyond the fenceline: Assessing protection gaps for the world's rivers. Conservation Letters, 10(4), 384-394. https://doi.org/10.1111/conl.12312

Allan, J. D. (2004). Landscapes and riverscapes: The influence of land use on stream ecosystems. Annual Review of Ecology Evolution and Systematics, 35, 257-284. https://doi.org/10.1146/annurev.ecolsys.35.120202.110122 
Argentina, J. E., Freeman, M. C., \& Freeman, B. J. (2010). The response of stream fish to local and reach-scale variation in the occurrence of a benthic aquatic macrophyte. Freshwater Biology, 55(3), 643-653. https://doi.org/Doi 10.1111/J.13652427.2009.02301.X

Astorga, A., Death, R., Death, F., Paavola, R., Chakraborty, M., \& Muotka, T. (2014). Habitat heterogeneity drives the geographical distribution of beta diversity: The case of New Zealand stream invertebrates. Ecology and Evolution, 4(13), 26932702.

Boddy, N. C., Booker, D. J., \& McIntosh, A. R. (2019). Confluence configuration of river networks controls spatial patterns in fish communities. Landscape Ecology, 34(1), 187-201. https://doi.org/10.1007/s10980-018-0763-4

Brown, D. J., \& Coon, T. G. (1994). Abundance and assemblage structure of fish larvae in the lower Missouri River and its tributaries. Transactions of the American Fisheries Society, 123(5), 718-732. https://doi.org/10.1577/15488659(1994)123<0718:AAASOF>2.3.CO;2

Brown, B. L., \& Swan, C. M. (2010). Dendritic network structure constrains metacommunity properties in riverine ecosystems. Journal of Animal Ecology, 79(3), 571-580. https://doi.org/10.1111/j.1365-2656.2010.01668.x

Brown, B. L., Swan, C. M., Auerbach, D. A., Grant, E. H. C., Hitt, N. P., Maloney, K. O., \& Patrick, C. (2011). Metacommunity theory as a multispecies, multiscale framework for studying the influence of river network structure on riverine communities and ecosystems. Journal of the North American Benthological Society, 30(1), 310-327. http://dx.doi.org/10.1899/10-129.1 
Cilleros, K., Allard, L., Vigouroux, R., \& Brosse, S. (2017). Disentangling spatial and environmental determinants of fish species richness and assemblage structure in Neotropical rainforest streams. Freshwater Biology, 62(10), 1707-1720. https://doi.org/10.1111/fwb.12981

Cucherousset, J., Santoul, F., Figuerola, J., \& Céréghino, R. (2008). How do biodiversity patterns of river animals emerge from the distributions of common and rare species? Biological Conservation, 141(12), 2984-2992. https://doi.org/10.1016/j.biocon.2008.09.004

Dodds, W. K., Gido, K., Whiles, M. R., Fritz, K. M., \& Matthews, W. J. (2004). Life on the edge: The ecology of Great Plains prairie streams. Bioscience, 54(3), 205216. https://doi.org/10.1641/0006-3568(2004)054[0205:LOTETE]2.0.CO;2

Erős, T. (2017). Scaling fish metacommunities in stream networks: Synthesis and future research avenues. Community Ecology, 18(1), 72-86. https://doi.org/10.1556/168.2017.18.1.9

Falke, J. A., Bailey, L. L., Fausch, K. D., \& Bestgen, K. R. (2012). Colonization and extinction in dynamic habitats: An occupancy approach for a Great Plains stream fish assemblage. Ecology, 93(4), 858-867. https://doi.org/10.1890/11-1515.1

Fellows, I. (2012). Deducer: a data analysis GUI for R. Journal of Statistical Software, 49 (8), 1-15. 10.18637/jss.v049.i08

Fernandes, C. C., Podos, J., \& Lundberg, J. G. (2004). Amazonian ecology: Tributaries enhance the diversity of electric fishes. Science, 305(5692), 1960-1962. DOI: 10.1126/science. 1101240 
Ferreira, F. C., Souza, U. P., Cetra, M., \& Petrere, M. (2019). Rhithronic and potamonic fishes coexist in wadeable streams under distinct metacommunity processes. Ecology of Freshwater Fish, 28(1), 85-96. https://doi.org/10.1111/eff.12433

Fluker, B. L., Kuhajda, B. R., \& Harris, P. M. (2014). The effects of riverine impoundment on genetic structure and gene flow in two stream fishes in the Mobile River basin. Freshwater Biology, 59(3), 526-543. https://doi.org/10.1111/fwb.12283

Galat D.L., Berry Jr C. R., Peters E.J. \& White R.G. (2005). Missouri River basin. In A.C. Benke \& C.E. Cushing (Eds.), Rivers of North America (pp. 427-464). Oxford, UK: Elsevier Academic Press.

Grenouillet, G., Pont, D., \& Hérissé, C. (2004). Within-basin fish assemblage structure: The relative influence of habitat versus stream spatial position on local species richness. Canadian Journal of Fisheries and Aquatic Sciences, 61(1), 93-102. https://doi.org/10.1139/f03-145

Grill, G., Lehner, B., Thieme, M., Geenen, B., Tickner, D., Antonelli, F., Babu, S., Borrelli, P., Cheng, L., Crochetiere, H., Ehalt Macedo, H., Filgueiras, R., Goichot, M., Higgins, J., Hogan, Z., Lip, B., McClain, M. E., Meng, J., Mulligan, M., ... Zarfl, C. (2019). Mapping the world's free-flowing rivers. Nature, 569(7755), 215-221. https://doi.org/10.1038/s41586-019-1111-9

Grossman G.D., Ratajczak Jr R.E., Farr M.D., Wagner C.M. \& Petty J.T. (2010). Why there are fewer fish upstream? In K.B. Gido \& D.A. Jackson (Eds.), Community ecology of stream fishes: Concepts, approaches, and techniques (pp.63-82).

Bethesda, MD: American Fisheries Society. 
Heino, J., Alahuhta, J., Ala-Hulkko, T., Antikainen, H., Bini, L. M., Bonada, N., Datry, T., Erős, T., Hjort, J., Kotavaara, O., Melo, A. S., \& Soininen, J. (2017). Integrating dispersal proxies in ecological and environmental research in the freshwater realm. Environmental Reviews, 25(3), 334-349. https://doi.org/10.1139/er-2016-0110

Henriques-Silva, R., Logez, M., Reynaud, N., Tedesco, P. A., Brosse, S., JanuchowskiHartley, S. R., Oberdorff, T., \& Argillier, C. (2019). A comprehensive examination of the network position hypothesis across multiple river metacommunities. Ecography, 42(2), 284-294. https://doi.org/10.1111/ecog.03908

Hitt, N. P., \& Angermeier, P. L. (2008). Evidence for fish dispersal from spatial analysis of stream network topology. Journal of the North American Benthological Society, 27(2), 304-320. https://doi.org/10.1899/07-096.1

Hudman, S. P., \& Gido, K. B. (2013). Multi-scale effects of impoundments on genetic structure of creek chub (Semotilus atromaculatus) in the Kansas River basin. Freshwater Biology, 58(2), 441-453. https://doi.org/10.1111/fwb.12079

Hughes, R. M., \& Gammon, J. R. (1987). Longitudinal changes in fish assemblages and water quality in the Willamette River, Oregon. Transactions of the American Fisheries Society, 116(2), 196-209. https://doi.org/10.1577/15488659(1987)116<196:LCIFAA>2.0.CO;2

Jackson, D. A., Peres-Neto, P. R., \& Olden, J. D. (2001). What controls who is where in freshwater fish communities the roles of biotic, abiotic, and spatial factors. 
Canadian Journal of Fisheries and Aquatic Sciences, 58(1), 157-170.

https://doi.org/10.1139/f00-239

Johnson, B. L., Richardson, W. B., \& Naimo, T. J. (1995). Past, present, and future concepts in large river ecology. Bioscience, 134-141. https://doi.org/10.2307/1312552

Kanno, Y., Russ, W. T., Sutherland, C. J., \& Cook, S. B. (2012). Prioritizing aquatic conservation areas using spatial patterns and partitioning of fish community diversity in a near-natural temperate basin: Diversity partitioning of stream fish communities. Aquatic Conservation: Marine and Freshwater Ecosystems, 22(6), 799-812. https://doi.org/10.1002/aqc.2266

King, S., O’Hanley, J. R., Newbold, L. R., Kemp, P. S., \& Diebel, M. W. (2017). A toolkit for optimizing fish passage barrier mitigation actions. Journal of Applied Ecology, 54(2), 599-611. https://doi.org/10.1111/1365-2664.12706

Koel, T. M. (2004). Spatial Variation in Fish Species Richness of the Upper Mississippi River System. Transactions of the American Fisheries Society, 133(4), 984-1003. https://doi.org/10.1577/T03-089.1

Krause, K. P., Wu, C.-L., Chu, M. L., \& Knouft, J. H. (2019). Fish assemblageenvironment relationships suggest differential trophic responses to heavy metal contamination. Freshwater Biology, 64(4), 632-642. https://doi.org/10.1111/fwb.13248

Laub, B. G., Thiede, G. P., Macfarlane, W. W., \& Budy, P. (2018). Evaluating the conservation potential of tributaries for native fishes in the upper Colorado River basin. Fisheries, 43(4), 194-206. https://doi.org/10.1002/fsh.10054 
López-Delgado, E. O., Winemiller, K. O., \& Villa-Navarro, F. A. (2018). Do

metacommunity theories explain spatial variation in fish assemblage structure in a pristine tropical river? Freshwater Biology, fwb.13229.

https://doi.org/10.1111/fwb.13229

Loury, E. K., Ainsley, S. M., Bower, S. D., Chuenpagdee, R., Farrell, T., Guthrie, A. G., Heng, S., Lunn, Z., Mamun, A. A., Oyanedel, R., Rocliffe, S., Satumanatpan, S., \& Cooke, S. J. (2018). Salty stories, fresh spaces: Lessons for aquatic protected areas from marine and freshwater experiences. Aquatic Conservation: Marine and Freshwater Ecosystems, 28(2), 485-500. https://doi.org/10.1002/aqc.2868

Magoulick, D. D., \& Kobza, R. M. (2003). The role of refugia for fishes during drought: A review and synthesis. Freshwater Biology, 48(7), 1186-1198. https://doi.org/10.1046/j.1365-2427.2003.01089.x

Matthews, W.J. (1998). Physical factors within drainages as related to fish assemblages. In W.J. Matthews (Ed.), Patterns in freshwater fish ecology (pp. 264-315). Norwell, MA: Kluwer Academic Publishers.

McCluney, K. E., Poff, N. L., Palmer, M. A., Thorp, J. H., Poole, G. C., Williams, B. S., Williams, M. R., \& Baron, J. S. (2014). Riverine macrosystems ecology: Sensitivity, resistance, and resilience of whole river basins with human alterations. Frontiers in Ecology and the Environment, 12(1), 48-58. https://doi.org/10.1890/120367

McGarvey, D. J., \& Hughes, R. M. (2008). Longitudinal zonation of Pacific Northwest (U.S.A.) fish assemblages and the species-discharge relationship. Copeia, 2008(2), 311-321. https://doi.org/10.1643/CE-07-020 
McGarvey, D. J., \& Ward, G. M. (2008). Scale dependence in the species-discharge relationship for fishes of the southeastern USA. Freshwater Biology, 53(11), 2206-2219. https://doi.org/10.1111/j.1365-2427.2008.02046.x

McKerrow, A. J., Tarr, N. M., Rubino, M. J., \& Williams, S. G. (2018). Patterns of species richness hotspots and estimates of their protection are sensitive to spatial resolution. Diversity and Distributions, 24(10), 1464-1477. https://doi.org/10.1111/ddi.12779

Mee, J. A., Robins, G. L., \& Post, J. R. (2018). Patterns of fish species distributions replicated across three parallel rivers suggest biotic zonation in response to a longitudinal temperature gradient. Ecology of Freshwater Fish, 27(1), 44-61. https://doi.org/10.1111/eff.12322

Meyer, J. L., Strayer, D. L., Wallace, J. B., Eggert, S. L., Helfman, G. S., \& Leonard, N. E. (2007). The contribution of headwater streams to biodiversity in river networks. Journal of the American Water Resources Association, 43(1), 86-103. https://doi.org/10.1111/j.1752-1688.2007.00008.x

Miranda, L. E., Killgore, K. J., \& Slack, W. T. (2018). Spatial organization of fish diversity in a species-rich basin. River Research and Applications, rra.3392. https://doi.org/10.1002/rra.3392

Miyazono, S., \& Taylor, C. M. (2013). Effects of habitat size and isolation on species immigration-extinction dynamics and community nestedness in a desert river system. Freshwater Biology, 58(7), 1303-1312.

https://doi.org/10.1111/fwb.12127 
Oberdorff, T., Guilbert, E., \& Lucchetta, J.-C. (1993). Patterns of fish species richness in the Seine River basin, France. Hydrobiologia, 259(3), 157-167. https://doi.org/10.1007/BF00006595

Osborne, L. L., \& Wiley, M. J. (1992). Influence of tributary spatial position on the structure of warmwater fish communities. Canadian Journal of Fisheries and Aquatic Sciences, 49(4), 671-681. https://doi.org/10.1139/f92-076

Palmer, M. A., Menninger, H. L., \& Bernhardt, E. (2010). River restoration, habitat heterogeneity and biodiversity: A failure of theory or practice? Freshwater Biology, 55(s1), 205-222. https://doi.org/10.1111/j.1365-2427.2009.02372.x

Peipoch, M., Brauns, M., Hauer, F. R., Weitere, M., \& Valett, H. M. (2015). Ecological simplification: Human influences on riverscape complexity. BioScience, 65(11), 1057-1065. https://doi.org/10.1093/biosci/biv120

Peláez, O., \& Pavanelli, C. S. (2019). Environmental heterogeneity and dispersal limitation explain different aspects of $\beta$-diversity in Neotropical fish assemblages. Freshwater Biology, 64(3), 497-505. https://doi.org/10.1111/fwb.13237

Perkin, J. S., \& Gido, K. B. (2012). Fragmentation alters stream fish community structure in dendritic ecological networks. Ecological Applications, 22(8), 2176-2187. https://doi.org/10.1890/12-0318.1

Pflieger W.L. (1989). Aquatic community classification system for Missouri. Jefferson City, MO: Missouri Department of Conservation.

Pflieger, W.L. (1997). The Fishes of Missouri. Jefferson City, MO: Missouri Department of Conservation. 
Rabeni, C. F., \& Jacobson, R. B. (1993). The importance of fluvial hydraulics to fishhabitat restoration in low-gradient alluvial streams. Freshwater Biology, 29(2), 211-220. https://doi.org/10.1111/j.1365-2427.1993.tb00758.x

Rice, S. P. (2017). Tributary connectivity, confluence aggradation and network biodiversity. Geomorphology, 277, 6-16. https://doi.org/10.1016/j.geomorph.2016.03.027

Roberts J.H. \& Hitt N.P. (2010). Longitudinal structure in temperate stream fish communities: evaluating conceptual models with temporal data. In K.B. Gido \& D.A. Jackson (Eds.), Community ecology of stream fishes: Concepts, approaches, and techniques (pp. 281-299). Bethesda, MD: American Fisheries Society.

Rosenfeld, J. S. (2017). Developing flow-ecology relationships: Implications of nonlinear biological responses for water management. Freshwater Biology, 62(8), 13051324. https://doi.org/10.1111/fwb.12948

Sarremejane, R., Mykrä, H., Bonada, N., Aroviita, J., \& Muotka, T. (2017). Habitat connectivity and dispersal ability drive the assembly mechanisms of macroinvertebrate communities in river networks. Freshwater Biology, 62(6), 1073-1082. https://doi.org/10.1111/fwb.12926

Schaefer, J. F., \& Kerfoot, J. R. (2004). Fish assemblage dynamics in an adventitious stream: A landscape perspective. American Midland Naturalist, 151(1), 134-145. https://doi.org/10.1674/0003-0031(2004)151[0134:FADIAA]2.0.CO;2

Schlosser I.J. (1987). A conceptual framework for fish communities in small warmwater streams. In W.J. Matthews and D.C. Heins (Eds.). Community and evolutionary 
ecology of North American stream fishes (17-24), Norman, OK: University of Oklahoma Press.

Schmera, D., Árva, D., Boda, P., Bódis, E., Bolgovics, Á., Borics, G., Csercsa, A., Deák, C., Krasznai, E. Á., Lukács, B. A., Mauchart, P., Móra, A., Sály, P., Specziár, A., Süveges, K., Szivák, I., Takács, P., Tóth, M., Várbíró, G., ... Erős, T. (2018). Does isolation influence the relative role of environmental and dispersal-related processes in stream networks? An empirical test of the network position hypothesis using multiple taxa. Freshwater Biology, 63(1), 74-85. https://doi.org/10.1111/fwb.12973

Schmidt, B. V., \& Schaefer, J. (2018). Ecological and landscape effects on genetic distance in an assemblage of headwater fishes. Ecology of Freshwater Fish, 27(2), 617-631. https://doi.org/10.1111/eff.12375

Schumann, D. A., Haag, J. M., Ellensohn, P. C., Redmond, J. D., \& Graeb, K. N. B. (2019). Restricted movement of prairie fishes in fragmented riverscapes risks ecosystem structure being ratcheted downstream. Aquatic Conservation: Marine and Freshwater Ecosystems, 29(2), 235-244. https://doi.org/10.1002/aqc.2996

Smale, M. A., \& Rabeni, C. F. (1995). Influences of hypoxia and hyperthermia on fish species composition in headwater streams. Transactions of the American Fisheries Society, 124(5), 711-725. https://doi.org/10.1577/15488659(1995)124<0711:IOHAHO>2.3.CO;2

Smith, R. J., Bennun, L., Brooks, T. M., Butchart, S. H., Cuttelod, A., Di Marco, M., Ferrier, S., Fishpool, L. D., Joppa, L., Juffe-Bignoli, D., Knight, A. T., Lamoreux, J. F., Langhammer, P., Possingham, H. P., Rondinini, C., Visconti, P., Watson, J. 
E., Woodley, S., Boitani, L., ... Scaramuzza, C. A. de M. (2018). Synergies between the key biodiversity area and systematic conservation planning approaches. Conservation Letters, e12625. https://doi.org/10.1111/conl.12625

Sowa, S. P., Annis, G., Morey, M. E., \& Diamond, D. D. (2007). A gap analysis and comprehensive conservation strategy for riverine ecosystems of Missouri. Ecological Monographs, 77(3), 301-334. https://doi.org/10.1890/06-1253.1

Stoll, S., Sundermann, A., Lorenz, A. W., Kail, J., \& Haase, P. (2013). Small and impoverished regional species pools constrain colonisation of restored river reaches by fishes: Colonisation of restored river reaches by fishes. Freshwater Biology, 58(4), 664-674. https://doi.org/10.1111/fwb.12068

Swan, C. M., \& Brown, B. L. (2017). Metacommunity theory meets restoration: Isolation may mediate how ecological communities respond to stream restoration. Ecological Applications, 27(7), 2209-2219. https://doi.org/10.1002/eap.1602

Taylor, C. M., \& Warren Jr, M. L. (2001). Dynamics in species composition of stream fish assemblages: Environmental variability and nested subsets. Ecology, 82(8), 2320-2330. https://doi.org/10.1890/00129658(2001)082[2320:DISCOS]2.0.CO;2

Thornbrugh, D. J., \& Gido, K. B. (2010). Influence of spatial positioning within stream networks on fish assemblage structure in the Kansas River basin, USA. Canadian Journal of Fisheries and Aquatic Sciences, 67(1), 143-156. https://doi.org/10.1139/f09-169

Tonkin, J. D., Altermatt, F., Finn, D. S., Heino, J., Olden, J. D., Pauls, S. U., \& Lytle, David. A. (2018). The role of dispersal in river network metacommunities: 
Patterns, processes, and pathways. Freshwater Biology, 63(1), 141-163. https://doi.org/10.1111/fwb.13037

Troia, M. J., Kaz, A. L., Niemeyer, J. C., \& Giam, X. (2019). Species traits and reduced habitat suitability limit efficacy of climate change refugia in streams. Nature Ecology \& Evolution, 3(9), 1321-1330. https://doi.org/10.1038/s41559-019-09707

Troia, M. J., \& McManamay, R. A. (2020). Biogeographic classification of streams using fish community- and trait-environment relationships. Diversity and Distributions, 26(1), 108-125. https://doi.org/10.1111/ddi.13001

USEPA (2013). National rivers and streams assessment 2013 -2014: Field operations manual-Non-wadeable (EPA-841-B-12-009a). Washington, DC: Office of Water, U.S. Environmental Protection Agency.

USGS (2014). NLCD 2011 land cover. Sioux Falls, SD: United States Geological Survey.

USGS \& USEPA. (2012). National hydrography dataset plus - NHDPlus v.2.10. Sioux Falls, SD: United States Environmental Protection Agency \& United States Geological Survey.

Van Looy, K., Tonkin, J. D., Floury, M., Leigh, C., Soininen, J., Larsen, S., Heino, J., LeRoy Poff, N., Delong, M., Jähnig, S. C., Datry, T., Bonada, N., Rosebery, J., Jamoneau, A., Ormerod, S. J., Collier, K. J., \& Wolter, C. (2019). The three Rs of river ecosystem resilience: Resources, recruitment, and refugia. River Research and Applications, 35(2), 107-120. https://doi.org/10.1002/rra.3396 
Vander Vorste R., McElmurray P., Bell S., Eliason K.M. \& Brown B.L. (2017). Does stream size really explain biodiversity patterns in lotic systems? A aall for mechanistic explanations. Diversity 9, 26. https://doi.org/10.3390/d9030026

Vannote, R. L., Minshall, G. W., Cummins, K. W., Sedell, J. R., \& Cushing, C. E. (1980). The river continuum concept. Canadian Journal of Fisheries and Aquatic Sciences, 37(1), 130-137. https://doi.org/10.1139/f80-017

Vitorino Júnior, O. B., Fernandes, R., Agostinho, C. S., \& Pelicice, F. M. (2016). Riverine networks constrain $\beta$-diversity patterns among fish assemblages in a large Neotropical river. Freshwater Biology, 61(10), 1733-1745. https://doi.org/10.1111/fwb.12813

Whitney, J. E., Gido, K. B., Martin, E. C., \& Hase, K. J. (2015). The first to arrive and the last to leave: Colonisation and extinction dynamics of common and rare fishes in intermittent prairie streams. Freshwater Biology. https://doi.org/10.1111/fwb.12668

Worthington, T. A., Echelle, A. A., Perkin, J. S., Mollenhauer, R., Farless, N., Dyer, J. J., Logue, D., \& Brewer, S. K. (2018). The emblematic minnows of the North American Great Plains: A synthesis of threats and conservation opportunities. Fish and Fisheries, 19(2), 271-307. https://doi.org/10.1111/faf.12254

Xenopoulos, M. A., \& Lodge, D. M. (2006). Going with the flow: Using speciesdischarge relationships to forecast losses in fish biodiversity. Ecology, 87(8), 1907-1914. https://doi.org/10.1890/00129658(2006)87[1907:GWTFUS]2.0.CO;2 
Xenopoulos, M. A., Lodge, D. M., Alcamo, J., Märker, M., Schulze, K., \& Vuuren, D. P. V. (2005). Scenarios of freshwater fish extinctions from climate change and water withdrawal. Global Change Biology, 11(10), 1557-1564. https://doi.org/10.1111/j.1365-2486.2005.001008.x

Zbinden, Z. D., \& Matthews, W. J. (2017). Beta diversity of stream fish assemblages: Partitioning variation between spatial and environmental factors. Freshwater Biology, 62(8), 1460-1471. https://doi.org/10.1111/fwb.12960

Zurr A.F., Ieno E.N., Walker N.J., Saveliev A.A. \& Smith, G.M. (2009). Things are not always linear: Additive modeling. In A.F. Zurr, E.N. Ieno, N.J. Walker, A.A. Saveliev \& G.M. Smith (Eds.), Mixed effects models and extensions in ecology with $R$ (pp. 35-69). Springer. 


\section{Tables}

Table 4.1. Habitat variables recorded at 21 transects at each of the 22 sites in the Grand $(N=10)$ and Meramec $(N=12)$ rivers in 2016 (Missouri, USA). Habitat diversity at sites were from transformed or raw (“-”) variables based on average dispersion of transects around site centroids in principal component space. Pearson product-moment correlations $(r)$ were between standard deviations of habitat variables at sites and habitat diversity or discharge. Positive correlations indicate multivariate habitat diversity and discharge represent variability in specific habitat variables. No sampled macrophytes prevented us from calculating correlations in the Grand River system.

\begin{tabular}{lcccccc}
\hline & & & \multicolumn{2}{c}{ Habitat diversity $(r)$} & \multicolumn{2}{c}{ Discharge $(r)$} \\
\cline { 5 - 6 } \multicolumn{1}{c}{ Variable } & Unit & Transformation & Grand & Meramec & Grand & Meramec \\
\hline Boulder & Count & $\log (\mathrm{x}+0.1)$ & 0.56 & 0.66 & 0.66 & 0.04 \\
Depth & $\mathrm{m}$ & $\log (\mathrm{x}+0.1)$ & 0.63 & 0.71 & 0.15 & -0.39 \\
Large wood & Count & $\log (\mathrm{x}+0.1)$ & 0.69 & 0.66 & 0.66 & -0.48 \\
Macrophyte & Ordinal & $\log (\mathrm{x}+0.1)$ & - & 0.70 & - & -0.44 \\
Off-channel & $\%$ & $\log (\mathrm{x}+0.1)$ & 0.37 & 0.49 & 0.02 & 0.05 \\
Pool & Count & - & 0.75 & 0.61 & 0.11 & -0.36 \\
Shoal & Count & - & 0.61 & 0.80 & 0.10 & -0.49 \\
Substrate size & Ordinal & - & 0.40 & 0.17 & 0.21 & 0.27 \\
Velocity & $\mathrm{m} \mathrm{s}^{-1}$ & $\sqrt{x}$ & 0.72 & 0.83 & -0.04 & -0.44 \\
\hline
\end{tabular}


Table 4.2. Parameters $(\mathrm{K})$ and evaluation criteria of competing linear regression models (hypotheses) explaining fish species richness of three stream-size fish guilds in the Grand $(N=10)$ and Meramec $(N=12)$ rivers in 2016 (Missouri, USA). Lower delta Akaike Information Criterion values $(\triangle \mathrm{AICc})$ and higher weights $\left(w_{i}\right)$ are better-supported models. Exempting intercept-only (null) models, each model included both an intercept $\left(\hat{\beta}_{0}\right)$ and slope $\left(\hat{\beta}_{1}\right) \pm$ standard errors (SE). Habitat diversity was the average dispersion of habitat transects around multivariate centroids. Downriver isolation is the watercourse distance $(\mathrm{km})$ to the mouth of each river. Headwater $(\mathrm{HW})$ isolation (basinwide) is the mean distance $(\mathrm{km})$ to $2^{\text {nd }}-3^{\text {rd }}$-order outlets within each river system. Headwater isolation (directional) is basinwide headwater isolation penalized for upstream movements.

Headwater sources are numbers of $2^{\text {nd }}-3^{\text {rd }}$-order outlets within specified watercourse distances of sites $(\mathrm{km})$.

\begin{tabular}{|c|c|c|c|c|c|c|}
\hline Hypothesis & $\begin{array}{c}\text { Log- } \\
\text { K likelihood } \\
\text { Grand }\end{array}$ & $\begin{array}{l}\Delta \text { AICc } \\
\text { Core sp }\end{array}$ & $\begin{array}{c}w_{i} \\
\text { pecies }\end{array}$ & $R^{2}$ & $\hat{\beta}_{0} \pm \mathrm{SE}$ & $\hat{\beta}_{1} \pm \mathrm{SE}$ \\
\hline Habitat diversity & -18.5 & 0.0 & 0.47 & 0.37 & $17.0 \pm 0.5$ & $1.3 \pm 0.6$ \\
\hline Interce & -20.9 & 0.4 & 0.38 & $<0.01$ & $17.0 \pm 0.6$ & - \\
\hline Down & -20.3 & 3.6 & 0.08 & 0.11 & $17.0 \pm 0.7$ & $-0.7 \pm 0.7$ \\
\hline HW i & -20.4 & 3.7 & 0.08 & 0.10 & $17.0 \pm 0.7$ & $-0.6 \pm 0.7$ \\
\hline \multicolumn{7}{|c|}{ Meramec: Core species } \\
\hline Tabit & -33.8 & 0.0 & 0.85 & 0.58 & $46.0 \pm 1.3$ & 5.01 .0 \\
\hline HW i & -35.9 & 4.1 & 0.11 & 0.41 & $46.0 \pm 1.5$ & $-4.2 \pm 1.6$ \\
\hline Interc & -39.0 & 6.7 & 0.03 & 0.00 & $46.0 \pm$ & \\
\hline ow & -38.5 & 9.2 & 0.01 & 0.09 & $46.0 \pm 1.9$ & $2.0 \pm 2.0$ \\
\hline \multicolumn{7}{|c|}{ Grand: Large-river species } \\
\hline ow & -20.8 & 0.0 & 0.62 & 0.44 & 12. & $-1.8 \pm 0.7$ \\
\hline Inter & -23.7 & 1 . & 0.29 & $<0.01$ & $12.5 \pm$ & \\
\hline Iabi & -22.7 & 3.9 & 0.09 & 0.18 & $12.5 \pm 0.8$ & $1.1 \pm 0.9$ \\
\hline \multicolumn{7}{|c|}{ Meramec: Large-river species } \\
\hline own & -24.7 & 0.0 & 1.00 & 0.91 & $9.8 \pm 0.6$ & $-6.4 \pm 0.6$ \\
\hline nter & -39.4 & 25.7 & 0.00 & 0.00 & $9.8 \pm 1.9$ & - \\
\hline abit: & -37.7 & 26.1 & 0.00 & 0.24 & $9.8 \pm 1.8$ & $-3.3 \pm 1.9$ \\
\hline \multicolumn{7}{|c|}{ Grand: Headwater species } \\
\hline HW sc & -7.8 & 0.0 & 0.91 & 0.85 & $3.9 \pm 0.2$ & $1.3 \pm 0.2$ \\
\hline $\mathrm{HW}$ i & -10.6 & 5.6 & 0.06 & 0.74 & $3.9 \pm 0.2$ & $-1.2 \pm 0.3$ \\
\hline $\begin{array}{l}\mathrm{HW} \text { i } \\
\text { (direc }\end{array}$ & 2 & 6.5 & 0.04 & 0.72 & 0.3 & $-1.2 \pm 0.3$ \\
\hline Intercept-only (null) & -17.4 & 14.9 & 0.00 & 0.00 & $3.9 \pm 0.5$ & 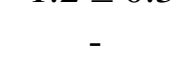 \\
\hline Discharge & -15.5 & 15.5 & 0.00 & 0.31 & $3.9 \pm 0.4$ & $-0.8 \pm 0.4$ \\
\hline Habit & -17.2 & 18.7 & 0.00 & 0.04 & $3.9 \pm 0.5$ & $0.3 \pm 0.5$ \\
\hline HW sources $(5 \mathrm{~km})$ & -17.2 & 18.9 & 0.00 & 0.03 & $3.9 \pm 0.5$ & $0.2 \pm 0.5$ \\
\hline
\end{tabular}


Table 4.2 continued: support for hypotheses explaining fish richness

Log-

$\begin{array}{llllll}\text { Hypothesis } & \mathrm{K} \text { likelihood } \triangle \mathrm{AICc} & w_{i} & R^{2} & \hat{\beta}_{0} \pm \mathrm{SE} & \hat{\beta}_{1 \pm \mathrm{SE}}\end{array}$

Meramec: Headwater species

$\begin{array}{llllllll}\text { Discharge } & 2 & -21.3 & 0.0 & 0.45 & 0.32 & 2.0 \pm 0.5 & -1.0 \pm 0.5\end{array}$

$\begin{array}{llllllll}\text { Intercept-only (null) } & 1 & -23.6 & 0.9 & 0.29 & 0.00 & 2.0 \pm 0.5 & -\end{array}$

$\mathrm{HW}$ isolation

$\begin{array}{llllllll}\text { (directional) } & 2 & -23.2 & 3.7 & 0.07 & 0.07 & 2.0 \pm 0.5 & 0.5 \pm 0.6\end{array}$

$\begin{array}{llllllll}\text { HW sources }(5 \mathrm{~km}) & 2 & -23.4 & 4.1 & 0.06 & 0.04 & 2.0 \pm 0.5 & 0.3 \pm 0.6\end{array}$

$\begin{array}{llllllll}\text { HW sources }(25 \mathrm{~km}) & 2 & -23.6 & 4.5 & 0.05 & 0.01 & 2.0 \pm 0.5 & -0.1 \pm 0.6\end{array}$

$\begin{array}{llllllll}\text { Habitat diversity } & 2 & -23.6 & 4.5 & 0.05 & 0.01 & 2.0 \pm 0.5 & 0.1 \pm 0.6\end{array}$

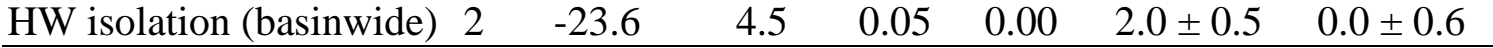


Table 4.3. Longitudinal positions and spatial extents of mainstem sites with fish species richness $\geq 75$ th percentile ("hotspot threshold") in the Grand ( $N=8$ mainstem sites) and Meramec ( $N=10$ mainstem sites) rivers in 2016 (Missouri, USA). Hotspot sites were first defined solely by core species and then with additional stream-size guilds (Appendix 4.1). Inclusion of headwater and/or large-river specialist species caused hotspot zones to shift and narrow relative to hotspots defined by core species (except core + headwater species). Positions are watercourse distances to respective mouths of each river. DS and US are downriver and upriver limits of hotspot zones, respectively.

\begin{tabular}{|c|c|c|c|c|c|c|c|c|}
\hline $\begin{array}{c}\text { Stream-size } \\
\text { guilds }\end{array}$ & $\begin{array}{l}\text { Hotspot } \\
\text { threshold } \\
\text { (species) }\end{array}$ & $\begin{array}{c}\text { Hotspo } \\
\text { sites }\end{array}$ & $\begin{array}{c}\text { Mean } \\
\text { position } \\
(\mathrm{km}) \\
\end{array}$ & $\begin{array}{c}\text { Hotspot } \\
\text { extent } \\
(\mathrm{km})\end{array}$ & $\begin{array}{c}\text { DS } \\
\text { limit } \\
(\mathrm{km})\end{array}$ & $\begin{array}{c}\text { US } \\
\text { limit } \\
(\mathrm{km})\end{array}$ & $\begin{array}{l}\text { Hotspot } \\
\text { shift }\end{array}$ & $\begin{array}{c}\text { Hotspot } \\
\text { extent }\end{array}$ \\
\hline \multicolumn{9}{|c|}{ Grand River } \\
\hline Core & 18 & 5 & 83 & 120 & 24 & 145 & - & - \\
\hline Core + headwater & 23 & 2 & 96 & 15 & 89 & 104 & Upriver & Narrowed \\
\hline Core + large-river & 32 & 3 & 72 & 80 & 24 & 104 & Downriver & Narrowed \\
\hline All species & 35 & 3 & 72 & 80 & 24 & 104 & Downriver & Narrowed \\
\hline \multicolumn{9}{|c|}{ Meramec River } \\
\hline Core & 49 & 5 & 102 & 132 & 53 & 184 & - & - \\
\hline Core + headwater & 51 & 6 & 121 & 162 & 53 & 215 & Upriver & Widened \\
\hline Core + large-river & 61 & 4 & 59 & 61 & 30 & 91 & Downriver & Narrowed \\
\hline All species & 62 & 3 & 69 & 39 & 53 & 91 & Downriver & Narrowed \\
\hline
\end{tabular}




\section{Figures}

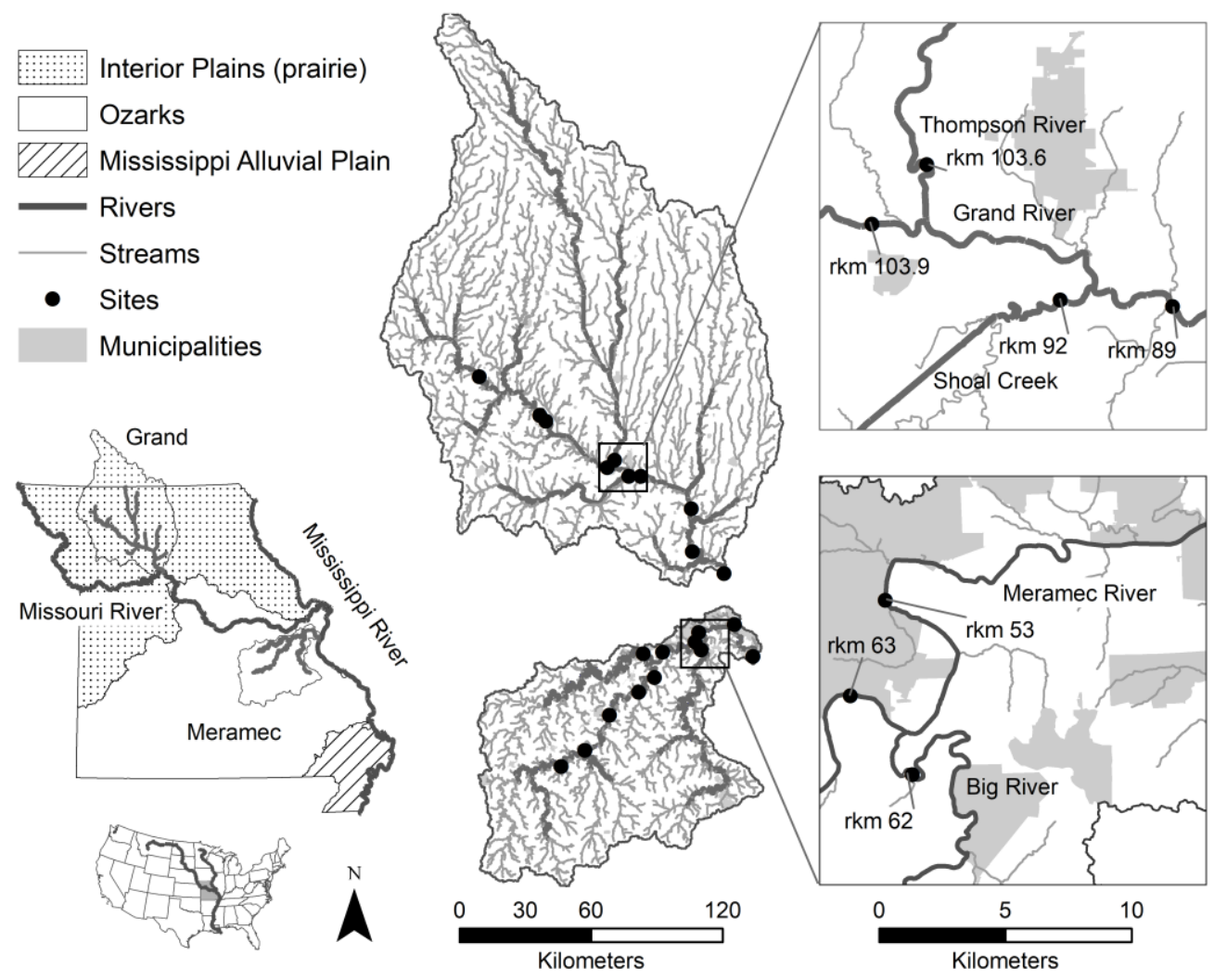

Figure 4.1. Non-wadeable mainstem and tributary branch sites in the Grand $(N=10$, Prairie region) and Meramec $(N=12$, Ozark region) river systems surveyed for fish in 2016 (Missouri, USA). Insets: sites extended at least $1 \mathrm{~km}$ away from major confluences, and watercourse distances (river km) are upriver of each river system's mouth. Gray areas are municipal boundaries indicative of urban development. 

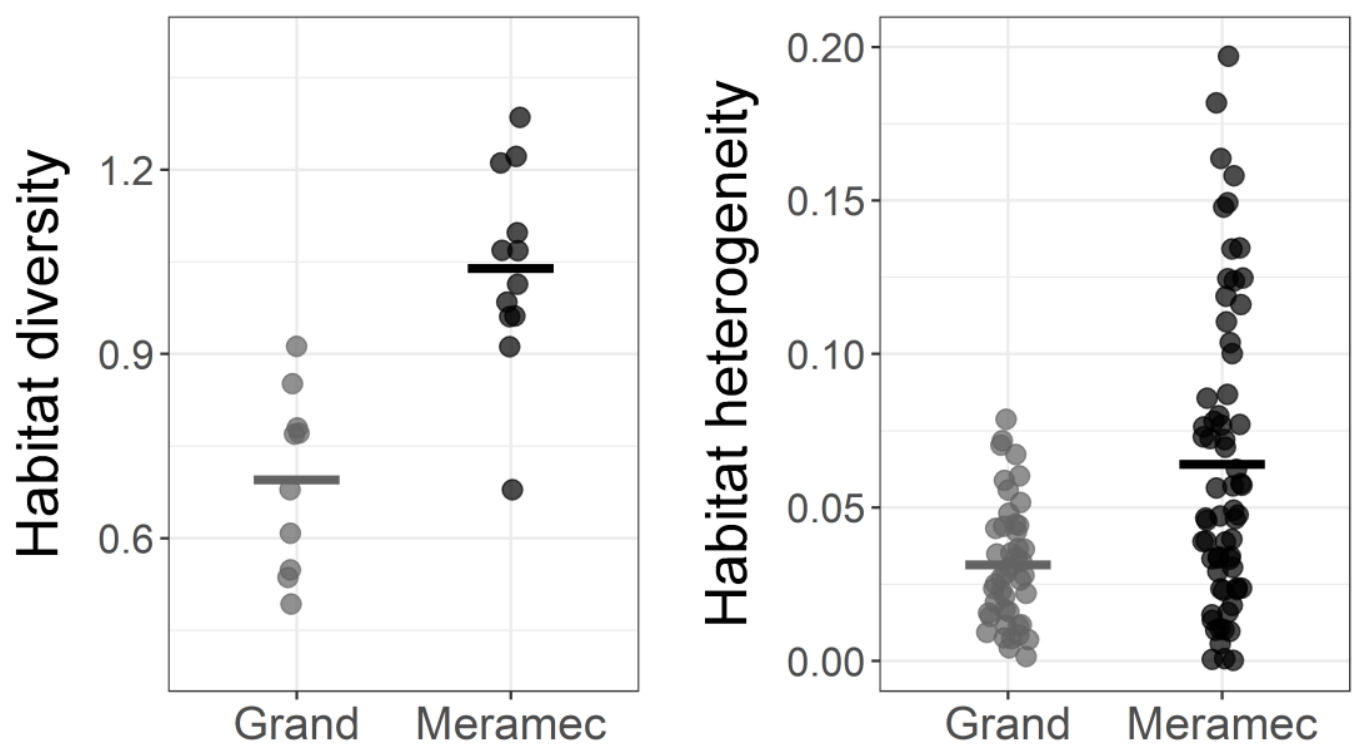

Figure 4.2. Left: within-site habitat diversity at sites in the Grand $(N=10)$ and Meramec $(N=12)$ rivers in 2016 (Missouri, USA). We calculated habitat diversity by first performing a principal component (PC) analysis of nine habitat variables summarized to 21 transects. Habitat diversity at each site was the average Euclidean distance of transects to a site's centroid in PC space (units = PC axes). Right: among-site habitat heterogeneity (dissimilarity) was the pairwise Euclidean distances among site habitat centroids in PC space (y-axis units = Euclidean distances in PC space). Horizontal bars are averages. 


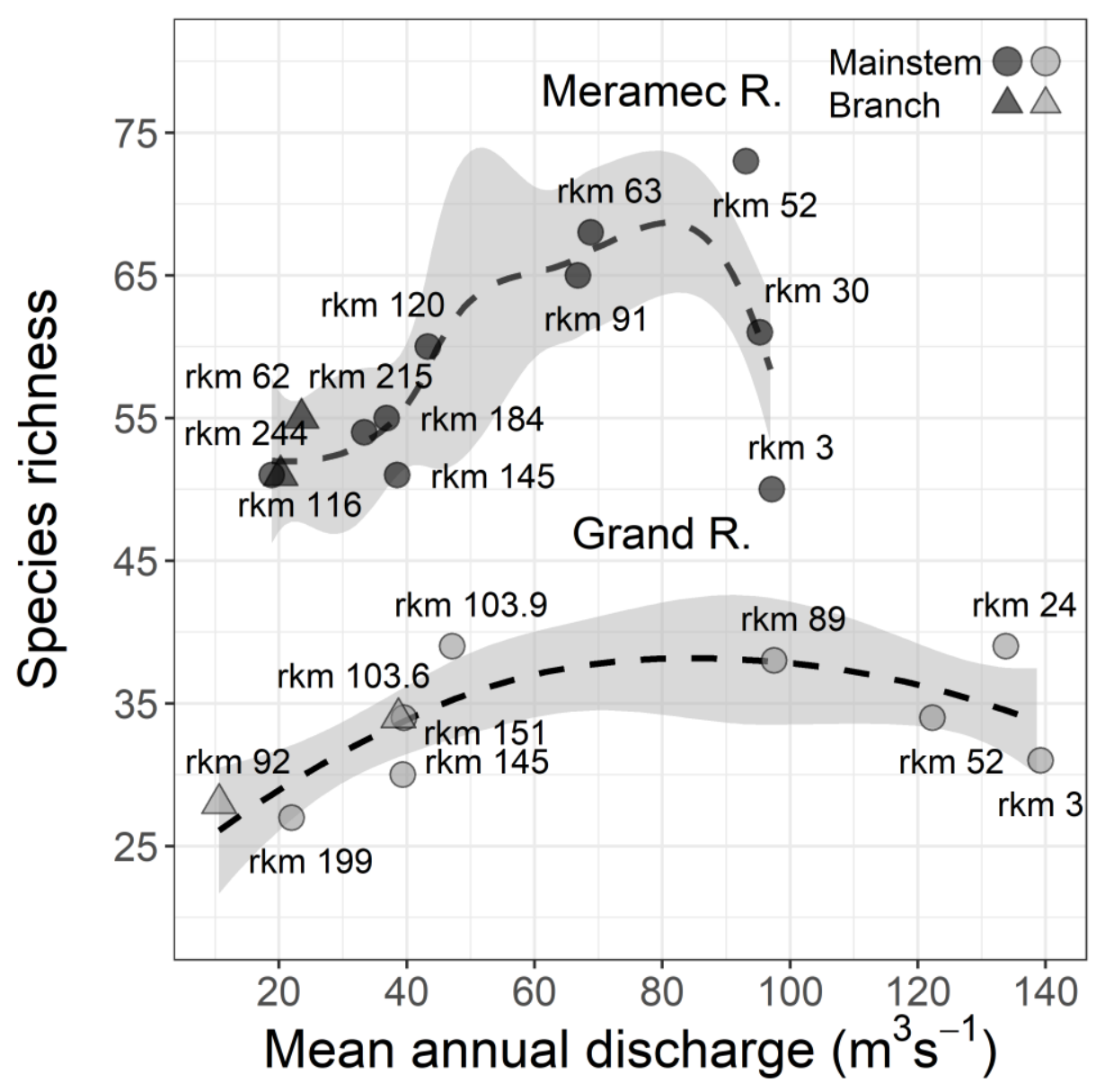

Figure 4.3. Species-discharge relationships between mean annual discharge and fish species richness in the Grand ( $N=10$ sites; bottom) and Meramec ( $N=12$ sites; top) rivers from 2016 (Missouri, USA). Pseudo- $R^{2}$ values (squared Pearson correlation $[r]$ between observed and predicted) are from Local Regression Smoothers (dashed lines \pm $90 \%$ confidence intervals) and were 0.60 and 0.71 for models in Grand and Meramec rivers, respectively. Labels are watercourse distances $(\mathrm{km})$ from the Missouri (Grand R.) and Mississippi (Meramec R.) rivers. 

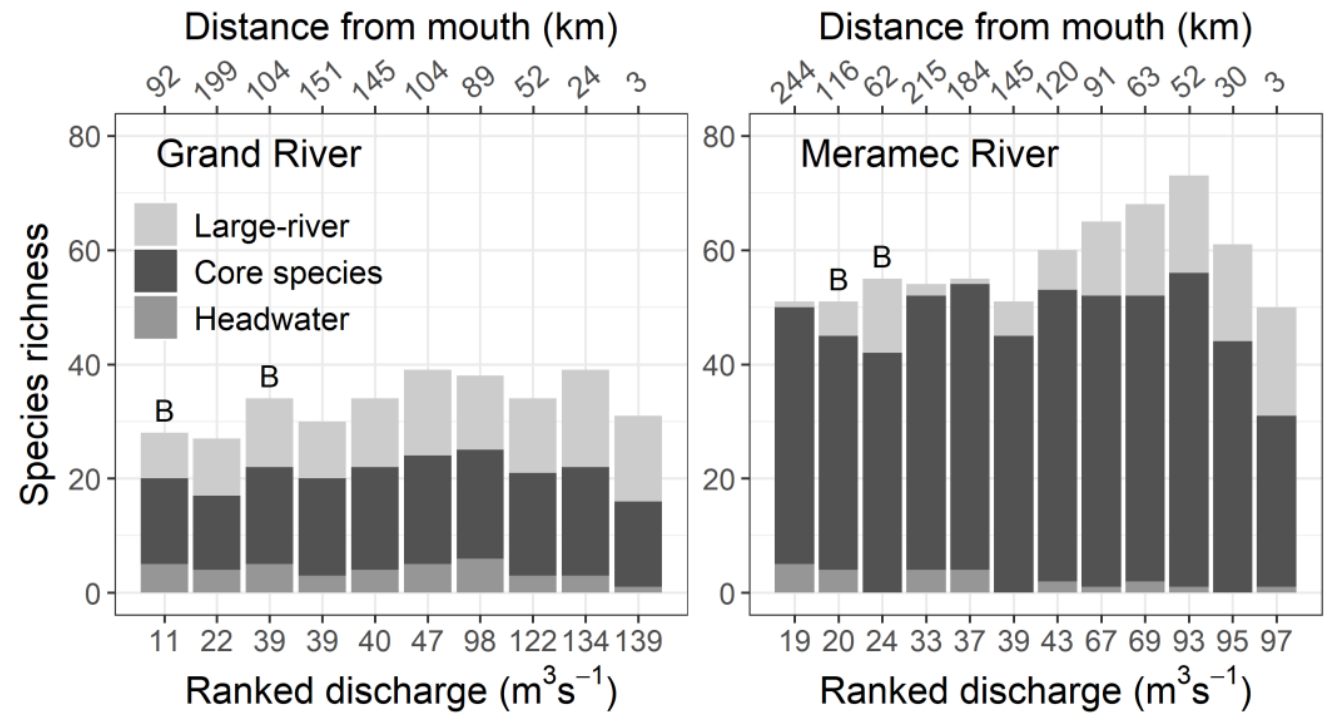

Figure 4.4. Relationships between mean annual discharge and fish species richness within three stream-size preference guilds (Appendix 4.1) for the Grand (left, $N=10$ sites) and Meramec (right, $N=12$ sites) rivers in 2016 (Missouri, USA). The top horizontal axis is watercourse distance upriver from a respective river mouth $(\mathrm{km})$. " $\mathrm{B}$ " = sites in tributary branches. 

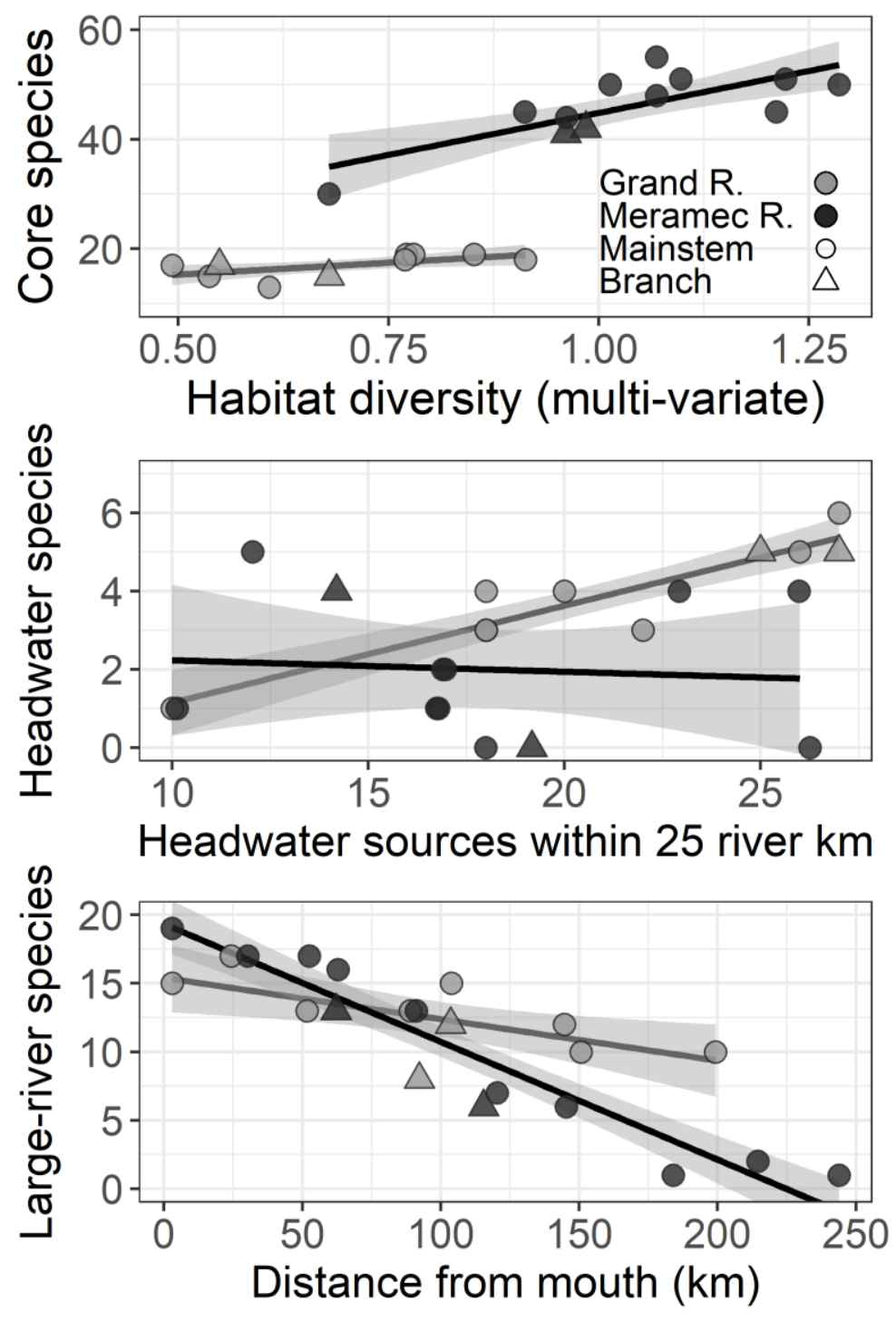

Figure 4.5. Habitat and spatial predictors of fish species richness $( \pm 90 \%$ confidence interval) for three river-size guilds in the Grand ( $N=10$ sites) and Meramec $(N=12$ sites) rivers in 2016 (Missouri, USA). Habitat diversity and distance-from-mouth were best-supported hypotheses explaining richness for core and large-river specialist species in both river systems, respectively. Headwater sources within $25 \mathrm{~km}$ of sites was the bestsupported hypothesis explaining headwater species for the Grand River system, but not the Meramec River system. Classifications for headwater and large-river species are in Appendix 4.1. 

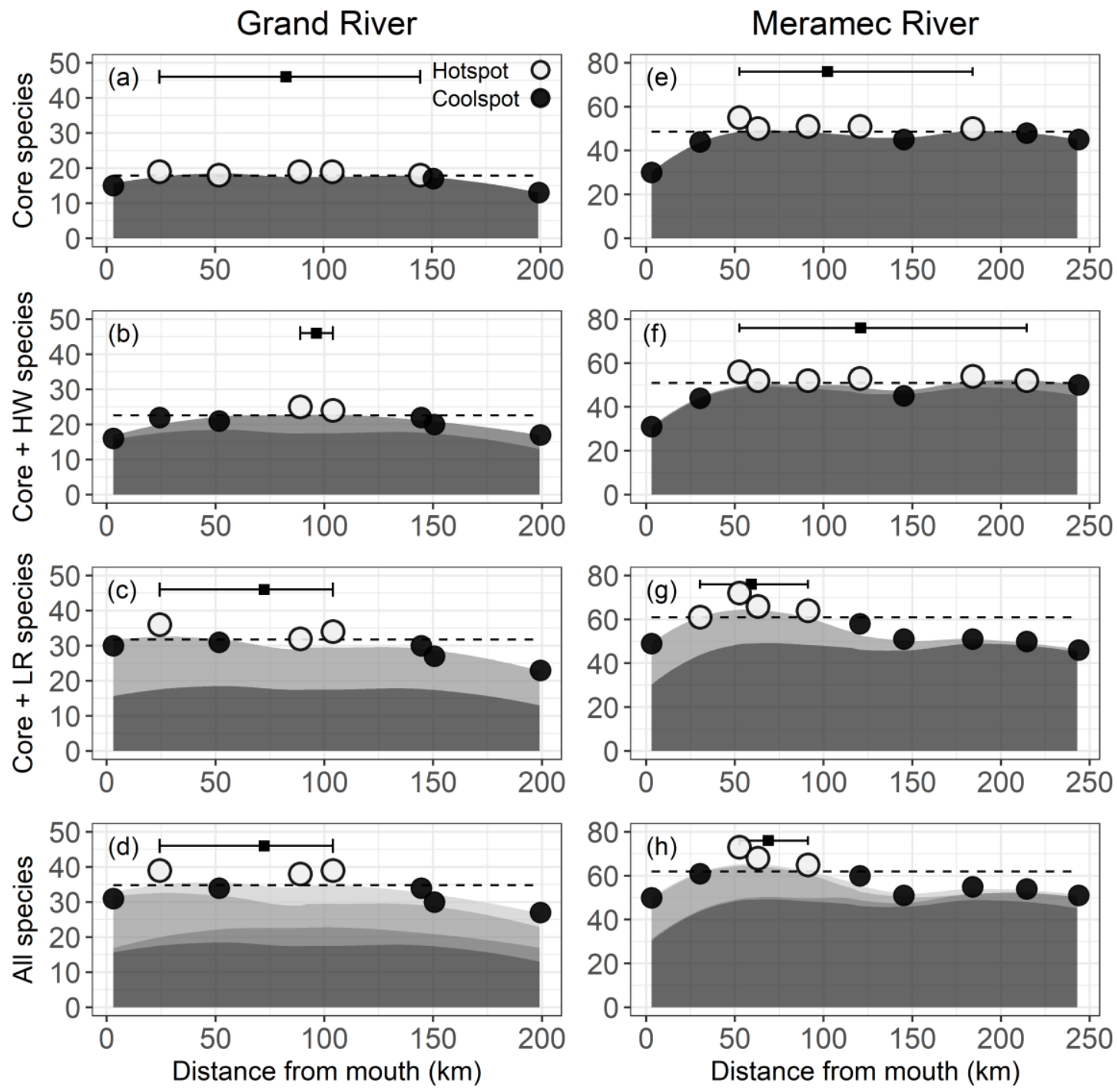

Figure 4.6. Longitudinal profiles of fish species richness for three stream-size guilds in the Grand ( $N=8$ mainstem sites) and Meramec ( $N=10$ mainstem sites) rivers in 2016 (Missouri, USA). Profiles are Local Regression Smoothers (LOESS) between distance from river mouth and richness. Hotspots (white) and coolspots (black) are sites where observed richness was $\geq 75$ th and $<75$ th percentile of predicted richness (dashed line), respectively. Shading reflects longitudinal richness profiles constructed from different stream-size guilds. Profiles were developed for four combinations of stream-size guilds: $(\mathrm{a}, \mathrm{e})$ core species, $(\mathrm{b}, \mathrm{f})$ core + headwater $(\mathrm{HW})$ species, $(\mathrm{c}, \mathrm{g})$ core + large-river specialist (LR) species, and $(\mathrm{d}, \mathrm{h})$ all species. Horizontal error bars show means and ranges of sites within hotspot zones. 


\section{Appendices}

Appendix 4.1. Memberships of fish species to three stream-size preference guilds for the Grand and Meramec river systems (Missouri, USA). Headwater fishes were likely sourced in $\leq 3^{\text {rd }}$-order streams. Their membership designations were slightly modified from the "headwater zone" (Pflieger 1989) to include updated records from Missouri Department of Conservation unpublished databases (Fish community database pre-2010; Resource Assessment and Monitoring program 1994-2014). Large-river specialist species in tributaries likely dispersed from, and/or have high population connectivity to, the Missouri (Grand R.) or Mississippi (Meramec R.) rivers. Large-river specialist designations were slightly modified from the "Big River" fishes group (Pflieger 1989) to include diadromous species, introduced large-river species, and lowland species associated with the Mississippi River floodplain. Species were either detected (1) or undetected (0) by our sampling in 2016, or unknown to occur (-) within a river system.

\begin{tabular}{|c|c|c|c|}
\hline Species & $\begin{array}{l}\text { Stream-size } \\
\text { guild }\end{array}$ & $\begin{array}{l}\text { Grand } \\
\text { River }\end{array}$ & $\begin{array}{c}\text { Meramec } \\
\text { River }\end{array}$ \\
\hline Banded Darter Etheostoma zonale & Core & - & 1 \\
\hline Bigeye Chub Hybopsis amblops & Core & - & 1 \\
\hline Bigeye Shiner Notropis boops & Core & - & 1 \\
\hline Black Crappie Pomoxis nigromaculatus & Core & 1 & 1 \\
\hline Black Redhorse Moxostoma duquesnei & Core & 0 & 1 \\
\hline Blackspotted Topminnow Fundulus olivaceus & Core & - & 1 \\
\hline Bleeding Shiner Luxilus zonatus & Core & - & 1 \\
\hline Bluegill Lepomis macrochirus & Core & 1 & 1 \\
\hline Bluntnose Minnow Pimephales notatus & Core & 1 & 1 \\
\hline Brook Silverside Labidesthes sicculus & Core & 0 & 1 \\
\hline Carmine Shiner Notropis percobromus & Core & - & 1 \\
\hline Channel Catfish Ictalurus punctatus & Core & 1 & 1 \\
\hline Chestnut Lamprey Ichthyomyzon castaneus & Core & - & 1 \\
\hline Common Carp Cyprinus carpio & Core & 1 & 1 \\
\hline Crystal Darter Crystallaria asprella & Core & - & 1 \\
\hline Flathead Catfish Pylodictis olivaris & Core & 1 & 1 \\
\hline Freckled Madtom Noturus nocturnus & Core & - & 1 \\
\hline Freshwater Drum Aplodinotus grunniens & Core & 1 & 1 \\
\hline Gilt Darter Percina evides & Core & - & 1 \\
\hline Gizzard Shad Dorosoma cepedianum & Core & 1 & 1 \\
\hline Golden Redhorse Moxostoma erythrurum & Core & 0 & 1 \\
\hline Golden Shiner Notemigonus crysoleucas & Core & 1 & 1 \\
\hline Gravel Chub Erimystax x-punctatus & Core & - & 1 \\
\hline Green Sunfish Lepomis cyanellus & Core & 1 & 1 \\
\hline Greenside Darter Etheostoma blennioides & Core & - & 1 \\
\hline Highfin Carpsucker Carpiodes velifer & Core & 0 & 1 \\
\hline Largemouth Bass Micropterus salmoides & Core & 1 & 1 \\
\hline
\end{tabular}




\begin{tabular}{|c|c|c|c|}
\hline \multicolumn{4}{|c|}{ Appendix 4.1 continued: species stream-size preference memberships } \\
\hline Species & $\begin{array}{l}\text { Stream-size } \\
\text { guild }\end{array}$ & $\begin{array}{l}\text { Grand } \\
\text { River }\end{array}$ & $\begin{array}{c}\text { Meramec } \\
\text { River }\end{array}$ \\
\hline Largescale Stoneroller Campostoma oligolepis & Core & - & 1 \\
\hline Logperch Percina caprodes & Core & 0 & 1 \\
\hline Longear Sunfish Lepomis megalotis & Core & 0 & 1 \\
\hline Longnose Gar Lepisosteus osseus & Core & 1 & 1 \\
\hline Meramec Saddled Darter Etheostoma erythrozonum & Core & - & 1 \\
\hline Mimic Shiner Notropis volucellus & Core & - & 1 \\
\hline Mooneye Hiodon tergisus & Core & 0 & 1 \\
\hline Northern Hogsucker Hypentelium nigricans & Core & - & 1 \\
\hline Northern Studfish Fundulus catenatus & Core & - & 1 \\
\hline Orangespotted Sunfish Lepomis humilis & Core & 1 & 1 \\
\hline Quillback Carpiodes cyprinus & Core & 0 & 1 \\
\hline Rainbow Darter Etheostoma caeruleum & Core & - & 1 \\
\hline Red Shiner Cyprinella lutrensis & Core & 1 & 1 \\
\hline Redear Sunfish Lepomis microlophus & Core & - & 1 \\
\hline River Redhorse Moxostoma carinatum & Core & - & 1 \\
\hline Rock Bass Ambloplites rupestris & Core & - & 1 \\
\hline Sand Shiner Notropis stramineus & Core & 1 & 1 \\
\hline Shorthead Redhorse Moxostoma macrolepidotum & Core & 1 & 1 \\
\hline Silver Redhorse Moxostoma anisurum & Core & - & 1 \\
\hline Slenderhead Darter Percina phoxocephala & Core & - & 1 \\
\hline Smallmouth Bass Micropterus dolomieu & Core & - & 1 \\
\hline Smallmouth Buffalo Ictiobus bubalus & Core & 1 & 1 \\
\hline Spotfin Shiner Cyprinella spiloptera & Core & - & 1 \\
\hline Spotted Bass Micropterus punctulatus & Core & 0 & 1 \\
\hline Spotted Sucker Minytrema melanops & Core & - & 1 \\
\hline Steelcolor Shiner Cyprinella whipplei & Core & - & 1 \\
\hline Stonecat Noturus flavus & Core & 1 & 1 \\
\hline Striped Shiner Luxilus chrysocephalus & Core & - & 1 \\
\hline Suckermouth Minnow Phenacobius mirabilis & Core & 1 & 0 \\
\hline Walleye Sander vitreus & Core & 1 & 1 \\
\hline Warmouth Lepomis gulosus & Core & - & 1 \\
\hline Wedgespot Shiner Notropis greenei & Core & - & 1 \\
\hline Western Mosquitofish Gambusia affinis & Core & 1 & 1 \\
\hline White Crappie Pomoxis annularis & Core & 1 & 1 \\
\hline Yellow Bullhead Ameiurus natalis & Core & 1 & 0 \\
\hline Banded Sculpin Cottus carolinae & Headwater & - & 1 \\
\hline Bigmouth Shiner Notropis dorsalis & Headwater & 1 & 0 \\
\hline Black Bullhead Ameiurus melas & Headwater & 0 & 0 \\
\hline Blackside Darter Percina maculata & Headwater & - & 0 \\
\hline Blackstripe Topminnow Fundulus notatus & Headwater & - & 0 \\
\hline
\end{tabular}




\begin{tabular}{|c|c|c|c|}
\hline \multicolumn{4}{|c|}{ Appendix 4.1 continued: species stream-size preference memberships } \\
\hline Species & $\begin{array}{l}\text { Stream-size } \\
\text { guild }\end{array}$ & $\begin{array}{l}\text { Grand } \\
\text { River }\end{array}$ & $\begin{array}{c}\text { Meramec } \\
\text { River }\end{array}$ \\
\hline Brassy Minnow Hybognathus hankinsoni & Headwater & 0 & - \\
\hline Central Stoneroller Campostoma anomalum & Headwater & 1 & 1 \\
\hline Common Shiner Luxilus cornutus & Headwater & 0 & - \\
\hline Creek Chub Semotilus atromaculatus & Headwater & 1 & 1 \\
\hline Creek Chubsucker Erimyzon claviformis & Headwater & - & 0 \\
\hline Fantail Darter Etheostoma flabellare & Headwater & - & 1 \\
\hline Fathead Minnow Pimephales promelas & Headwater & 1 & 0 \\
\hline Grass Pickerel Esox americanus & Headwater & - & 1 \\
\hline Hornyhead Chub Nocomis biguttatus & Headwater & - & 1 \\
\hline *Johnny Darter Etheostoma nigrum & Headwater & 1 & - \\
\hline Least Brook Lamprey Lampetra aepyptera & Headwater & - & 0 \\
\hline Mottled Sculpin Cottus bairdii & Headwater & - & 1 \\
\hline Northern Brook Lamprey Ichthyomyzon fossor & Headwater & - & 0 \\
\hline Orangethroat Darter Etheostoma spectabile & Headwater & 0 & 1 \\
\hline Ozark Minnow Notropis nubilus & Headwater & - & 1 \\
\hline Redfin Shiner Lythrurus umbratilis & Headwater & 0 & 0 \\
\hline Silverjaw Minnow Notropis buccatus & Headwater & - & 1 \\
\hline Slender Madtom Noturus exilis & Headwater & - & 1 \\
\hline Southern Redbelly Dace Chrosomus erythrogaster & Headwater & - & 1 \\
\hline Stippled Darter Etheostoma punctulatum & Headwater & - & 0 \\
\hline Topeka Shiner Notropis topeka & Headwater & 0 & - \\
\hline Trout-Perch Percopsis omiscomaycus & Headwater & 0 & - \\
\hline White Sucker Catostomus commersonii & Headwater & 1 & 0 \\
\hline Alabama Shad Alosa alabamae & Large-river & 0 & 1 \\
\hline Alligator Gar Atractosteus spatula & Large-river & - & 0 \\
\hline American Eel Anguilla rostrata & Large-river & 0 & 1 \\
\hline Bighead Carp Hypophthalmichthys nobilis & Large-river & 1 & 1 \\
\hline Bigmouth Buffalo Ictiobus cyprinellus & Large-river & 1 & 1 \\
\hline Black Buffalo Ictiobus niger & Large-river & 1 & 1 \\
\hline Blue Catfish Ictalurus furcatus & Large-river & 1 & 1 \\
\hline Blue Sucker Cycleptus elongatus & Large-river & 1 & 1 \\
\hline Bowfin Amia calva & Large-river & - & 1 \\
\hline Bullhead Minnow Pimephales vigilax & Large-river & 1 & 1 \\
\hline Channel Shiner Notropis wickliffi & Large-river & 0 & 1 \\
\hline Emerald Shiner Notropis atherinoides & Large-river & 1 & 1 \\
\hline Flathead Chub Platygobio gracilis & Large-river & 0 & 0 \\
\hline Ghost Shiner Notropis buchanani & Large-river & 0 & 1 \\
\hline Goldeye Hiodon alosoides & Large-river & 1 & 1 \\
\hline Grass Carp Ctenopharyngodon idella & Large-river & 1 & 1 \\
\hline Lake Sturgeon Acipenser fulvescens & Large-river & 0 & 0 \\
\hline
\end{tabular}




\begin{tabular}{|c|c|c|c|}
\hline \multicolumn{4}{|c|}{ Appendix 4.1 continued: species stream-size preference memberships } \\
\hline Species & $\begin{array}{l}\text { Stream-size } \\
\text { guild }\end{array}$ & $\begin{array}{l}\text { Grand } \\
\text { River }\end{array}$ & $\begin{array}{c}\text { Meramec } \\
\text { River }\end{array}$ \\
\hline Mississippi Silvery Minnow Hybognathus nuchalis & Large-river & - & 0 \\
\hline Mud Darter Etheostoma asprigene & Large-river & - & 1 \\
\hline Paddlefish Polyodon spathula & Large-river & 0 & 0 \\
\hline Pallid Sturgeon Scaphirhynchus albus & Large-river & 0 & 0 \\
\hline Plains Minnow Hybognathus placitus & Large-river & 1 & 0 \\
\hline River Carpsucker Carpiodes carpio & Large-river & 1 & 1 \\
\hline River Darter Percina shumardi & Large-river & - & 1 \\
\hline River Shiner Notropis blennius & Large-river & 0 & 1 \\
\hline Sauger Sander canadensis & Large-river & 0 & 1 \\
\hline Shoal Chub Macrhybopsis hyostoma & Large-river & 1 & 1 \\
\hline Shortnose Gar Lepisosteus platostomus & Large-river & 1 & 1 \\
\hline Shovelnose Sturgeon Scaphirhynchus platorynchus & Large-river & 1 & 1 \\
\hline Sicklefin Chub Macrhybopsis meeki & Large-river & 0 & 0 \\
\hline Silver Carp Hypophthalmichthys molitrix & Large-river & 1 & 1 \\
\hline Silver Chub Macrhybopsis storeriana & Large-river & 1 & 1 \\
\hline Silver Lamprey Ichthyomyzon unicuspis & Large-river & 0 & 1 \\
\hline Silverband Shiner Notropis shumardi & Large-river & 0 & 0 \\
\hline Skipjack Herring Alosa chrysochloris & Large-river & 1 & 1 \\
\hline Spottail Shiner Notropis hudsonius & Large-river & - & 0 \\
\hline Sturgeon Chub Macrhybopsis gelida & Large-river & 0 & 0 \\
\hline Threadfin Shad Dorosoma petenense & Large-river & 0 & 0 \\
\hline Western Sand Darter Ammocrypta clara & Large-river & - & 1 \\
\hline Western Silvery Minnow Hybognathus argyritis & Large-river & 0 & 0 \\
\hline White Bass Morone chrysops & Large-river & 1 & 1 \\
\hline Yellow Bass Morone mississippiensis & Large-river & 0 & 1 \\
\hline
\end{tabular}

* Johnny Darters are specialized for headwaters in the Grand River system, but not the Meramec River system where the species is common in larger streams and rivers (Pflieger 1997). 
Appendix 4.2. Means (standard deviation) for habitat variables summarized to transects $(N=21$ transects per site) at sites in the Grand and Meramec river systems in 2016 (Missouri, USA). Distances are to the mouths of each system.

\begin{tabular}{|c|c|c|c|c|c|c|c|c|c|}
\hline $\begin{array}{c}\text { Location } \\
\text { (rkm) }\end{array}$ & $\begin{array}{c}\text { Boulder } \\
\text { (count) }\end{array}$ & $\begin{array}{l}\text { Depth } \\
\text { (m) }\end{array}$ & $\begin{array}{c}\text { Large } \\
\text { wood } \\
\text { (count) }\end{array}$ & $\begin{array}{c}\text { Macro- } \\
\text { phytes } \\
\text { (ordinal) }\end{array}$ & $\begin{array}{c}\text { Off } \\
\text { channel } \\
(\%)\end{array}$ & $\begin{array}{c}\text { Pool } \\
\text { (count) }\end{array}$ & $\begin{array}{l}\text { Shoal } \\
\text { (count) }\end{array}$ & $\begin{array}{c}\text { Sub- } \\
\text { strate } \\
\text { (ordinal) }\end{array}$ & $\begin{array}{c}\text { Velocity } \\
\left(\mathrm{m} \mathrm{s}^{-1}\right)\end{array}$ \\
\hline \multicolumn{10}{|c|}{ Grand River } \\
\hline 3 & $0.6(1.9)$ & $2.7(0.5)$ & $0.5(0.7)$ & $0.0(0.0)$ & $0(0)$ & $4.8(1.1)$ & $0.0(0.0)$ & $1.1(0.3)$ & $0.1(0.0)$ \\
\hline 24 & $1.7(4.4)$ & $1.4(0.8)$ & $0.7(1$. & $0.0(0.0)$ & $0(0)$ & $1.0(2.0)$ & $0.7(1.8)$ & $1.8(0.3)$ & $0.2(0.1)$ \\
\hline 52 & $1.4(3.9)$ & 1. & 0 & $0.0(0.0)$ & $1(3)$ & $1.4(2.3)$ & $1.7(2.4)$ & $1.8(0.3)$ & $0.4(0.1)$ \\
\hline 89 & $0.4(1.7)$ & $0.8(0$ & 1.0 & $0.0(0.0)$ & $1(2)$ & $0.5(1.5)$ & $1.2(2.2)$ & $1.9(0.3)$ & $0.3(0.1)$ \\
\hline b 92 & $0.4(1.7)$ & 1.0 & 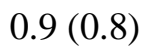 & $0.0)$ & $0(0)$ & $3.3(2.4)$ & $0.0(0.0)$ & $1.4(0.4)$ & $0.1(0.1)$ \\
\hline b103.6 & $0.0(0.2)$ & & & 0) & $0(1)$ & $0.0(0.0)$ & $0.6(2.0)$ & $1.9(0.1)$ & $0.3(0.1)$ \\
\hline 103.9 & $0.0(0.0)$ & 0.7 & 0.5( & $0.0(0.0)$ & $0(0)$ & $1.4(2.3)$ & $1.0(2.0)$ & $1.8(0.1)$ & $0.3(0.1)$ \\
\hline 145 & $0.4(0.9)$ & $0.8(0$ & $0.3(0$ & $0.0(0.0)$ & $1(3)$ & $1.0(2.0)$ & $0.8(1.7)$ & $1.9(0.4)$ & $0.2(0.1)$ \\
\hline 151 & $0.0(0.0)$ & $0.6(0$ & $0.2(0$. & $0.0(0.0)$ & $0(0)$ & $0.2(1.1)$ & $0.3(1.3)$ & $2.1(0.3)$ & $0.3(0.1)$ \\
\hline 199 & $0.1(0.7)$ & 0.4 & 0 . & $0.0(0.0)$ & $0(1)$ & $0.2(1.1)$ & $0.7(1.8)$ & $2.0(0.2)$ & $0.3(0.1)$ \\
\hline Mean & $0.5(1.5)$ & $1.0(0$. & 0.5 & $0.0(0.0)$ & $0(0)$ & $1.4(1.6)$ & $0.7(1.5)$ & $1.8(0.3)$ & $0.3(0.1)$ \\
\hline \multicolumn{10}{|c|}{ Meramec River } \\
\hline 3 & $1.3(3.3)$ & $3.5(0$ & $0.4(0$. & $0.0(0.0)$ & $4(5)$ & $5.0(0.0)$ & $0.0(0.0)$ & $2.2(0.4)$ & $0.0(0.0)$ \\
\hline 30 & $2.6(3.4)$ & $1.8(0.6)$ & $0.7(0$. & $0.0(0.0)$ & $2(4)$ & $3.3(2.4)$ & $1.0(1.8)$ & $3.0(0.6)$ & $0.2(0.1)$ \\
\hline 53 & $4.0(4.6)$ & $1.2(0.4)$ & $0.5(0$ & $0.9(1.1)$ & $7(13)$ & $1.2(2.2)$ & $1.4(2.3)$ & $3.0(0.4)$ & $0.3(0.1)$ \\
\hline${ }^{\mathrm{b}} 62$ & $1.8(2.4)$ & $1.0(0$. & $0.8(0$ & $0.9(1.1)$ & $0(0)$ & $1.7(2.4)$ & $1.5(2.2)$ & $3.0(0.5)$ & $0.3(0.2)$ \\
\hline 63 & $3.7(4.3)$ & $0.9(0$ & 0.5( & $1.2(1.1)$ & $2(6)$ & $0.5(1.5)$ & $1.3(2.0)$ & $3.1(0.4)$ & $0.4(0.1)$ \\
\hline 91 & $4.3(7.0)$ & $1.1(0.4)$ & $0.9(1.3)$ & $1.0(0.9)$ & $3(5)$ & $1.4(2.2)$ & $1.4(2.2)$ & $2.8(0.4)$ & $0.3(0.2)$ \\
\hline b 116 & $0.3(1.1)$ & $0.7(0.3$ & $0.6(1$. & $0.5(0.7)$ & $3(8)$ & $1.7(2.4)$ & $1.2(1.9)$ & $3.0(0.3)$ & $0.2(0.1)$ \\
\hline 120 & $7.1(8.4)$ & $1.2(0.7)$ & $0.8(0$. & $1.1(1.1)$ & $11(18)$ & $2.8(2.5)$ & $1.5(2.1)$ & $3.0(0.5)$ & $0.3(0.2)$ \\
\hline 145 & $3.9(6.6)$ & $0.9(0.3)$ & $1.0(1$. & $1.2(1.0)$ & $9(18)$ & $0.9(1.8)$ & $1.7(2.3)$ & $2.8(0.4)$ & $0.3(0.1)$ \\
\hline 184 & $8.0(10.5)$ & $0.7(0.4)$ & $1.0(1.6)$ & $1.1(0.9)$ & $12(20)$ & $0.7(1.8)$ & $2.4(2.6)$ & $2.9(0.5)$ & $0.4(0.2)$ \\
\hline 215 & $4.0(8.3)$ & $0.9(0.4)$ & $0.6(0.8$ & $0.7(0.9)$ & $5(13)$ & $1.4(2.3)$ & $1.5(2.4)$ & $2.8(0.5)$ & $0.3(0.1)$ \\
\hline 244 & $3.8(4.2)$ & $0.7(0.2)$ & $0.6(0.7$ & $1.2(0.5)$ & $5(13)$ & $0.5(1.5)$ & $1.0(1.9)$ & $2.8(0.3)$ & $0.2(0.1)$ \\
\hline Mean & $3.7(5.4)$ & $1.2(0.4)$ & $0.7(1.0)$ & $0.8(0.8)$ & $5(10)$ & $1.8(1.9)$ & $1.3(2.0)$ & $2.9(0.4)$ & $0.3(0.1)$ \\
\hline
\end{tabular}

${ }^{\mathrm{b}}$ branch sites. $\mathrm{km}=92$ Shoal Creek, 103.6 Thompson River, 62 Big River, 116 Bourbeuse River 
Appendix 4.3. Raw data for sites in the Grand $(N=10)$ and Meramec $(N=12)$ river systems in 2016 (Missouri, USA). Headwater (HW) sources were counts of $2^{\text {nd }}$ - and $3^{\text {rd }}$ order stream outlets within specified distances. System connectivity is mean distance of sites to $2^{\text {nd }}-3^{\text {rd }}-$ order stream outlets across each river system. Upriver distances were penalized $20 \%$ (distance x $1.2 \mathrm{~km}$ ) for directional (system) connectivity. LRS = largeriver specialist species (spp.). Abbreviations: Spp. = species, conn $=$ connectivity.

\begin{tabular}{|c|c|c|c|c|c|c|c|c|c|c|}
\hline $\begin{array}{c}\text { Location } \\
\text { (rkm) }\end{array}$ & $\begin{array}{l}\text { Total } \\
\text { spp. }\end{array}$ & $\begin{array}{l}\text { Core } \\
\text { spp. }\end{array}$ & $\begin{array}{l}\text { LRS } \\
\text { spp. }\end{array}$ & $\begin{array}{l}\text { HW } \\
\text { spp. }\end{array}$ & $\begin{array}{l}\text { Dis- } \\
\text { charge } \\
\left(\mathrm{m}^{3} \mathrm{~s}^{-1}\right)\end{array}$ & $\begin{array}{l}\text { Habitat } \\
\text { diversity }\end{array}$ & $\begin{array}{c}\mathrm{HW} \\
\text { sources } \\
(5 \mathrm{~km})\end{array}$ & $\begin{array}{c}\text { HW } \\
\text { sources } \\
(25 \mathrm{~km}) \\
\end{array}$ & $\begin{array}{c}\text { System } \\
\text { conn. } \\
(\mathrm{km})\end{array}$ & $\begin{array}{l}\text { Directional } \\
\text { conn. } \\
(\mathrm{km})\end{array}$ \\
\hline \multicolumn{11}{|c|}{ Grand River } \\
\hline 3 & 31 & 15 & 15 & 1 & 139 & 0.54 & 3 & 10 & 182 & 182 \\
\hline 24 & 39 & 19 & 17 & 3 & 134 & 0.85 & 4 & 18 & 160 & 160 \\
\hline 52 & 34 & 18 & 13 & 3 & 122 & 0.91 & 3 & 22 & 138 & 138 \\
\hline 89 & 38 & 19 & 13 & 6 & 98 & 0.78 & 6 & 27 & 116 & 118 \\
\hline b 92 & 28 & 15 & 8 & 5 & 11 & 0.68 & 4 & 27 & 115 & 117 \\
\hline${ }^{b} 103.6$ & 34 & 17 & 12 & 5 & 39 & 0.55 & 1 & 25 & 113 & 115 \\
\hline 103.9 & 39 & 19 & 15 & 5 & 47 & 0.77 & 1 & 26 & 112 & 115 \\
\hline 145 & 34 & 18 & 12 & 4 & 40 & 0.77 & 1 & 20 & 122 & 130 \\
\hline 151 & 30 & 17 & 10 & 3 & 39 & 0.49 & 1 & 18 & 124 & 132 \\
\hline 199 & 27 & 13 & 10 & 4 & 22 & 0.61 & 2 & 18 & 144 & 159 \\
\hline \multicolumn{11}{|c|}{ Meramec River } \\
\hline 3 & 50 & 30 & 19 & 1 & 97 & 0.68 & 6 & 10 & 207 & 208 \\
\hline 30 & 61 & 44 & 17 & 0 & 95 & 0.96 & 4 & 18 & 181 & 181 \\
\hline 53 & 73 & 55 & 17 & 1 & 93 & 1.07 & 4 & 17 & 161 & 162 \\
\hline${ }^{\mathrm{b}} 62$ & 55 & 42 & 13 & 0 & 24 & 0.98 & 1 & 19 & 155 & 156 \\
\hline 63 & 68 & 50 & 16 & 2 & 69 & 1.01 & 2 & 17 & 153 & 154 \\
\hline 91 & 65 & 51 & 13 & 1 & 67 & 1.10 & 3 & 17 & 144 & 147 \\
\hline b 116 & 51 & 41 & 6 & 4 & 20 & 0.96 & 4 & 14 & 145 & 150 \\
\hline 120 & 60 & 51 & 7 & 2 & 43 & 1.22 & 1 & 17 & 141 & 146 \\
\hline 145 & 51 & 45 & 6 & 0 & 39 & 1.21 & 2 & 26 & 144 & 152 \\
\hline 184 & 55 & 50 & 1 & 4 & 37 & 1.29 & 7 & 23 & 154 & 167 \\
\hline 215 & 54 & 48 & 2 & 4 & 33 & 1.07 & 3 & 26 & 166 & 182 \\
\hline 244 & 51 & 45 & 1 & 5 & 19 & 0.91 & 2 & 12 & 182 & 203 \\
\hline
\end{tabular}

${ }^{\mathrm{b}}$ branch sites: $\mathrm{rkm}=92$ Shoal Creek, 103.6 Thompson River, 62 Big River, 116 Bourbeuse River 
Appendix 4.4. Relationships among fish and habitat diversity (core species) or dispersal source (headwater, large-river specialist species) for mainstem sites along the Grand $(N=$ 8 sites) and Meramec ( $N=10$ sites) rivers sampled in 2016 (Missouri, USA). The dispersal source for large-river species is the mouth of respective rivers. See Fig. 4.5 for direct linear relationships.
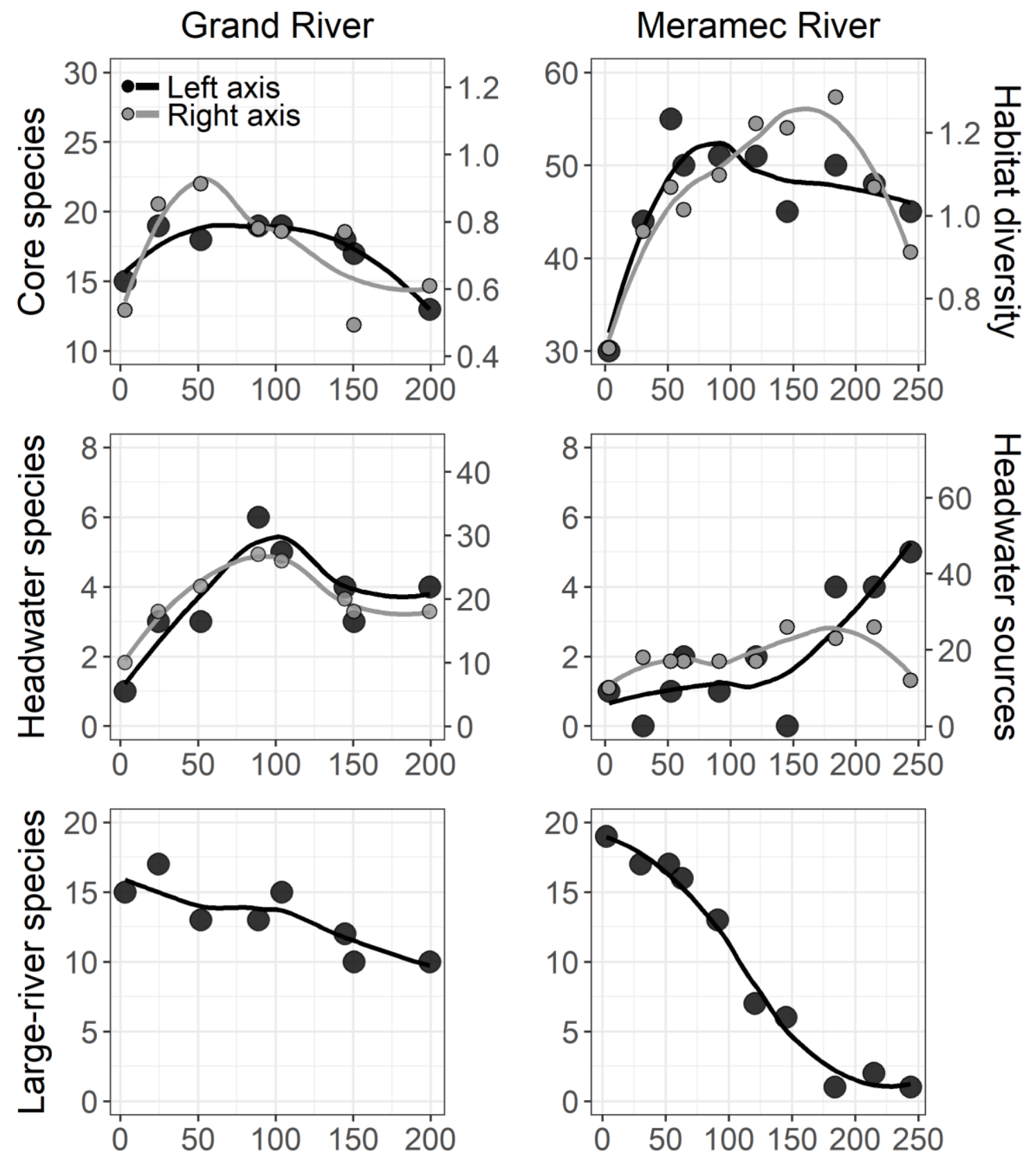

Distance from mouth $(\mathrm{km})$ 


\section{CHAPTER 5: CONCLUSIONS AND FUTURE RESEARCH DIRECTIONS}

\section{Conclusions}

I presented results from two of the larger coordinated fish-survey efforts of nonwadeable rivers to date. Altogether, I addressed a mixture of applied and basic research questions benefitting management of rivers and their biota. I had two broad directives from the Missouri Department of Conservation (MDC): i) improve methods for measuring riverine fish richness and ii) examine the roles of non-wadeable rivers for supporting both riverine and broader fish populations. MDC has been a forerunner in funding science to improve natural-resources management, particularly with landscapescale conservation and planning (e.g., Sowa, Annis, Morey, \& Diamond, 2007). Thus, it was inevitable that after decades of standardized sampling within Missouri's wadeable streams and great rivers, Missouri's mid-sized rivers would emerge as critical conservation gaps within Missouri's riverscapes. Although the geographical scope of this research is limited, its findings have broad implications beyond Missouri because the magnitude and complexity of rivers present sampling challenges for investigators worldwide (Erős, Kuehne, Dolezsai, Sommerwerk, \& Wolter, 2019; Flotemersch et al., 2011). Consequently, rivers and riverine fishes are global knowledge and conservation gaps (Cooke, Paukert, \& Hogan, 2012; Thorp, 2014). Below I highlight primary conclusions, management takeaways, and theoretical advancements from this dissertation. I listed at the bottom of this chapter potential research directions that would build on this dissertation's primary findings.

The timing of this research coincided with a period of growing awareness that local population and community patterns in freshwater systems often result from regional 
phenomena - especially dispersal from neighboring and distant locations within watersheds (Hugueny, Oberdorff, \& Tedesco, 2010). This awareness has been formulated into three important and emerging concepts that are especially relevant to riverine population and community ecology: i) fish life cycles often require distinct habitat patches spanning broad spatial scales (i.e., the riverscape concept; Fausch, Torgersen, Baxter, \& Li, 2002; Schlosser, 1991), ii) varying movements and habitat requirements of individuals result in freshwater communities being assembled from both regional- and local-scale processes (i.e., the metacommunity framework; Brown et al., 2011; Leibold et al., 2004), and iii) idiosyncratic disturbance regimes, network configurations, and resources within watersheds give rise to quantifiable basin-wide properties (i.e., watersheds as riverine macrosystems; McCluney et al., 2014). Although rivers are conceptually and spatially at the centers of these concepts, surprisingly few studies underpinning these concepts are set in non-wadeable rivers (Erös, 2017; Thorp, 2014). Thus, this dissertation was an opportunity to validate at broad scales hypothesized processes embedded in these concepts - namely, the roles of riverine connectivity and local habitat diversity for structuring riverine fish richness.

I developed a protocol capable of sampling most major riverine habitats (exempting isolated floodplain waterbodies; Chapter 2). This was necessary because riverine habitat diversity increases downriver through expanding vertical, lateral, and temporal dimensions (Ward, 1989). However, most traditional riverine fish assessments were modeled after low-dimensional wadeable-stream assessments (e.g., single gear, longitudinally continuous effort, one season; Hughes \& Peck, 2008). Consequently, mismatches between traditional riverine fish assessments and underlying habitat diversity 
likely increase downriver, which might distort the true distribution of fish richness at the riverscape scale. I deviated from traditional fish assessments with three key surveydesign properties meant to diversity sampling effort across space and time: i) using six complementary gears, ii) spatially distributing effort within sites via stratified discrete sub-samples, and iii) temporal sampling (diel, seasonal). Moreover, I developed an analysis that generated all sampling outcomes from each combination of gear and effort, allowing protocols to be tailored to specific objectives and sampling criteria. In Chapter 2, I optimized protocols solely for efficiency, but I also worked with Missouri’s Fisheries Management Biologists who identified eight sampling criteria (e.g., minimizing gears, maximizing imperiled-species detections) that caused slight differences between protocols in Chapter 2 and those in Dunn (2019). To my knowledge, Dunn (2019) presents the only manager-defined protocols for sampling lotic fishes.

In addition to identifying the most effective gears (i.e., electrofishing, seining, mini-fyke nets), there were several key findings in Chapter 2. First, there are likely far more fish species inhabiting non-wadeable sites than existing distributional data indicate, and potentially, many biologists realize. For example, fish species richness at sites in Chapter 2 was on average 221\% (16.8 spp. versus 37.1 spp.) and 247\% (24.1 spp. versus 59.6 spp.) higher than the mean richness per survey historically reported in Missouri's prairie and Ozark mid-sized rivers (Missouri Department of Conservation unpublished fish community database 1970-2009; Resource Assessment and Monitoring program 1994-2014). One potential reason for underreported fish richness is that historically, surveyors often relied on single gears (e.g., electrofishing or seining), which Chapter 2 revealed on average will at best detect $63 \%$ of available species. Consequently, multiple 
gears are likely necessary to detect high-levels of site-level richness ( $\geq 75 \%$ of species) traditionally targeted by riverine fish sampling protocols (Kanno et al., 2009). However, Chapter 2 also revealed multi-gear protocols can be more efficient than single-gear protocols if using complementary gear pairings, meaning multi-gear protocols are likely feasible within timeframes typically afforded to managers.

Most existing North American riverine protocols were developed and refined to monitor riverine integrity and water quality (Erős et al., 2019; Yoder \& Kulik, 2003). Consequently, it is unclear whether advantages of protocols in Chapter 2 will outweigh inertia of long-term data and regulatory precedent within existing riverine assessment programs. However, protocols in Chapter 2 could be broadly useful as complementary protocols for biodiversity monitoring and research; the hierarchical design and clustered sampling (i.e., sites, sections, gears, and sub-samples) should allow investigators to monitor both community- (richness, composition) and species-level (density, occupancy, habitat use) patterns. In Missouri, the approach in Chapter 2 could eventually lead to the development of riverine biocriteria (i.e., ecosystem assessment) that could be paired with the existing wadeable-stream monitoring. Potential extensions of protocols in Chapter 2 include a standardized riverine habitat assessment using emerging technologies that allow for near-census data collection (Gaeuman \& Jacobson, 2007; Tamminga, Hugenholtz, Eaton, \& Lapointe, 2015) and extending fish sampling protocols to include floodplain waterbodies (Erős et al., 2019). Both of these extensions would be steps toward holistic monitoring of riverine landscape diversity (Ward, Tockner, Arscott, \& Claret, 2002). First, however, protocols need to be further validated with independent datasets and refined by input from fisheries managers. 
Many non-wadeable tributaries are components of broader riverine ecosystems that include the Missouri and Mississippi rivers (hereafter, "great rivers"). Within river networks, tributaries are increasingly viewed as habitats for large-river fishes (Pracheil, McIntyre, \& Lyons, 2013) and opportunities for habitat restoration (Neeson et al., 2015; Laub, Thiede, Macfarlane, \& Budy, 2018). However, there are little fine-scale data to i) inform which tributaries support the most large-river species, and ii) identify which reaches in tributaries are used most by large-river fishes. In Chapter 3, I validated at local scales that river discharge could serve as an easily measured indicator of large-river richness within tributaries (Laub et al., 2018; Pracheil et al., 2013). However, amongtributary and -reach differences in available habitat affected the slopes of speciesdischarge relationships, indicating that even similarly sized tributaries and sites support different levels of fish richness. Moreover, my results revealed large-river fish richness in tributaries is spatially structured likely by dispersal. Consequently, conservation-planning frameworks that solely rely on discharge as an indicator of large-river richness will likely undervalue connected low-discharge sites while overvaluing isolated higher-discharge sites.

Ultimately, the value of tributaries for large-river fishes depends on whether tributaries increase individual fecundity and survival and if these increases translate to population-level persistence. Beyond discharge, it is not clear which specific habitats attract many large-river fishes into tributaries, and importantly, which tributary habitats are lacking within the mainstems of the Missouri and Mississippi rivers. Based on Chapter 3 and other studies, key potential complementary habitats within tributaries are low-velocity nursery habitats within confluence zones (Brown \& Coon, 1994; Love, 
Phelps, Tripp, \& Herzog, 2017; Naus \& Reid Adams, 2018) and spawning shoals upriver of confluence zones (Lyons, Walchak, Haglund, Kanehl, \& Pracheil, 2016; Vokoun, Guerrant, \& Rabeni, 2003). Moreover, tributaries might provide thermal and flow refugia for some overwintering large-river fishes (Quist, Tillma, Burlingame, \& Guy, 1999) and barrier-free drift-ways for fish with drift-dependent early life stages (Perkin \& Gido, 2011). Promising approaches that could provide insight to the roles of tributaries for supporting large-river fishes are detailed movement investigations into spatiotemporal habitat use (e.g., Garrett \& Rabeni, 2011; Neely, Pegg, \& Mestl, 2009) and molecular techniques capable of retracing environmental histories of fish by life cycle (Laughlin, Whitledge, Oliver, \& Rude, 2016; Rude \& Whitledge, 2019).

In Chapter 4, I expanded the scope of investigation to examine whether local communities at sites were actually amalgamations of large-river specialist fishes and at least two other species pools: core riverine species responsive to local habitat diversity and headwater species responsive to regional headwater connectivity. This question is particularly important for advancing metacommunity theory because at the time of data collection, there were no metacommunity-framed studies of freshwater fishes in nonwadeable rivers. Metacommunity theory predicts that dispersal is especially high in mainstem rivers (Brown \& Swan, 2010). It is unclear, however, whether dispersal is high enough to decouple fish-habitat relationships (i.e. mass effects). Moreover, use of mainstems by each of the three species groups is expected if watersheds operate as macrosystems (McCluney et al., 2014).

The main finding of Chapter 4 was that riverine fishes are organized as metacommunities. Mixtures of core and non-core species occurred at each site, and 
richness levels of each of the three stream-size guilds were structured by different organizing processes. Although connectivity structured richness of headwater and largeriver species, the richness of core species was structured by local habitat diversity. Consequentially, preserving areas of high riverine richness will likely require actions that maintain regional connectivity and local habitat diversity. Preserving the most species, however, could require prioritizing different management actions depending on river basin. For example, habitat diversity has heightened importance in the Meramec River system, whereas headwater connectivity is likely particularly important in the Grand River system.

Multiple unanswered research questions arose from Chapter 4. First, it would be interesting to determine whether specific stressors result in characteristic shapes of longitudinal profiles of riverine richness. If so, longitudinal richness profiles could serve as tools for diagnosing impacts to riverine fish richness. However, it is unclear whether longitudinal profiles change through time. For example, hotspots might shift farther downriver through time where colonization and extirpations rates are higher and lower, respectively (Gotelli \& Taylor, 1999). Finally, it is unclear which management actions would preserve mainstem habitat diversity. For example, preserving local habitat diversity in mainstems could require limiting intensive upstream watershed land uses (Abell, Lehner, Thieme, \& Linke, 2017) and restoring headwaters. In the Grand River system, extensive channelization of headwaters has imbalanced sediment loads and caused infilling of mainstem pools (Pitchford, \& Kerns, 1999). Thus, even preserving key mainstem habitats that contribute to local habitat diversity could require basinwide management actions. 


\section{Future research directions}

Chapter 2: Riverine fish sampling protocols

- Research direction 1: How do physical-based survey protocols compare to emerging molecular survey methods (environmental DNA and metabarcording)?

- Research direction 2: Are sampling protocols transferable to new sites and regions?

- Research direction 3: Are there alternative criteria for refining protocols to meet sampling preferences of protocol users?

- Research direction 4: Can emerging technologies (sonar, real-time aerial imagery) be used to develop a rapid riverine habitat protocol to accompany fish sampling protocols?

- Research direction 5: How can protocols be adapted to provide fish biocriteria necessary for riverine ecosystem integrity monitoring?

Chapter 3: Tributary use by large-river specialist fishes

- Research direction 6: Do other dimensions of flow regime (timing and duration) impact the extent of tributary use by larger-river fishes (e.g., timing, duration)?

- Research direction 7: Which specific habitats within tributaries support survival, growth, or reproduction of large-river fishes?

- Research direction 8: What percentage of fish and fishes within great rivers use tributaries for some portion of their life cycle?

Chapter 4: Distributions of riverine fish richness in non-wadeable rivers 
- Research direction 9: Do common stressors result in consistent changes in longitudinal profiles of riverine richness? For example, do rivers with low downriver connectivity have mid-course peak richness, and does reduced habitat diversity dampen peak richness along rivers?

- Research direction 10: Are longitudinal profiles of riverine fish richness temporally stable?

- Research direction 11: What specific environmental variables limit dispersal through mainstems by headwater fishes, and do these variables ultimately impact genetics and demographics of headwater fish populations?

- Research direction 12: Does habitat degradation in mainstem rivers further limit their use as dispersal corridors by headwater fishes?

\section{References}

Abell, R., Lehner, B., Thieme, M., \& Linke, S. (2017). Looking beyond the fenceline: Assessing protection gaps for the world's rivers. Conservation Letters, 10(4), 384-394. https://doi.org/10.1111/conl.12312

Brown, D. J., \& Coon, T. G. (1994). Abundance and assemblage structure of fish larvae in the lower Missouri River and its tributaries. Transactions of the American Fisheries Society, 123(5), 718-732. https://doi.org/10.1577/15488659(1994)123<0718:AAASOF>2.3.CO;2

Brown, B. L., \& Swan, C. M. (2010). Dendritic network structure constrains metacommunity properties in riverine ecosystems. Journal of Animal Ecology, 79(3), 571-580. https://doi.org/10.1111/j.1365-2656.2010.01668.x 
Brown, B. L., Swan, C. M., Auerbach, D. A., Grant, E. H. C., Hitt, N. P., Maloney, K. O., \& Patrick, C. (2011). Metacommunity theory as a multispecies, multiscale framework for studying the influence of river network structure on riverine communities and ecosystems. Journal of the North American Benthological Society, 30(1), 310-327. http://dx.doi.org/10.1899/10-129.1

Cooke, S., Paukert, C., \& Hogan, Z. (2012). Endangered river fish: Factors hindering conservation and restoration. Endangered Species Research, 17(2), 179-191. https://doi.org/10.3354/esr00426

Dunn, C.G. (2019). Conservation and management of Missouri's mid-sized rivers: development of sampling protocols and application to priority watershed rivers. Retrieved from the Missouri Department of Conservation.

Erős, T. (2017). Scaling fish metacommunities in stream networks: Synthesis and future research avenues. Community Ecology, 18(1), 72-86. https://doi.org/10.1556/168.2017.18.1.9

Erős, T., Kuehne, L., Dolezsai, A., Sommerwerk, N., \& Wolter, C. (2019). A systematic review of assessment and conservation management in large floodplain rivers Actions postponed. Ecological Indicators, 98, 453-461. https://doi.org/10.1016/j.ecolind.2018.11.026

Fausch, K. D., Torgersen, C. E., Baxter, C. V., \& Li, H. W. (2002). Landscapes to riverscapes: Bridging the gap between research and conservation of stream fishes. Bioscience, 52(6), 483-498. https://doi.org/10.1641/00063568(2002)052[0483:ltrbtg]2.0.co;2 
Flotemersch, J. E., Stribling, J. B., Hughes, R. M., Reynolds, L., Paul, M. J., \& Wolter, C. (2011). Site length for biological assessment of boatable rivers. River Research and Applications, 27(4), 520-535. https://doi.org/10.1002/rra.1367

Gaeuman, D., \& Jacobson, R. B. (2007). Quantifying fluid and bed dynamics for characterizing benthic physical habitat in large rivers. Journal of Applied Ichthyology, 23(4), 359-364. https://doi.org/10.1111/j.1439-0426.2007.00888.x

Garrett, D.L., \& Rabeni, C.F. (2012). Intra-annual movement and migration of Flathead Catfish and Blue Catfish in in the lower Missouri River and tributaries. In P.H. Michaletz \& V.H. Travnichek (Eds.), Conservation, ecology, and management of catfish: the second international symposium (pp. 495-509). Bethesda, MD: American Fisheries Society.

Gotelli, N. J., \& Taylor, C. M. (1999). Testing metapopulation models with stream-fish assemblages. Evolutionary Ecology Research, 1(7), 835-845.

Hughes, R. M., \& Peck, D. V. (2008). Acquiring data for large aquatic resource surveys: The art of compromise among science, logistics, and reality. Journal of the North American Benthological Society, 27(4), 837-859. https://doi.org/10.1899/08028.1

Hugueny, B., Oberdorff, T., \& Tedesco, P. A. (2010). Community ecology or river fishes: a large-scale perspective. In K.B. Gido \& D.A. Jackson (Eds.), Community ecology of stream fishes: Concepts, approaches, and techniques (pp. 29-62). Bethesda, MD: American Fisheries Society.

Kanno, Y., Vokoun, J. C., Dauwalter, D. C., Hughes, R. M., Herlihy, A. T., Maret, T. R., \& Patton, T. M. (2009). Influence of rare species on electrofishing distance when 
estimating species richness of stream and river reaches. Transactions of the American Fisheries Society, 138(6), 1240-1251. https://doi.org/10.1577/T08210.1

Laub, B. G., Thiede, G. P., Macfarlane, W. W., \& Budy, P. (2018). Evaluating the conservation potential of tributaries for native fishes in the upper Colorado River basin. Fisheries, 43(4), 194-206. https://doi.org/10.1002/fsh.10054

Laughlin, T. W., Whitledge, G. W., Oliver, D. C., \& Rude, N. P. (2016). Recruitment sources of Channel and Blue catfishes inhabiting the middle Mississippi River: natal environment of Mississippi River catfishes. River Research and Applications, 32(8), 1808-1818. https://doi.org/10.1002/rra.3015

Leibold, M. A., Holyoak, M., Mouquet, N., Amarasekare, P., Chase, J. M., Hoopes, M. F., ... Tilman, D. (2004). The metacommunity concept: A framework for multiscale community ecology. Ecology Letters, 7(7), 601-613. https://doi.org/10.1111/j.1461-0248.2004.00608.x

Love, S. A., Phelps, Q. E., Tripp, S. J., \& Herzog, D. P. (2017). The Importance of shallow-low velocity habitats to juvenile fish in the middle Mississippi River: The importance of shallow-low velocity habitats to juvenile fish. River Research and Applications, 33(3), 321-327. https://doi.org/10.1002/rra.3075

Lyons, J., Walchak, D., Haglund, J., Kanehl, P., \& Pracheil, B. (2016). Habitat use and population characteristics of potentially spawning shovelnose sturgeon Scaphirhynchus platorynchus (Rafinesque, 1820), blue sucker (Cycleptus elongatus (Lesueur, 1817), and associated species in the lower Wisconsin River, 
USA. Journal of Applied Ichthyology, 32(6), 1003-1015.

https://doi.org/10.1111/jai.13201

McCluney, K. E., Poff, N. L., Palmer, M. A., Thorp, J. H., Poole, G. C., Williams, B. S., ... Baron, J. S. (2014). Riverine macrosystems ecology: Sensitivity, resistance, and resilience of whole river basins with human alterations. Frontiers in Ecology and the Environment, 12(1), 48-58. https://doi.org/10.1890/120367

Naus, C. J., \& Reid Adams, S. (2018). Fish nursery habitat function of the main channel, floodplain tributaries and oxbow lakes of a medium-sized river. Ecology of Freshwater Fish, 27(1), 4-18. https://doi.org/10.1111/eff.12319

Neely, B. C., Pegg, M. A., \& Mestl, G. E. (2009). Seasonal use distributions and migrations of blue sucker in the Middle Missouri River. Ecology of Freshwater Fish, 18(3), 437-444. https://doi.org/10.1111/j.1600-0633.2009.00360.x

Neeson, T. M., Ferris, M. C., Diebel, M. W., Doran, P. J., O’Hanley, J. R., \& McIntyre, P. B. (2015). Enhancing ecosystem restoration efficiency through spatial and temporal coordination. Proceedings of the National Academy of Sciences, 112(19), 6236-6241. https://doi.org/10.1073/pnas.1423812112

Perkin, J. S., \& Gido, K. B. (2011). Stream fragmentation thresholds for a reproductive guild of Great Plains fishes. Fisheries, 36(8), 371-383. https://doi.org/10.1080/03632415.2011.597666

Pitchford, G., \& Kerns, H. (1999). Grand River watershed inventory and assessment. St. Joseph, Missouri: Missouri Department of Conservation. 
Pracheil, B. M., McIntyre, P. B., \& Lyons, J. D. (2013). Enhancing conservation of largeriver biodiversity by accounting for tributaries. Frontiers in Ecology and the Environment, 11(3), 124-128. https://doi.org/10.1890/120179

Quist, M. C., Tillma, J. S., Burlingame, M. N., \& Guy, C. S. (1999). Overwinter habitat use of shovelnose sturgeon in the Kansas River. Transactions of the American Fisheries Society, 128(3), 522-527. https://doi.org/10.1577/15488659(1999) $128<0522:$ OHUOSS $>2.0 . C O ; 2$

Rude, N. P., \& Whitledge, G. W. (2019). Natal environments of age-0 paddlefish in the middle Mississippi River inferred from dentary microchemistry. River Research and Applications, rra.3526. https://doi.org/10.1002/rra.3526

Schlosser, I. J. (1991). Stream fish ecology: A landscape perspective. Bioscience, 41(10), 704-712. https://doi.org/10.2307/1311765

Sowa, S. P., Annis, G., Morey, M. E., \& Diamond, D. D. (2007). A gap analysis and comprehensive conservation strategy for riverine ecosystems of Missouri. Ecological Monographs, 77(3), 301-334. https://doi.org/10.1890/06-1253.1

Tamminga, A., Hugenholtz, C., Eaton, B., \& Lapointe, M. (2015). Hyperspatial remote sensing of channel reach morphology and hydraulic fish habitat using an unmanned aerial vehicle (UAV): A first assessment in the context of river research and management: Remote sensing using UAVs. River Research and Applications, 31(3), 379-391. https://doi.org/10.1002/rra.2743

Thorp, J. H. (2014). Metamorphosis in river ecology: From reaches to macrosystems. Freshwater Biology, 59(1), 200-210. https://doi.org/10.1111/fwb.12237 
Vokoun, J. C., Guerrant, T. L., \& Rabeni, C. F. (2003). Demographics and chronology of a spawning aggregation of blue sucker (Cycleptus elongatus) in the Grand River, Missouri, USA. Journal of Freshwater Ecology, 18(4), 567-575. https://doi.org/10.1080/02705060.2003.9663997

Ward, J. V. (1989). The four-dimensional nature of lotic ecosystems. Journal of the North American Benthological Society, 8(1), 2-8. https://doi.org/10.2307/1467397

Ward, J. V., Tockner, K., Arscott, D. B., \& Claret, C. (2002). Riverine landscape diversity. Freshwater Biology, 47(4), 517-539. https://doi.org/10.1046/j.13652427.2002.00893.x

Yoder, C. O., \& Kulik, B. H. (2003). The development and application of multimetric indices for the assessment of impacts to fish assemblages in large rivers: A review of current science and applications. Canadian Water Resources Journal, 28(2), 301-328. https://doi.org/10.4296/cwrj2802301 


\section{VITA}

Corey Garland Dunn is an ecologist whose research aims to produce knowledge and tools to mitigate environmental issues impacting freshwater biota and ecosystems. Much of his research has focused geographically on fish populations and communities within southeastern (USA) streams and rivers - a temperate and sub-tropical freshwater biodiversity hotspot. He is originally from Powhatan, Virginia and graduated summa cum laude from Virginia Tech with a Bachelor of Science in Biological Sciences. Thereafter, he received a Master of Science in Fish and Wildlife Conservation at Virginia Tech, where he researched conservation issues impacting the endangered Candy Darter Etheostoma osburni. Following his Ph.D. in Natural Resources at the University of Missouri, Corey will be a Postdoctoral Associate at Mississippi State University where he will be developing a standardized quantitative framework for evaluating imperilment among southeastern fishes. 